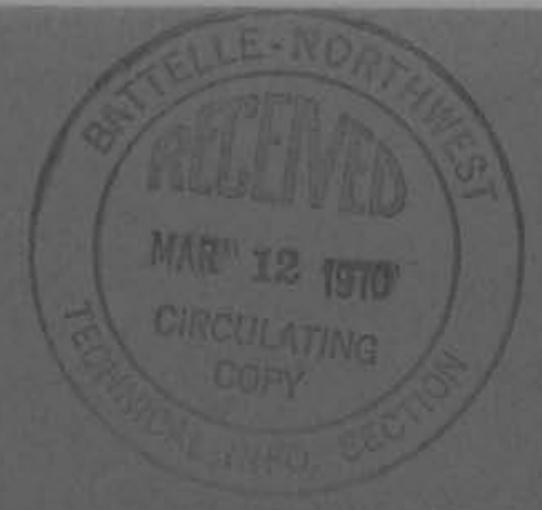

${ }^{B}$

BNWL-1244
UC-41
$5-$
2.78

\title{
REMOVAL OF IODINE AND PARTICLES FROM CONTAINMENT ATMOSPHERES BY SPRAYS-- CONTAINMENT SYSTEMS EXPERIMENT INTERIM REPORT
}

February 1970

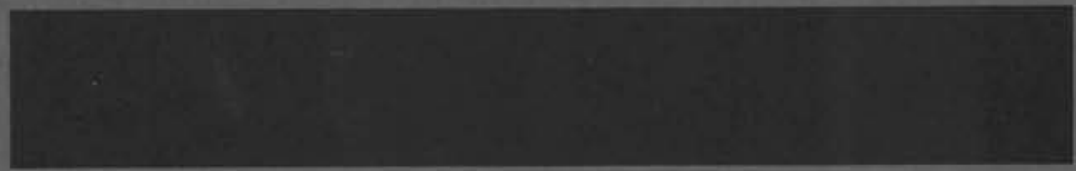

\section{AEC RESEARCH \& \\ DEVELOPMENT REPORT}

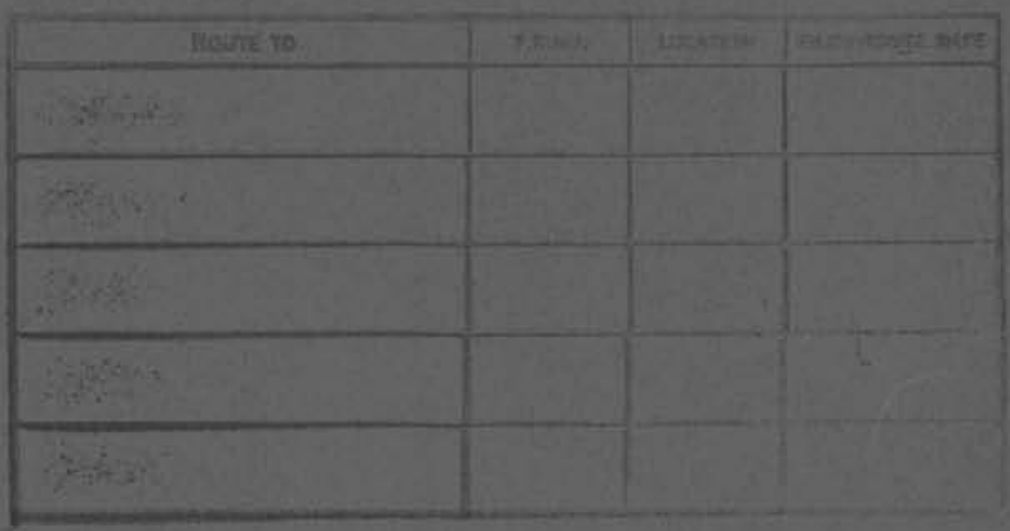




\section{LEGAL NOTICE}

This report was prepared as an account of Government sponsored work. Neither the Unifed States, nor the Commission, nor any person acting on behalf of the Commission:

A. Makes any warranty or representation, expressed or implied, with respect to the accuracy, completeness, or usefulness of the information contained in this report, or that the use of any information, apparatus, method, or process disclosed in this report may not infringe privately owned rights; or

B. Assumes ony llabilities with respect to the use of, or for damages resulting from the use of any information, apparatus, method, or process disclosed in this report.

As used in the above, "person acting on behalf of the Commission" includes any employee or contractor of the Commission, or employee of such contractor, to the extent that such employee or contractor of the Commission, or emplayee of such contractor prepares, disseminates, or provides access to, any information pursuant to his employment or contract with the Commission, or his employment with such contractor.

\section{PACIFIC NORTHWEST LABORATORY \\ RICHLAND, WASHINGTON \\ operated by}

BATTELLLE MEMORIAL INSTITUTE

for the

UNITED STATES ATOMIC ENERGY COMMISSION UNDER CONTRACT AT(45-1)-1830 
BNWL-124 4

UC-41, Health and Safety

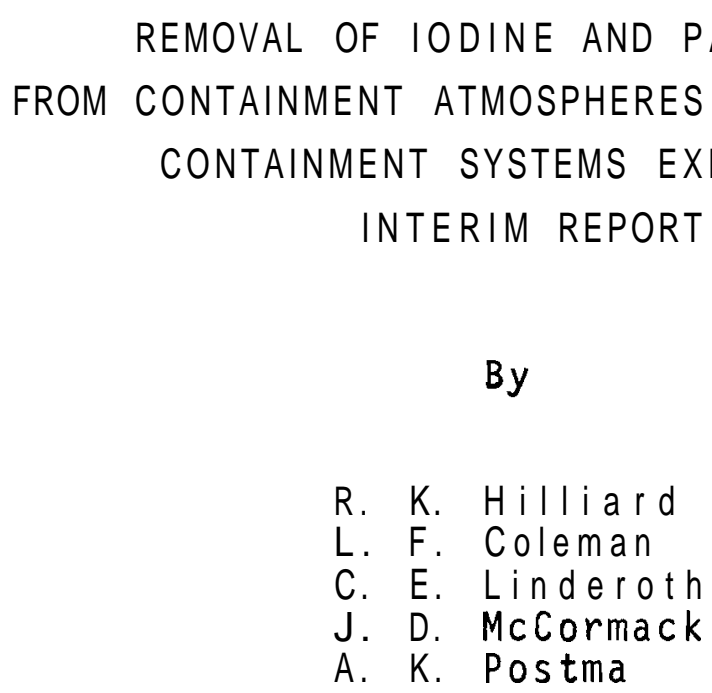

Fluid and Energy Systems Department

Physics and Engineering Division

February 1970 
BNWL- 1244

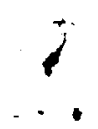

Printed in the United States of America Available from

Clearinghouse for Federal Scientific and Technical Information National Bureau of Standards, U.S. Department of Commerce Springfield, Virginia 22151

Price: Printed Copy $\$ 3.00 ;$ Microfiche $\$ 0.65$ 


\title{
REMOVAL OF IODINE AND PARTICLES \\ FROM CONTA I NMENT ATMOSPHERES BY SPRAYS-- CONTAINMENT SYSTEMS EXPERIMENT \\ INTERIM REPORT \\ R. K. Hilliard, L. F. Coleman, C. E. Linderoth, J. D. McCormack, A. K. Postma
}

\begin{abstract}
The experimental data obtained in five spray experiments in the Containment Systems Experiment (CSE) are reported in detail. The performance of caustic-borate sprays in decontaminating the containment atmosphere of elemental iodine, methyl iodide, particulate iodine, cesium, and uranium is discussed in terms of theoretical models. Parameters investigated were spray flow rate, spray drop size, atmosphere temperature and pressure, and chemical composition of the spray solution.

Removal rates were in agreement with predictions by mathematical models based on mean spray drop diameters. Large concentration reduction factors ( $>1000$ ) were obtained for a 11 species except methyl iodide, which was removed only slowly by the caustic sprays. Based on these experiments, the models predict 2-hr time-integrated dose reduction factors attributable to continuous sprays in a large power reactor building ranging from 1.5 for methyl iodide to 50 for elemental iodine, with intermediate values for cesium, uranium, and particulate iodine.
\end{abstract}


BNWL- 1244

\section{CONTENTS}

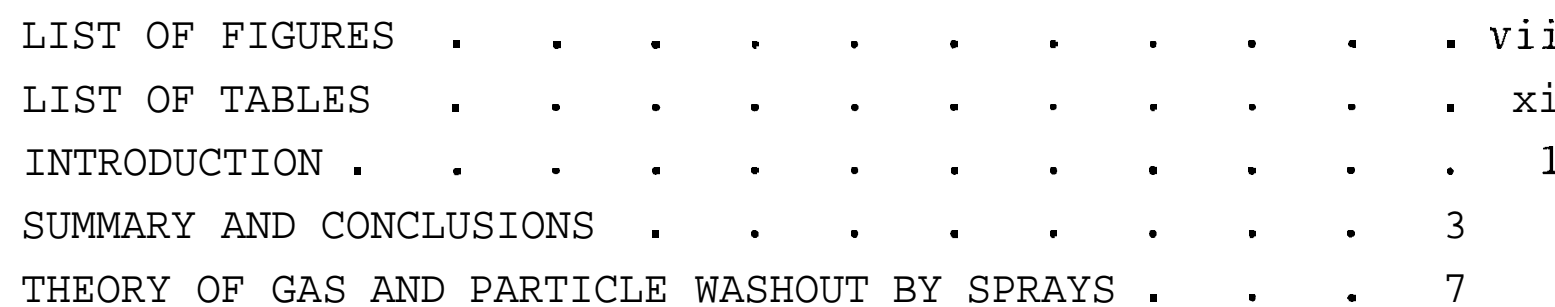

General • • • • • . • • • • • • 7

Absorption of Airborne Gases by Reactive Liquids . . 7

Negligible Back Pressure of Dissolved Gas

at Interface : • • • • • • • • • . 12

Liquid Phase Mass Transfer Controlling. • . . . 17

Effect of Recirculation . • . • • • • . 21

Removal of Aerosol Particles . . . . . . . . 22

Gravitational Settling. • • • • • • • . 23

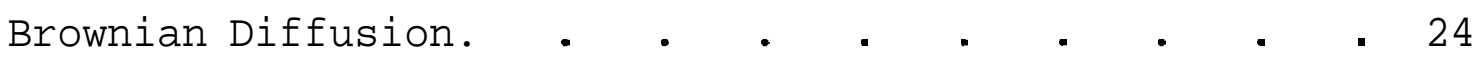

Inertial Impaction. • . . . . . . . 25

Interception . • • • • • • • • • . 25

Diffusiophoresis . . . . . . . . . . . 25

Thermophoresis. • • • • • • • • • . 27

Electrical Attraction. . . . . . . . . 27

Effect of Recirculation on Airborne Particle

Washout • • • • • • • • • • • . 27

Effect of Partial Spray Coverage. . . . . . . 28

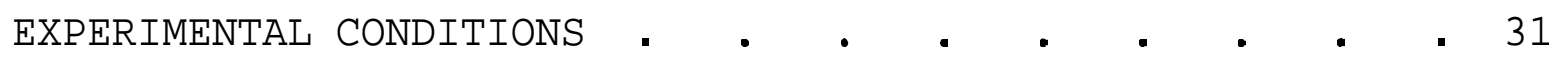

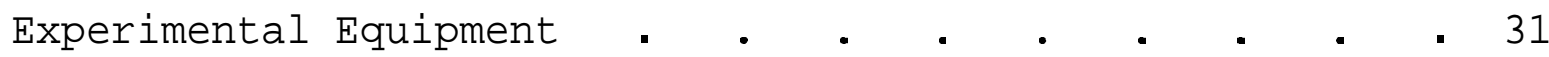

Experimental Procedure . . . . . . . . . 35

Test Conditions . . . . . . . . . . . . 38

Sample Analysis and Data Handling. . . . . . . 44

RESULTS AND DISCUSSION . . . . . . . .

Release to the Containment Atmosphere. * 45

Overall Mass Balances. . . . . . . . . 45

Visual Observations of the Containment Atmosphere . . 49

Aerosol and Iodine Forms in the Containment

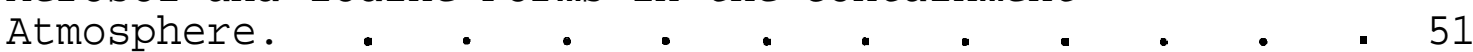

Spray Operation . . . . . . . . . . 52 
Spray System Characteristics . . . . . . 52

Heat Removal by Sprays. . . . . . . . . 54

Variation in Gas Phase Spatial Concentration. . . . 56

Concentration Variations Within the Main Room . . . 56

Concentration Variations Between Compartments . • . 65

Removal from Containment Atmospheres by Sprays . . . 67

Maypack Data Interpretation . . . . . . . 67

Concurrent Removal by Natural Processes . . . . 70

Elemental Iodine . . . . . . . . . . 72

Particulate-Associated Iodine . . . . . . . 78

Iodine on Charcoal Paper . . • • • • • . 78

Methyl Iodide . . . . . . . . . • • 92

Total Iodine . . . . . . . . . . . . . 92

Cesium. . . . . . . . . . . . . 105

Uranium . . . . . . . . . . . 105

Concentration in Liquid Phases . . . . . . . 118

Collection in Vessel Sumps. . . . . . . . 118

Concentration in Spray Drops . . . . . . . 130

Concentration in the Wall Film. . . . . . . 135

Final Equilibrium . . . . . . . . . . 140

Particle Size Measurement. . . . . . . . . 142

Deposition Coupon Data . . . . . . . . . . 143

COMPARISON OF THEORY WITH EXPERIMENT . . . . . . 149

Elemental Iodine. . . . . . . . . . . 149

Initial Spray Washout Rate. • . . • . . . 149

Equilibrium Gas Phase Concentration . . . . 157

Dose Reduction Factors. . . . . . . . . 160

Methyl Iodide. . . . . . . . . . . . 161

Methyl Iodide Reaction Rates . . . . . . . 162

Removal of Methyl Iodide by Nonreactive Sprays. • . 163

Removal of Methyl Iodide by Reactive Sprays . . . 166

Aerosol Particles. . . . . . . . . . . 168

ACKNOWLEDGEMENTS . $\cdot$ •

NOMENCLATURE $\cdot$ •

REFERENCES • • • • • • • • • • • • • 179

APPENDIX: FACILITY DESCRIPTION . . . . . . . A-1 


\section{FIGURES}

1 Schematic Diagram of Liquid Flow in the CSE Vessel

2 Schematic Diagram of Transport Between Sprayed and Unsprayed Regions

3 Schematic Diagram of Containment Arrangement Used in CSE Spray Tests

4 Containment Vapor Temperature and Pressure Response to Spray in Run A7

5 Location of Maypack Clusters in CSE

6 Typical Buildup of Concentration in Lower Rooms

7 Concentration of Elemental Iodine in the Main Room, Run A3

8 Concentration of Elemental Iodine in the Main Room, Run A4

9 Concentration of Elemental Iodine in the Main Room, Run A6

10 Concentration of Elemental Iodine in the Main Room, Run A7

11 Concentration of Elemental Iodine in the Main Room, Run A8

12 Concentration of Particulate Iodine in the Main Room, Run A3

13 Concentration of Particulate Iodine in the Main Room, Run A4

14 Concentration of Particulate Iodine in the Main Room, Run A6

15 Concentration of Particulate Iodine in the Main Room, Run A7

16 Concentration of Particulate Iodine in the Main Room, Run A8

17 Concentration in Main Room of Iodine Associated with Charcoal Paper, Run A3

18 Concentration in Main Room of Iodine Associated with Charcoal Paper, Run A4

19 Concentration in Main Room of Iodine Associated with Charcoal Paper, Run A6

20 Concentration in Main Room of Iodine Associated with Charcoal Paper, Run A7 
Concentration in Main Room of Iodine Associated with Charcoal Paper, Run A8

Concentration of Methyl Iodide in the Main Room, Run A3

Concentration of Methyl Iodide in the Main Room, Run A4

Concentration of Methyl Iodide in the Main Room, Run A 6

Concentration of Methyl Iodide in the Main Room, Run A7

Concentration of Methyl Iodide in the Main Room, Run A8

27 Total Iodine Concentration in the Main Room, Run A3 99

28 Total Iodine Concentration in the Main Room, Run A4 100

29 Total Iodine Concentration in the Main Room, Run A6 101

30 Total Iodine Concentration in the Main Room, Run A7 102

31 Total Iodine Concentration in the Main Room, Run A8 103

32 Cesium Concentration in the Main Room, Run A3 106

33 Cesium Concentration in the Main Room, Run A4 107

34 Cesium Concentration in the Main Room, Run A6 108

35 Cesium Concentration in the Main Room, Run A7 109

36 Cesium Concentration in the Main Room, Run A8 110

37 Uranium Concentration in the Main Room, Run A3 112

38 Uranium Concentration in the Main Room, Run A4 113

39 Uranium Concentration in the Main Room, Run A6 114

40 Uranium Concentration in the Main Room, Run A7 115

41 Uranium Concentration in the Main Room, Run A8 116

42 Liquid Volumes and Concentrations in Vessel Sumps, Run A3

Liquid Volumes and Concentrations in Vessel Sumps, Run A 4

Liquid Volumes and Concentrations in Vessel Sumps, Run A6

Liquid Volumes and Concentrations in Vessel Sumps, Run A 7

Liquid Volumes and Concentrations in Vessel Sumps Versus Time--Run A8 
BNWL -

47 Iodine Distribution Versus Time--Run A3 126

48 Iodine Distribution Versus Time--Run A7 127

49 Cesium Distribution Versus Time--Run A3 128

50 Cesium Distribution Versus Time--Run A7 129

51 Iodine and Cesium Concentrations in Spray Drops-Run A3

131

52 Iodine and Cesium Concentration in Spray Drops-Run A4

132

53 Iodine and Cesium Concentration in Spray Drops-Run A7

133

54 Iodine and Cesium Concentration in Spray Drops-Run A8

134

55 Iodine and Cesium Concentration in Wall Film, Run A3

136

56 Iodine and Cesium Concentration in Wall Film, Run A4

57 Iodine and Cesium Concentration in Wall Film, Run A 7

138

58 Wall Trough Concentration Versus Time--Run A8 139

59 Drop Size Distribution for Sprays Used in CSE 152

60 Effect of Initial Downward Velocity on Drop Absorption

154

61 Comparison of Experimental Initial Washout of Elemental Iodine with Drop Absorption Model

156

62 Predicted Particle Collection Efficiency for Falling Drops

170

A-1 Phantom View of CSE Facility

A- 2

A-2 An Exterior View of the Upper Half of the CSE Vessel Before Thermal Insulation Was Installed

A -4

A-3 Schematic Diagram of CSE Aerosol Sampling System

A -7

A-4 A View of CSE Maypack Cluster with Cover Removed

A- 8

A-5 Schematic Diagram of a CSE Maypack Showing Filter and Adsorber Arrangement

A -9

A-6 Flowsheet of CSE Spray System 


\section{$\underline{\text { TABLES }}$}

$1 \quad$ Physical Conditions Common to All Spray Experiments 39

2 Nozzles Used in CSE Spray Experiments 40

3 Atmospheric Conditions in CSE Spray Experiments 41

4 Spray Flow Rates and Solutions Used in CSE Experiments

5 Timing of Spray Periods 43

6 Iodine Material Balances 46

7 Cesium Material Balances 47

8 Average Distribution of Iodine and Cesium at End of Experiment

9 Iodine Form at Beginning of First Spray 51

10 Measured Spray Liquid Distribution in CSE Tests 52

11 Heat Removal from Upper Vapor Space by a Spray 56

12 Locations of Maypack Clusters Used in CSE Spray Experiments

13 Iodine Concentrations at Various Vessel Locations During First Spray Period - CSE Run A3

14 'Iodine Concentrations at Various Vessel Locations During First Spray Period - CSE Run A4

15 Iodine Concentrations at Various Vessel Locations During First Spray Period - CSE Run A6

16 Iodine Concentrations at Various Vessel Locations During First Spray Period - CSE Run A7

17 Cesium Concentrations in Vapor Space at Various Vessel Locations During First Spray Period

18 Comparison of Concentrations in Sprayed and Nonsprayed Regions Within the Main Room 65

19 Removal of Elemental Iodine in CSE Spray Tests 79

20 Removal of Particulate Iodine in CSE Spray Tests 85

21 Removal of Iodine Form Associated with Charcoal Paper in CSE Spray Tests 91

22 Removal of Methyl Iodide in CSE Spray Tests 98

23 Removal of Total Iodine in CSE Spray Tests 104

24 Removal of Cesium in CSE Spray Tests 111

25 Removal of Uranium in CSE Spray Tests 117

26 Typical Water Balance--Run A7 120 
27 Comparison of Iodine and Cesium Mass Gained by Liquids with Loss by Gas--Run A4

28 Equilibrium After Recirculation 141

29 Particle Size Analyses - CSE Spray Tests 143

30 Iodine Deposition on Various Noncondensing Surfaces 145

31 Cesium Deposition on Various Noncondensing Surfaces 146

32 Deposition on Vessel Surfaces Inferred from Coupon Data

33 Comparison of Deposition by Coupon Data with Material Balance Calculations

34 Observed Washout of Elemental Iodine During First Spray Period

35 Predicted Washout Constants for CSE Spray Tests 155

36 Partition Coefficients for Elemental Iodine 159

37 Estimated Reaction Rate Constants of Spray Solutions with Methyl Iodide

38 Methyl Iodide Washout by Unreactive Water Sprays 165

39 Estimated Reaction Rates and Pàrtition Coefficients for Thiosulfate Sprays

40 Methyl Iodide Absorption by Thiosulfate Sprays in CSE

41 Washout of Cesium Particles by CSE Sprays 171

42 Washout of Uranium Oxide Aerosol by CSE Sprays 171 


\section{REMOVAL OF IODINE AND PARTICLES \\ FROM CONTAINMENT ATMOSPHERES BY SPRAYS-- CONTAINMENT SYSTEMS EXPERIMENT \\ INTERIM REPORT \\ R. K. Hilliard, L. F. Coleman, C. E. Linderoth, J. D. McCormack, A. K. Postma}

\section{INTRODUCTION}

The trend in the nuclear power industry is for more reliance on engineered safety features to meet the licensing requirements set forth by the AEC reactor site criteria. $(1,2)$ The containment spray system, a common safety feature in many second generation nuclear power reactors, usually is designed for the dual purposes of pressure suppression and fission product removal. To permit evaluation of the latter function, each specific reactor spray system must be considered on the basis of fundamental knowledge of the processes involved coupled with adequate demonstration tests under conditions similar to those expected in the design basis accident (DBA). An extensive experimental program to furnish this information is sponsored by the USAEC Division of Reactor Development and Technology. (3) Work reported in this document is a part of this program.

Because iodine is usually the critical fission product in reactor siting calculations, much study has been conducted on its behavior. Griffiths (4) applied standard engineering correlations to develop equations for predicting the rate of removal of iodine from reactor building atmospheres by water and chemical sprays. Griffiths' equations, although largely substantiated by small scale experiments, cannot be applied with complete confidence to large power reactor systems until largescale experiments explaining the effects of certain unknown factors related to size and geometry can be performed. 
The Containment Systems Experiment (CSE) has many features of an actual power reactor containment building. Its $30,000 \mathrm{ft}^{3}$ shell, painted and with many typical penetrations, has several smaller compartments which can affect concentration gradients. Its size permits spray experiments, with most important parameters appearing in the mathematical models, to be conducted either at full scale or within a factor of four of full scale. Aspects best adapted to study by large-scale experiments include the effect of natural deposition on surfaces, desorption, wall impingement by spray drops, intercompartment transfer, mixing in the vapor space, partial spray coverage, drop coalescence, and approach to drop saturation. All of these effects have been studied in the CSE experiments.

Because the information derived from the CSE spray experiments is urgently needed for licensing purposes, this interim report is being issued before the entire CSE experimental program has been completed. The information presented here is in final form for the five experiments reported, and is considered to provide an adequate basis for several important conclusions. Subsequent experiments were not fully evaluated at the time this report was written, but preliminary analyses show the later experiments to be in agreement with the conclusions made in this report. 


\section{SUMMARY AND CONCLUSIONS}

The results of five CSE experiments (Runs A3, A4, A6, A7, and A8) employing aqueous sprays are reported in detail. The prime objective of these tests was to verify theoretical models capable of predicting the removal by sprays of fission products from the atmospheres of large power reactor containment vessels under postaccident conditions. Therefore, these experiments were performed in a manner designed to obtain information needed for verification of mathematical models. Later runs, to be reported separately, were performed in a manner more closely representing spray system performance under accident conditions.

After the desired atmospheric conditions were established in the vessel, fission product simulants were injected in essentially an instantaneous manner. The initial elemental iodine concentration was in the maximum range expected for an accident to a large PMR $\left(\sim 100 \mathrm{mg} / \mathrm{m}^{3}\right)$. Particulate concentrations were a factor of 10 lower. The sprays were then operated periodically, with extensive sampling during and between spray periods to determine the effect of each spray period on the concentrations of each fission product species. A final spray recirculation period was included.

A major parameter was changed in each experiment. Two values for each of two parameters appearing in the theoretical models were used. These were spray flux $\left(0.004\right.$ and $0.018 \mathrm{f} \mathrm{t}^{3} /$ hr per $\mathrm{ft}^{3}$ of contained gas space) and spray drop size (770 and $1210 \mu \mathrm{MMD})$. In addition, two parameters indirectly influencing spray performance were investigated. These were the containment atmospheric condition (room air at barometric pressure or steamair at $\left.250^{\circ} \mathrm{F}, 48 \mathrm{psia}\right)$ and the chemical composition of the spray solution (base-borate, $\mathrm{pH} 9.5$ or boric acid, $\mathrm{pH} 5$ ). The latter two affected either the mass transfer coefficient, the drop fall velocity, chemical reaction rates, collection 
efficiency for particles, or the iodine equilibrium gas-liquid distribution coefficient, all of which appear in one or more versions of the mathematical models. In two experiments, sodium thiosulfate was added to determine its effect on removal of methyl iodide. The only major parameters not varied were the drop fall height (38.5 ft for all tests) and the gas to liquid volume ratio ( 280$)$.

Time-dependent measurements are reported for mass concentrations in the vapor spaces and for liquid concentrations in the pools, wall film, and in spray drops during flight. Fission product species studied were elemental iodine, methyl iodide, particulate iodine, cesium, and uranium.

The following conclusions are based on evaluation of the experimental data presented in this report.

- Good agreement (20\% for all tests) was obtained between experimental values of initial removal rate for elemental iodine and predictions based on gas phase limited transfer and on mean drop size. The measured concentration half lives of 0.6 to $2.0 \mathrm{~min}$ are in the range expected for large power reactor systems.

- The gas phase limited rate for elemental iodine lasted only until the airborne concentration was reduced to about 0.01 of the initial value, after which the concentration decreased more slowly. A quasi-equilibrium attained in all tests gave an overall concentration reduction factor of about 1000 after one day.

- Based on these experiments, the 2-hr time-integrated dose reduction factor (DRF) for a large PWR is estimated to be about 50 for elemental iodine. At longer times, the DRF would be appreciably greater.

- Removal of methyl iodide by hot base-borate sprays was too slow for accurate measurement in these experiments $\left(t_{1 / 2}>500 \mathrm{~min}\right)$. 
- Removal of methyl iodide by hot base-borate-sodium thiosulfate sprays agreed well with predictions by a model based on a chemical reaction rate limiting process. The removal rate is highly temperature dependent and the wall film is more effective than the drops. A low 2-hr DRF ( 1.5 ) would be expected in a large PWR. The 24-hr DRF for methyl iodide would be about 8 for a containment atmosphere assumed to remain at $240{ }^{\circ} \mathrm{F}$.

- Removal of aerosol particles (cesium, uranium, and particulate iodine) was significantly higher than predicted by a model using particle size data obtained during the tests. Agreement could be obtained for mass mean diameters of 2-4 $\mu$ MMD, instead of the 0.25-2 $\mu$ range measured by a cascade impactor. The measured size is suspected of bias toward low values due to evaporation of water from the particles during pasage through the sizing apparatus.

- The overall concentration reduction factor for cesium and particulate iodine was about 1000 . For uranium it was 2500. Assuming the particle sizes in these five experiments to be typical of those accompanying a LOCA for a large power reactor, the 2-hr DRF for cesium would be about 20 and, for uranium, about 10 .

- The concentrations of all fission product species were essentially uniform throughout the main containment vapor space regardless of removal rates or fraction of gas space sprayed.

- The effect of spray drop size on initial washout rate for elemental iodine was about as predicted, with smaller drops giving more rapid removal. In two tests with other factors equal, $1210 \mu$ MMD drops gave a 2.1 min initial concentration half life, while $770 \mu$ MMD drops gave $0.64 \mathrm{~min}$. Based on the equilibrium reached after 
$\mathrm{C}_{\mathrm{g}}=0.01 \mathrm{C}_{\mathrm{go}}$, as observed in these experiments, the equivalent 2 -hr DRF for $1210 \mu$ drops would be 30 while, for $770 \mu$ drops, it would be 57 .

- The initial washout rate of all fission product materials was directly proportional to spray rate. However, the maximum spray flux used was somewhat low compared to that planned for some recently announced plants.

- A boric acid spray, $\mathrm{pH}$ 5, was nearly as effective as sprays containing sodium hydroxide at a $\mathrm{pH}$ of 9.5. The low $\mathrm{pH}$ solution's efficiency for removing elemental iodine indicates that a fast reaction other than hydrolysis was involved.

- About $40 \%$ of the elemental iodine injected was retained by the phenolic paint and could not be removed by posttest steaming and spraying. Most of the deposition occurred during the short period after release but before sprays were started. Essentially no cesium was retained on the paint. 


\section{THEORY OF GAS AND PARTICLE WASHOUT BY SPRAYS}

\section{GENERAL}

The removal of airborne fission products by sprays within containment systems occurs at surfaces within the chamber. The development of the capability for predicting fission product removal under wide ranges of conditions can be realized only if the mechanisms causing surface deposition are understood. The theory presented here is intended to serve as a framework for interpreting experimental measurements of spray washout obtained in the Containment systems Experiment. For more detailed theoretical developments, the reader is referred to the references cited.

\section{ABSORPTION OF AIRBORNE GASES BY REACTIVE LIQUIDS}

In gas absorption, solute gas diffuses from the bulk of the gas to the surface of the liquid. The rate of this transport is governed by the magnitudes of the concentration gradient and the diffusion coefficient (laminar and turbulent) transporting the solute to the absorbing surface. At the gas-liquid interface, the solute dissolves in the liquid. Interfacial dissolution is a very rapid process under ordinary conditions and, for this reason, surface saturation exists:

$$
\mathrm{C}_{1 \mathrm{i}}=\mathrm{H}_{\mathrm{e}} \mathrm{C}_{\mathrm{gi}}
$$

where $\mathrm{C}_{1 i}=$ solute gas concentration on liquid side of interface, $\mathrm{C}_{\mathrm{gi}}=$ solute gas concentration on gas side of interface, $\mathrm{H}_{\mathrm{e}} \quad$ gas-liquid partition coefficient.

The gas-liquid partition coefficient is the equilibrium constant for dissolution of the solute. For example, the gas-liquid partition coefficient for elemental iodine is the equilibrium constant for the reaction: 


$$
I_{2} \stackrel{\left.K_{1}\right)}{=} I_{2(l)}
$$

with

$$
\mathrm{H}_{\mathrm{e}}=\frac{\left[\mathrm{I}_{2(\mathrm{l})}\right]}{\left[\mathrm{I}_{2(\mathrm{~g})}\right]}=\mathrm{K}_{1} .
$$

The brackets are used here to denote concentrations.

For some systems, the dissolved species may undergo a very rapid reaction within the liquid to form a nonvolatile species. Using $\mathrm{I}_{2}$ as an example, this may be indicated as

$$
I_{2(\ell)} \stackrel{K_{2}}{=} I_{2}(\text { reacted })
$$

(very rapid equilibrium) .

If this reaction is very fast compared to the absorption process, then an effective partition coefficient can be used to relate the interfacial gas phase composition to the total $\mathrm{I}_{2}$ in solution. From Equations (2) and (3), we can define

$$
H=\frac{\left[I_{2(\ell)}\right]+\left[I_{2(\text { reacted })}\right]}{\left[I_{2(g)}\right]}=K_{1}\left(1+K_{2}\right)
$$

where

$$
\begin{aligned}
{\left[\mathrm{I}_{2(\ell)}\right]+\left[\mathrm{I}_{2 \text { (reacted) }]=}\right.} & \text { effective partition coefficient, } \\
& \text { liquid, } \\
\mathrm{K}_{1}= & \text { equilibrium constant for } \\
& \text { unreacted species, } \\
\mathrm{K}_{2}= & \text { equilibrium constant for instan- } \\
& \text { taneous reaction. }
\end{aligned}
$$

In this report, we will use $\mathrm{H}$ as defined by Equation (4), and will include very fast reactions occurring in the liquid. Relatively slow chemical reactions cannot be handled in this 
way and their influence must be treated as a kinetic problem. Since the extent of chemical reactions may be influenced by the solute gas concentration and impurities in solution, the magnitude of $\mathrm{H}$ as defined by Equation (4) cannot be expected to be constant at low concentrations. The definition of $\mathrm{H}$ in terms of unreacted species, as in Equation (2) is consistent with Henry's Law and, hence, the partition coefficient for the unreacted species would be expected to remain constant at low concentrations.

The solute gas dissolved at the surface of the liquid will diffuse away from the interface by laminar and turbulent processes. If a chemical reaction occurs within the liquid, the absorbed substance will be destroyed at a rate depending on its concentration and reaction rate. Destruction of the solute species will enhance the absorption by increasing the magnitude of the concentration gradient at the gas-liquid interface.

Mass transfer coefficients governing the absorption rate may be defined by the flux equations in terms of the film theory. (5)

$$
\text { Flux }=\frac{\text { mols transferred }}{(\text { area })(\text { time })}=k_{g}\left(C_{g b}-C g l ̣\right)=k_{\ell}\left(C_{\ell i}-C_{\ell b}\right)
$$

where

$$
\begin{aligned}
\mathrm{k}_{\mathrm{g}} & =\text { gas phase mass transfer coefficient, } \\
\mathrm{k}_{\ell} & =\text { liquid phase mass transfer coefficient, } \\
\mathrm{C}_{\mathrm{gb}} & =\text { solute concentration in bulk of gas, } \\
\mathrm{C}_{\ell b} & =\text { solute concentration in bulk of liquid. }
\end{aligned}
$$

The use of film coefficients as defined in Equation (5) is physically consistent only with systems in which each phase is well mixed in the bulk. Studies $(6,7,8)$ on natural transport of fission products in containment vessels indicate that the 
gas phase would be well mixed beyond a thin boundary layer. Sprays would induce considerable mixing and, in the models applied here, the bulk gas phase within a single compartment was assumed to be well mixed. The degree of mixing in the liquid phase is less certain. Numerical limits on $k_{\ell}$ values may be obtained by assuming stagnant, or well mixed liquid phases. Actual values of $k_{\ell}$ depend strongly on the degree of mixing.

The airborne concentration of a fission product aerosol or gas may be related to the flow parameters of a containment vessel by making a material balance on the gas contained within the vessel. A schematic diagram of the liquid flow in the CSE containment vessel is shown in Figure 1. Since there are three interconnected volumes, a material balance allowing for transfer between rooms should be made on each room. For the main containment volume, the material balance input terms for a single component are:

$$
\text { input rate }=\mathrm{G}+\left(\mathrm{C}_{\mathrm{g} 2}-\mathrm{C}_{\mathrm{g}}\right) \mathrm{B}_{12}
$$

where

$$
\begin{aligned}
\mathrm{G}= & \text { generation rate of component within main contain- } \\
& \text { ment volume, } \\
\mathrm{C}_{\mathrm{g} 2}= & \text { gas phase concentration in middle room, } \\
\mathrm{C}_{\mathrm{g}}= & \text { gas phase concentration in main containment volume, } \\
\mathrm{B}_{12}= & \text { exchange coefficient for inter-room transport. }
\end{aligned}
$$

The output rate terms are

$$
\text { output rate }=\left[\mathrm{k}_{\mathrm{g}}\left(\mathrm{C}_{\mathrm{g}}-\mathrm{C}_{\mathrm{gi}}\right) \mathrm{A}\right] \text { drops, wall film }+\mathrm{R}_{\mathrm{G}}
$$

where

$$
\begin{aligned}
\mathrm{k}_{\mathrm{g}} & =\text { gas phase mass transfer coefficient } \\
\mathrm{A} & =\text { interfacial area for mass transfer, } \\
\mathrm{R}_{\mathrm{G}} & =\text { rate of gas phase reaction. }
\end{aligned}
$$


BNWL -1244

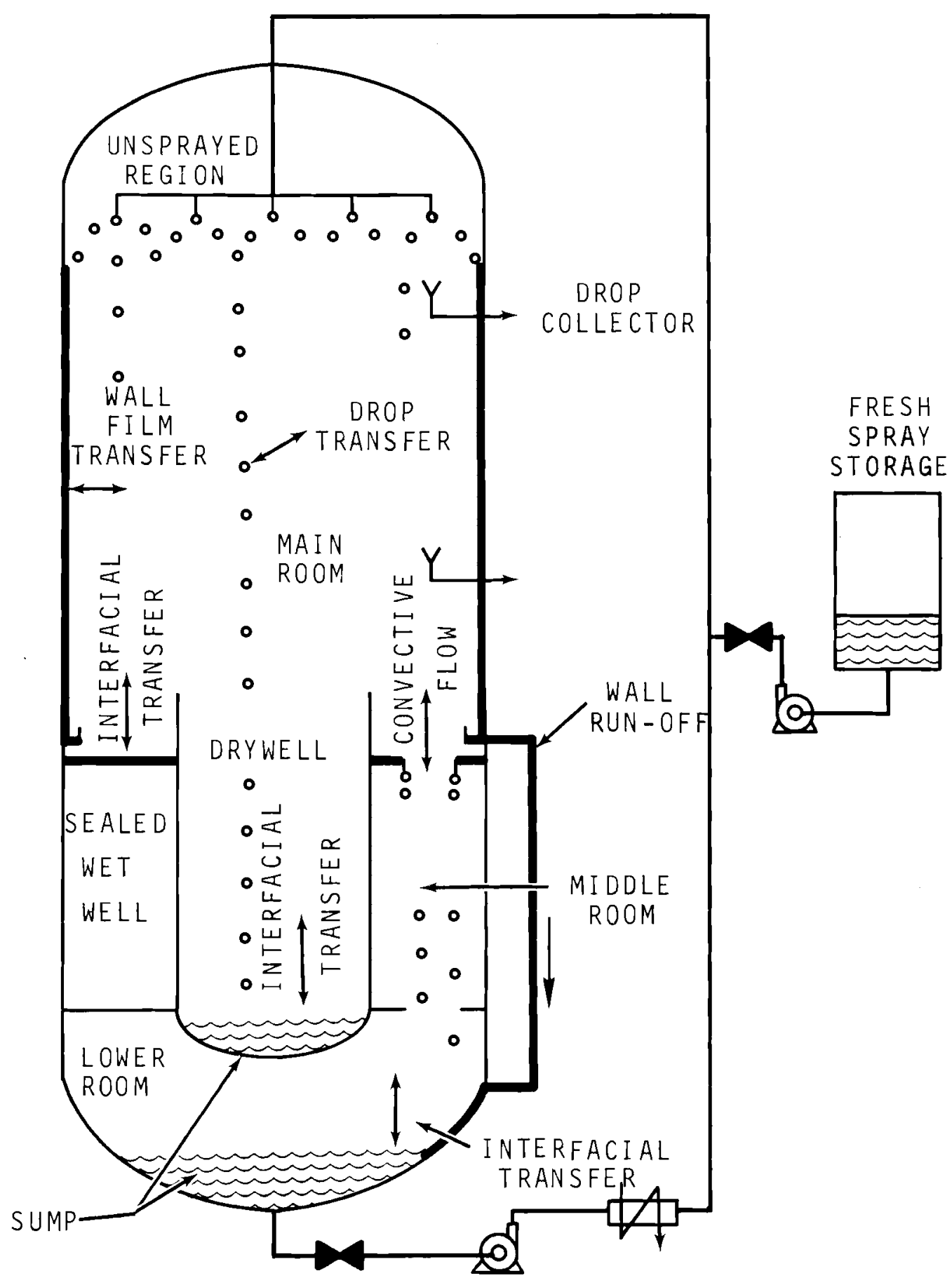

FIGURE 1. Schematic Diagram of Liquid Flow in the CSE Vessel 
BNWL -1244

The accumulation term is

$$
\text { accumulation rate }=\frac{d}{d t}\left(\begin{array}{ll}
\mathrm{V} & \mathrm{C}_{\mathrm{g}}
\end{array}\right)
$$

where

$$
\mathrm{V}=\text { volume of the main containment vessel. }
$$

From mass conservation, Equations (6), (7), and (8) give

$$
\begin{aligned}
\mathrm{G}_{1}+\left(\mathrm{C}_{\mathrm{g} 2}-\mathrm{C}_{\mathrm{g}}\right) \mathrm{B}_{12}= & {\left[\mathrm{k}_{\mathrm{g}}\left(\mathrm{C}_{\mathrm{g}}-\mathrm{C}_{\mathrm{gi}}\right) \mathrm{A}\right] \mathrm{drops} \text {, wall film }+\mathrm{R}_{\mathrm{G}} } \\
& +\mathrm{V} \frac{\mathrm{dC} g}{\mathrm{dt}} .
\end{aligned}
$$

An equation similar to (9) is required for each of the 3 rooms within the containment vessel for each fission product component. Similarly, material balances on the liquid phase would be required to permit evaluation of $\mathrm{C}_{\mathrm{gi}}$. Simultaneous solution of the material balance equations would give the timeconcentration history. Solution of material balance equations can be realized only after the mass transfer coefficients, interfacial areas, reaction rates, generation rates, and interroom transport coefficient are known as functions of the basic system parameters. For special cases, the form of the material balance equations may be simplified, and several of these situations will be briefly noted.

Negligible Back Pressure of Dissolved Gas at Interface

At the beginning of a spray period, the concentration of the solute gas in the liquid phases is zero. For a reactive gas such as elemental iodine, dissolution is accompanied by rapid chemical reactions which enhances its solubility as indicated by Equation (4). If the equilibrium of the chemical reaction, Equation (3), lies far enough to the right, the gas concentration at the interface, $\frac{C_{l i}}{H}$, would be very small compared to $\mathrm{C}_{\mathrm{g}}$ in the bulk and, hence, could be neglected. The 
inter-room transport would be expected to be relatively small compared to the spray washout rate at the beginning of a spray period and, hence, the initial spray washout rate would not be greatly influenced by inter-room transport. For a puff release of elemental iodine under conditions where no appreciable reversible sink-sources are present, the generation rate may be taken as zero. This assumption is not necessarily valid even at the beginning of a spray period inasmuch as appreciable desorption of iodine from fog drops has been noted on occasion. For these assumptions, and neglecting gas phase reactions, the material balance equation gives, for constant conditions, a washout half-time of

$$
\begin{aligned}
t_{1 / 2} & =\frac{0.693 \mathrm{~V}}{\left(\mathrm{k}_{\mathrm{g}} \mathrm{A}\right) \mathrm{drops}^{+}\left(\mathrm{k}_{\mathrm{g}}{ }^{A}\right) \text { wall film }} \\
\text { or } t_{1 / 2} & =\frac{1}{\frac{1}{t_{1 / 2} \text { (drops) }}+\frac{1}{t_{1 / 2}(\text { wall film) }}}
\end{aligned}
$$

The gas phase transfer coefficient for falling drops may be estimated from an empirical equation proposed by Frossling, ( 9 ) and modified by Ranz and Marshall (10) as follows:

$$
\frac{k_{g} d}{D}=2+0.6 \mathrm{Re}^{0.5} \mathrm{Sc}^{0.33}
$$

where

$$
\begin{aligned}
\mathrm{d} & =\text { drop diameter } \\
\mathrm{D} & =\text { gas phase diffusivity of solute gas, } \\
\mathrm{Re} & =\text { Reynolds number of falling drop, } \\
\mathrm{SC} & =\text { Schmidt number. }
\end{aligned}
$$

This equation may be applied to a spray of known drop size distribution. The interfacial area for drops of diameter $d$ is

$$
A=\frac{6 F t_{e}}{d}
$$


where

$$
\begin{aligned}
A & =\text { surface area of drops, } \\
F & =\text { volumetric generation rate of drops of size d, } \\
t_{e} & =\text { exposure time in chamber for a drop of size d. }
\end{aligned}
$$

The average drop exposure time for a vessel in which there are different fall heights is

$$
t_{e}=\sum_{i} \frac{F_{i}}{F} t_{e i}
$$

where

$$
\begin{aligned}
F_{i} & =\text { volume flow rate of spray for } t_{e}=t_{e i}, \\
F & =\text { total volume flow rate of spray. }
\end{aligned}
$$

For a particular drop fall height, $h_{i}$, the exposure time may be calculated by assuming terminal velocity for the whole trajectory as

$$
t_{e i}=\frac{h_{i}}{v_{g}}
$$

where

$$
\begin{aligned}
& v_{g}=\text { terminal setting velocity, and } \\
& \mathrm{h}_{\mathrm{i}}=\text { fall height. }
\end{aligned}
$$

Using Equations (11), (12), (13), and (14), the washout rate constant for falling drops of size d is

$$
\left(k_{g}^{A}\right)_{d r o p s}=\frac{6 F D t_{e}\left(2+0.6 \mathrm{Re}^{0.5} \mathrm{Sc}^{0.33}\right)}{\mathrm{d}^{2}}
$$

Theoretically, it would be better to evaluate the product $t_{e}\left(2+0.6 \mathrm{Re}^{0.5} \mathrm{Sc}^{0.33}\right)$ as a function of distance from the nozzle. Also, the washout rate for the whole spray could best be obtained by integrating Equation (15) over the whole drop size spectrum. Based on average values of the parameters shown 
in Equation (15), the rate of concentration decrease as a result of drop absorption, neglecting source terms is:

$$
\frac{\mathrm{C}_{g}}{\mathrm{C}_{\mathrm{go}}}=\exp -\frac{\left(6 \mathrm{k}_{\mathrm{g}} \mathrm{F} \mathrm{ht}\right)}{\mathrm{V}_{\mathrm{g}} \mathrm{d}}
$$

where $h$ is the average fall height, determined by weighting each fall height with the flow rate for that fall height.

The transfer coefficient to wetted wall surfaces is less amenable to calculation than transfer to drops. The magnitude of the gas phase mass transfer coefficient for the wetted wall will depend on the flow conditions and mixing within the gas phase boundary layer. During the first spray period, gas phase flow along the wall will be induced by a thermal gradient between the wall and the bulk gas. Prior to initiation of sprays, the wall is cooler than the bulk gas which causes a natural convection flow down the wall. Spray liquid introduced may be substantially cooler than the containment temperature and, hence, the gas is rapidly cooled to a temperature below the wall temperature. This temperature change would cause a natural convection flow up the wall. The natural convection current would be influenced by the liquid film flowing down the wall and by the falling spray drops. The influence of these two factors will be neglected in predicting the wall film absorption.

In the absence of spray, the mass transport to a vertical wall may be estimated from a heat transfer analogy. Knudsen and Hilliard ${ }^{(6)}$ have shown that, for large chambers, the wall deposition of iodine vapor may be satisfactorily predicted from a heat transfer correlation obtained empirically for no condensation. For negligible surface concentration, the mass flux is

$$
\text { mass flux }=k_{s} C_{g}+k_{C} C_{g}=\left(k_{g} C_{g}\right) \text { wall film }
$$


BNWL - 1244

where

$$
\begin{aligned}
k_{c}= & \text { natural convection mass transfer coefficient, } \\
k_{S}= & \text { mass transfer coefficient due to condensing steam } \\
& (\text { sweep effect) } .
\end{aligned}
$$

The heat transfer correlation for turbulent flow may be used to obtain $k_{c}$ by substituting the schmidt number for the Prandt 1 number:

$$
\frac{k_{C} L}{D}=0.13(\text { Gr } \quad \text { Sc }) 1 / 3
$$

where

$$
\begin{aligned}
\mathrm{L} & =\text { length of vertical surface, } \\
\mathrm{Gr} & =\text { Grashov number } \\
\mathrm{SC} & =\text { Schmidt number }
\end{aligned}
$$

The value of $k_{s}$ is equal to the steam sweep velocity:

$$
k_{s}=\frac{n_{s} R T}{18 \mathrm{P}}
$$

where

$$
\begin{aligned}
\mathrm{n}_{\mathbf{S}} & =\text { mass flux of steam toward wall, } \\
\mathrm{R} & =\text { gas constant, } \\
\mathrm{T} & =\text { absolute temperature in gas film, } \\
\mathrm{P} & =\text { total pressure in vessel. }
\end{aligned}
$$

The Grashov number must be obtained from thermal hydraulic calculations, or from actual temperature measurements. During the initial spraying period, water would evaporate from the wall giving a negative $\mathrm{n}_{\mathrm{s}}$ and, consequently, a negative $\mathrm{k}_{\mathrm{s}}$.

It should be noted that the mass transfer correction due to the condensing steam flux indicated in Equations (17) and (19) is not rigorous. Theoretically, the change in the boundary layer flow should be accounted for as a result of this steam 
flux, (11) However, since the "correct" influence of the condensation on the turbulent boundary layer is not precisely known, and since the correction is relatively small, little error will be introduced by the use of the correction indicated in Equations (17 and (19). Using Equations (15) and (17), a washout half-time may be calculated for the case of negligible interfacial concentration. This case would be expected to apply to initial absorption of elemental. iodine. Griffiths, (4) in presenting calculations for this case, neglects wall film absorption and assumes a constant drop fall height and that the drops fall at terminal velocity. Parsly (12) has calculated washout rates accounting for drops entering at a velocity higher than terminal velocity.

Liauid Phase Mass Transfer Controlling

At the opposite end of the scale from Case I is absorption controlled entirely by liquid phase resistance. Liquid phase resistance would be expected to control the absorption of slightly soluble gases such as methyl iodide. For gases obeying Henry's Law, the overall resistance to mass transfer may be expressed as

$$
\frac{1}{\mathrm{~K}_{\mathrm{g}}}=\frac{1}{\mathrm{~K}_{\mathrm{g}}}+\frac{1}{\mathrm{Hk}_{\ell}}
$$

where

$$
\begin{aligned}
& \mathrm{K}_{\mathrm{g}}=\text { overall mass transfer coefficient, } \\
& \mathrm{k}_{\mathrm{g}}=\text { gas phase mass transfer coefficient, } \\
& \mathrm{k}_{\ell}=\text { liquid phase mass transfer coefficient, and } \\
& \mathrm{H}=\text { gas-liquid equilibrium partition coefficient. }
\end{aligned}
$$

Liquid phase resistance will be controlling if $\frac{1}{\mathrm{Hk}_{\ell}}$ is large compared to $\frac{1}{k_{\sigma}}$. Generally, $k_{\ell}$ values are smaller than $k_{g}$ values so that liquid phase resistance is important unless $\mathrm{H}$ is large compared to unity. 
The numerical value of the liquid phase mass transfer coefficient depends on the rate and extent of chemical reactions which destroy the solute, and on the rapidity of mixing in the liquid phase. In the following paragraph, the calculation of absorption rates for falling drops and wall films allows for first order chemical reactions for several limiting cases of mixing.

For a stagnant falling drop, the absorption in time $t_{e}$ is given by Danckwerts(13) as

$$
\begin{aligned}
& \frac{Q}{C_{\ell i}}=8 \pi a D_{\ell} \sum_{n=1}^{\infty}\left\{k a^{2} t_{e}+\frac{D_{\ell} n^{2} \pi^{2}}{k+\frac{D_{\ell} n^{2} \pi^{2}}{a^{2}}}[1\right. \\
& \left.-\exp \left[-t e\left(k+\frac{D_{\ell} n^{2} \pi^{2}}{a^{2}}\right)\right]\right] /\left(k a^{2}+D_{\ell} n^{2} \pi^{2}\right) \text {. }
\end{aligned}
$$

where

$$
\begin{aligned}
Q & =\text { amount absorbed in time } t_{e}, \\
D_{\ell} & =1 \text { liquid phase diffusivity, } \\
\mathrm{a} & =\text { drop radius, } \\
\mathrm{k} & =\text { first order reaction rate constant, } \\
\mathrm{t}_{\mathrm{e}} & =\text { drop exposure time. }
\end{aligned}
$$

Equation (21) would be expected to yield the lower limit of absorption as only diffusional transport is assumed. An upper limit to absorption may be estimated by assuming the drop to be perfectly mixed at all times. The absorption equation for a perfectly mixed drop is:

$$
\frac{Q}{C_{l i}}=\frac{4}{3} \pi a^{3}\left(k t_{e}+1\right) \text {. }
$$


Unfortunately, data are not available to permit adequate assessment of the mixing effect. Studies on larger drops $(14,15,16,17)$ have shown that circulation can occur, but small amounts of surface active agents can effectively inhibit circulation. A comparison between absorption rates calculated from Equations (21) and (22) has been presented. (18)

Transfer rates may be calculated from the penetration theory type models, or from laminar flow theory for liquid phase controlled wall film absorption. The differential equation describing absorption into a smooth laminar film is

$$
u_{\max }\left[1-\left(\frac{x}{\delta}\right)^{2}\right] \frac{\partial C}{\partial z}=D_{\ell} \frac{\partial^{2} C}{\partial x^{2}}-k C
$$

where

$$
\begin{aligned}
u_{\max } & =\text { velocity at the gas-liquid interface, } \\
\mathrm{x} & =\text { distance from surface of film, } \\
\delta & =\text { thickness of film, } \\
z & =\text { distance measured along film, } \\
\mathrm{k} & =\text { first order reaction rate constant. }
\end{aligned}
$$

For short laminar films, the solute does not have time to penetrate far into the film and, hence, the absorption takes place as though the film were infinite in thickness. The differential equation for absorption in such films may be obtained from Equation (23) by setting $x=0$. This is the penetration theory approximation, and the mathematical solution is given by Danckwerts. (19) Most experimental laminar flow data obtained for short wetted wall columns agree reasonably with this penetration theory solution.

For the long films encountered in containment vessels, laminar flow calculations indicate that the solute may diffuse all the way through the film. A lower limit to absorption in thin films, estimated by solving Equation (23) for $\frac{a c}{\partial z}=0$, gives 


$$
\frac{\mathrm{dq}}{\mathrm{dt}}=C_{\ell i} \sqrt{\mathrm{kD}} \tanh \left(\sqrt{\mathrm{k} / \mathrm{D}_{\ell}} 6\right)
$$

where

$$
\frac{d q}{d t}=\text { absorption rate per unit area. }
$$

The film thickness, 6, used in Equation (24), may be estimated from laminar flow theory and experimental measurements of the wall flow rate.

Turbulence, waves, and rivulet formation will cause mixing in actual films. An upper limit to film absorption may be estimated by considering the film to be perfectly mixed. For this case, the total film absorption rate for the whole vessel would be

$$
\text { Absorption Rate }=\mathrm{kC}_{\ell i} \mathrm{~V}_{W F}+\mathrm{C}_{\ell i} \mathrm{~L}_{F}
$$

where

$$
\begin{aligned}
\mathrm{V}_{\mathrm{WF}} & =\text { volume of liquid held up on walls as film, } \\
\mathrm{L}_{\mathrm{F}} & =\text { flow rate of liquid film. }
\end{aligned}
$$

In this analysis of wall film absorption, we have neglected reaction and dissolution of methyl iodide by the paint or surface of the wall. Appreciable transfer into the solid wall would enhance film absorption. Considerable effort has been devoted to developing paint additives capable of reacting with methyl iodide. (20) If these were incorporated, an accounting of the transfer rate from the liquid film to the wall would be required. An extensive review of absorption and fluid dynamics of thin films has been presented by Fulford. (21)

In addition to vertical wall surfaces, liquid pools formed in the bottom of containment vessels represent a region of additional absorption. Absorption in this volume may be significant if a chemical reaction destroys the dissolved gas. 
Realistic calculation of the absorption rate into the pool surface is possible only if surface renewal rates are known. Upper and lower limits based on a stagnant or a well mixed. pool may be computed.

\section{Effect of Recirculation}

In reactor containment systems, the spray liquid introduced to cool the postaccident atmosphere and to trap fission products will be cooled by heat exchange and recirculated through the spray nozzles. Thus, after an initial period of fresh spray, the spray liquid entering the chamber with a nonzero solute concentration will decrease the concentration driv ing force and slow the rate of absorption. The rate of decrease in gas phase concentration depends on the way in which the liquid is mixed within the chamber, and on the rate and extent of chemical reactions occurring within the chamber.

One case amenable to simple calculation is based on the assumptions that (1) Henry's Law applies (Equation 4), (2) no liquid is held up within the chamber except in the sump, (3) the liquid in the sump is well mixed, and (4) drop and atmosphere concentrations do not change appreciably during drop fall time. For this case, simultaneous material balances on the gas and liquid phases give:

$$
\frac{C_{g}}{C_{g O}}=\frac{V}{V+L H}+\frac{L H}{V+L H} \exp \left[-\left(\frac{K_{g} A}{V}\right)\left(\frac{V+L H}{L H}\right) t\right]
$$

where

$$
\begin{aligned}
\mathrm{K}_{\mathrm{g}} & =\text { overall mass transfer coefficient, } \\
\mathrm{L} & =\text { liquid hold-up in sump, } \\
\mathrm{A} & =\text { interfacial area for transport. }
\end{aligned}
$$

This equation would be expected to apply reasonably well to the absorption of elemental iodine by sprays. 
For a slightly soluble species such as methyl iodide, the effect of recirculation depends on the reaction rate. For negligible reaction rates, the liquid will approach saturation during one pass through the chamber and recirculation will not influence the gas phase concentration. The net effect of liquid phase reaction rates too small to enhance absorption during a single pass but fast enough to destroy the dissolved gas within the sump will be to make the spray "fresh." For this case, the gas phase washout would follow

$$
\frac{C_{g}}{C_{g O}}=\exp \left(-\frac{F t}{H V}\right)
$$

where

$$
\begin{aligned}
& F=\text { liquid flow rate, and } \\
& H=\text { partition coefficient for unreacted species }
\end{aligned}
$$

For still faster reactions, appreciable absorption enhancement would occur, and an equation similar to Equation (27) would apply, with H calculated to account for the enhanced absorption due to chemical reaction.

REMOVAL OF AEROSOL PARTICLES

The mechanisms contributing to capture of aerosol particles by sprays in containment vessels include gravitational settling, inertial impaction, Brownian diffusion, thermophoresis, diffusiophoresis, electrical attraction, and the interception effect. This capture will occur at the surface of falling drops and at the walls and floor of the vessel. The purpose of the review presented here is to show how the removal rate due to the several mechanisms can be related to the basic parameters of the system.

Particle capture by a spray may be evaluated by considering the spray as an assemblage of noninteracting single drops. This assumption may not be precisely true, but appears reasonable 
for the spray systems of interest here. Based on this assumption, the rate of washout may be related to the collection efficiency for a single drop.

A material balance on the gas phase of a well mixed containment vessel gives, for the washout half-time,

$$
t_{1 / 2}=\frac{0.693 v}{\frac{3}{2}\left(\frac{h E F}{d}\right)+v_{G} A_{F}+v_{W} A_{W}}
$$

where

$$
\begin{aligned}
\mathrm{h} & =\mathrm{fall} \text { height, } \\
\mathrm{E} & =\text { total collection efficiency of drop, } \\
\mathrm{F} & =\text { flow rate for drops, } \\
\mathrm{v}_{\mathrm{G}} & =\text { gravitational settling deposition velocity, } \\
\mathrm{v}_{\mathrm{W}} & =\text { wall deposition velocity of particles, surface average, } \\
\mathrm{A}_{\mathrm{F}} & =\text { floor area (horizontal projection), } \\
\mathrm{A}_{\mathrm{W}} & =\text { area of effective wall surface. }
\end{aligned}
$$

Equation (28) is for a single drop size, and application to sprays containing a wide spectrum of sizes should be done incrementally to account for the effect of drop size.

Gravitational Settling

Gravitational settling will cause particles to deposit on horizontal surfaces. For a well mixed chamber, the gravitational settling deposition velocity may be taken as the terminal settling velocity of the particles:

$$
\mathrm{v}_{\mathrm{G}}=\text { terminal velocity }=\mathrm{mgB}
$$

where

$$
\begin{aligned}
& \mathrm{m}=\text { particle mass } \\
& \mathrm{B}=\text { particle mobility, and } \\
& \mathrm{g}=\text { acceleration due to gravity }
\end{aligned}
$$


Brownian Diffusion

Very small particles are capable of appreciable diffusional transfer as a result of Brownian motion. Thus, they will behave as gases qualitatively, but with much lower diffusion coefficients. For a falling drop, the transfer coefficient may be predicted from the Frossling equation (Equation 11) using as diffusivity the value calculated from Einstein's(22) equation:

$$
D_{p}=k T B
$$

where

$$
\begin{aligned}
\mathrm{D}_{\mathrm{P}} & =\text { diffusion coefficient for particle, } \\
\mathrm{T} & =\text { absolute temperature, } \\
\mathrm{B} & =\text { particle mobility } \\
\mathrm{k} & =\text { Boltzmann's constant. }
\end{aligned}
$$

For drops moving at terminal velocity, the target efficiency is

$$
E_{B D}=\frac{4 D_{p}\left(2+0.6 \mathrm{Re}^{0.5} \mathrm{Sc}^{0.33}\right)}{d v_{g}}
$$

where

$$
\begin{aligned}
\mathrm{E}_{\mathrm{BD}} & =\text { target efficiency for Brownian diffusion, } \\
\mathrm{V}_{\mathrm{g}} & =\text { drop terminal velocity, } \\
\mathrm{Re} & =\text { Reynolds number for drop, } \\
\mathrm{d} & =\text { drop diameter. }
\end{aligned}
$$

Use of Equation (11) for predicting aerosol deposition due to Brownian diffusion is not fully justified because the Schmidt numbers associated with aerosol particles are generally much larger than the Schmidt numbers for the experiments verifying Equation (11). 


\section{Inertial Impaction}

Inertial impaction occurs because particles are able to cross stream lines due to their inertia. For impaction on the forward part of a sphere or drop, the target efficiency is a function of the ratio of the particle stopping distance to the diameter of the sphere (Stokes number). ${ }^{(23)}$ The target efficiency measured by Ranz and Wong $(24)$ appears to agree with the predictions based on potential flow. Very few data are available for particles below 2 microns, the size range of primary interest here. For Stokes numbers less than 0.0834, an impaction efficiency of zero is predicted.

\section{Interception}

The interception effect requires no inertia. A particle will be intercepted by a collector if its trajectory passes within one particle radius. For potential flow around a sphere, the interception target efficiency is: (24)

$$
E_{\text {INT }}=3 \frac{d}{d}
$$

where

$$
\begin{aligned}
\mathrm{d}_{\mathrm{P}} & =\text { spherical particle diameter, } \\
\mathrm{d} & =\text { drop diameter. }
\end{aligned}
$$

\section{Diffusiophoresis}

Pressure suppression sprays will enter the containment vessel considerably cooler than the atmosphere temperature. Steam will condense on the cool droplets and the vapor flux thus produced will cause particle motion toward the drop. An estimate of the particle capture can be made by considering condensation on a stationary drop.

The diffusiophoretic velocity in the slip flow regime for spherical particles is (25) 


$$
\mathrm{V}_{\mathrm{D}}=\left(1+\sigma_{12} \gamma_{2}\right) \frac{\mathrm{D}}{\gamma_{2}} \nabla \gamma_{1 \infty}
$$

where

$$
\begin{aligned}
\mathrm{V}_{\mathrm{D}} & =\text { diffusiophoretic velocity, } \\
\sigma_{12} & =\text { slip factor }=0.95 \frac{\mathrm{M}_{1}-\mathrm{M}_{1}+\mathrm{M}_{2}}{2}-1.05 \frac{\mathrm{d}}{\mathrm{d}} \frac{\mathrm{d}}{\mathrm{d}}, \\
\gamma_{2} & =\text { mole fraction of air, } \\
\gamma_{1 \infty} & =\text { mole fraction of water vapor far from particle, } \\
D & =\text { diffusivity of water in air, } \\
\mathrm{M}_{1} & =\text { molecular weight of water, } \\
\mathrm{M}_{2} & =\text { molecular weight of air, } \\
\mathrm{d}_{1} & =\text { molecular diameter of water molecules, } \\
\mathrm{d}_{2} & =\text { molecular diameter of air molecules. }
\end{aligned}
$$

The concentration gradient $\nabla \gamma_{1_{\infty}}$ at the surface of a drop may be obtained in terms of the condensation rate. The time integrated velocity multiplied by the drop surface area gives the volume of the gas swept to the surface. The effective target efficiency is found to be approximately

$$
\mathrm{E}_{\mathrm{D}}=\frac{4\left(1+\sigma_{12} \gamma_{2}\right) \rho_{\ell} \mathrm{aC}_{\mathrm{P \ell}} \mathrm{T}_{\ell}}{3 \mathrm{Ch} \Delta \mathrm{H}_{\mathrm{C}}}
$$

where

$$
\begin{aligned}
\Delta \mathrm{T}_{\ell}= & \text { temperature rise of spray drops in chamber, } \\
\rho_{\ell}= & \text { density of liquid spray, } \\
\Delta \mathrm{H}_{\mathrm{C}}= & \text { latent heat of condensation per mole, } \\
\mathrm{C}_{\mathrm{Pl}}= & \text { heat capacity of spray liquid, } \\
\mathrm{C}= & \text { total gas concentration in containment volume, } \\
& \text { mole/cm } 3
\end{aligned}
$$




\section{Thermophoresis}

Thermal gradients associated with the heat transfer will also cause particle movement towards the surface on which vapor is condensing. However, for steam-air mixtures of interest here, thermophoresis will be small compared to diffusiophoresis. $(26,27)$ Hence, thermophoresis will be neglected. Electrical Attraction

Electrical forces can be very effective in causing particle capture by falling drops. If the particle and drop charges are known, the target efficiency may be calculated. (28) Some calculations for containment sprays have been given. (29) For the CSE experiments, existing electrical charges were tentatively concluded to be too low to provide appreciable particle collection. (30)

Effect of Recirculation on Airborne Particle Washout

Aerosol particles captured by water sprays will exhibit no tendency to escape from the liquid phase, and may be considered to have zero equilibrium back-pressure. Hence, recirculation of spray liquid will not cause a levelling in the gas concentration of aerosol particles as would be expected for a gaseous species such as $\mathrm{I}_{2}$. If the particle generation rate is zero, the aerosol concentration will fall to zero as a result of spray recirculation.

Two effects of spray recirculation which could affect the spray washout rate are worthy of note. First, if the spray liquid is not cooled by heat exchange, little condensation would occur on the drop and, hence, the diffusiophoretic capture mechanism will vanish. Second, changes in the thermodynamic conditions of the atmosphere as a result of recirculation could cause particle growth or evaporation. This effect applies to soluble particles such as cesium existing in the containment atmosphere as solution drops. The amount of particle growth or 
evaporation which could occur depends on the changes in relative humidity resulting from recirculation. Because the change in relative humidity is not easy to predict with certainty, theoretical prediction of particle size change as a result of recirculation could be considered only if verified by experimental measurements.

\section{EFFECT OF PARTIAL SPRAY COVERAGE}

The preceding theoretical treatment of washout by spray drops is based on the assumption that all the gas within a single compartment is of uniform concentration. This assumption is probably valid for cases where the entire gas space is covered by the spray. In some practical cases, the spray might wash only a fraction of the total volume because of irregular geometry or spray systems not purposely designed to cover all the gas space. It is of interest to estimate the maximum concentration difference which might exist between sprayed and nonsprayed regions, and to evaluate this effect on the accuracy of predictions based on uniform concentration.

Assume that the nonsprayed and sprayed regions can be represented by two separate volumes, $\mathrm{V}_{1}$ and $\mathrm{V}_{2}$, respectively, as depicted in Figure 2. Each region is assumed to be individually well mixed. Gas at concentration $\mathrm{C}_{2}$ leaves the sprayed region and enters the unsprayed region at flow rate $Q$. A similar flow of concentration $C_{1}$ returns to the sprayed region. For simplification, it is further assumed that there is no deposition on structural surfaces within $v_{1}$ or $v_{2}$, and the only removal is due to spray drops within $v_{2}$ with a first order rate constant, $\mathrm{A} \mathrm{min}^{-1}$.

A mass balance of the fission product material taken on the gas space $V_{1}$ gives

$$
\frac{d C_{1}}{d t}=\frac{Q}{V_{1}}\left(C_{1}-C_{2}\right) \text {. }
$$


BNWL - 1244

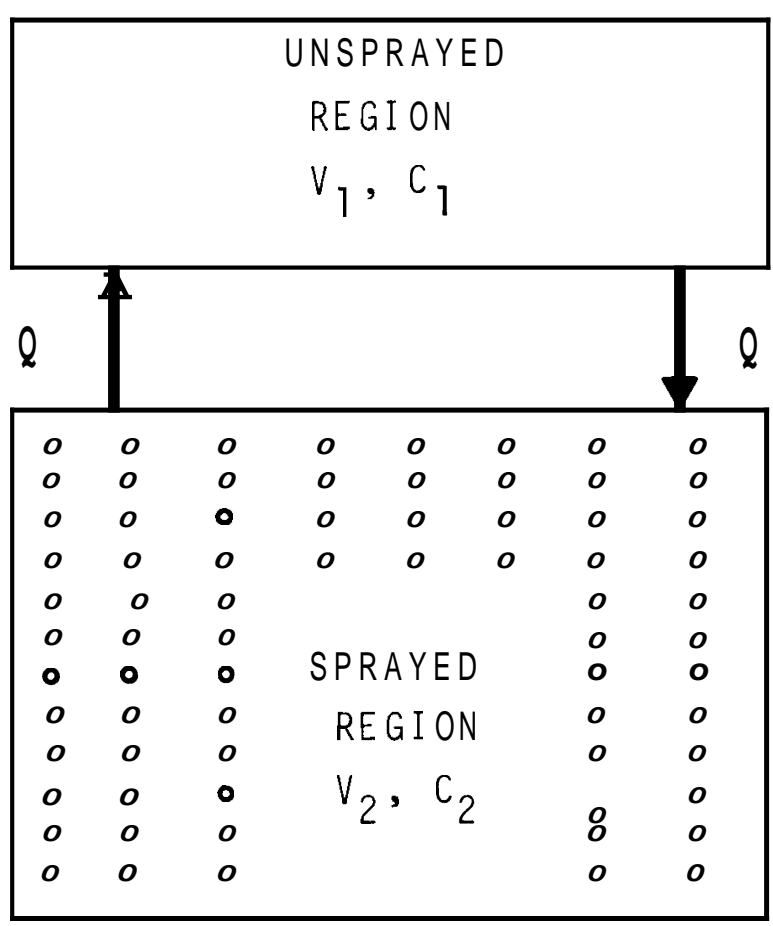

FIGURE 2. Schematic Diagram of Transport Between Sprayed and Unsprayed Regions

A similar balance on $\mathrm{V}_{2}$ gives

$$
\frac{d C_{2}}{d t}=\frac{Q}{V_{2}}\left(C_{1}-C_{2}\right)-\lambda C_{2} .
$$

The maximum concentration difference will occur when

$$
\mathrm{dC}_{1}=\frac{\mathrm{dC}_{2}}{\mathrm{dt}}
$$

For this case,

$$
\frac{\mathrm{L}_{1}}{\mathrm{C}_{2}}=1+\frac{\mathrm{f}(1-\mathrm{f}) \lambda \mathrm{V}}{\mathrm{Q}}
$$

where

$$
\begin{aligned}
& \mathrm{V}=\mathrm{V}_{1}+\mathrm{V}_{2} \text {, and } \\
& \mathrm{f}=\text { fraction of combined volumes not sprayed. }
\end{aligned}
$$


Since there is no physical membrane separating the two regions, the exchange rate of gas, Q, especially for the case of cold sprays in a steam atmosphere, should be large. The value of $V / Q$ is estimated to be in the range of 1 to 5 min for the CSE system. Thus, for removal of $\mathrm{I}_{2}$ at $\lambda=0.5 \mathrm{~min}^{-1}$ and a vessel in which $20 \%$ of the volume is not sprayed, $C_{1}$ should be $8-40 \%$ greater than the concentration in the region washed by the spray. The mass of iodine remaining airborne should be $<8 \%$ greater (not a large difference) than if the entire vessel volume were washed. 
BNWL -1244

\section{EXPERIMENTAL CONDITIONS}

\section{EXPERIMENTAL EQUIPMENT}

The CSE experimental equipment can be grouped for discussion purposes into six systems:

- the containment vessel system

- the fission product simulant generation and injection system

- the gas and liquid sampling system

- the instrumentation system

- the sample analysis system, and

- the containment spray system.

Each system is described in some detail in Appendix $A$, and the total system is depicted schematically in Figure 3. An outer vessel of $30,680 \mathrm{ft}^{3}$ called the main containment vessel, an inner vessel of $2286 \mathrm{ft}^{3}$ called the drywell, and the vessel of $4207 \mathrm{ft}^{3}$ occupying four-fifths of the annular space between the drywell and the main containment vessel called the wetwell are the three interconnected vessels basically comprising the containment vessel system. The main containment vessel is $25 \mathrm{ft}$ in diam and $66.7 \mathrm{ft}$ in overall height. All interior surfaces are coated with a modified phenolic paint.*

The top of the wetwell forms a solid deck which effectively separates the contained gases into what we term the "main room" above the deck and the lower rooms below the deck. For the present spray experiments, the lid of the 11 -ft diam drywe11 was raised to make its volume common to the main room. The combined volume of this "main room" is $21,005 \mathrm{ft}^{3}$. One-fifth of the annular space between drywell and main containment vessel is a small access of $2089 \mathrm{ft}^{3}$ known as the "middle room." Below the middle room, the drywe11, and the wetwell is a third space of $3380 \mathrm{ft}^{3}$ called the "lower room." The wetwe11 was

Phenoline 302. The Carboline Co., St. Louis, Missouri. 


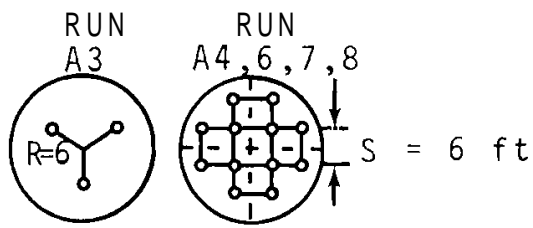

PLAN VIEW OF

NOZZLE ARRANGEMENT

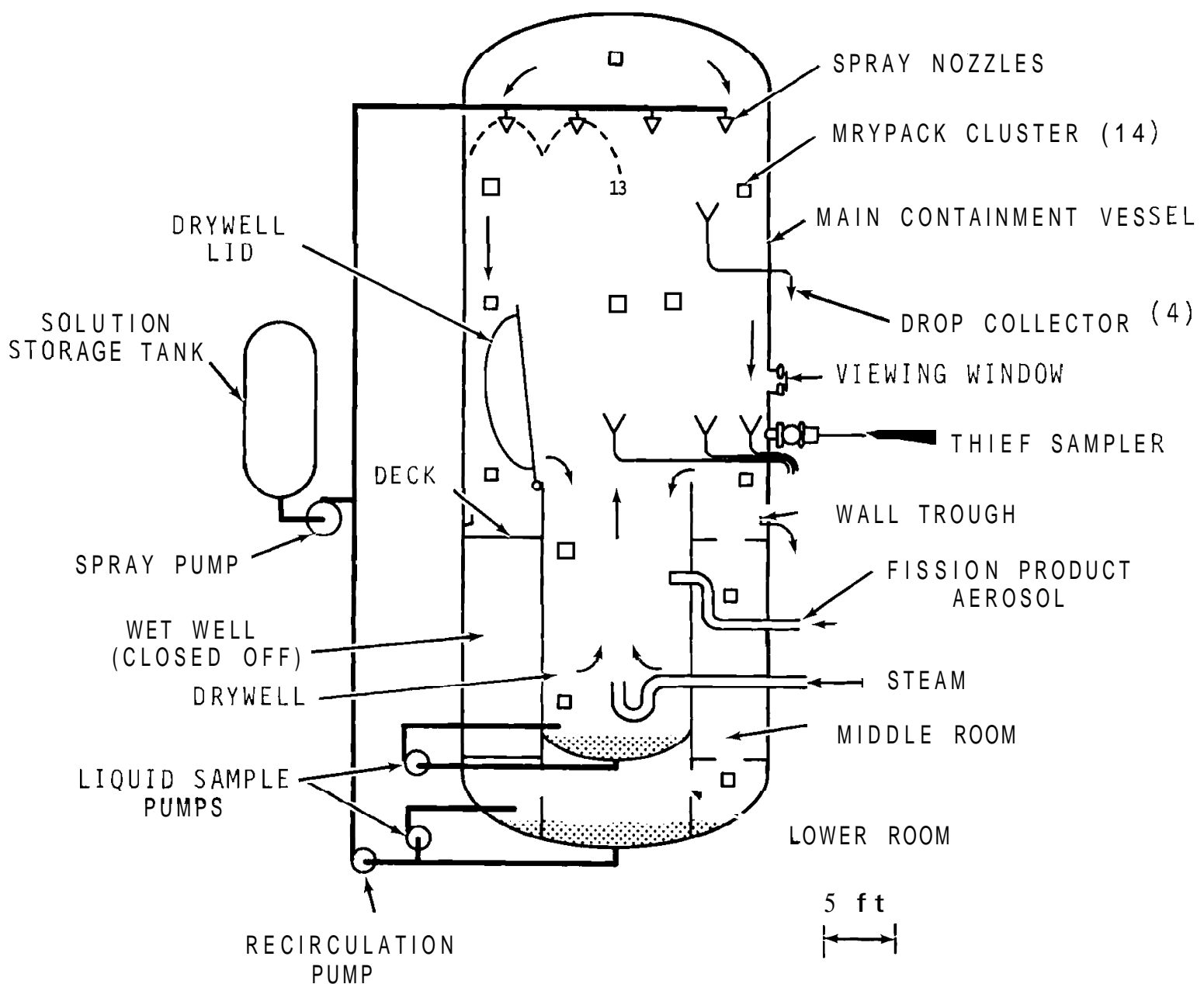

FIGURE 3. Schematic Diagram of Containment Arrangement Used in CSE Spray Tests 
sealed off and not exposed to steam or fission product simulant in these experiments. Two 4 -ft diam holes in the deck connect the main room to the middle room, while one $4-\mathrm{ft}$ opening connects the middle room to the lower room.

Steam condensate and spray liquid accumulate in the drywell pool, the main vessel pool located in the lower room, and on the flat deck of the main room. The first two are stirred, sampled frequently, and the liquid volume monitored. The unmonitored liquid on the deck drains into the main vessel pool and, together with the main room wall trough, is the source of the main vessel pool.

A line from the plant steam boiler terminates near the bottom of the drywell to provide the steam for experiments at elevated temperatures. For the two experiments with room temperature air atmospheres, a small fan was located at the bottom of the drywell discharging $2300 \mathrm{ft}^{3} / \mathrm{min}$ in an upward direction to provide mixing of the aerosol before activating the sprays.

Coleman (31) has described the method of generating the fission product simulant in detail, but a brief description is given here. Four materials released in these experiments to permit mass transfer measurements were elemental iodine, methyl iodide, cesium, and particles formed by melting unirradiated Zircaloy-clad $\mathrm{UO}_{2}$. About $100 \mathrm{~g}$ of stable elemental iodine was equilibrated with about one curie of ${ }^{131}$ I as described by Coleman. (31) The ${ }^{131}$ I served as a tracer for analytical purposes. When release was desired, the flask containing the iodine was heated electrically and air, swept through the flask, carried the elemental iodine through the hot zone of the $\mathrm{UO}_{2}$ melting furnace. Some particulateassociated iodine and organic iodides were always produced. 
About one gram of iodine in the form of reagent grade methyl iodide was equilibrated with ${ }^{131}$ I in methyl alcohol in a stainless steel U-tube. When release was desired, air was passed through the U-tube to sweep the methyl iodide directly into the containment vessel (bypassing the $\mathrm{UO}_{2}$ furnace).

About $12 \mathrm{~g}$ of stable cesium as cesium carbonate was equilibrated with about one curie of ${ }^{137} \mathrm{Cs}$ in a nickel boat and dried at a temperature $<400{ }^{\circ} \mathrm{C}$. When release was desired, the nickel boat was heated inductively to $\sim 1200^{\circ} \mathrm{C}$ and an air stream carried the volatilized cesium and cesium oxides through the $\mathrm{UO}_{2}$ furnace into the containment vessel.

In all the spray experiments, the $\mathrm{UO}_{2}$ was melted for $10 \mathrm{~min}$ before and during the iodine and cesium release period. Zero time was defined as the start of iodine and cesium release. A steam jet at the drywell acted as a compressor for injecting the volatilized simulant into the pressurized vessel.

The suitability of the fission product simulant generated by these methods as tracers to represent actual fission products in containment behavior experiments was demonstrated by small scale tests in the Aerosol Development Facility (ADF) (33) and elsewhere. (34)

The main gas sampling system consisted of Maypack clusters located throughout the vapor space. This system is described in the Appendix and by McCormack. (32) Supplementary gas samples, known as "thief" Maypack samples, were taken by manually inserting a Maypack through an airlock into the containment atmosphere and immediately withdrawing it for analysis. Flow through each Maypack was $0.5 \mathrm{scfm}$ air for $3 \mathrm{~min}$ duration.

Liquid sampling was extensive. Some of the liquid samples were filtered to determine the insoluble fraction and extracted with benzene to determine the iodine forms. The pH was determined on about half the liquid samples. 
The CSE facility was adequately instrumented for characterization of atmospheric conditions. Details are given in the Appendix.

About 2000 samples, obtained from each experiment, were analyzed by the CSE staff for iodine and for cesium by gamma energy analytical techniques, and for uranium by alpha counting. Additional details are given in the Appendix and by Coleman. (31)

The containment spray system was composed of spray solution makeup and storage tanks, a line and pump to the spray manifold, the spray manifold inside the main containment vessel, the spray nozzles, and a recirculation pump, line, and heat exchanger for recirculating the liquid from the main vessel pool back to the spray manifold. Associated instrumentation consisted of spray solution flow rate meter, liquid level gages on all tanks and pools, a differential pressure gage for measuring pressure drop across the spray nozzles, and thermocouples and recorders for measuring spray liquid temperature at various locations.

\section{EXPERIMENTAL PROCEDURE}

Before each experiment was begun, a comprehensive description of all phases of the proposed experiment was written. These "Run Plans," serving primarily as a guide to the operations staff in conducting the experiment, were also useful for planning the experimental details and as handy references to the selected conditions and procedures. Because exact conditions might differ slightly from those planned, the use of instrument charts and log sheets would usually be required.

The general procedures used in all the experiments is outlined as follows:

1. The containment vessel was readied. Spray nozzles were installed and tested for flow rate and coverage. Maypack clusters were installed and tested. 
2. The vessel was pressurized with air and leak tested.

3. The air in the vessel was vented until barometric pressure and room temperature prevailed. The vessel was then sealed and the air recirculated through an absolute filter until condensation nuclei concentration was $<300 \mathrm{~cm}^{-3}$. For tests where a steam-air atmosphere at elevated temperature and pressure was specified, steam was fed into the system near the bottom of the drywe 11.

5. When the desired temperature in the main room $\left(250 \pm 2{ }^{\circ} \mathrm{F}\right)$ was reached, as measured by an average of several thermocouples, the steam feed was reduced to that required to maintain steady temperature in the main room. (For the two room-temperature experiments, this was not necessary, of course).

6. The liquid pools formed by steam condensate during warmup were drained and discarded.

The $\mathrm{UO}_{2}$ was melted and $\mathrm{UO}_{2}$-Zircaloy particles injected into the containment atmosphere by an air flow of $1.8 \mathrm{f} \mathrm{t}^{3} / \mathrm{min}(\mathrm{STP})$. The release point was at mid elevation in the drywell.

8. After 10 min of $\mathrm{UO}_{2}$-Zircaloy particle injection, the iodine and cesium release was started. Methyl iodide was then released through a separate line. Ten minutes after iodine and cesium release started, all valves were closed. Zero time was defined as start of iodine release.

9. During simulant injection and throughout the remainder of the experiment (24-36 hr), steam feed was continued at the rate previously determined necessary to maintain the temperature at $250{ }^{\circ} \mathrm{F}$ in the main room.

10. Samples were taken over a 30 -min period to determine, in the absence of sprays, the behavior of the fission product simulant materials.

11. The first spray period was started at the specified time. Fresh solution at room temperature from the storage tank 
outside containment was used. A set of gas samples was taken during and immediately following this spray.

12. Liquid samples were taken frequently during the first spray period from liquid pools and from wall trough and spray drop collectors.

13. Upon completion of the first spray period, Maypack gas samples again were taken at various times to determine the natural behavior.

14. The second spray period was started at the specified time. This period was continued for a total of $40 \mathrm{~min}$ of fresh spray, including the first period.

15. During all spray periods, the primary control was the differential pressure across the spray nozzles. This pressure was held constant to maintain the same drop size distribution. In Runs A6, A7, and A8, the temperature dropped from the initial $250{ }^{\circ} \mathrm{F}$ because of introduction of cold spray, but the steam feed was left at its original low setting.

16. After a specified waiting period with no spray (usually overnight, but in Run A8 within a few hours), a third spray period was started. This spray was produced by recirculating the solution from the main containment vessel pool. The heat exchanger was bypassed so that the solution was hot, usually about $200^{\circ} \mathrm{F}$. The vapor temperature would usually return to $250{ }^{\circ} \mathrm{F}$ by the time the third spray started.

17. A fourth fresh, cold spray (sodium thiosulfate, boric acid, pH 9.4) was used in kuns A7 and A8.

18. After the last spray, a final set of samples was taken, the steam feed shut off, and the vessel allowed to cool to about $100^{\circ} \mathrm{F}$. The air was purged through a charcoal adsorber to a stack and the vessel was entered to retrieve the samplers. 
19. After sample hardware recovery, the vessel was resealed and steamed for several days with alternate water spraying to decontaminate the painted surfaces.

20. Each of the Maypacks was removed from the cluster assemblies and carefully marked with its proper identification. The Maypacks were brought into a sample preparation room and disassembled. Each component (or group of components) was carefully removed and placed in a small, flat polyethylene bag marked with its proper identification, and heat sealed. The charcoal granules were poured into a small plastic jar.

21. Liquid samples were taken in 500-ml polyethylene bottles, marked as to volume or aliquot, and identification symbols applied. Specified samples were filtered, extracted, or measured for $\mathrm{pH}$.

22. Deposition coupons were placed in flat polyethylene bags, marked, and heat sealed.

23. Gamma analysis began during the experiment and continued on a 24-hr basis for about one week.

24. Alpha analysis of Maypack filters continued for several weeks after the experiment.

\section{TEST CONDITIONS}

The conditions used in each experiment are best reported in tabular form. Table 1 lists the physical dimensions common to all the experiments. Table 2 describes the spray nozzles used and Table 3 lists the atmospheric conditions. Table 4 presents spray solution details and applicable flow rates, and Table 5 lists the starting and stopping times of each spray period. 
TABLE 1. Physical Conditions Common to A 11 Spray Experiments

Volume above deck including drywe11

Surface area above deck including drywe11

Surface area/volume

Cross section area, main vessel

Cross section area, drywell

$$
\begin{array}{rr}
21,005 \mathrm{ft}^{3} & 595 \mathrm{~m}^{3} \\
6,140 \mathrm{ft}^{2} & 569 \mathrm{~m}^{2} \\
0.293 \mathrm{ft}^{-1} & 0.958 \mathrm{~m}^{-1} \\
490 \mathrm{ft}^{2} & 45.5 \mathrm{~m}^{2} \\
95 \mathrm{ft}^{2} & 8.8 \mathrm{~m}^{2} \\
2,089 \mathrm{ft}^{3} & 59 \mathrm{~m}^{3} \\
1,363 \mathrm{ft}^{2} & 127 \mathrm{~m}^{2} \\
3,384 \mathrm{ft}^{3} & 96 \mathrm{~m}^{3} \\
2,057 \mathrm{ft}^{2} & 191 \mathrm{~m}^{2} \\
26,477 \mathrm{ft}^{3} & 751 \mathrm{~m}^{3} \\
9,560 \mathrm{ft}^{2} & 888 \mathrm{~m}^{2} \\
33.8 \mathrm{ft}^{2} & 10.3 \mathrm{~m}^{2} \\
50.5 \mathrm{ft}^{2} & 15.4 \mathrm{~m}^{2}
\end{array}
$$

Volume, middle room

Surface area, middle room

Volume, lower room

Surface area, lower room

Total volume of a 11 rooms

Total surface area, a 11 rooms

Drop fall height to deck

Surface coating

Thermal insulation
A 11 interior surfaces coated with phenolic paint(a)

A 11 exterior surfaces covered with 1 -in. fiberglass insulation(b)

a. Two coats Phenoline 302 over one coat Phenoline 300 primer. The Carboline Co., St. Louis, Missouri.

b. $k=0.027 \mathrm{Btu} /\left(h_{r}\right)\left(f t^{2}\right)\left({ }^{o} F / f t\right)$ at $200{ }^{\circ}$, Type PF-615, Owens-Corning Fiberglas Corp. 
TABLE 2. Nozzles Used i n CSE Spray Experiments

Runs A3, 4, 6, 7

Nozzle Type:

Spraying Systems Co. 3/4 - 7G3

Nozzle Characteristics: Fog Type, full cone

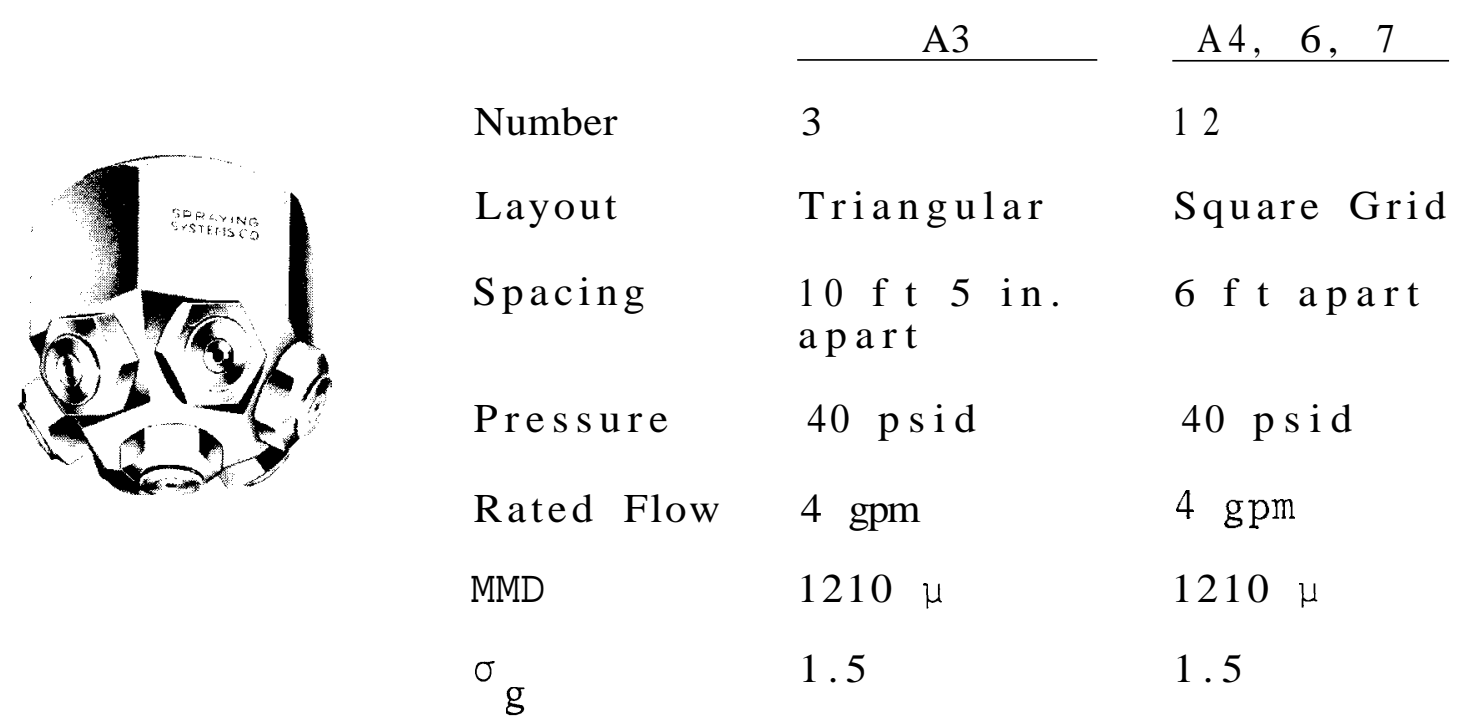

Run A8

Nozzle Type: $\quad$ Spraying Systems Co. 3/8 A 20

Nozzle Characteristics: Fine atomization, hollow cone

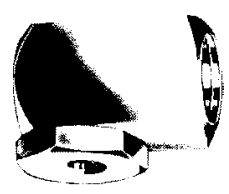

$\begin{array}{ll}\text { Number used } & 12 \\ \text { Lavout } & \text { Sauare Grid } \\ \text { Spacing } & 6 \mathrm{f} \mathrm{t} \mathrm{apart} \\ \text { Pressure } & 40 \mathrm{psid} \\ \text { Rated Flow } & 4 \mathrm{gpm} \\ \text { MMD } & 770 \mathrm{\mu} \\ \sigma \mathrm{g} & 1.5\end{array}$


BNWL - 1244

TABLE 3. Atmospheric Conditions in CSE Spray Experiments

\begin{tabular}{|c|c|c|c|c|c|}
\hline & $\begin{array}{l}\text { Run } \\
\text { A3 }\end{array}$ & $\begin{array}{l}\text { Run } \\
\text { A4 }\end{array}$ & $\begin{array}{l}\text { Run } \\
\text { A6 }\end{array}$ & $\begin{array}{l}\text { Run } \\
\text { A7 }\end{array}$ & $\begin{array}{l}\text { Run } \\
\text { A } 8\end{array}$ \\
\hline $\begin{array}{l}\text { Containment vessel } \\
\text { nsulated }\end{array}$ & No & No & Yes & Yes & Yes \\
\hline $\begin{array}{l}\text { orced a ir } \\
\text { irculation(a) }\end{array}$ & Yes & Yes & No & No & No \\
\hline $\begin{array}{l}\text { tart of } 1 \text { st } \text { Spray }_{\circ}(b) \\
\text { Vapor temp., }{ }^{\circ}(b) \\
\text { Pressure, psia } \\
\text { Relative humidity, } \%\end{array}$ & $\begin{array}{l}77 \\
14.6 \\
70\end{array}$ & $\begin{array}{l}77 \\
14.6 \\
88\end{array}$ & $\begin{array}{c}255 \\
44.2 \\
100\end{array}$ & $\begin{array}{r}248.7 \\
50.0 \\
100\end{array}$ & $\begin{array}{l}250 \\
50.7 \\
100\end{array}$ \\
\hline $\begin{array}{l}\text { nd of } 1 \text { st Spray } \\
\text { Vapor temp., }{ }^{\circ} \mathrm{F}(\mathrm{b}) \\
\text { Pressure, psia }\end{array}$ & $\begin{array}{l}77 \\
14.6\end{array}$ & $\begin{array}{l}77 \\
14.6\end{array}$ & $\begin{array}{l}229 \\
38.6\end{array}$ & $\begin{array}{r}234.5 \\
44.4\end{array}$ & $\begin{array}{l}243 \\
48.2\end{array}$ \\
\hline $\begin{array}{l}\text { tart of 2nd Spray } \\
\text { Vapor temp., }{ }^{\circ} \mathrm{F}(\mathrm{b}) \\
\text { Pressure, psia }\end{array}$ & $\begin{array}{l}77 \\
14.6\end{array}$ & $\begin{array}{l}77 \\
14.6\end{array}$ & $\begin{array}{r}237 \\
40.8\end{array}$ & $\begin{array}{l}240 \\
46.0\end{array}$ & $\begin{array}{r}243 \\
49.3\end{array}$ \\
\hline $\begin{array}{l}\text { nd of } 2 \text { nd Spray } \\
\text { Vapor temp., }{ }^{\circ} \text { F (b) } \\
\text { Pressure, psia }\end{array}$ & $\begin{array}{l}77 \\
14.6\end{array}$ & $\begin{array}{l}77 \\
14.6\end{array}$ & $\begin{array}{r}202 \\
29.5\end{array}$ & $\begin{array}{r}203 \\
36\end{array}$ & $\begin{array}{l}188 \\
34.1\end{array}$ \\
\hline $\begin{array}{l}\text { tart of } 3 r d S_{\text {Spray }} \\
\text { Vapor temp., }{ }^{\circ} \text { F(b) } \\
\text { Pressure, psia }\end{array}$ & $\begin{array}{l}77 \\
14.6\end{array}$ & $\begin{array}{l}77 \\
14.6\end{array}$ & $\begin{array}{r}246 \\
43.9\end{array}$ & $\begin{array}{l}248 \\
46.8\end{array}$ & $\begin{array}{r}217 \\
41.5\end{array}$ \\
\hline $\begin{array}{l}\text { ind of } 3 \text { rd Spray } \\
\text { Vapor temp., }{ }^{\circ} \mathrm{F}(\mathrm{b}) \\
\text { Pressure, psia }\end{array}$ & $\begin{array}{l}77 \\
14.6\end{array}$ & $\begin{array}{l}77 \\
14.6\end{array}$ & $\begin{array}{r}233 \\
40.7\end{array}$ & $\begin{array}{r}230 \\
41.8\end{array}$ & $\begin{array}{r}218 \\
32.2\end{array}$ \\
\hline $\begin{array}{l}\text { Start of } 4 \text { th Spray } \\
\text { Vapor temp. }{ }^{\circ} F(b) \\
\text { Pressure, psia }\end{array}$ & $\begin{array}{l}(c) \\
(c)\end{array}$ & $\begin{array}{l}\text { (c) } \\
\text { (c) }\end{array}$ & $\begin{array}{l}\text { (c) } \\
\text { (c) }\end{array}$ & $\begin{array}{l}232 \\
42.4\end{array}$ & $\begin{array}{r}247 \\
52.4\end{array}$ \\
\hline $\begin{array}{l}\text { End of } 4 \text { th Spray } \\
\text { Vapor temp., }{ }^{\circ} \mathrm{F}(\mathrm{b}) \\
\text { Pressure, psia }\end{array}$ & $\begin{array}{l}(c) \\
(c)\end{array}$ & $\begin{array}{l}\text { (c) } \\
\text { (c) }\end{array}$ & $\begin{array}{l}\text { (c) } \\
\text { (c) }\end{array}$ & $\begin{array}{r}192 \\
32.7\end{array}$ & $\begin{array}{l}175 \\
32.4\end{array}$ \\
\hline
\end{tabular}

a. Fan without duct Located in bottom of drywe zz. $2400 \mathrm{ft}^{3} /$ min discharge.

b. Average of 5 thermocouples Located at various elevations and radii.

c. No fourth spray. 
BNWL - 1244

TABLE 4. Spray Flow Rates and Solutions Used in CSE Experiments

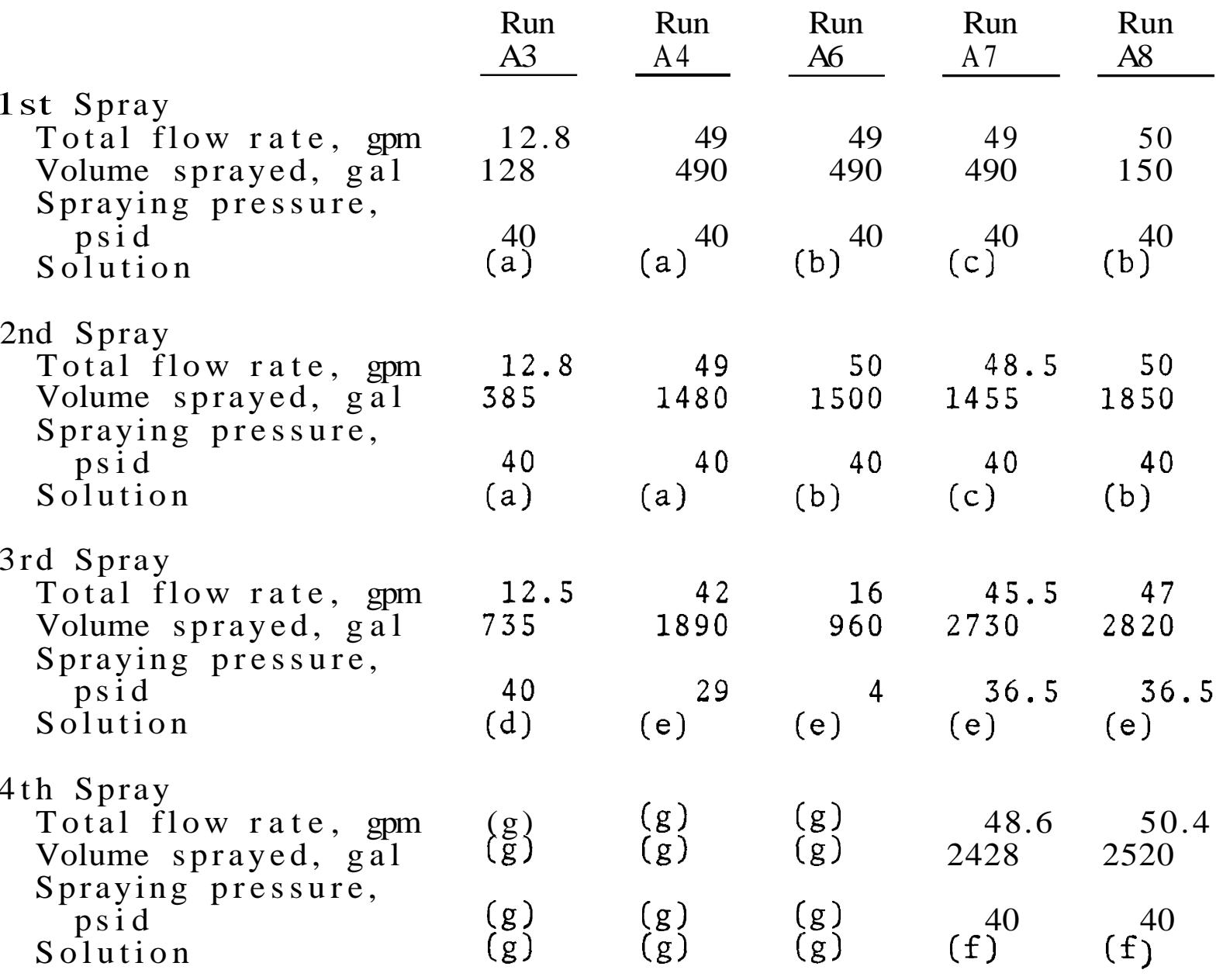

a. Fresh, room temperature. 525 ppm boron as $\mathrm{H}_{3} \mathrm{BO}_{3}$ in demineralized water. $\mathrm{NaOH}$ added to pH of 9.5 .

b. Fresh, room temperature. $3000 \mathrm{ppm}$ boron as $\mathrm{H}_{3} \mathrm{BO}_{3}$ in demineralized water. $\mathrm{NaOH}$ added to $\mathrm{pH}$ of $9.5^{3}{ }^{3}{ }^{3}$

c. Fresh, room temperature. $3000 \mathrm{ppm}$ boron as $\mathrm{H}_{3} \mathrm{BO}_{3}$ in demineralized water. No NaOH added. $p H 5$.

d. Fresh, room temperature demineralized water.

e. Solution in main vessel sump recirculated. No heat exchanger used.

f. Fresh, room temperature. 1 wt\% $\mathrm{Na}_{2} \mathrm{~S}_{2} \mathrm{O}_{3}, 3000$ ppm boron as $\mathrm{H}_{3} \mathrm{BO}_{3}$ in demineralized water. $\mathrm{NaOH}$ added to pH 9.4.

g. No fourth spray. 
BNWL- 1244

TABLE 5. Timing of Spray Periods

Time after Start of Iodine Release. min

\begin{tabular}{|c|c|c|c|c|c|}
\hline & $\begin{array}{l}\text { Run } \\
\mathrm{A} 3\end{array}$ & $\begin{array}{l}\text { Run } \\
\text { A4 }\end{array}$ & $\begin{array}{l}\text { Run } \\
\text { A6 }\end{array}$ & $\begin{array}{l}\text { Run } \\
\text { A7 }\end{array}$ & $\begin{array}{l}\text { Run } \\
\text { A8 }\end{array}$ \\
\hline \multicolumn{6}{|l|}{ First Spray } \\
\hline Start & 40 & 40.5 & 30 & 30 & 30 \\
\hline Stop & 50 & 50.5 & 40 & 40 & 33 \\
\hline Duration & 10 & 10 & 10 & 10 & 3 \\
\hline \multicolumn{6}{|c|}{ Second Spray } \\
\hline Start & 140 & 140 & 80 & 80 & 80 \\
\hline stop & 170 & 170 & 110 & 110 & 117 \\
\hline Duration & 30 & 30 & 30 & 30 & 37 \\
\hline \multicolumn{6}{|l|}{ Third Spray } \\
\hline Start & 1473 & 1205 & 1565 & 1323 & 200 \\
\hline Stop & 1533 & 1250 & 1625 & 1383 & 260 \\
\hline Duration & 60 & 45 & 60 & 60 & 60 \\
\hline \multicolumn{6}{|c|}{ Fourth Spray } \\
\hline Start & (a) & (a) & (a) & 1443 & 1350 \\
\hline Stop & (a) & (a) & (a) & 1493 & 1400 \\
\hline Duration & (a) & (a) & (a) & 50 & 50 \\
\hline
\end{tabular}

\section{a. No fourth spray.}

The conditions of each experiment differed in some important aspect. Run $\mathrm{A} 3$ used a low flow rate spray in room temperature air. Run A4 was a duplicate except for an increase in the flow rate by a factor of four. Run A6 was a duplicate of A4 except for the use of a steam-air atmosphere at $250{ }^{\circ} \mathrm{F}$ instead of room temperature air.

Run A7 conditions were nearly the same as those in Run A6, but an acid spray was used. Also, a rupture disc on the wetwell broke in this experiment just before time zero, thus requiring addition of the $4207 \mathrm{ft}^{3}$ wetwell volume to the $26,477 \mathrm{f} \mathrm{t}^{3}$ space in the normal three-room space for pressure calculations. However, not much steam entered the wetwell 
because the break was near the bottom of the vessel, and very little iodine or cesium was recovered afterwards from the wetwe 11 area.

A nozzle giving a smaller drop size distribution represented the chief change in Run A8. The nozzles used in this experiment were of the hollow cone type, while those in earlier tests were of the full cone type.

\section{SAMPLE ANALYSIS AND DATA HANDLING}

Between 1500 and 2000 samples of liquids, deposition coupons, and Maypack components were obtained from each experiment. These samples were analyzed for iodine and cesium by the CSE staff by gamma energy analysis. A multichannel analyzer system coupled to a small digital computer $(31,35,36)$ converted the raw counts to concentration values, corrected for radiodecay, aliquots, rotometer pressure differences, and atmospheric changes. The output, stored on magnetic tape, was later transferred to a tape compatible with a larger computer. The final output was concentration data in tabular form correlated in terms of fission product simulant form and located within containment and time of sampling. The computer also provided averages and standard deviations, subtracted "blank" values, corrected for elemental iodine adsorption on Maypack filters, and made other time-saving computations.

Some equipment malfunctions and operator errors are to be expected in large-scale experiments such as those reported here. Fortunately, the number and severity of these cases were low, and those encountered had little effect on the overa 11 accuracy of the experimental measurements. However, some anomolous results noted on the first machine data output sheets for every experiment were checked, and engineering judgement was used in deciding whether the data were valid or should be discarded. A revised data output was then obtained from the computer. 


\section{RESULTS AND DISCUSSION}

\section{RELEASE TO THE CONTAINMENT ATMOSPHERE}

Overall Mass Balances

The procedures and starting masses for generating and injecting the fission product simulant materials were nearly identical in each of the five experiments. Tables 6 and 7 give the overall mass balances for iodine and cesium, respectively. The top halves of the tables relate to the generation and release to the containment, while the lower halves are based on the masses released into the containment vessel.

After the release period was completed, valves were closed to isolate the generation equipment and delivery line from the containment vessel. The amount of material retained in the generation equipment and deposited in the delivery line was determined by careful decontamination and analysis. The small amount of material withdrawn by samplers on the delivery line was also accounted for. The sum of the material found exterior to the vessel was subtracted from the known starting mass to determine the amount actually delivered to the contain ment vessel. The mass of iodine delivered, listed in Table 6, is believed to be accurate to $\pm 5 \%$. For cesium, less complete release and higher plateout in the delivery line resulted in less certainty of its delivered mass. The values listed in Table 7 are believed accurate to $\pm 10 \%$.

The initial gas phase concentration, $\mathrm{C}_{g o}$, can be calculated by dividing the mass delivered by the gas space above the main deck, including the open-topped drywe11. This volume, $595 \mathrm{~m}^{3}$, is the proper volume to use at times shortly after injection because, as will be shown later, the iodine and cesium were dispersed uniformly throughout this region, with only traces diffusing into the regions below deck initially. 


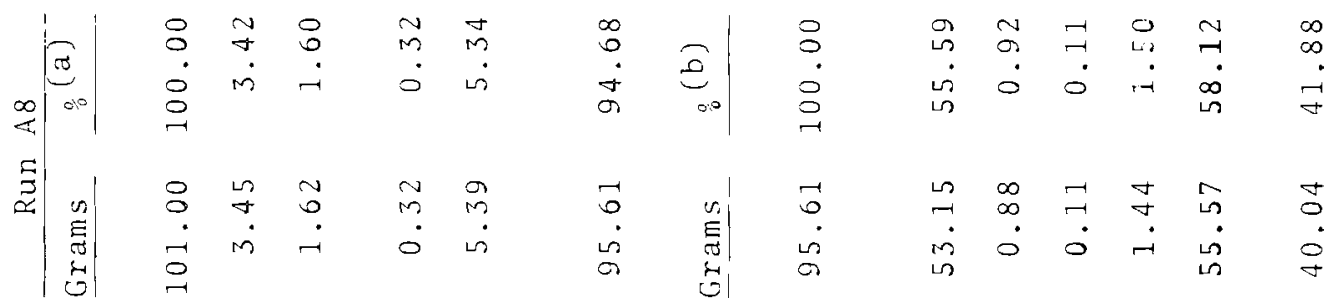

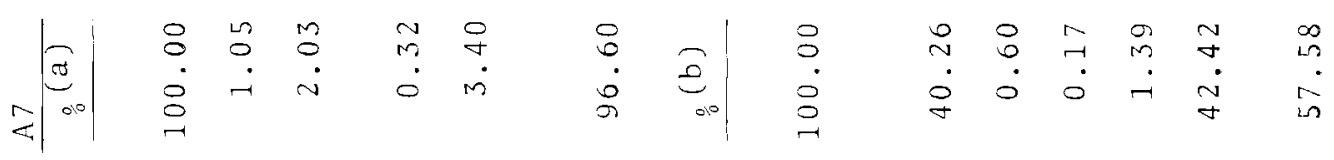

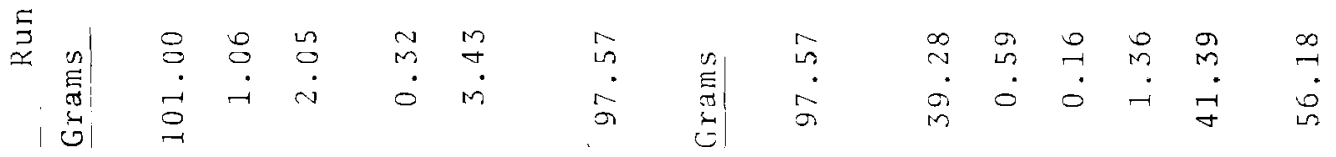

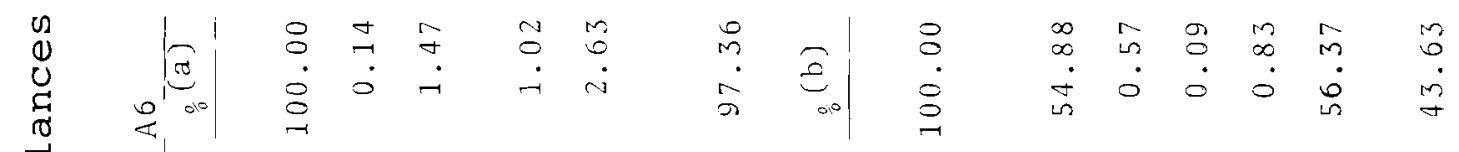

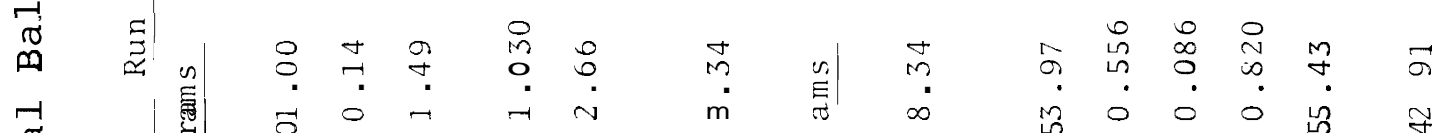

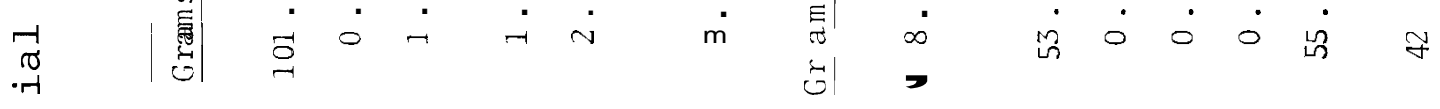

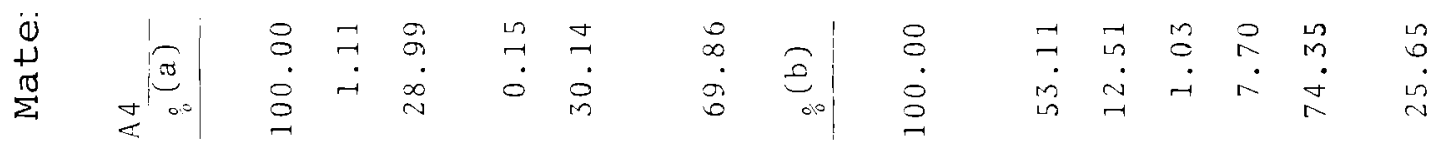

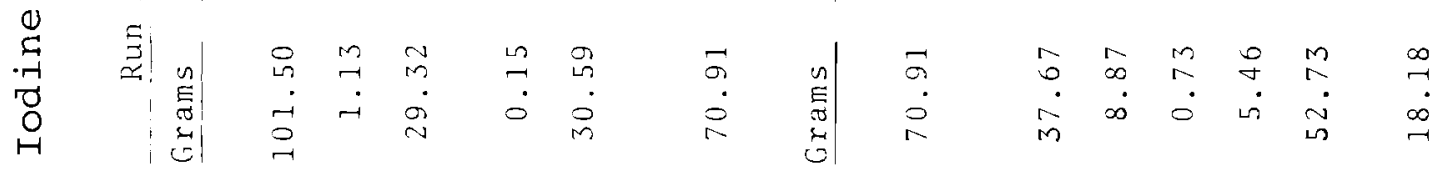

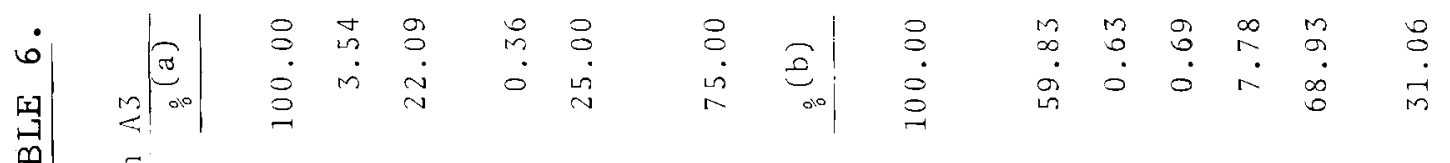

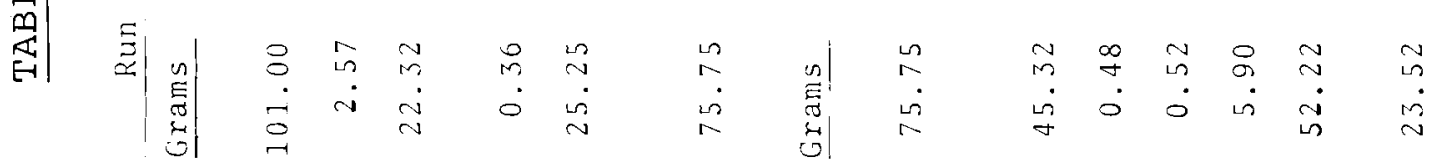
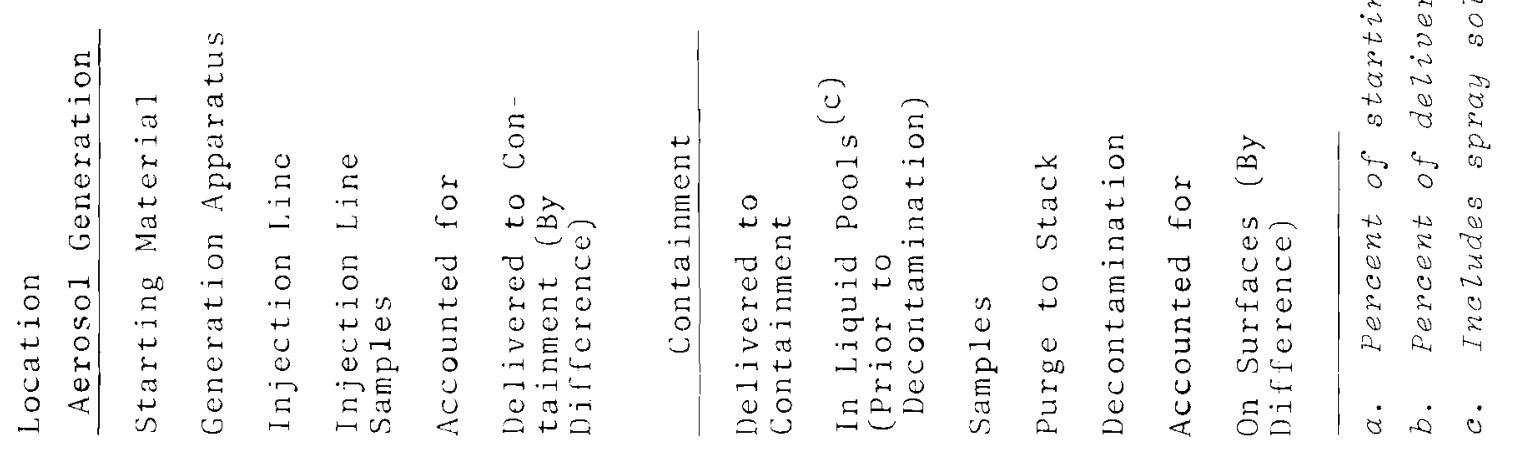


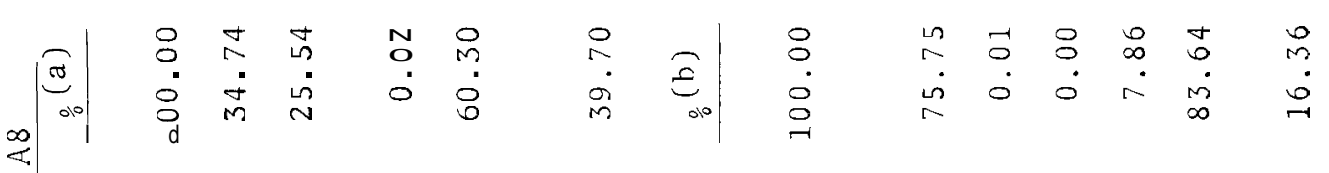

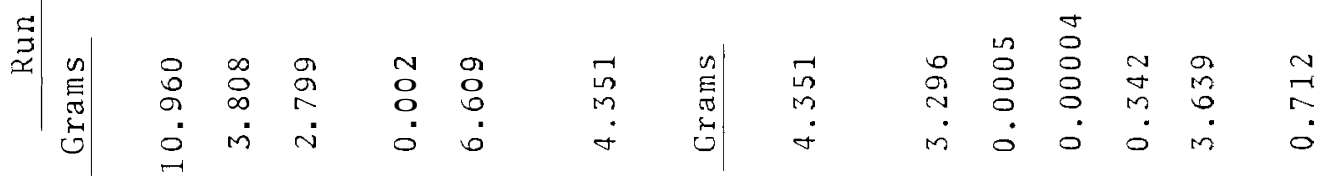

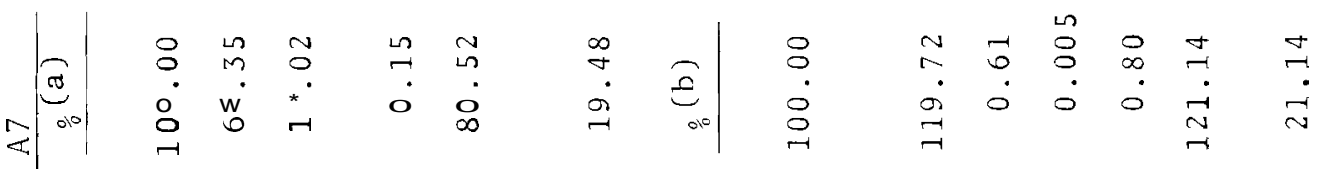

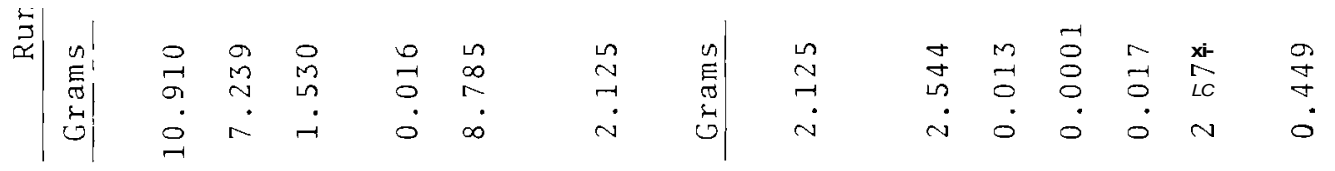

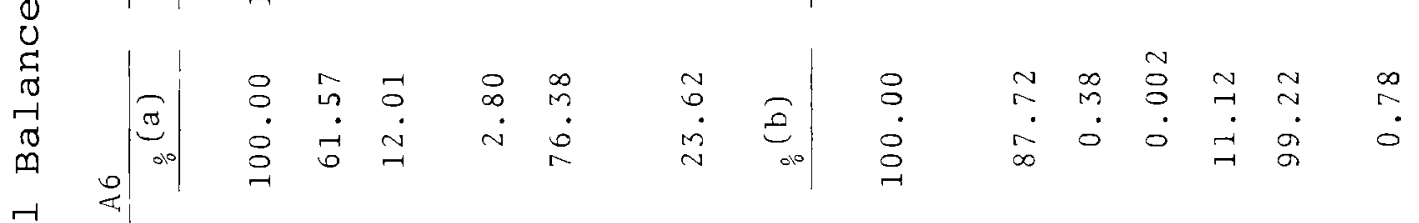

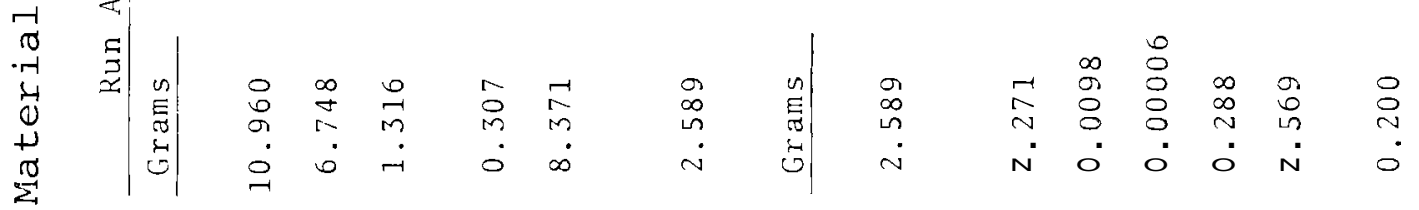

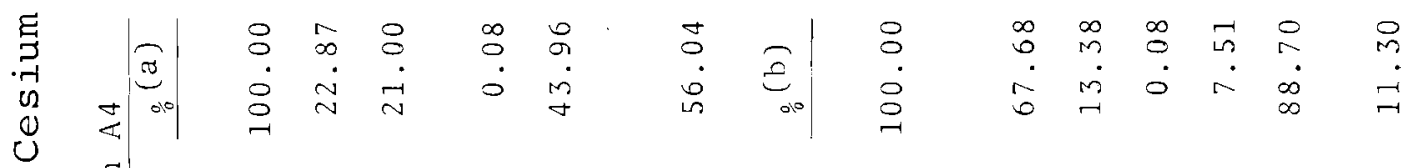

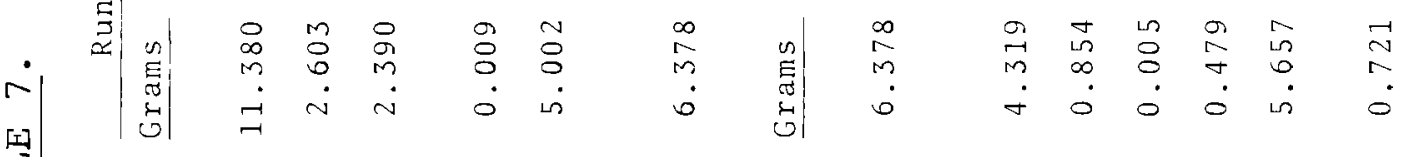

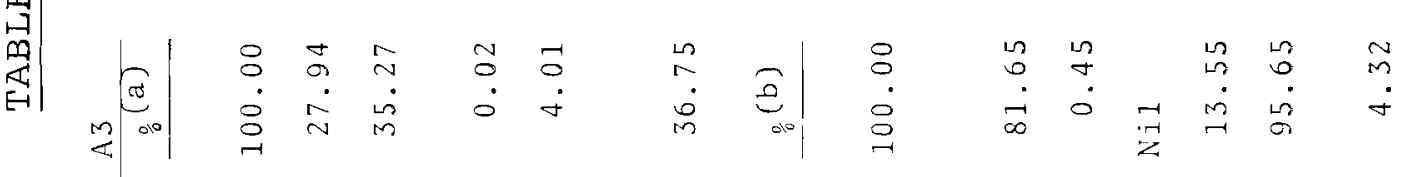

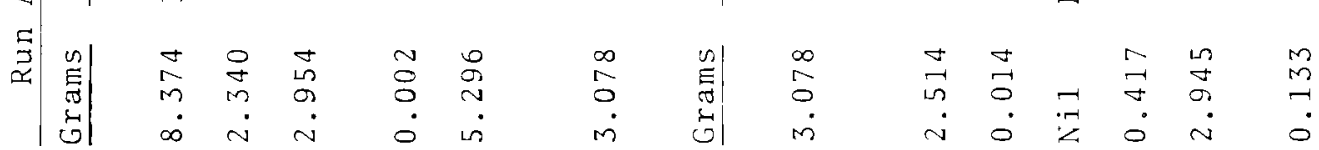

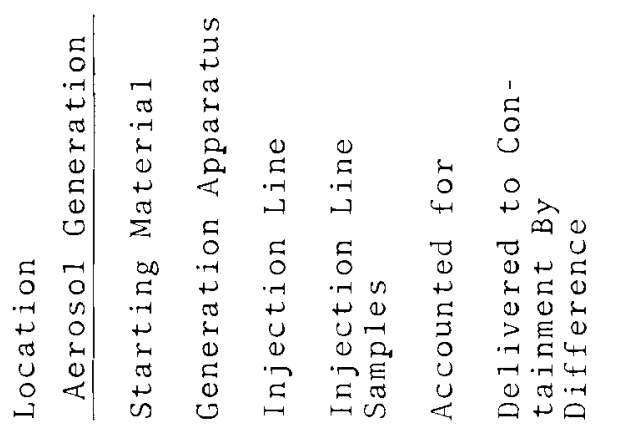

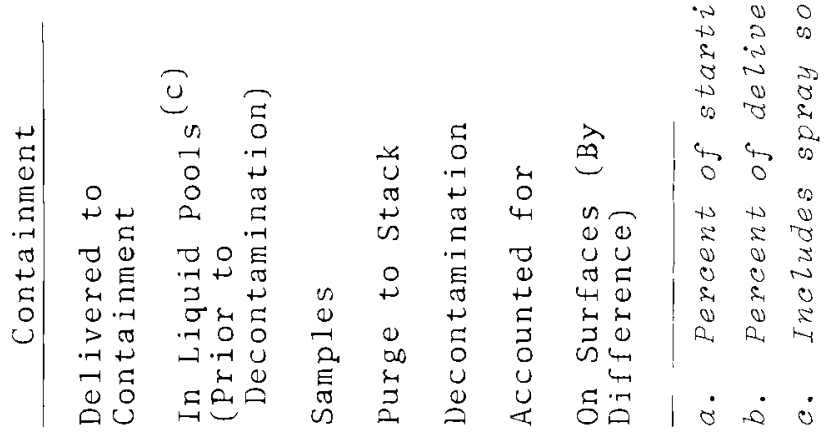


No material balance is given for uranium because liquid samples were not analyzed for this material. On the basis of tests in the Aerosol Development Facility (ADF), an estimated $100 \mathrm{mg} / \mathrm{min}$ of combined oxides of uranium, zirconium, and tin were delivered to the containment atmosphere, about half of which was uranium. On the basis of Maypack gas samples, the initial gas phase concentration of uranium ranged from 2 to $15 \mathrm{mg} / \mathrm{m}^{3}$.

Tables 6 and 7 also show the recovery of iodine and cesium from the containment vessel at the termination of each experiment. The material found in four locations are reported as (1) the liquid pools accumulated in vessel sumps, (2) the material removed in samples, (3) the material remaining airborne and purged to stack, and (4) the surface decontamination liquid. Not measured directly was the material remaining on structural surfaces after decontamination efforts were completed. The latter was estimated by two methods. The method shown in Tables 6 and 7 was to assume that any materials not found elsewhere were still on the surfaces. A second method, discussed in an ensuing section, was to extrapolate the amount found on small deposition coupons located throughout the vessel to an equivalent amount on the total surface area exposed to the vapor phase. The latter method is believed to be less accurate but serves as a check on the first.

Although there were variations from test to test, as might be expected because of the differences in conditions employed, the general pattern of the fate of iodine and cesium was similar. The average distribution between the five locations, expressed as percent of the mass delivered to the containment vessel, is given in Table 8 , along with the standard deviation between tests. 
TABLE 8. Average Distribution of Iodine and Cesium at End of Experiment

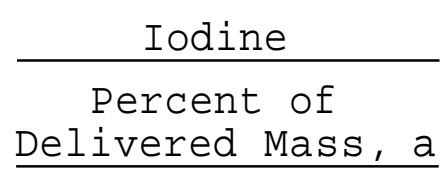

Liquid Pools

Samples

Gas Phase

Decontamination

Surfaces

$$
\begin{array}{r}
52.8 \pm 7.4 \\
3.0 \pm 5.3 \\
0.4 \pm 0.4 \\
3.8 \pm 3.6 \\
40.0 \pm 12.2
\end{array}
$$

$\frac{\text { Cesium }}{\text { Percent of }}$
Delivered Mass, $\sigma$

$86.5 \pm 20.0$
$3.0 \pm 5.8$
$0.03 \pm 0.04$
$8.2 \pm 4.8$
$2.3 \pm 14.4$

It is evident that, although nearly all the cesium was found. in the liquid phase, a large fraction of the iodine remained on the painted vessel surfaces. These behaviors are consistent with experiences in small-scale ADF tests (33) and with iodine-paint reaction rates published by Batte1leColumbus. (37) It should be remembered that sprays were not operated until 20 or 30 min after the end of aerosol injection and, that during this period, up to $70 \%$ of the iodine had plated out on surfaces (or in condensate film). A lower fraction of iodine would presumably have been found reacted with paint if the containment sprays had been operated during the release period.

Visual Observations of the Containment Atmosphere

A view of the interior of the containment vessel was possible by means of a 6-in. diam window and lights located within the vessel. The window was kept free of condensation by a heat lamp located externally. The visual observations, similar in all the experiments, are summarized as follows.

When steam was injected into the cold, sealed vessel, a fog formed which rapidly filled the vapor space and reduced visibility to 6 to $8 \mathrm{ft}$. After the desired temperature of $250^{\circ} \mathrm{F}$ was attained and the steam feed was reduced to that 
required to maintain thermal equilibrium, the fog dissipated and the atmosphere was clear except for a very light mist. Convection velocities were noted both by motion of aluminum foil ribbons, the swaying of 1 ines, and by recording anemometers.* Motion of the occasional mist particles observed was erratic but generally downward at 50 to $100 \mathrm{ft} / \mathrm{min}$. Not much change was noticed when uranium and Zircaloy oxide fumes were injected, but as soon as release of the mixture of cesium and iodine began, a dense cloud of fog appeared which rapidly filled all the space viewed. The visibility was reduced to about one foot by the end of the release period. A definite violet tinge was evident immediately after $\mathrm{I}_{2}$ injection. Visibility slowly improved to 3 to $5 \mathrm{ft}$ at the time the containment spray was first operated. Visibility improved slightly during the first short spray period. The spray appeared similar to a hard rainfall except that the drops were smaller. Sometimes they seemed to swirl and occasionally seemed to vary in intensity. Convection velocities increased during the spray period. As soon as the spray stopped, which was very abrupt because of the electric ball valve control, the atmosphere became very clear. Some residual small droplets remained visible for 1 to 2 min. This behavior was the same in each test, even for Run A8 when the first spray lasted only 3 min.

Immediately after the spray stopped, the walls were seen to have a thin sheet of spray solution running down in waves. This run-off decreased within a few minutes and, after about 10 min the walls appeared to become dry. This drying appeared to commence as a front progressing slowly from the upper region above the viewing area downward.

When the second and third spray periods were started, a fog became apparent to several observers even though visibility

Heated thermopile type--Manufactured by the Hastings-Raydist Co., Hampton Virginia. 
was hindered by density of the spray drops. Termination of the second and third sprays resulted in the same observations described for the first spray termination.

Aerosol and Iodine Forms in the Containment Atmosphere

Iodine was released in three intended forms consisting of elemental $\mathrm{I}_{2}$, methyl iodide, and a small fraction attached to solid particles. Undetermined forms were probably also released in small amounts. The relative proportion of these amounts as sampled from the delivery lines was 0.97, 0.01, 0.02 , and $<0.01$, respectively. As soon as they entered the steam-air containment atmosphere, these relative proportions changed rapidly due to absorption of some elemental iodine in fog drops $(38)$ and different rates of deposition on surfaces. The typical fraction of iodine in each of the four forms at the start of the first spray period is listed in Table 9.

TABLE 9. Iodine Form at Beginning of First Spray

\begin{tabular}{lll}
- & Form & $\begin{array}{c}\text { Average } \\
\text { Experiment }\end{array}$ \\
\cline { 3 - 4 } Elemental I 2 & $86 \pm 6.3$ \\
Particulate-associated & $9.3 \pm 3.9$ \\
Methyl Iodide & $2.4 \pm 0.4$ \\
Unknown(a) & $2.4 \pm 1.8$
\end{tabular}

Material deposited on inlet to Maypack and on charcoal
paper.

Cesium was volatilized as cesium metal and cesium oxide particles of about $0.25 \mu \mathrm{MMD}$. Some growth occurred by agglomeration during the 18 -sec transit time to the containment atmosphere. The rapid fog formation observed upon release to the containment atmosphere is indicative of the rapid dissolution of cesium particles to form solution droplets. A later section discusses particle size measurements. 
SPRAY OPERATION

Spray System Characteristics

The spray system for the tests was arranged to provide (1) uniform distribution of the spray over the vessel cross section, (2) minimum impingement of spray on the vessel wall, (3) control of flow rate and nozzle pressure, (4) known duration of each spray period, and (5) known fraction of the vessel volume sprayed. By arranging the spray nozzles in a regular array with the droplet envelopes of each nozzle just touching the wall and the adjacent nozzle envelopes, the first and second requirements were met reasonably well. Liquid distribution was measured during prerun tests by measuring the collection rate in 50 jars located at the bottom of the vessel, and by monitoring the liquid flow from the wall trough and to the main sump and to the dry well sump. The observed liquid distribution for the various spray runs is given in Table 10 .

TABLE 10. Measured Spray Liquid Distribution in CSE Tests

Total Spray Volume Recovered, \%

\begin{tabular}{llll} 
Wall & Dry Well & Deck Distr. \\
Trough & Main Sump & Sump & \\
\hline
\end{tabular}

Cross Section

Area, \%

Run A3 (a)

Run A4 (a)

Run A6 and

A 7 (b) and

Run A8 ( $\left.{ }^{\mathrm{a}}\right)$
2.0

0.7

10.9

2.1

$\sim 6.0$
78.5

62.8

68.9

68.4

73.0
19.5

37.5

20.2

64.8

46.7

28.5

21.0

46.2

a. Measured during shakedown test.

b. Measured from Ziquid Zevel change during run. Normal condensation deducted. 
Although the same nozzle arrangement was used in Runs A4, 6, and 7, a change in spray distribution can be seen between Runs $A 4$ and $A 6$. This change, due to the increased drag on the drops at the higher containment atmosphere pressures, results in fewer drops reaching the vessel walls and a slightly higher amount of liquid reaching the drywell sump. Also given is the standard deviation of the distribution of the liquid on the main and drywell decks as measured by the volume captured in jars during the shakedown tests.

The fraction of the gas volume in the main room washed by the sprays was estimated on the basis of the known spray height and envelope diameter. While the fraction of the gas space sprayed does not appear as a parameter in removal equations (for the "well mixed" model), spraying a substantial fraction of the gas space eases the necessity for the gas to be well mixed. It is estimated that spray drops washed $50 \%$ of the vessel volume in Run A3, and $80 \%$ in Runs A4, A6, A7, and A8, for the nozzle arrangements used.

The spray flow was controlled to maintain a constant pressure drop across the spray nozzles. By maintaining a constant nozzle pressure drop, it was hoped that the drop size spectrum could be kept reasonably constant during the spray test. The flow to the nozzles was measured by use of a calibrated orifice and a strip chart recorder. Spray duration was determined by use of a fast operating ball valve to obtain an abrupt flow start and stop. All spray system piping was primed prior to the test with the solution to be used. In addition, the nozzles were fed from the top of the header to minimize draining at the end of the spray period. It is estimated that spraying times were known to within $\pm 0.2 \mathrm{~min}$, total flow $\pm 4 \%$, and AP (across the nozzles) \pm 1 psi. The measured flow rates for the runs are summarized in Table 4. 
The spray drop diameter, an important parameter, was changed for Run A8 by using a different nozzle. The drop size used for each test was obtained from data provided by the nozzle manufacturer.* The drop size spectrum was determined by the manufacturer by electronically scanning a large number of drop images formed on a vidicon tube. The observed size distributions deviate only slightly from log-normal, or can be fitted well to an upper limit type of distribution. Both distributions have been used to predict the behavior of the CSE sprays. No estimate or literature references to the accuracy of the drop size information provided by the manufacturer can be made, and at this time no independent drop size measurements are available. However, the elemental iodine removal rate is approximately related to $1 / \mathrm{d}^{2}$, and the good agreement between the measured removal rates reported in a later section of this report and those calculated using the manufacturer's drop size data indicates the use of reasonable drop sizes. Heat Removal by Sprays

While the primary purpose of the CSE spray tests was to study fission product removal, pressure suppression information was also obtained. The temperatures and pressures at the start and end of the spray periods are listed in Table 3 for the various runs. The conditions during a typical spray are shown in more detail in Figure 4 where the observed average vapor temperature, pressure, and heat flux are given. The partial pressure of the air in the main room was derived from a mass balance on the air in the total vessel, based on the temperature and pressures in the various regions. It was assumed that the air was initially saturated and that air from the cooler regions of the vessel was saturated at $118^{\circ} \mathrm{F}$. The partial pressure shown for steam was calculated by difference

Spraying Systems Company, Belzwood, Izzinois. 


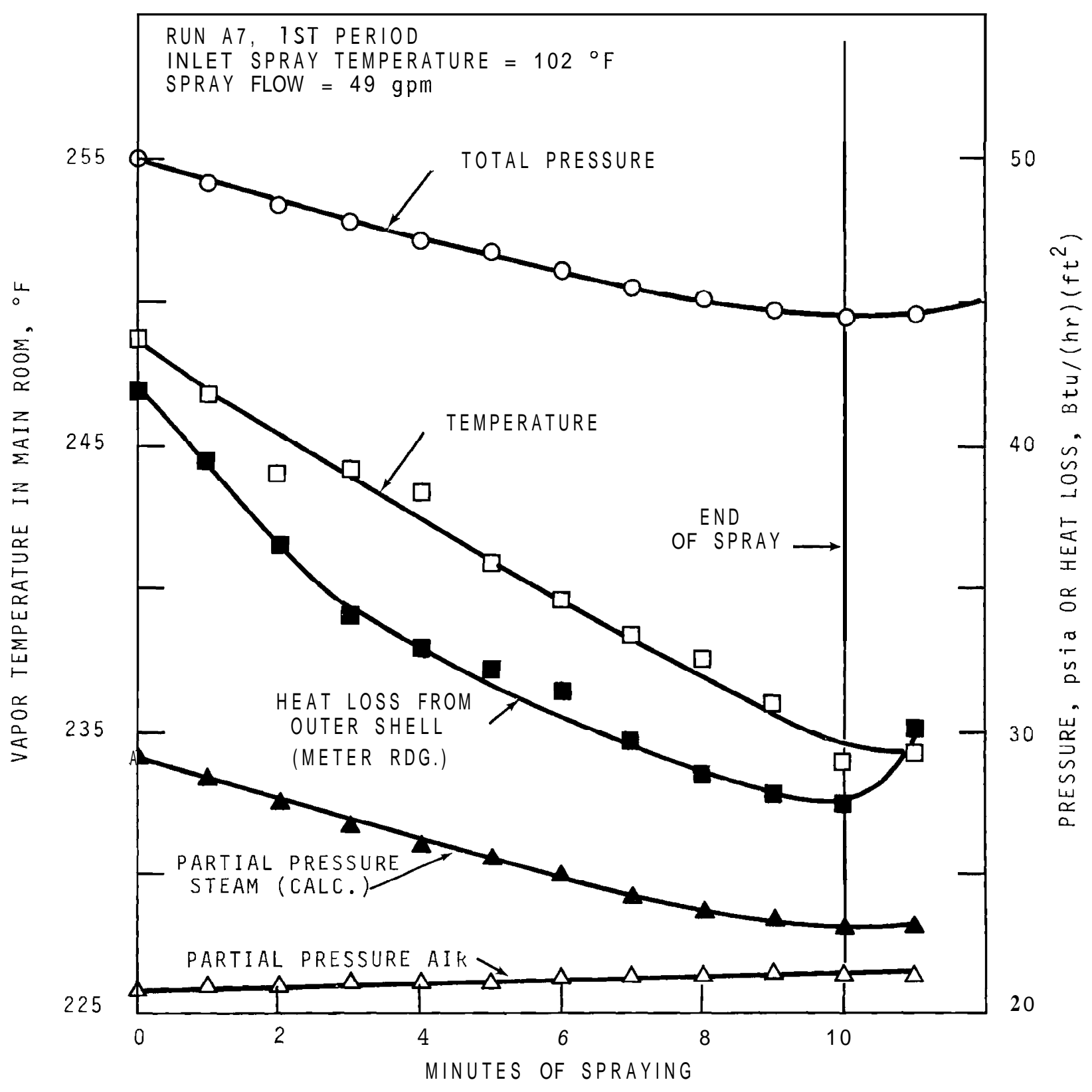

FIGURE 4. Containment Vapor Temperature and Pressure Response to Spray in Run A7 
and, incidentally, follows the saturation pressure within the expected experimental error of the temperature of the vapor space. No superheating of the vapor due to desiccation of the steam-air mixture by the cold spray drops could be observed.

A detailed heat balance has not been made. The CSE vessel has a high heat capacity relative to the heat capacity of the contained atmosphere due to the inability to scale V/A ratios and shell thickness independently of the linear size. As a consequence, the heat content of steel (total weight 380,000 1b) is important in the overall heat balance.

Heat exchange in the upper region during the first spray period of Run A7 was calculated and is shown in Table 11.

TABLE 11. Heat Removal from Upper Vapor Space by a Spray

$\begin{array}{ll}\text { Steam condensed from atmosphere } & 4.8 \times 10^{5} \text { BTU } \\ \text { Heat removed from a i } & 0.08 \times 10^{5} \text { BTU } \\ \text { Excess steam feed over heat loss } & 0.07 \times 10^{5} \text { BTU } \\ \text { Total Heat Removed from Atmosphere } & 4.95 \times 10^{5} \text { BTU }\end{array}$

The maximum possible heat removal capability of the entering cold spray of $5.85 \times 10^{5}$ BTU was based on an initial liquid temperature of $102^{\circ} \mathrm{F}$ and a maximum temperature rise to the containment atmosphere temperature. Hence, the spray resulted in a heat removal from the atmosphere of $85 \%$ of the maximum possible in spite of the presence of the inordinately massive, hot steel shell.

VARIATION IN GAS PHASE SPATIAL CONCENTRATION

Concentration Variations Within the Main Room

In a 11 five experiments, Maypack Clusters were hung at various locations throughout the main room as shown in Table 12 and Figure 5. A single Maypack Cluster was installed in both 
TABLE 12. Locations of Maypack Clusters Used in CSE Spray Experiments

\begin{tabular}{|c|c|c|c|c|}
\hline $\begin{array}{l}\text { Maypack } \\
\text { Cluster } \\
\text { Number } \\
\end{array}$ & $\begin{array}{l}\text { Elevation (a) } \\
\text { ft }\end{array}$ & $\begin{array}{c}\text { Radius } \\
\text { ft }\end{array}$ & $\begin{array}{l}\text { Azimuth (b) } \\
\text { degrees }\end{array}$ & \\
\hline M 02 & +12 & 0 & C & C of Main Room \\
\hline M 05 & +33 & 0 & $G$ & Top dome \\
\hline M 12 & -6 & 4.5 & 135 & Drywe11, near top \\
\hline M 13 & -18 & 4.5 & 135 & Drywe11, near bottom \\
\hline M 14 & -12 & 10 & 260 & Middle room \\
\hline M 15 & -24 & 10 & 260 & Bottom room \\
\hline M 16 & +24 & 11 & 45 & \\
\hline M 18 & 0 & 11 & 45 & \\
\hline M 19 & 0 & 11 & 135 & \\
\hline M 21 & +24 & 0 & L & \\
\hline M 22 & +12 & 6 & 270 & \\
\hline M 23 & 0 & 11 & 270 & \\
\hline M 24 & +12 & 11 & 45 & \\
\hline M 25 & +24 & 11 & 270 & \\
\hline
\end{tabular}

a. Main deck is at -5.5 ft.

b. Zero degrees is at center of 8 ft equipment access entry.

the Middle Room and the Lower Room. As discussed in previous reports $(7,39)$, the concentration within the Main Room was essentially uniform during times when sprays were not operated. An indication of the uniformity during spray periods is possible by comparing the airborne concentrations at different locations as determined by Maypack sampling during the time 

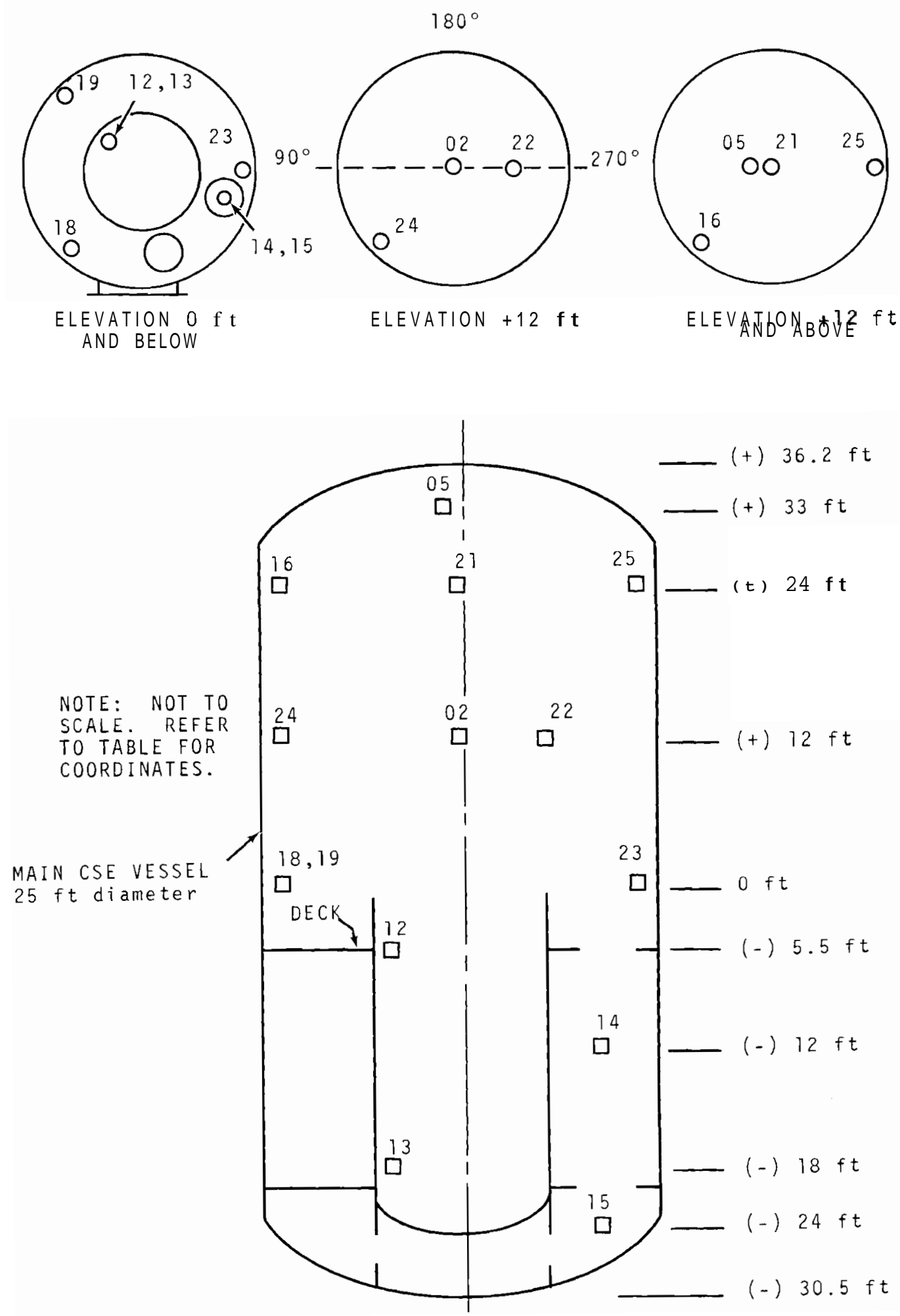

FIGURE 5. Location of Maypack Clusters in CSE 
BNWL - 1244

sprays were operated. Tables 13 through 16 list the concentrations for the various forms of iodine for Runs A3, A4, A6, and A7. No samples were taken during spray periods in Run A8. Table 17 lists the concentration of cesium as determined by the filters in the Maypacks for these four experiments. The mean concentrations in the Main Room and attendant standard deviations are also shown. These tables show the spatial concentrations of the various aerosol and gaseous forms to be essentially uniform during the time that sprays were operating. Most of the scatter is believed caused by sampling error.

One sampling location, M 05 , was located above the spray manifold and thus sampled the gas in the nonsprayed region. Except for Run A7, the concentrations measured by this Maypack were within one standard deviation of the mean values for all samplers located within the sprayed region. Sample flow control problems, occasionally encountered in the CSE experiments, are believed to be the cause of the somewhat high value for M 05 obtained in Run A7. This belief is substantiated by the fact that the fairly inert iodine material, methyl iodide, found on the charcoal bed was also high. The concentration of methyl iodide should not differ significantly inasmuch as only a limited amount was removed by the spray.

Table 18 summarizes the ratio of the concentration measured in a nonsprayed region ( $M$ 05) to that in the sprayed region. The conclusion is that the concentration in the nonsprayed region was not significantly different during spray periods than that in the region covered by sprays. This observation can be compared to 9.4\% calculated by Equation (37) for elemental iodine for conditions of Run A6, where the effective velocity between regions was assumed to be $50 \mathrm{ft} / \mathrm{min}$. 


\section{TABLE 13. Iodine Concentrations at Various Vessel Locations} During First Spray Period - CSE Run A3

Location in $(a)$
Main Room
M02
M12
M13
M16
M18
M19
M21
M22
M23
N25
Mean
Std Dev

\begin{tabular}{r} 
\\
Filter \\
\hline 2.04 \\
1.81 \\
1.31 \\
1.34 \\
1.42 \\
1.16 \\
1.17 \\
1.50 \\
1.33 \\
1.50 \\
1.39
\end{tabular}

Concentration on Maypack Component, $\mathrm{mg} / \mathrm{m}^{3}$

\begin{tabular}{lccl} 
Silver & $\begin{array}{c}\text { Charcoal } \\
\text { Paper }\end{array}$ & $\begin{array}{c}\text { Charcoal } \\
\text { Bed }\end{array}$ & Total \\
\cline { 2 - 2 } 21.3 & 0.23 & 1.06 & 24.6 \\
21.8 & 0.27 & 0.90 & 24.8 \\
18.3 & 0.24 & 0.89 & 20.7 \\
18.0 & 0.24 & 0.98 & 20.6 \\
20.0 & 0.41 & 1.04 & 22.9 \\
18.4 & 0.36 & 1.17 & 21.1 \\
17.7 & 0.59 & 1.17 & 20.6 \\
19.1 & 0.24 & 1.01 & 21.8 \\
19.9 & 0.24 & 0.97 & 22.4 \\
19.2 & 0.22 & 1.23 & 22.4 \\
18.9 & 0.21 & 0.98 & 21.5
\end{tabular}

$\begin{array}{llll}19.3 & 0.30 & 1.04 & 22.1 \\ 1.32 & 0.12 & 0.35 & 1.49\end{array}$

Midale

Room .
$M 14$
1.35
19.2
0.41
1.20
$22 \cdot 2$

Lower

Room
M15
0.62
9.62
0.08
0.32
10.6

a. Refer to Table 12 for vessel coordinates. 
TABLE 14. Iodine Concentrations at Various Vessel Locations During First Spray Period - CSE Run A4

Location in (a

Main Room

M02

M05

M12

M13

MI 6

M19

M21

M24

Mi25

Mean

Std Dev
0.35

0.21

$(+58.5 \%)$
0.44

0.10

$( \pm 23.2 \%)$
Concentration On Maypack Components, $\mathrm{mg} / \mathrm{m}^{3}$ Charcoal

Paper

0.18

0.19

0.20

0.06

0.19

0.21

0.19

0.20

0.08

0.16

0.98

0.05

0.20

$( \pm 32.9 \%)$

$( \pm 20.4 \%)$
TotaI

2.27

0.94

1.73

0.72

2.09

1.14

2.40

1.01

1.81

0.96

1.75

0.61

1.56

1.27

2.17

1.00

1.60

Middle

Room

MI 4

0.36

2.26

0.12

0.34

3.08

Lower

Room

M15

0.22

1.65

0.06

0.15

2.07

a. Refer to Table 12 for coordinates. 
TABLE 15. Iodine Concentrations at Various Vessel Locations During First Spray Period - CSE Run A6

Location in (a) Main Room

M02

M05

M12

M13

M16

M18

M19

M21

M22

M23

M24

Mean

Std Dev
Concentration On Maypack Co

$\underline{\text { Filter }}$

0.25

0.39

0.24

0.33

0.30

0.29

0.19

0.33

0.45

0.47

0.23

0.31

0.09

(土 $28.4 \%)$ $\underline{\text { Silver }}$

0.62

0.66

0.64

0.65

0.55

0.59

0.62

0.58

0.78

1.12

0.68

0.68

0.16

$(+23.5 \%)$
Paper

0.33

0.35

0.33

0.35

0.31

0.32

0.31

0.30

0.35

0.53

0.33

0.35

0.06

$( \pm 18.2 \%)$

Charcoal
Bed

1.34

1. 31

1.41

1.11

1.32

0.94

1. 37

1.27

1.55

1.42

1.11

1.29

0.17

$(+13.2 \%)$

$$
( \pm 14.6 \%)
$$

Middle

Room

M14

0.005

0.02

0.01

0.007

0.17

Lower

Room

M15

0.002

0.02

0.10

0.006

0.13

a. Refer to Table 12 for coordinates. 
TABLE 16. Iodine Concentrations at Various Vessel Locations During First Spray Period - CSE Run A7

Location in (a)

Main Room

M02

M05

M12

M13

MI6

M18

M19

M21

M22

M23

M25

Mean

Std Dev

\begin{tabular}{|c|c|c|c|c|}
\hline Filter & $\underline{\text { Silver }}$ & $\begin{array}{c}\text { Charcoal } \\
\text { Paper }\end{array}$ & $\begin{array}{c}\text { Charcoal } \\
\text { Bed }\end{array}$ & Total \\
\hline 1.53 & 2.90 & 3.39 & 1.38 & 9.20 \\
\hline 2.07 & 6.11 & 5.68 & 2.47 & 16.33 \\
\hline 1.12 & 3.29 & 3.52 & 1.32 & 9.25 \\
\hline 1.40 & 3.04 & 3.57 & 1.52 & 9.53 \\
\hline 1.31 & 4.22 & 3.45 & 1.42 & 10.40 \\
\hline 1.56 & 3.11 & 3.31 & 1.35 & 9.33 \\
\hline 1.26 & 3.31 & 3.10 & 1.33 & 9.00 \\
\hline 1.17 & 3.50 & 3.07 & 1.43 & 9.17 \\
\hline 1.22 & 3.19 & 2.95 & 1.32 & 8.68 \\
\hline 1.03 & 4.78 & 3.60 & 1.35 & 10.76 \\
\hline 0.95 & 2.71 & 2.83 & 0.20 & 6.69 \\
\hline
\end{tabular}

$\begin{array}{cr}1.33 & 3.65 \\ 0.31 & 1.01 \\ \pm 23.3 \%) & ( \pm 27.7 \%)\end{array}$

3.50

I. 37

9.85

0.77

0.51

2.38

$( \pm 37.3 \%) \quad( \pm 24.2 \%)$

Middle

Room
MI 4
0.05
0.22
0.60
0.02
0.89

Lower

Room

M15

0.03

0.31

0.21

0.01

0.56

a. Refer to Table 22 for coordinates. 
BNWL -1244

TABLE 17. Cesium Concentrations in Vapor Space at Various Vessel Locations During First Spray Period

\begin{tabular}{|c|c|c|c|c|}
\hline Location in $(a)$ & Cesium & Concentration & On Filters, & $\mathrm{mg} / \mathrm{m}^{3}$ \\
\hline Main Room & $\underline{\mathrm{A}}$ & A4 & $A 6$ & $\mathrm{A7}$ \\
\hline MO2 & 1.97 & 1.00 & 0.38 & 0.37 \\
\hline MO5 & 2.15 & 0.90 & 0.39 & 0.70 \\
\hline $\mathrm{M} 12$ & 1.79 & 1.05 & 0.40 & 0.42 \\
\hline M13 & 1.83 & 1.04 & 0.41 & 0.43 \\
\hline MI 6 & 2.03 & 0.96 & 0.40 & 0.41 \\
\hline $\mathrm{MI} 8$ & 1.86 & (b) & 0.38 & 0.40 \\
\hline M19 & 1.48 & 1.01 & 0.39 & 0.40 \\
\hline M2I & 1.96 & 0.93 & 0.36 & 0.42 \\
\hline M22 & 1.96 & (b) & 0.42 & 0.39 \\
\hline M23 & 1.96 & (b) & 0.42 & 0.48 \\
\hline M24 & (b) & 1.05 & 0.40 & (b) \\
\hline M25 & 1.91 & 0.83 & 1.07 & 0.36 \\
\hline Mean & 1.90 & 0.98 & 0.45 & 0.44 \\
\hline Std Dev & 0.21 & 0.08 & 0.20 & 0.009 \\
\hline & $( \pm 11.0 \%)$ & $( \pm 7.7 \%)$ & $( \pm 43.2 \%)$ & $( \pm 21.3 \%)$ \\
\hline
\end{tabular}

Middle

Room

M14

1.66

0.81

0.008

0.04

Lower

$\underline{\text { Room }}$

M15

0.81

0.43

0.001

0.0009

a. Refer to Table 12 for coordinates.

b. Not Analyzed. 
TABLE 18. Comparison of Concentrations in Sprayed and Nonsprayed Regions Within the Main Room

\begin{tabular}{|c|c|c|c|c|c|}
\hline & & Iodine & Iodine & & \\
\hline $\begin{array}{l}\text { Iodine } \\
\text { Filter }\end{array}$ & $\begin{array}{l}\text { Iodine } \\
\underline{\text { Silver }}\end{array}$ & $\begin{array}{c}\text { Charcoal } \\
\text { Paper }\end{array}$ & $\begin{array}{c}\text { Charcoal } \\
\text { Bed }\end{array}$ & $\begin{array}{l}\text { Iodine } \\
\text { Total. }\end{array}$ & $\begin{array}{l}\text { Cesium } \\
\text { Filter }\end{array}$ \\
\hline
\end{tabular}

$\begin{array}{lllllll}\text { Run A-3 } & 1.25 & 1.13 & 0.92 & 0.87 & 1.12 & 1.13 \\ \text { Run A-4 } & 0.49 & 0.98 & 1.16 & 0.96 & 0.90 & 0.92 \\ \text { Run A-6 } & 1.24 & 0.97 & 1.00 & 1.02 & 1.02 & 0.87 \\ \text { Run A-7 } & \underline{1.56} & \underline{1.67} & \underline{1.62} & \underline{1.80} & \underline{\mathbf{i}} .66 & 1.60 \\ \text { Average } & 1.14 & 1.19 & 1.18 & 1.16 & 1.18 & 1.13\end{array}$

Concentration Variations Between Compartments

Concentration differences between compartments connected by a relatively small opening are expected to be much greater than within a single compartment because of the relatively small convective flow between compartments. Knudsen and Hilliard (6) and Morrison et al.(40) have discussed intercompartment transport. Reliable predictions are not possible unless the flow between compartments can be predicted accurately.

The Main Room, Middle Room, and Lower Room acted in the CSE experiments as three separate compartments connected in series by relatively small openings in the floors. Tables 13 through 17 show the concentration in the three rooms during the first spray period. Figure 6 is a graph of $\mathrm{C}_{\mathrm{g}}$ versus $t$ for a typical experiment, Run A6, showing how the concentration of total iodine builds up in the lower rooms during spray periods. Operation of sprays reduced the concentration differences faster than had previously been measured in the absence of sprays in Runs Al, A2, and A5. This development is partly attributable to the more rapid reduction in the main room concentration as well as to the increased intercompartment flow and perhaps to the liquid-gas absorption reversibility. 
BNWL- 1244

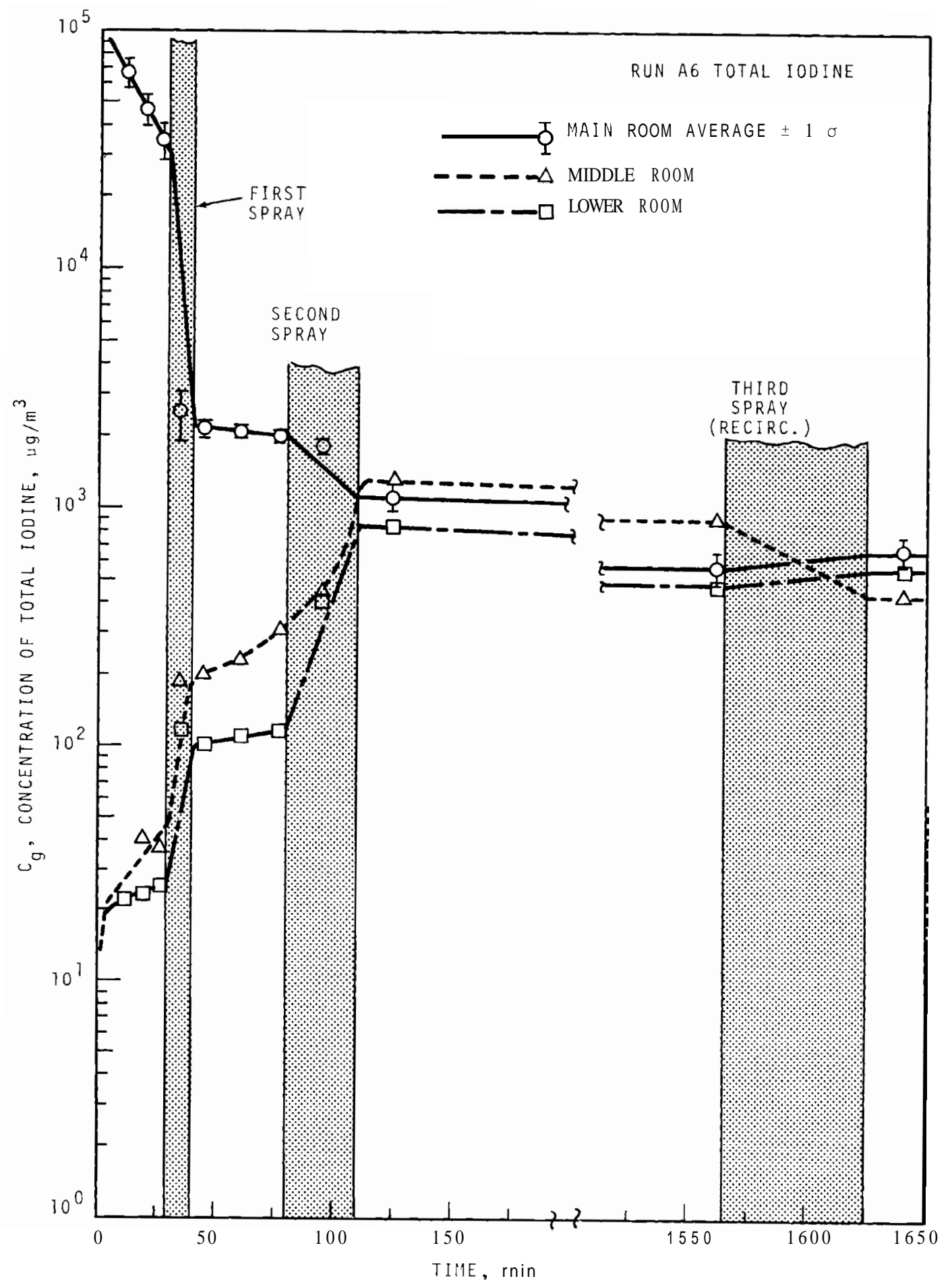

FIGURE 6. Typical Buildup of Concentration in Lower Rooms 
REMOVAL FROM CONTAINMENT ATMOSPHERES BY SPRAYS

Maypack Data Interpretation

McCormack (32) has discussed the CSE Maypack gas sampling system and the interpretation of results obtained with this type of sampling system. A brief discussion is included here to acquaint the reader with the basic manipulations performed on the raw data to obtain the results shown in the following sections of this report.

Reference to Figure A-5, Appendix, shows passage of the fission product, a laden mixture of steam and air, through a series of media in the following sequences:

1. free-floating Teflon ball check valve

2. two glass fiber filters

3. six silver-plated screens

4. one silver membrane

5. 'one thin charcoal-impregnated paper filter

6. a two-in. deep bed of activated charcoal granules.

The fission product simulant materials are removed by one or more of the individual Maypack components by filtration, adsorption, or chemical reactions. The decontaminated steamair passes through the Maypack and out of the containment vessel via insulated lines to the flow control station where the steam is condensed, the pressure reduced, the air dried, and the flow rate of dry air metered by rotometer. Backup, refrigerated charcoal traps retain any of the fission product simulant materials which might leak through the Maypack. Solenoid valves start and stop the flow through each Maypack. A record is kept of the pressure and temperature of the steamair atmosphere entering the Maypack, the pressure at which the rotometer operates, and the average rotometer reading.

The actual volume of containment atmosphere sampled is calculated by Equation (38): 
BNWL -1244

$$
V_{s}=R t_{s} f_{r} f_{a}
$$

where

$$
\begin{aligned}
\mathrm{V}_{\mathbf{S}} & =\text { gas volume sampled at containment conditions, } \mathrm{m}^{3}, \\
\mathrm{R} & =\text { average rotometer reading, } \mathrm{m}^{3} / \mathrm{min} \text { (STP), } \\
\mathrm{t}_{\mathrm{S}}= & \text { time sampled, min, } \\
\mathrm{f}_{\mathrm{r}}= & \text { correction factor for rotometer pressure, } \\
\mathrm{f}_{\mathrm{a}}= & \text { ratio of air volume in containment to standard tem- } \\
& \text { perature and pressure. }
\end{aligned}
$$

The ratio, $f$, of air volume at containment conditions to that for which thè rotometer is calibrated (32 ${ }^{\circ} \mathrm{F}, 14.7$ psia), was calculated by assuming the air entering the Maypack to be saturated with water vapor and by using Equation (39):

$$
\mathrm{f}_{\mathrm{a}}=\frac{(14.7) \mathrm{T}_{\mathrm{b}}}{(492)\left(\mathrm{P}-\mathrm{P}_{\mathrm{s}}\right)}
$$

where

$$
\begin{aligned}
\mathrm{T}_{\mathrm{b}} & =\text { temperature of air entering Maypack, }{ }^{\circ} \mathrm{R}, \\
\mathrm{P} & =\text { total pressure in containment vessel, psia, } \\
\mathrm{P}_{\mathrm{S}} & =\text { vapor pressure of water at } \mathrm{T}_{\mathrm{b}} \text {, psia, }
\end{aligned}
$$

Separate radiometric analyses were made of five components taken from each Maypack:

$\mathrm{N}$, decontamination of Teflon check valve and nose cone,

A, the two fiber glass filters,

$B$, the six silver screens plus the silver membrane,

$C$, the charcoal paper,

D, the charcoal bed.

Component $\mathrm{N}$, the nose cone and Teflon ball, retained about 1-5\% of the total fission product material. For cesium, this material was added to the filter component result to give total 
cesium. Since, for iodine, the material deposited in the nose probably consisted of a mixture of elemental and particulateassociated iodine of unknown proportion, it was not added to either the filter or the silver component analyses but was included in the total iodine.

Iodine found on the two fiberglass filters was chiefly associated with particles, but some elemental iodine is known to plate on the glass fibers. A correction recommended by McCormack (32) was applied to the filter result to subtract the estimated amount of elemental iodine deposited, and this same amount was then added to the amount found on the silver components. Results shown in the following sections for elemental iodine and particulate associated iodine have been corrected in this manner.

The thin charcoal-impregnated paper, component $C$, acts as a buffer between the silver section and the charcoal bed. It is very efficient for elemental iodine and ensures that the slight amount of elemental iodine penetrating the silver components does not reach the charcoal bed. The component probably catches trace amounts of heavy organic iodides, but methyl iodide retention is quite low because of the short exposure time in passing through the 0.03-in. thickness. McCormack(32) reports that, for the air tests, $1 \%$ of the methyl iodide was retained on component $\mathrm{C}$ and, for the $250^{\circ} \mathrm{F}$ steam-air atmosphere tests, $3 \%$ of the methyl iodide was retained on the charcoal paper.

The charcoal bed is efficient for methyl iodide at the sampling conditions used in these experiments. Since all other forms of iodine are removed by components upstream of the charcoal bed, component $\mathrm{D}$ is an accurate measure of the methyl iodide entering the Maypack. 
Gamma analyses for each component, corrected for radioactive decay to a common reference time, were multiplied by the specific activity of the fission product simulant material and divided by the volume of gas sampled to give the mass concentration in the containment atmosphere as follows:

$$
\mathrm{C}_{\mathrm{g}}=\underline{(\mathrm{d} / \mathrm{m})(\text { Spec }} \mathrm{v}_{\mathrm{s}}^{\prime} \frac{\text { Activity })}{\mathrm{s}}
$$

where

$$
\begin{aligned}
\mathrm{C}_{\mathrm{g}}= & \text { concentration in containment atmosphere, } \\
& \mu \mathrm{g} / \mathrm{m}, \\
\mathrm{d} / \mathrm{m}= & \text { radioactivity on a Maypack component, } \\
& \text { corrected for radiodecay, } \\
\text { Spec. Activity }= & \mu \mathrm{g} \text { of stable iodine or cesium per } \mathrm{d} / \mathrm{m} \\
& \text { equilibrated, } \\
\mathrm{V}_{\mathrm{s}}= & \text { volume of gas sampled at containment } \\
& \text { temperature and pressure, } \mathrm{m}^{3} .
\end{aligned}
$$

One Maypack in each cluster was never used and served as a blank. Some fission product simulant material was always found on the blanks, due either to slight leakage of the solenoid valve or breathing through the loose-fitting Teflon check valve. On the assumption that all Maypacks gained this much material during nonsampling periods, the average amount on all the blanks was subtracted from the corresponding component of the other Maypacks. This correction was inconsequential until gas phase concentrations had been reduced to $<0.1 \%$ of initial values. It caused large uncertainties in results at long containment times.

Concurrent Removal by Natural Processes

The objective of these experiments was to measure the removal by sprays of the several types of fission product materials, and to relate the observed removal rates to those that could be expected in other containment systems, especially 
to those of larger power reactors. Because removal by natural processes occurred concurrently with removal by spray drops, and because these two rates do not always proceed in the same relative ratio, it was necessary to measure each independently for comparison with their respective theoretical models. Application to conditions in a large power reactor containment system can then be made by inserting the proper values of parameters to each model and summing.

Theory for removal by natural processes is only partially verified. Furthermore, the operation of sprays probably perturbs the natural removal mechanisms and makes it difficult to predict natural removal during spray periods. Therefore, for the present experiments, sprays were operated for short, welldefined periods and the removal $r a t e$ before and after each period (by natural processes) was determined by sampling. The decrease in gas phase concentration occurring during the spray period was attributed to the combined process of removal by spray drops and removal by natural processes at the average of the rates before and after the spray period. For example, if both processes are first order with respect to gas phase concentration,

$$
\frac{d C_{g}}{d t}=-\left(\lambda_{s}+\lambda_{n}\right) C_{g}
$$

where

$$
\begin{aligned}
& \lambda_{\mathrm{S}}=\text { removal rate constant for spray drops, min }{ }^{-1}, \\
& \lambda_{\mathrm{n}}=\text { removal rate constant for natural processes, } \min ^{-1},
\end{aligned}
$$

and

$$
\lambda N=\frac{\lambda N_{1}+\lambda N_{2}}{2}
$$


BNWL- 1244

where

$$
\begin{aligned}
& \lambda N_{1}=\text { removal rate constant before spray, } \\
& \lambda N_{2}=\text { removal rate constant after spray. }
\end{aligned}
$$

\section{Elemental Iodine}

The time dependence of the gas phase concentration of elemental iodine in the main room is shown for each experiment in Figures 7 through 11. The experimental points are the average values of the 12 Maypack clusters located at various positions throughout the main room. Plus and minus one standard deviation from the mean is indicated by the horizontal bars above and below each point. The figures show:

- The gas space to be well mixed within the main room (small standard deviation).

- A large decrease in gas phase concentration during the first, short spray period.

- Less decrease in gas phase concentration with subsequent sprays after decline in the concentration to $<1 \%$ of in itial value.

- Only small changes during recirculation periods, and

- Greater uncertainty of results for the samples taken after $\mathrm{C}_{\mathrm{g}} / \mathrm{C}_{\mathrm{go}}<0.001$.

A line was drawn connecting points outside the spray periods and extrapolated to start and stop times of the spray periods. Judgement was used in determining the best fit of the data. A straight line was drawn through the spray period connecting the concentration at start and stop. The curves are marked with the concentration half lives, $t_{1 / 2}$, before, during, and after each spray period. The half-life is the time required to reduce the concentration by a factor of two. It is related to the removal rate constant by 


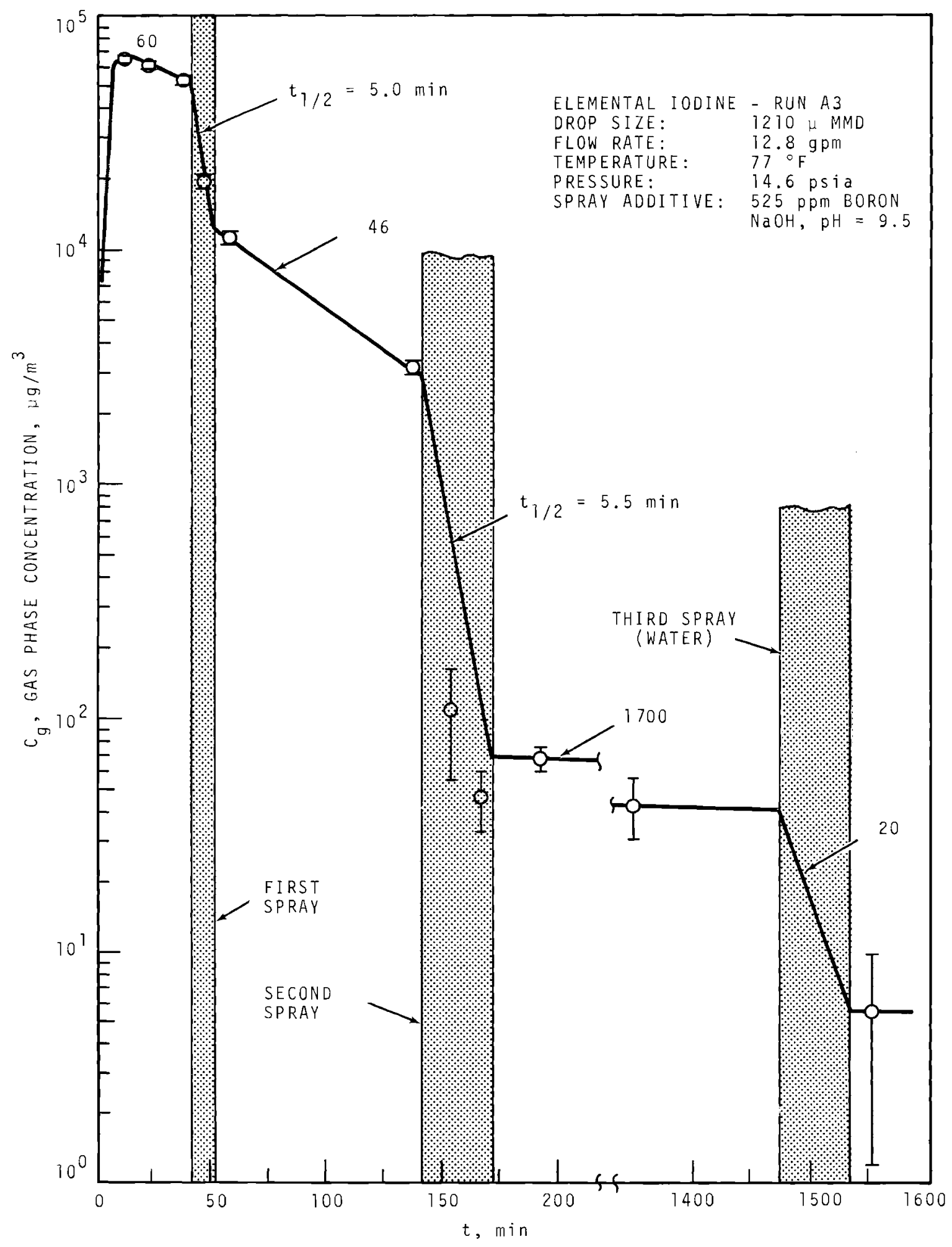

FIGURE 7. Concentration of Elemental Iodine in the Main Room, Run A3 
BNWL- 1244

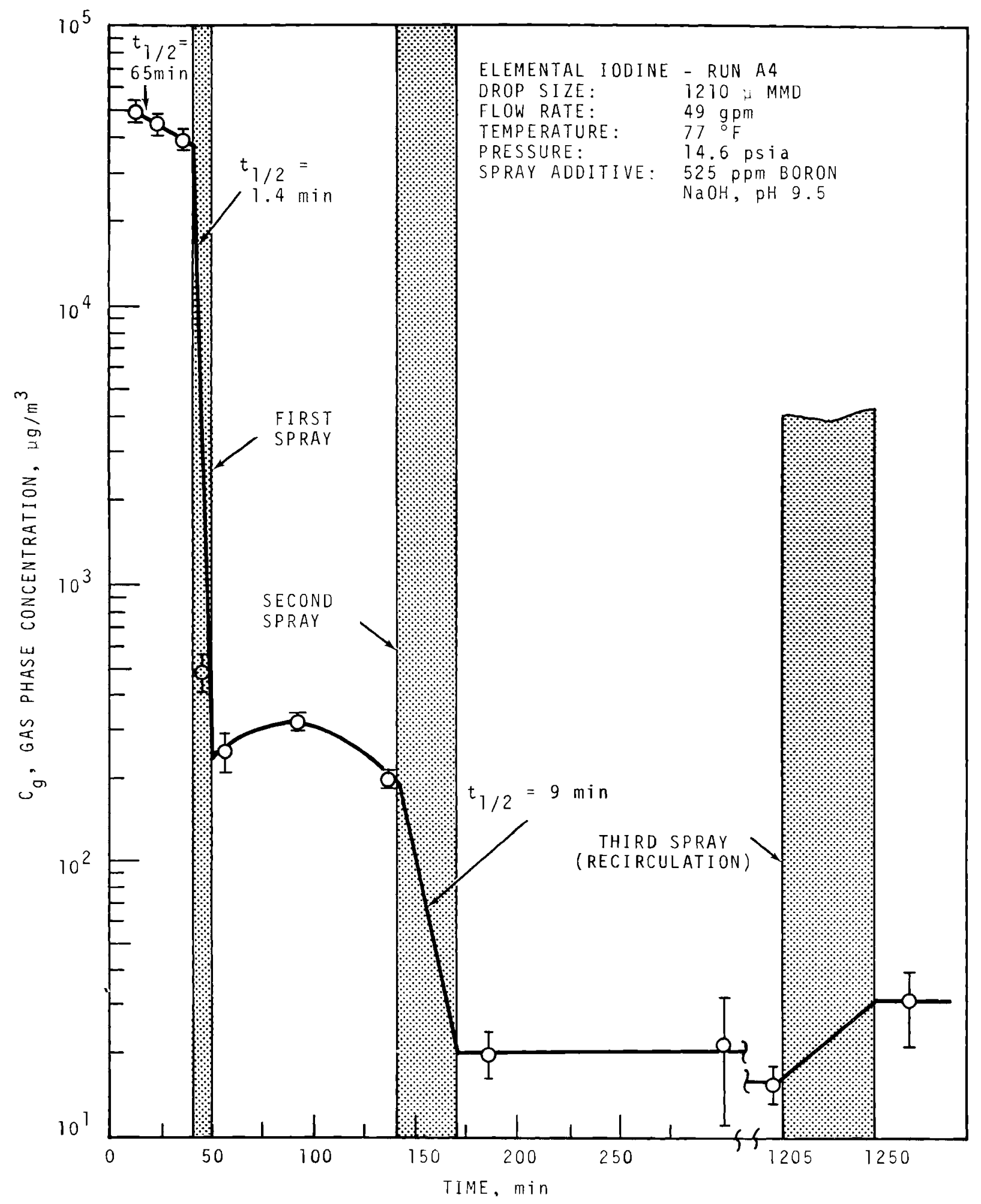

FIGURE 8. Concentration of Elemental Iodine in the Main Room, Run A4 
BNWL -1244

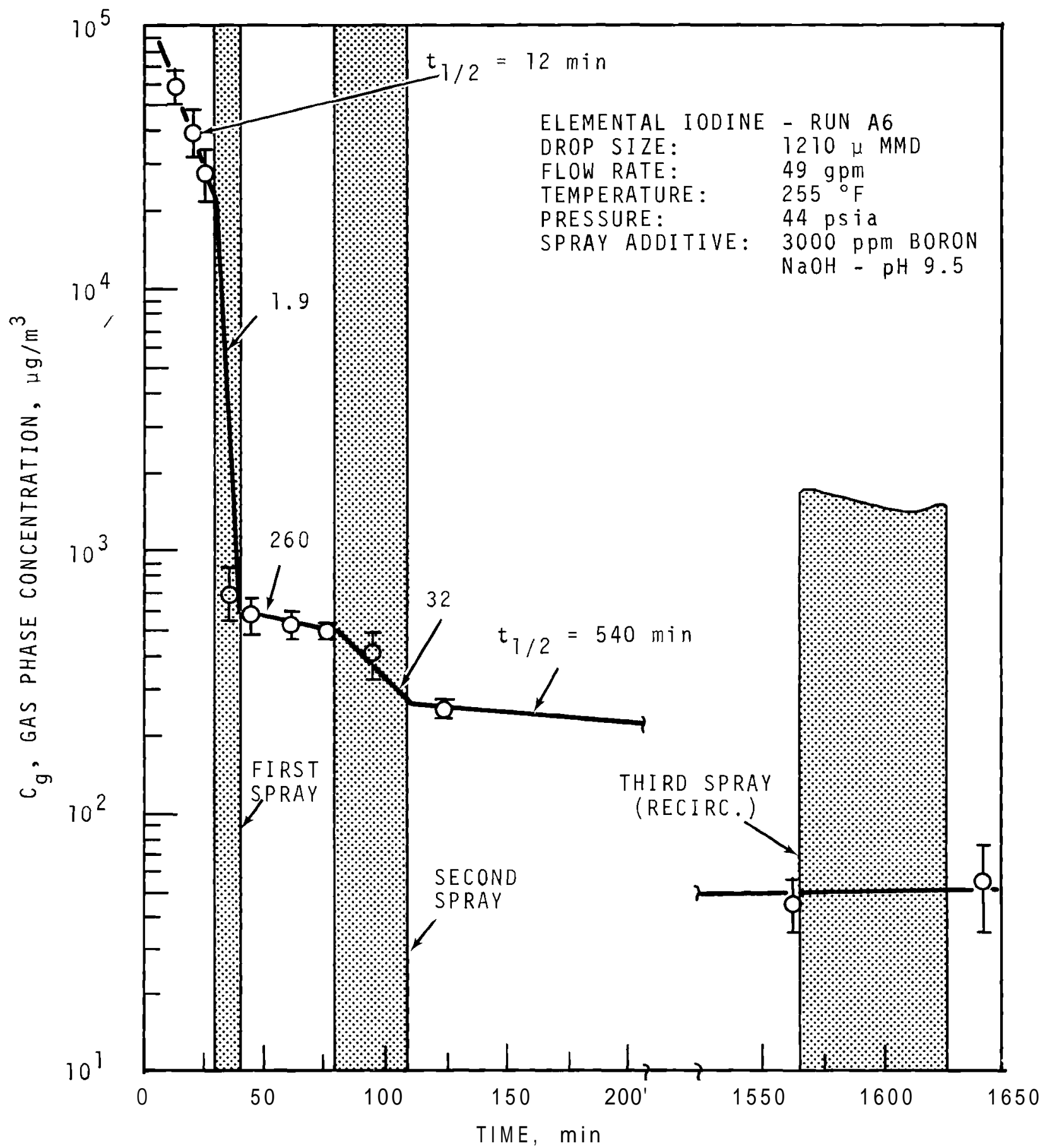

FIGURE 9. Concentration of Elemental Iodine in the Main Room, Run A6 


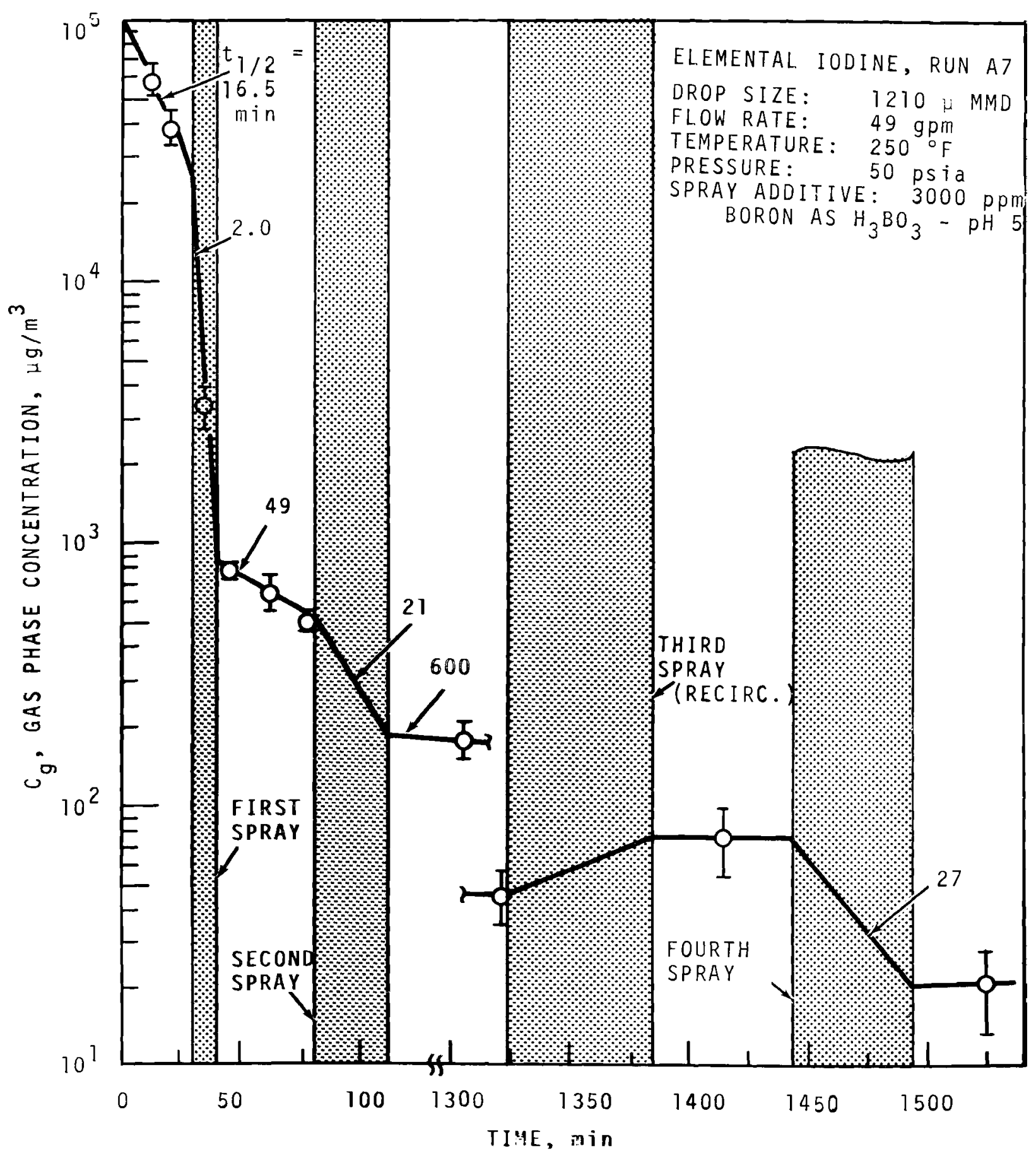

FIGURE 10. Concentration of Eilenertai Ioxine in thè Main Room, Run A7 
BNWL- 1244

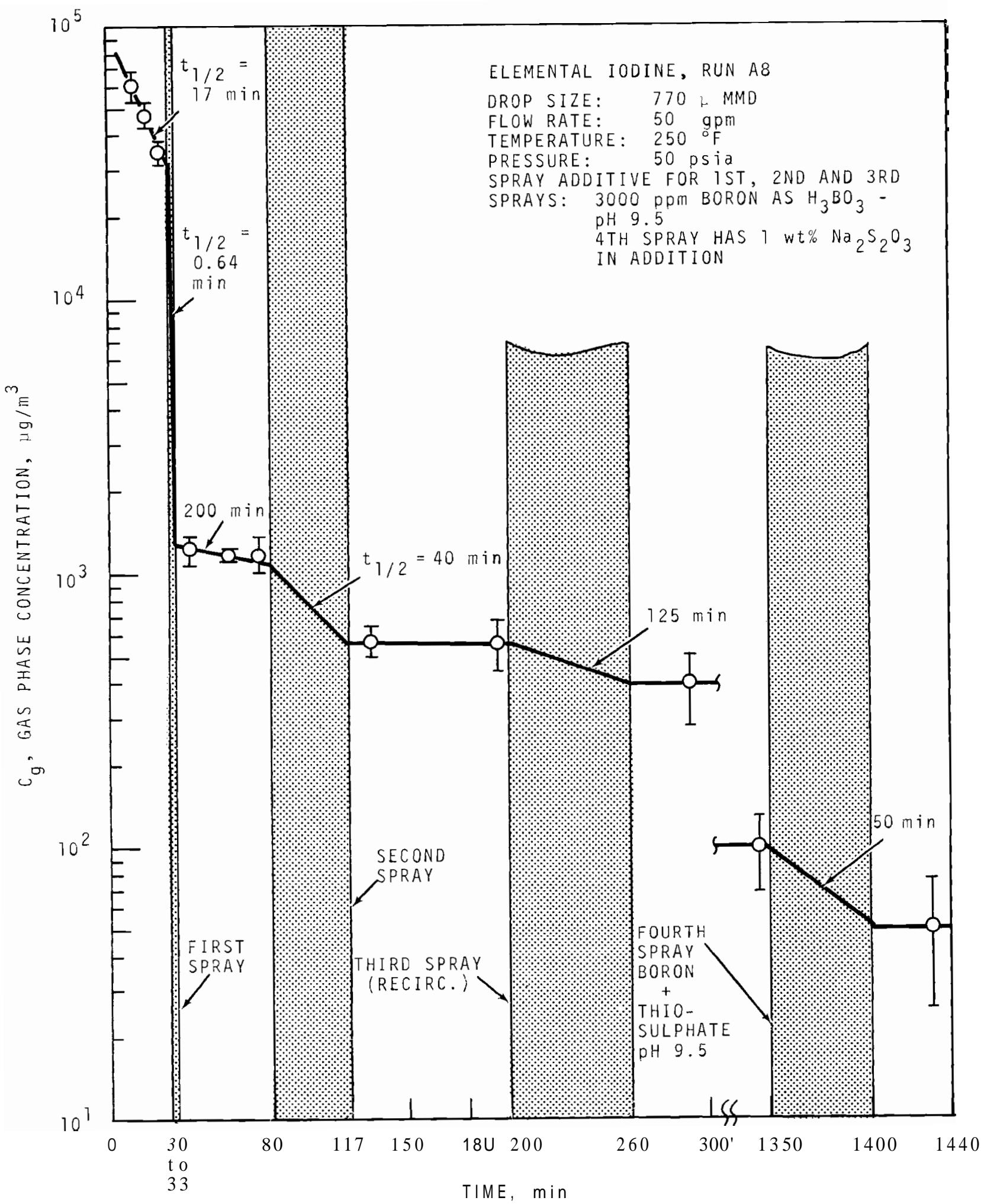

FIGURE 11. Concentration of Elemental Iodine in the Main Room, Run A8 


$$
t_{1 / 2}=\frac{0.693}{\lambda}
$$

The observed half-lives obtained in this manner are listed in Table 19 for each of the five experiments. The half-lives due to spray only, after correcting for natural process removal according to Equation (42), are also listed.

Particulate-Associated Iodine

Figures 12 through 16 show the time dependence of particulate-associated iodine in the main room for the five experiments. Two conclusions are evident. The particulate iodine is rapidly removed at rates roughly equivalent to those for elemental iodine, and the amount left at later time is either very small or not detected. Two explanations are possible. The first is that iodine associated with particles in these experiments is not a permanent, solid particle, but rather iodine absorbed reversibly in fog drops. When the gas concentration is depleted of elemental iodine, the iodine desorbs from the fog drops. Second, the correction applied to equate the water found on Maypack filters to particulate iodine might be wrong. Each of the possibilities is being explored further. In any event, however, very little particulate iodine remained after the first two spray periods in these two experiments. Table 20 lists the observed half-life and those due to spray only.

Iodine on Charcoal Paper

Figures 17 through 21 show the time dependence of the concentration of the iodine retained on the Maypack charcoal paper for each of the five experiments. As discussed previously, this is a mixture of several forms of iodine and thus its transport behavior cannot be discussed in terms of a single species. This concentration, included only for the sake of completeness, is added, of course, to all the other Maypack components to obtain the total iodine concentration. Table 21 lists the observed half-lives for the mixture measured by this Maypack component. 
BNWL - 1244

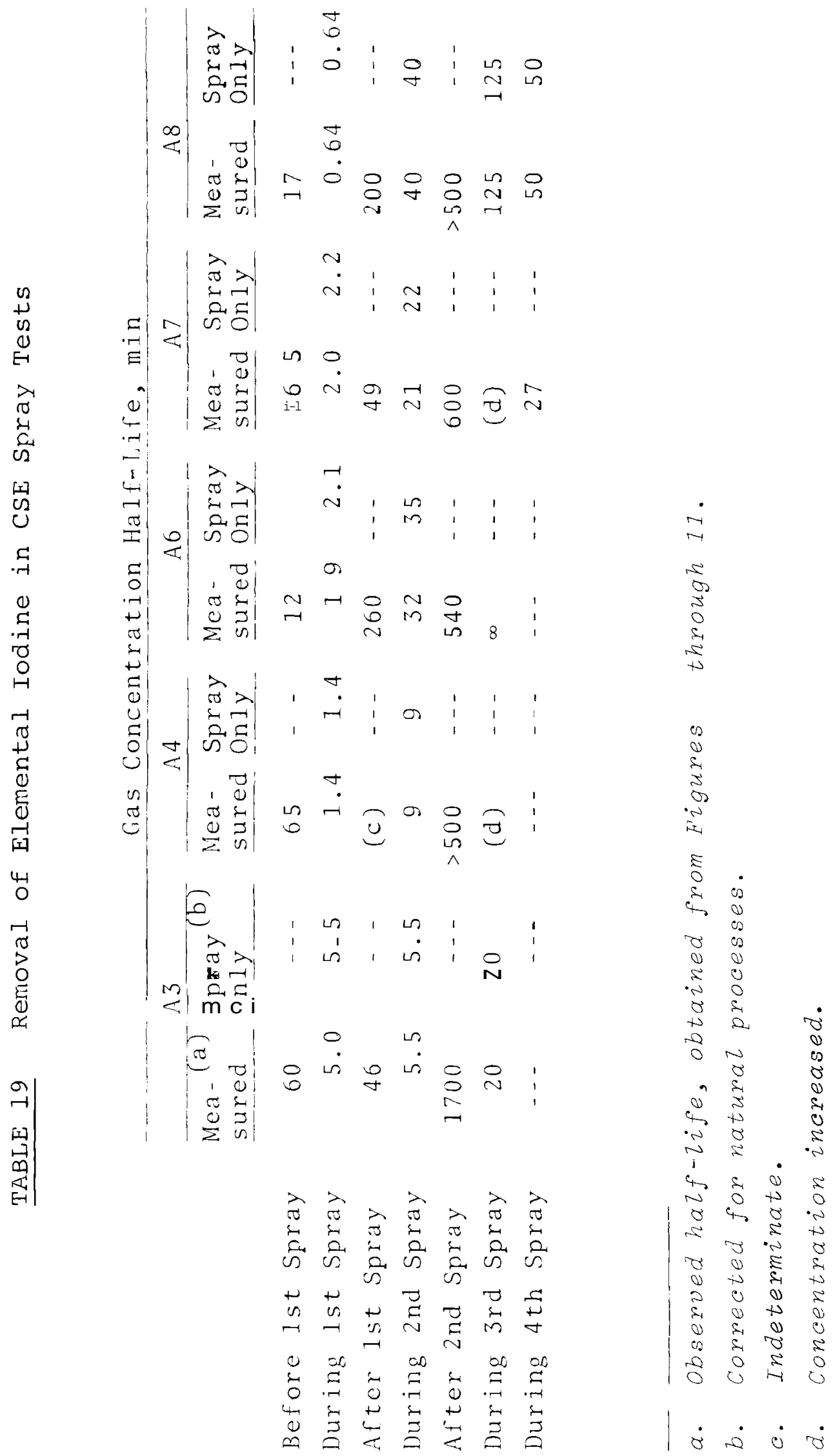




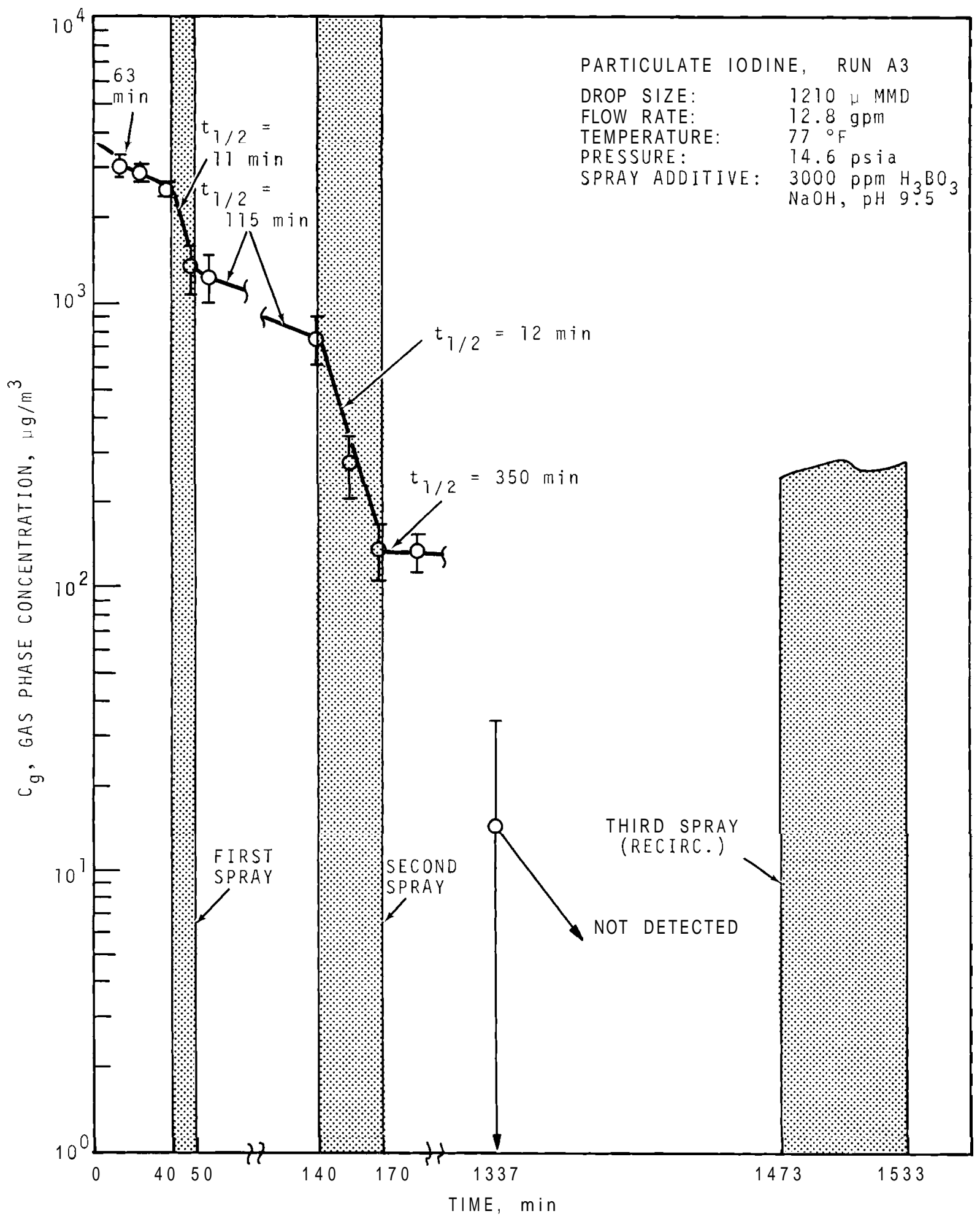

FIGURE 12. Concentration of Particulate Iodine in the Main Rocsm, Run A3 
BNWL - 1244

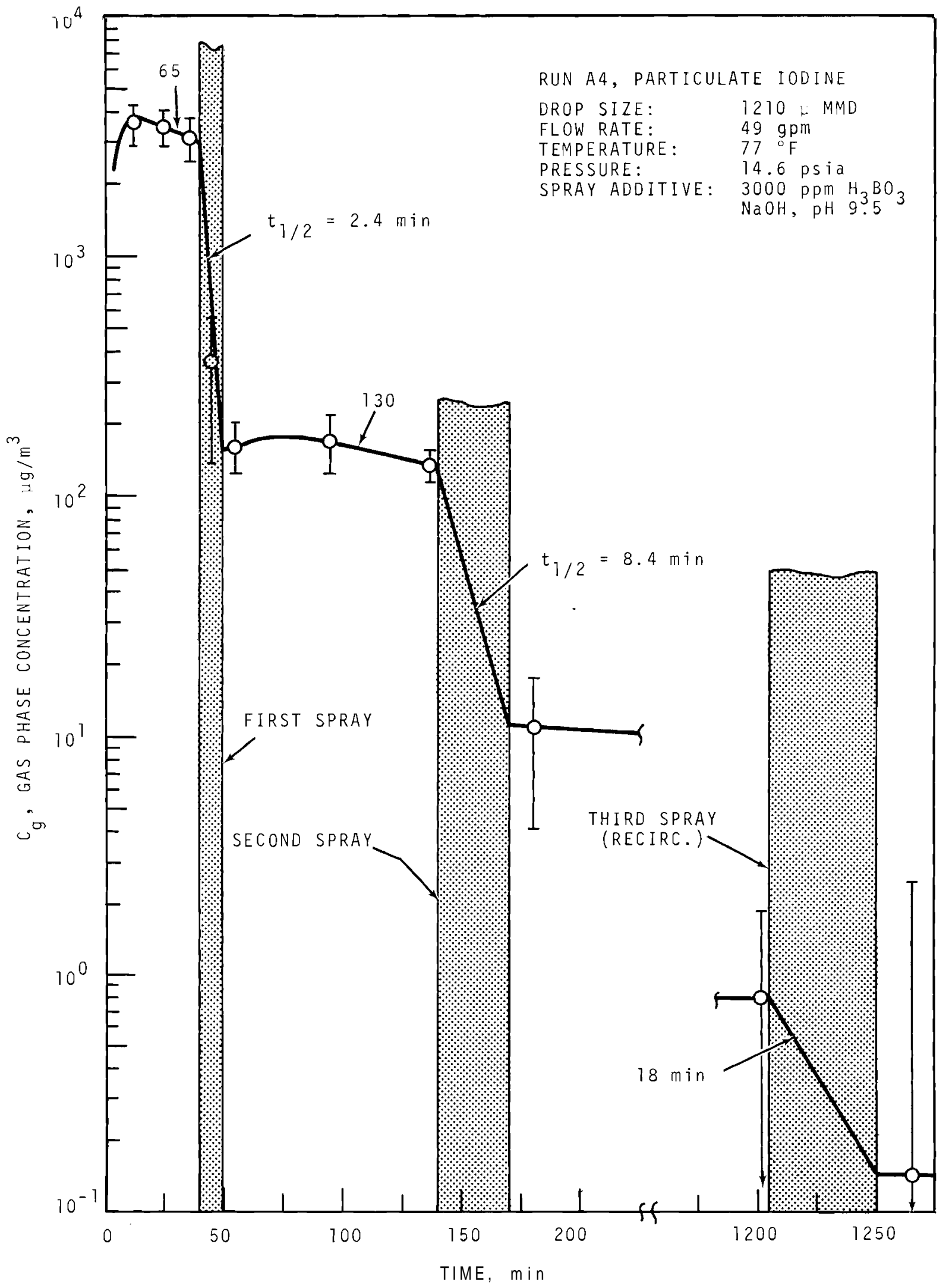

FIGURE 13. Concentration of Particulate Iodine in the Main Room, Run A4 


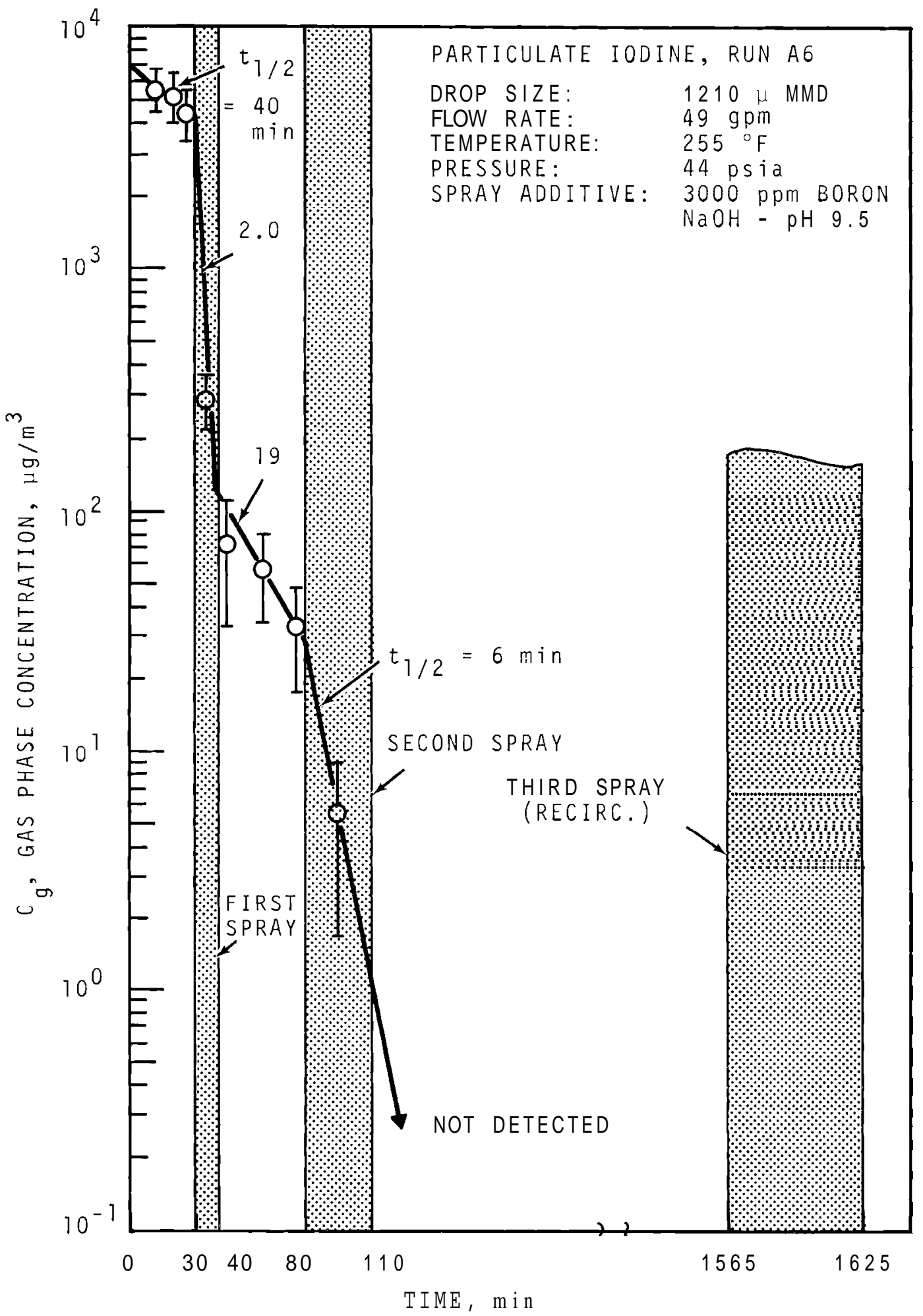

FIGURE 14. Concentration of Particulate Iodine in the Main Room, Run A6 
BNWL -1244

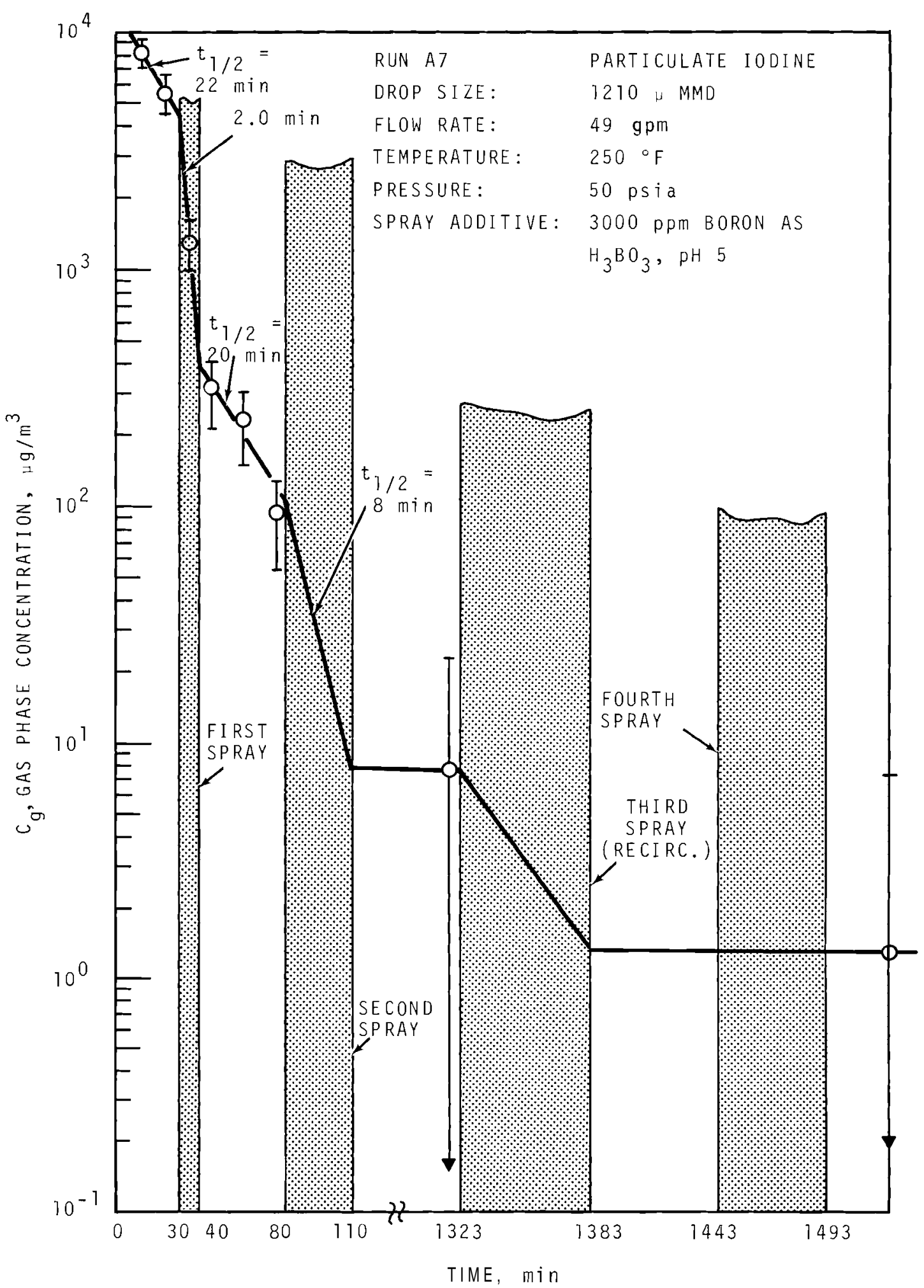

FIGURE 15. Concentration of Particulate Iodine in the Main Room, Run A7 
BNWL -1244

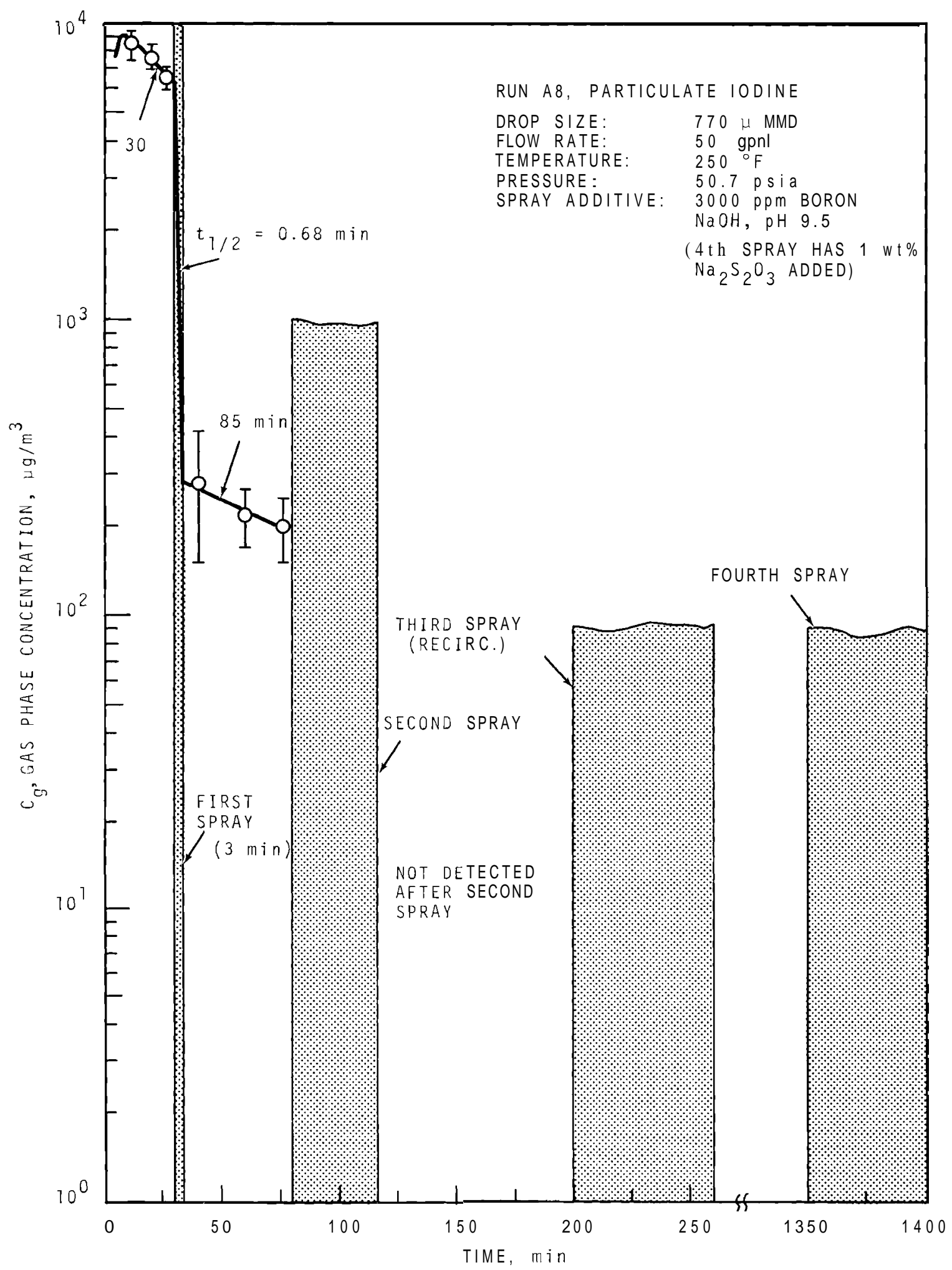

FIGURE 16. Concentration of Particulate Iodine in the Main Room, Run A8 

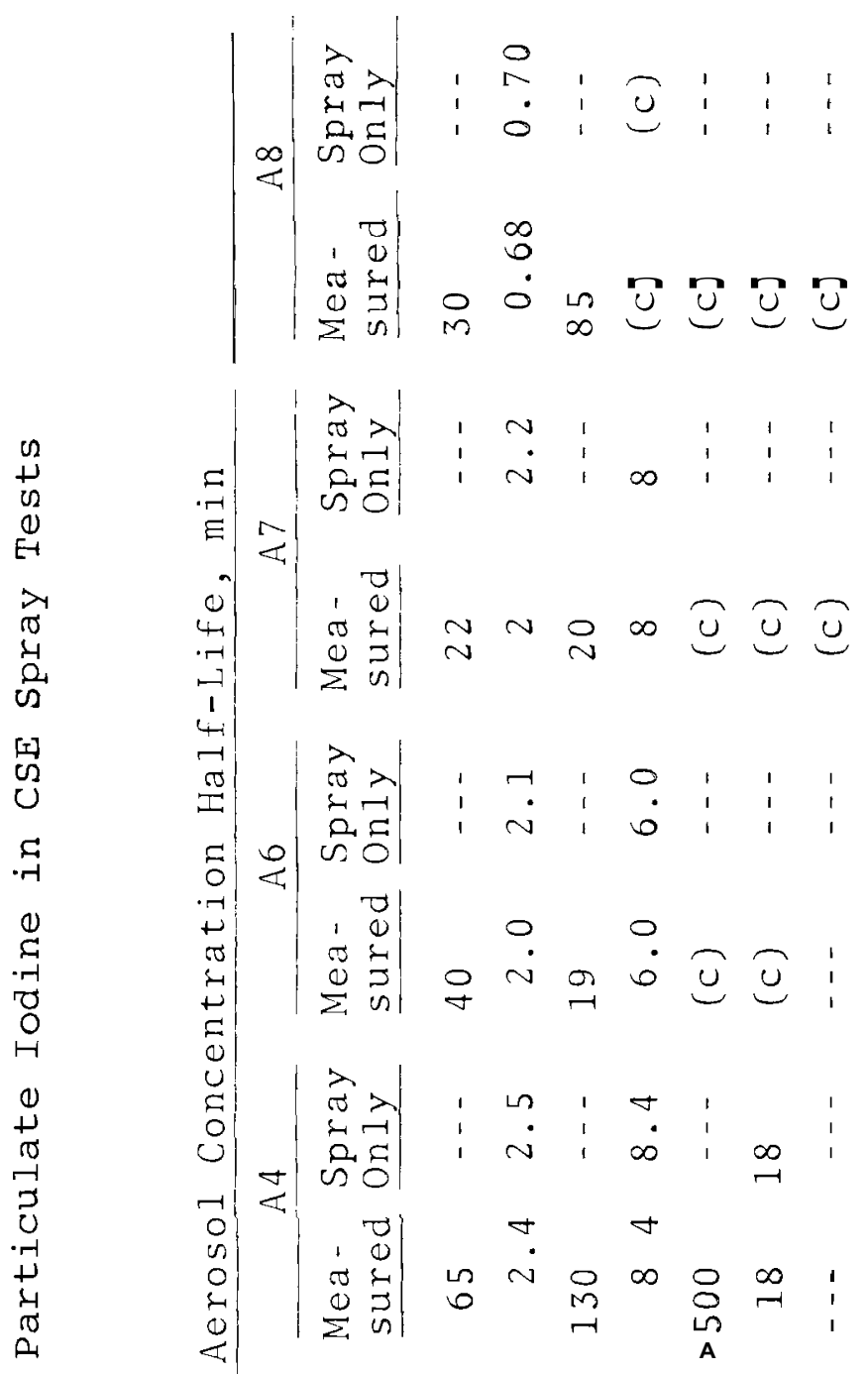

4
0
-1
0
0
0
0
0

它

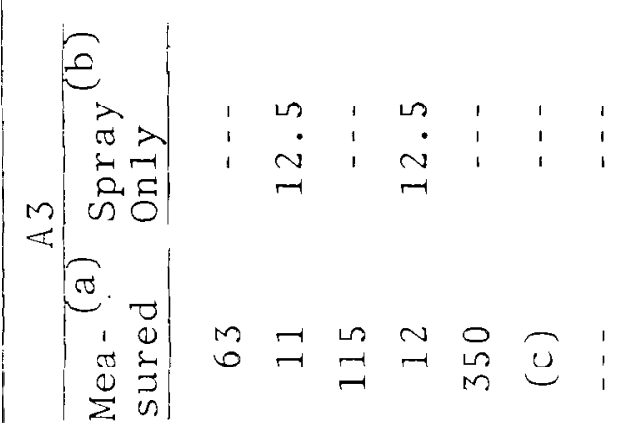

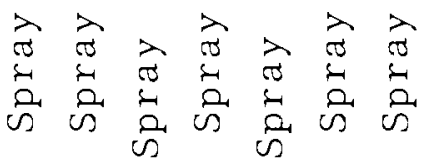

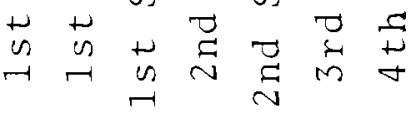

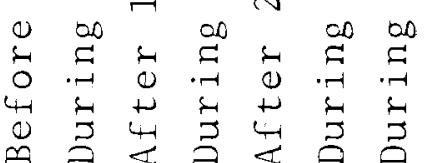

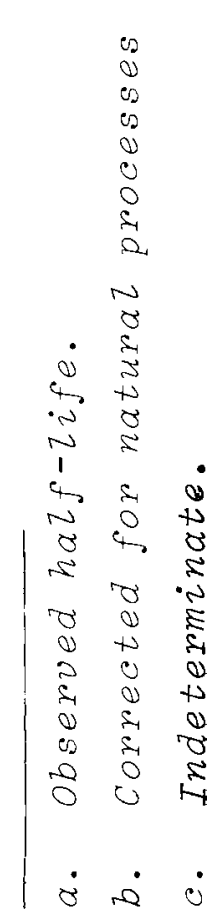


BNWL -1244

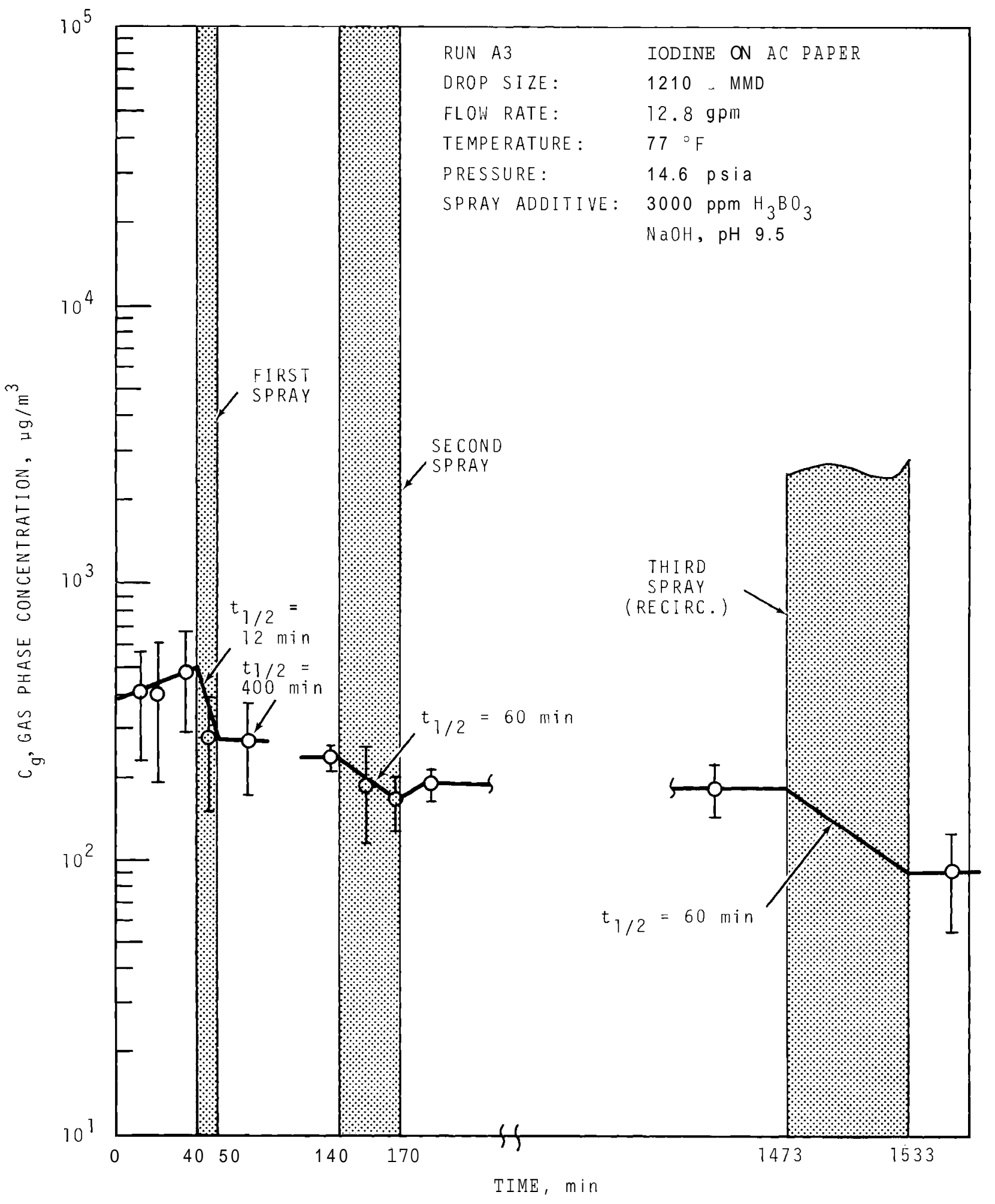

FIGURE 17. Concentration in Main Room of Iodine Associated with Charcoal Paper, Run A3 


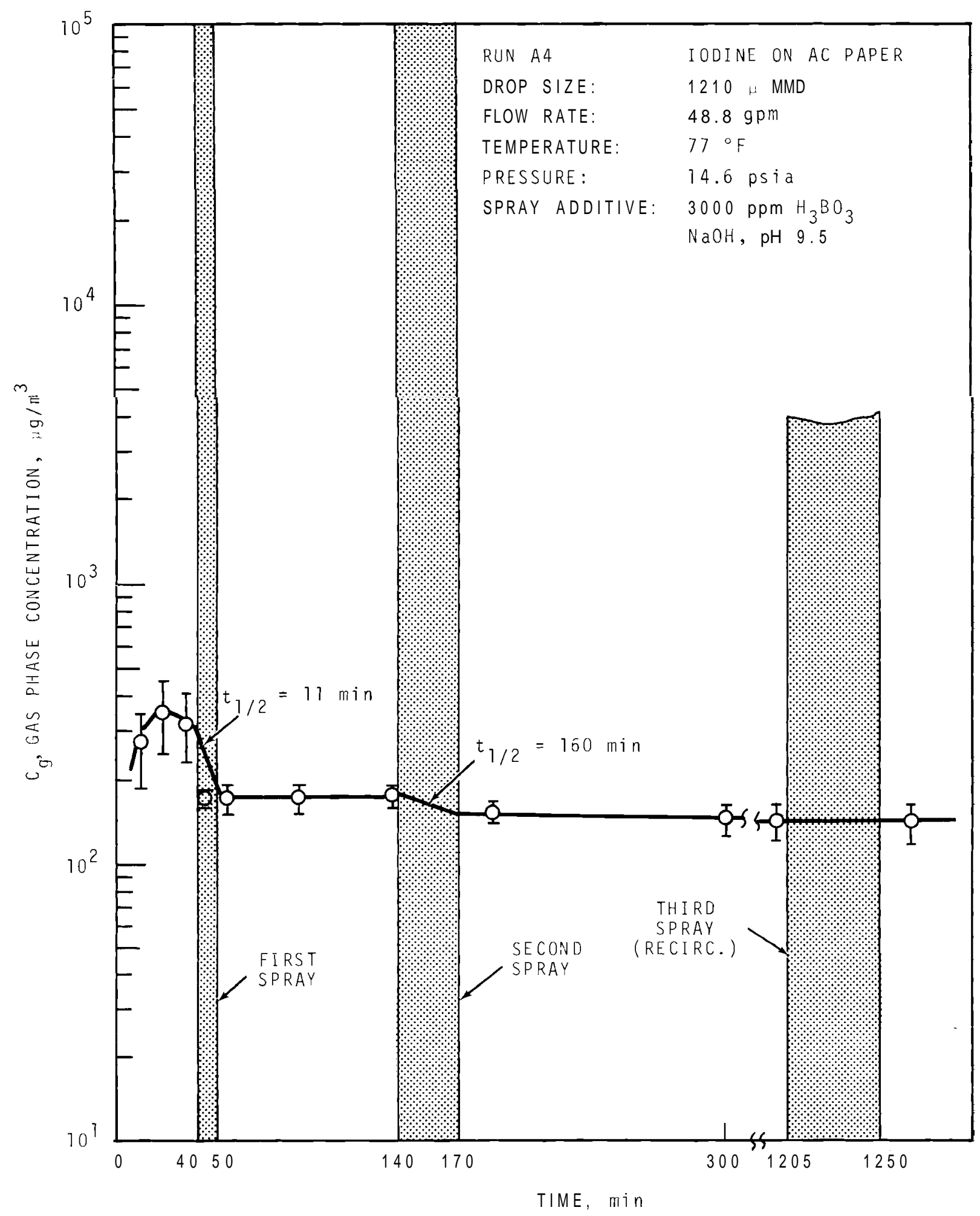

FIGURE 18. Concentration in rain Room of Iodine Associated with Charcoal Paper, 2 un A4 


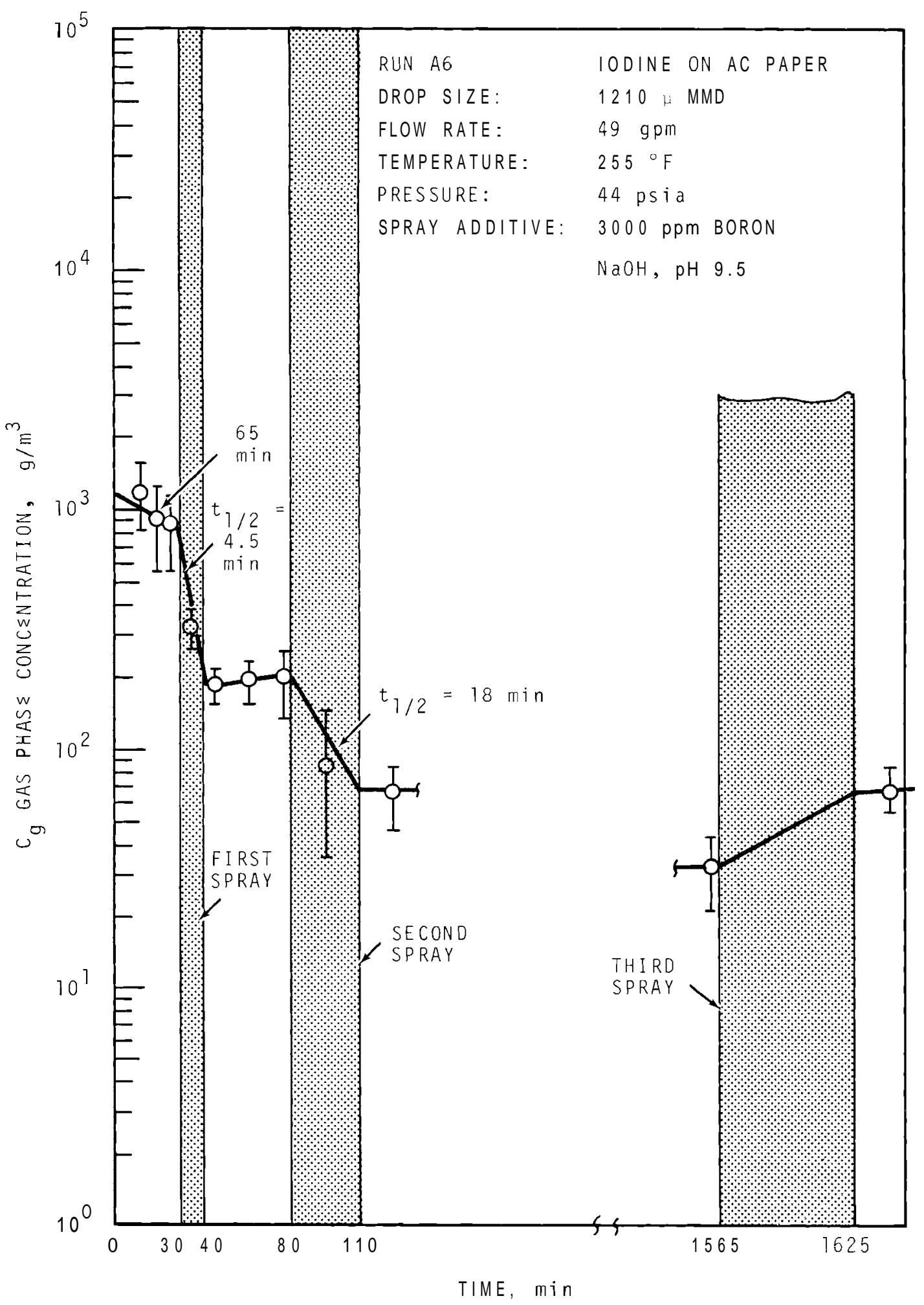

FIGURE 19. Concentration in Main Room of Iodine Associated with Charcoal Paper, Run A6 
BNWL -1244

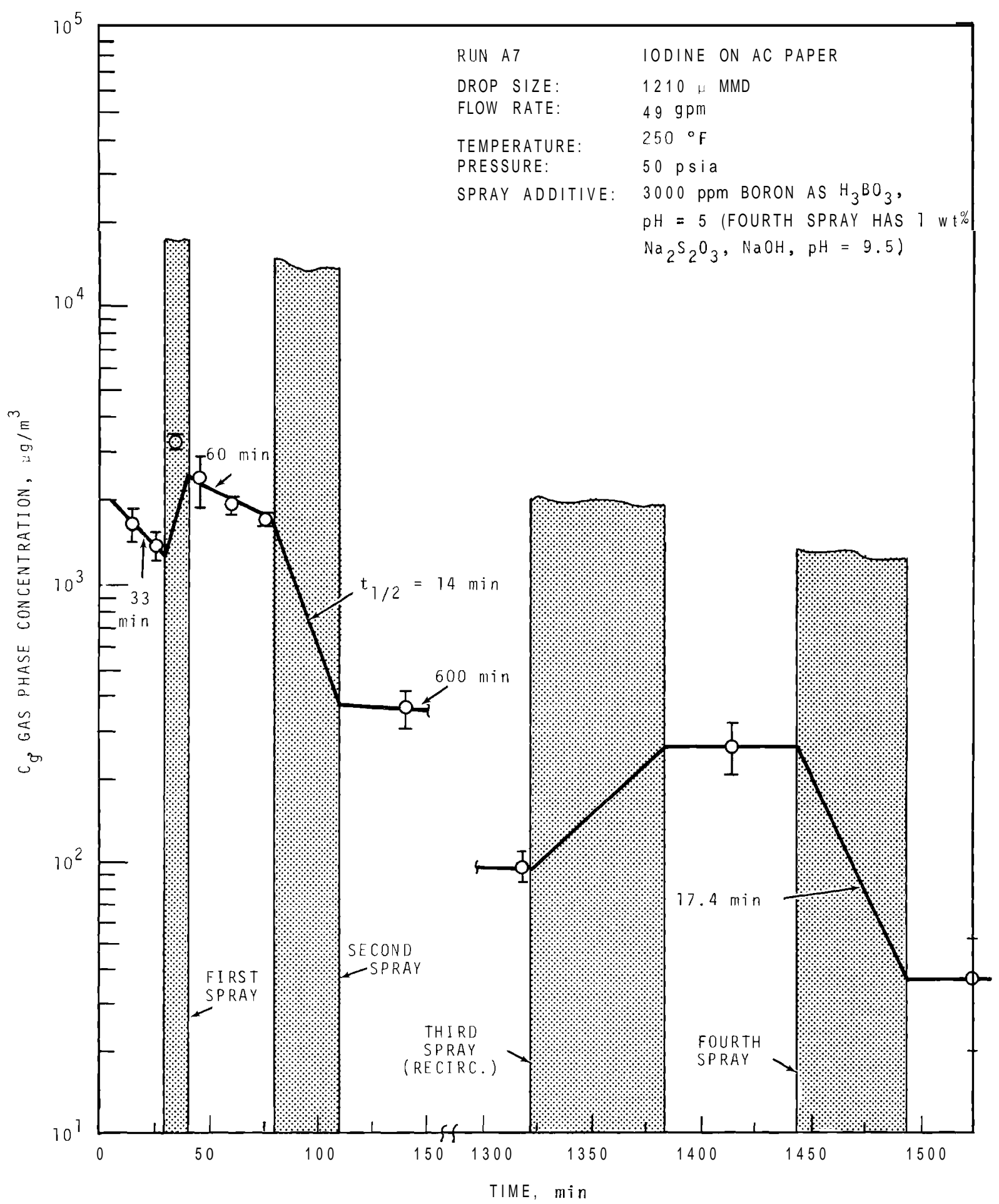

FIGURE 20. Concentration in Main Room of Iodine Associated with Charcoal Paper, Run A7 


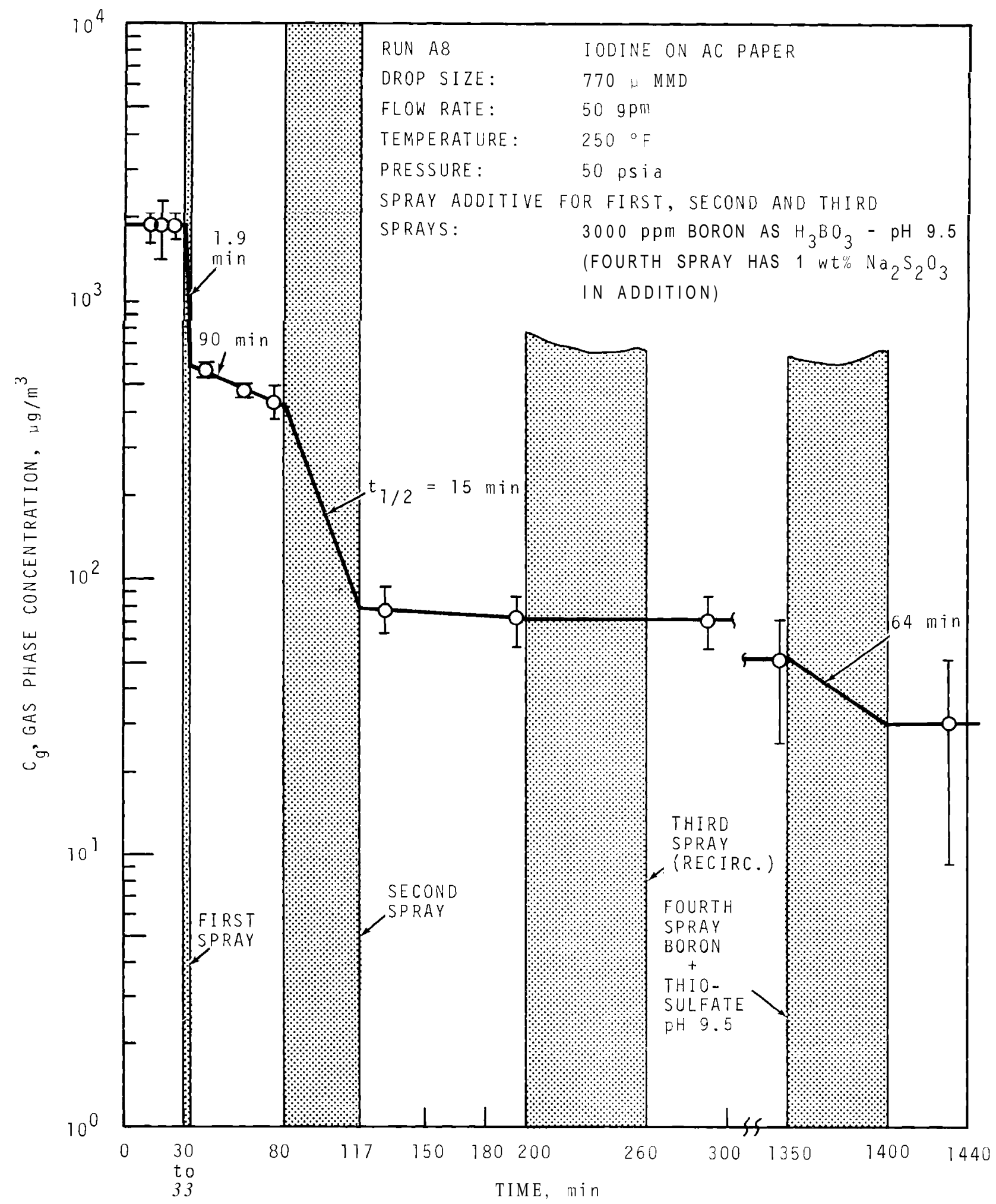

FIGURE 21. Concentration in Main Room of Iodine Associated with Charcoal Paper, Run A8 
BNWL - 1244

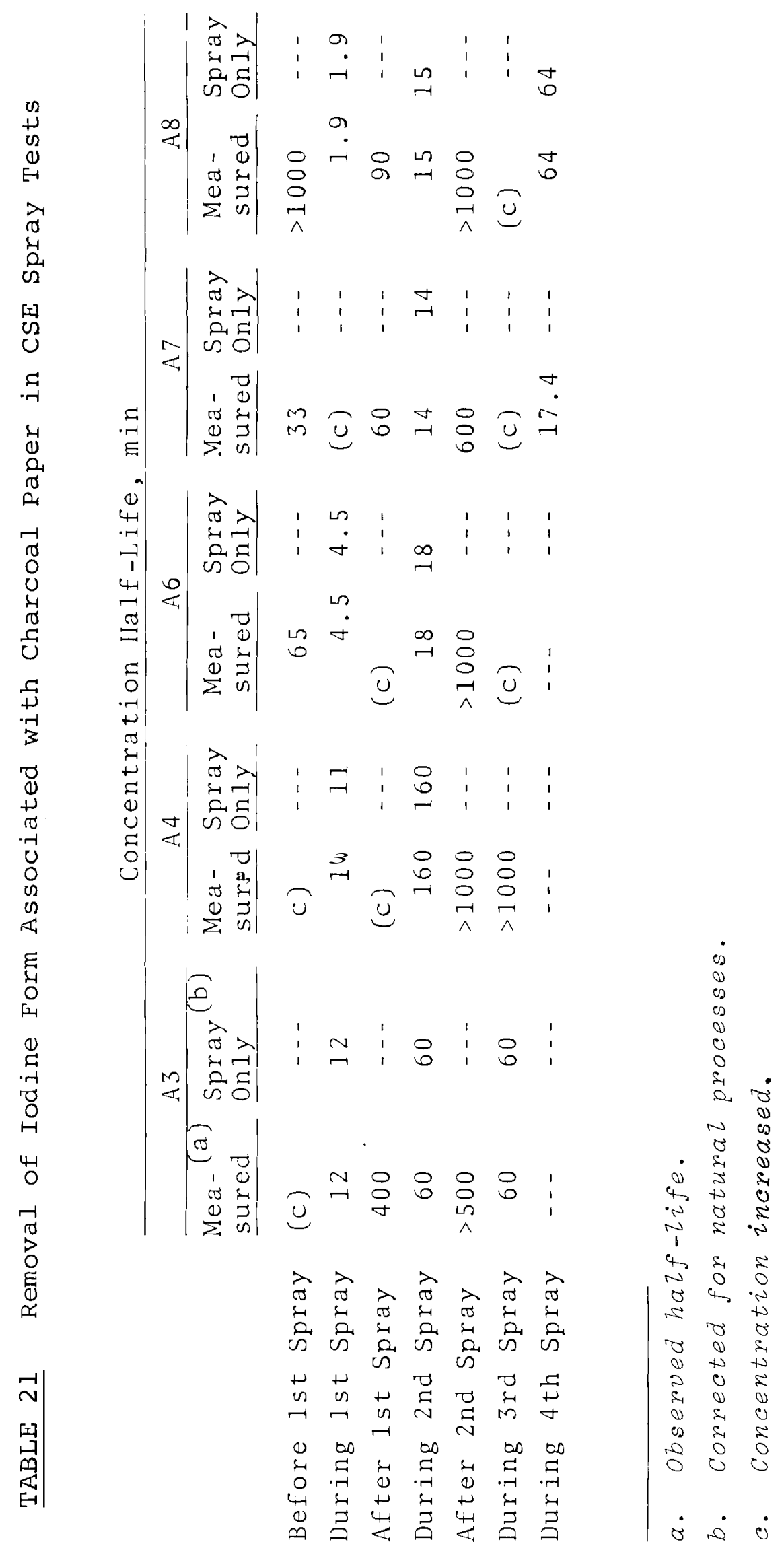


BNWL -1244

Methyl Iodide

The time dependence of methyl iodide concentration in the gas phase of the main room is given for each experiment in Figures 22 through 26. The concentration decreased by about $20 \%$ by diffusion into the middle and lower rooms. Usually, by the end of the second spray period, the concentrations in the three rooms were about equal. Other than for this effect, the methyl iodide concentration due to operation of the sprays with either fresh or recirculated alkaline borate solution did not decrease appreciably.

In experiments $A 7$ and $A 8$, a fourth spray using 1 wt $\mathrm{Na}_{2} \mathrm{~S}_{2} \mathrm{O}_{3}$ added to alkaline borate was made at the end of the experiment. A definite decrease in methyl iodide concentration was noted in these two cases. Table 22 lists the concentration half-lives measured and corrected for natural removal processes. Total Iodine

The total iodine concentration was obtained by summing the iodine forms found on all five of the Maypack components. Behavior of the total iodine concentration, although understandable only in terms of its constituent parts, is of interest for its graphical display as affected by the sprays, such plots are shown in Figures 27 through 31. Before the first spray, the iodine was largely in the form of elemental iodine (see Table 9). Therefore, its behavior matched that of elemental iodine quite closely. At later times, the iodine was mostly methyl iodide and the total iodine concentration behavior reflected this fact. Table 23 lists the observed and corrected concentration halflives for the five experiments. 
BNWL - 1244

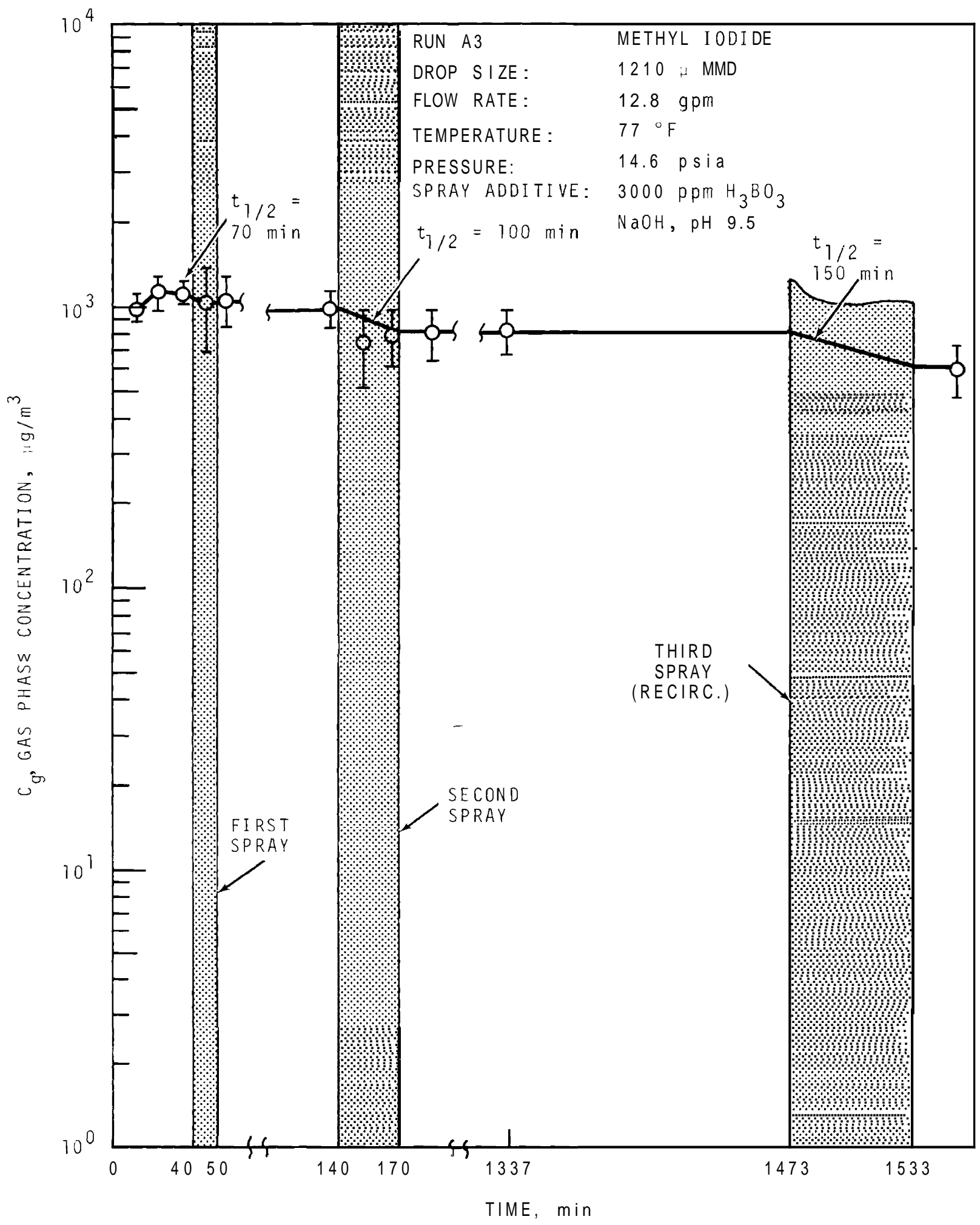

FIGURE 22. $\begin{aligned} & \text { Concentration of Methyl Iodide in the Main Room, } \\ & \text { Run A3 }\end{aligned}$ 
BNWL - 1244

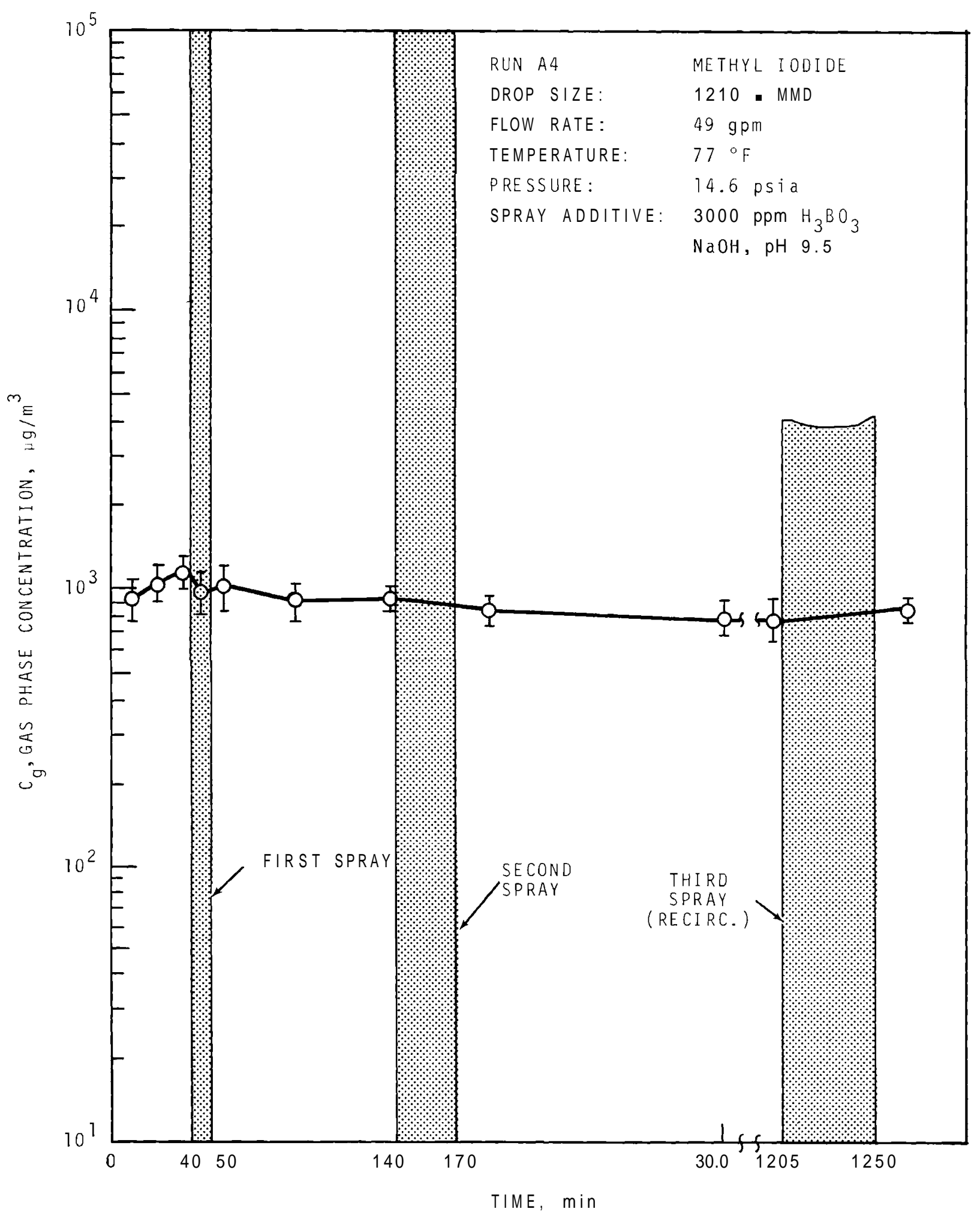

FIGURE 23. Concentration of Methyl Iodide in the Main Room, Run A4 
BNWL -1244

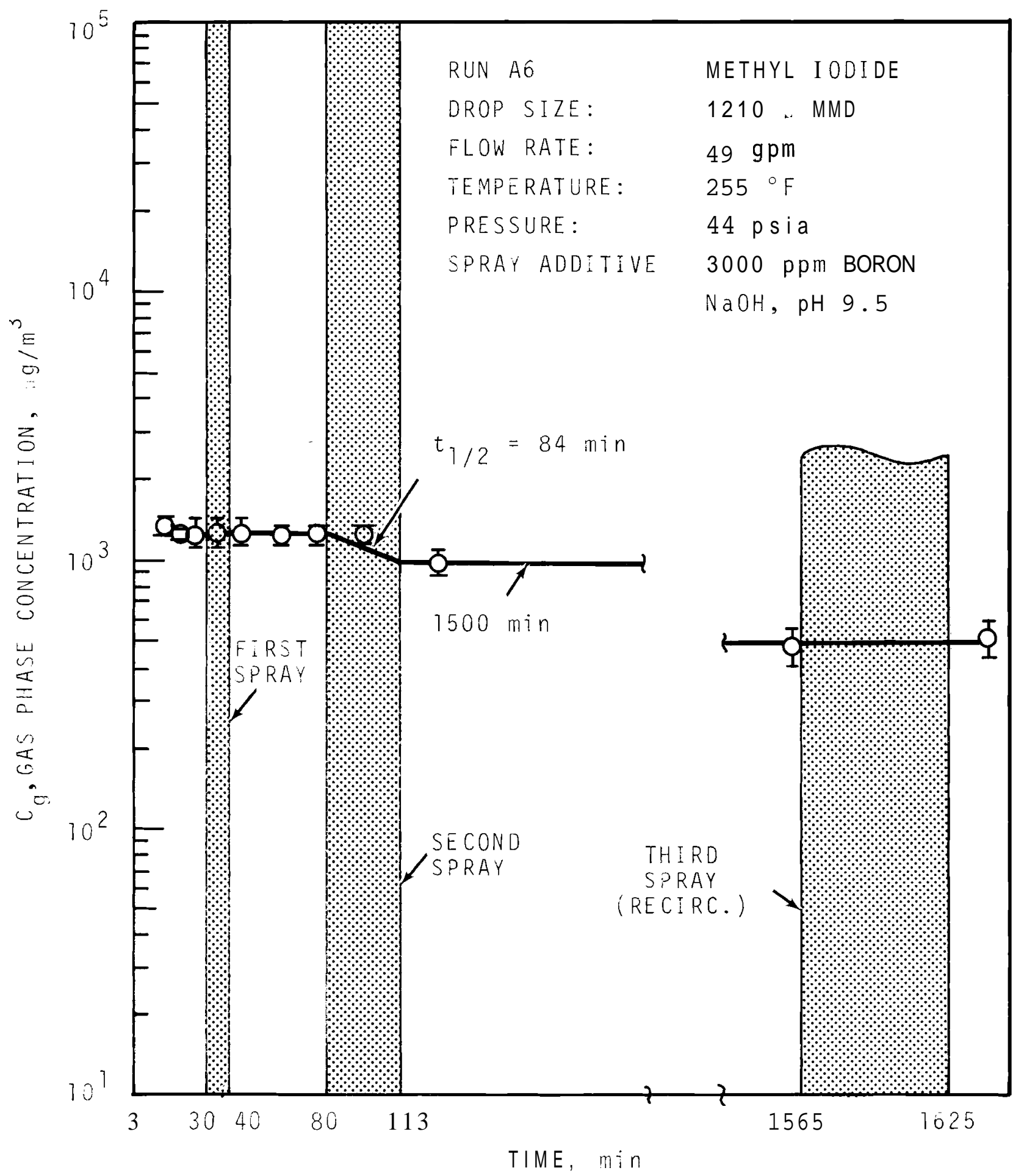

FIGURE 24. Concentration of Methyl Iodiảe in the ilain Room, Run A6 
BNWL - 1244

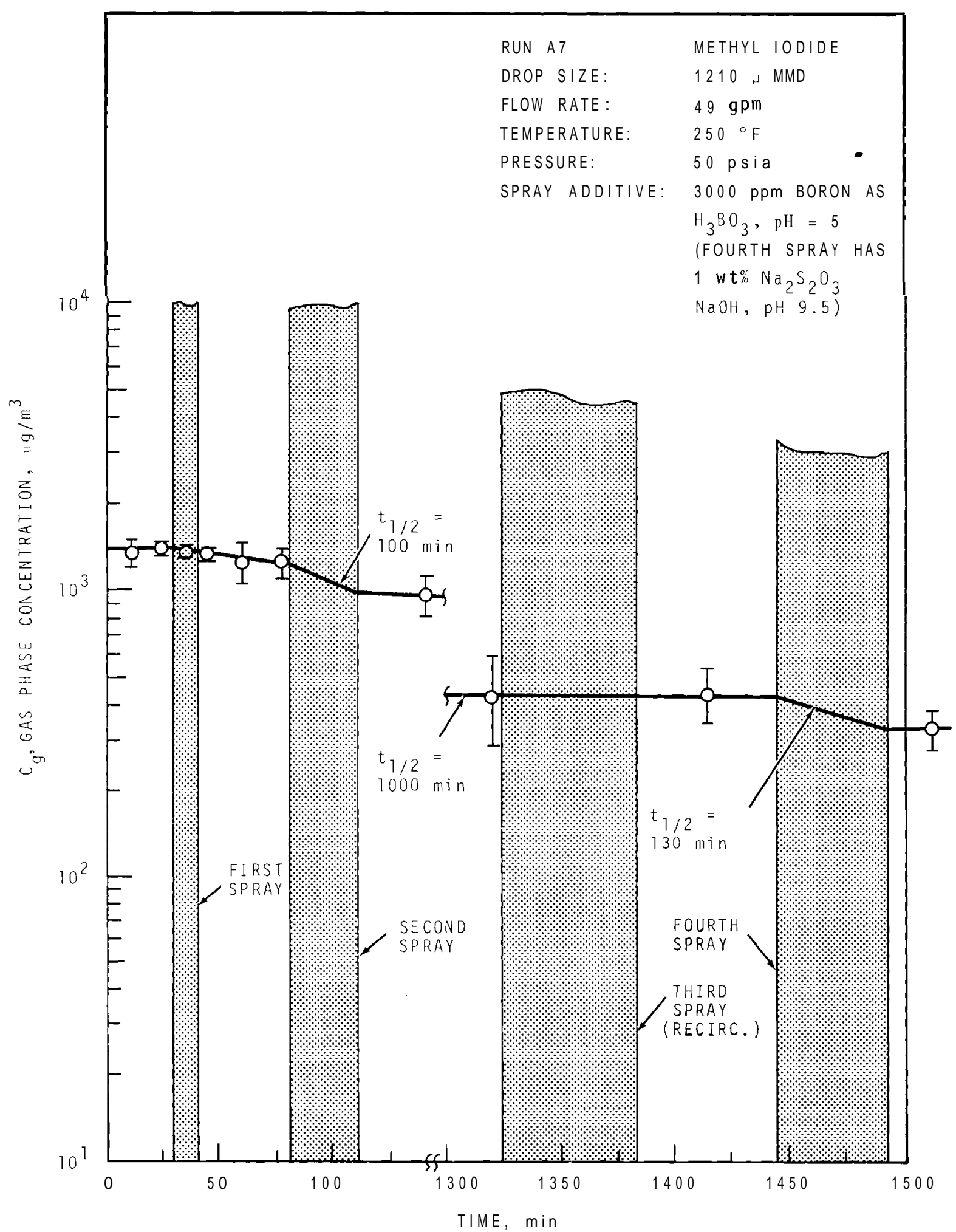

FIGURE 25. Concentration of Methyl Iodide in the Main Room, Run A7 


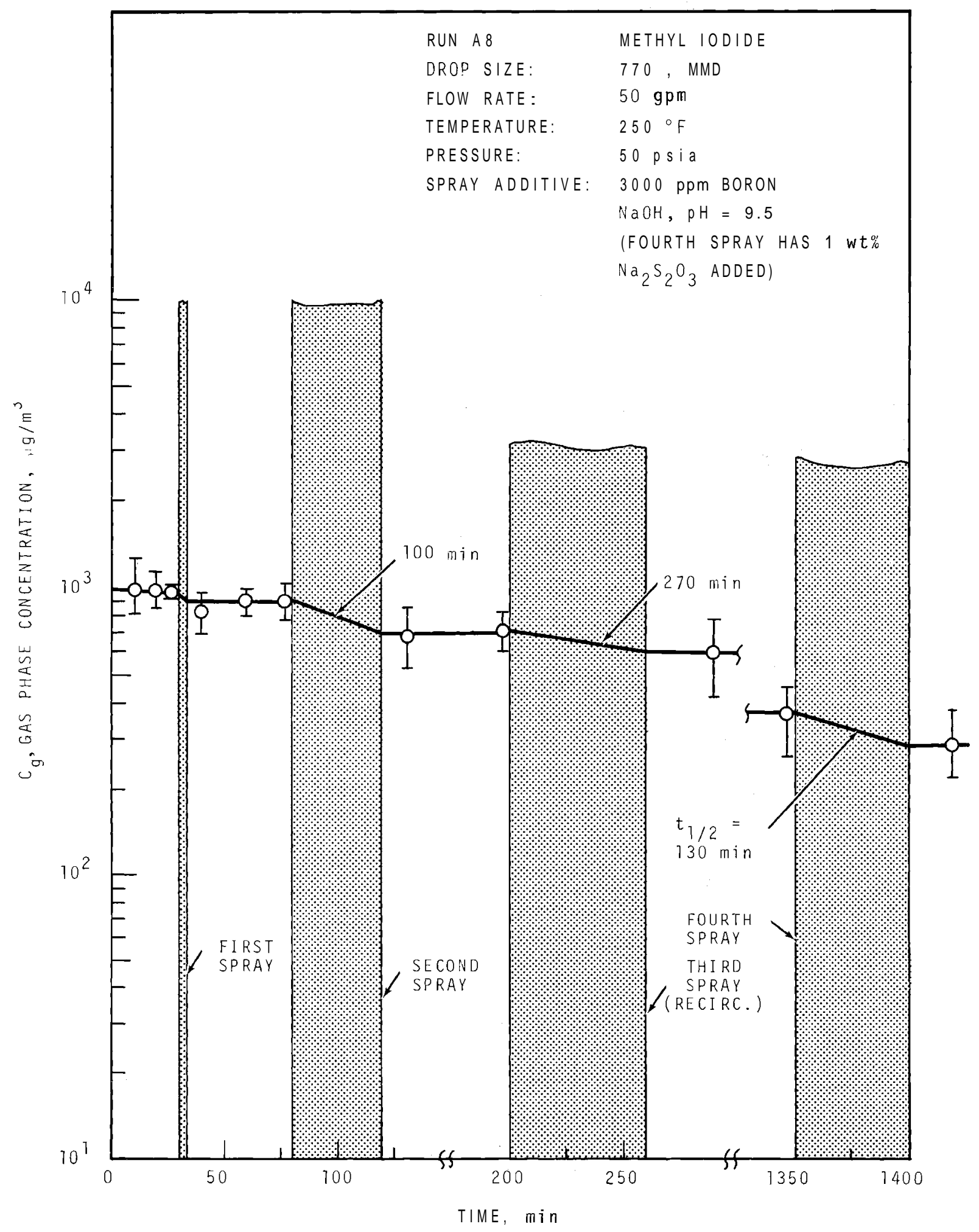

FIGURE 26. Concentration of Methyl Iodide in the Main Room, Run A 8 
TABLE 22 Renoval of liethyl Iodide in CSE spray Tests

Gas Concentration Half-Life, min

Mea-(a) Spray (b) $\frac{A 4}{\text { Mea- Spray }} \frac{\text { A6 }}{\text { Mea- Spray Mea- Spray Mea- Spray }}$

sured Only sured Only sured only sured Only sured Only

$\begin{array}{lllllllllll}\text { Before 1st Spray } & \text { (d) } & \ldots & \text { (d) } & \ldots & \text { (c) } & \ldots & \text { (c) } & \ldots & >1000 & \ldots \\ \text { During 1st Spray } & \text { (c) } & \text { (c) } & \text { (c) } & \text { (c) } & \text { (c) } & \text { (c) } & \text { (c) } & \text { (c) } & \text { (c) } & \text { (c) } \\ \text { After 1st Spray } & >1000 & \ldots & >500 & \ldots & \text { (c) } & \ldots & \text { (c) } & \ldots & \text { (c) } & -. \\ \text { During 2nd Spray } & 100 & \text { (c) } & \text { (c) } & \text { (c) } & 84 & \text { (c) } & 100 & \text { (c) } & 100 & \text { (c) } \\ \text { After 2nd Spray } & >1000 & \ldots- & >500 & \ldots- & >1000 & \ldots & \text { (c) } & \ldots & \text { (c) } & \ldots \\ \text { During 3rd Spray } & 150 & \text { (c) } & \text { (c) } & \text { (c) } & \text { (c) } & \text { (c) } & \text { (c) } & \ldots & 270 & \text { (c) } \\ \text { During 4th Spray } & \ldots & \ldots & \ldots- & \ldots & \ldots & \ldots & 130 & 130 & 130 & 130\end{array}$

a. Observed half-life.

b. Corrected for natural processes

c. Indeterminate.

d. Concentration increased. 


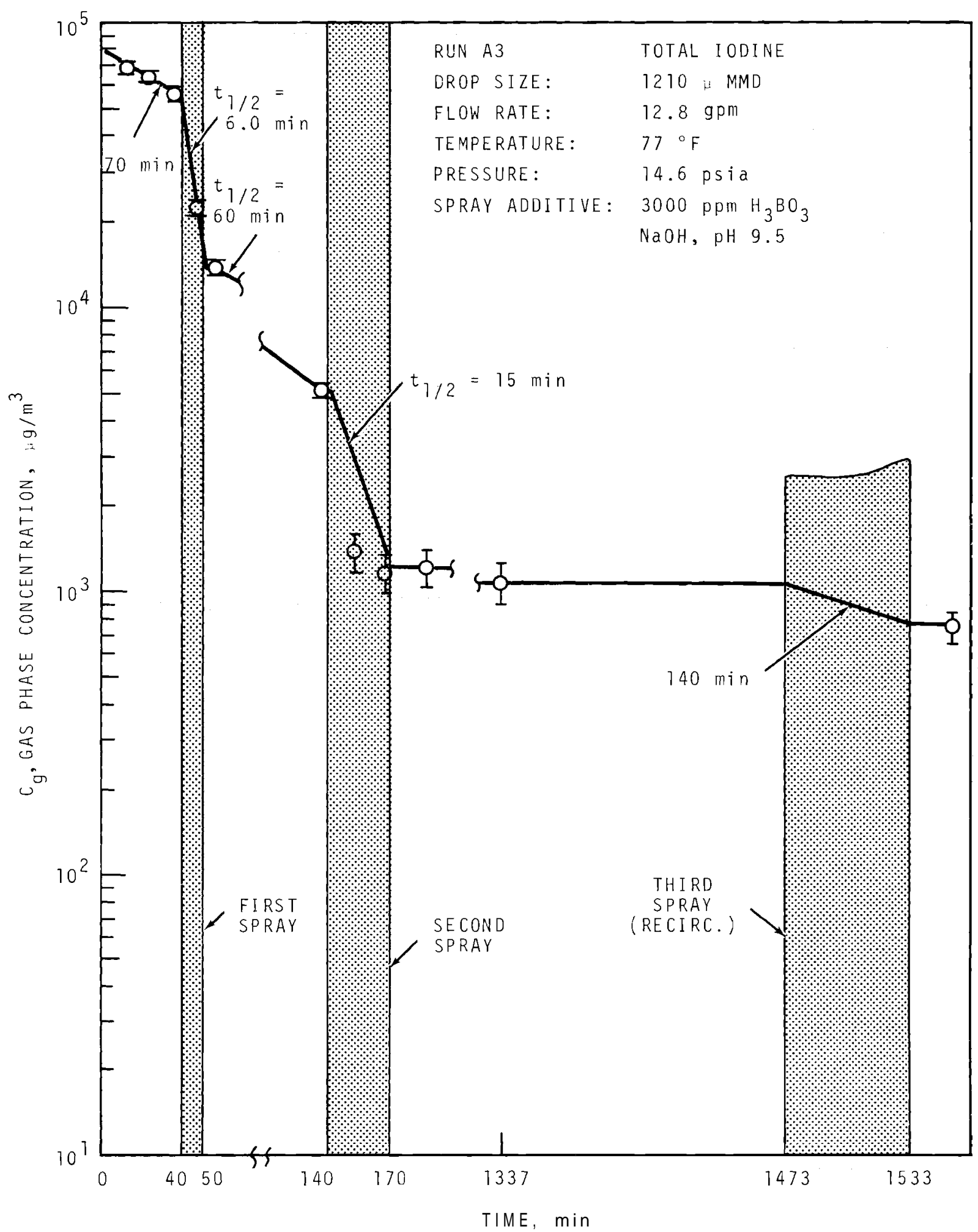

FIGURE 27. Total Iodine Concentration in the Main Room, Run A3 


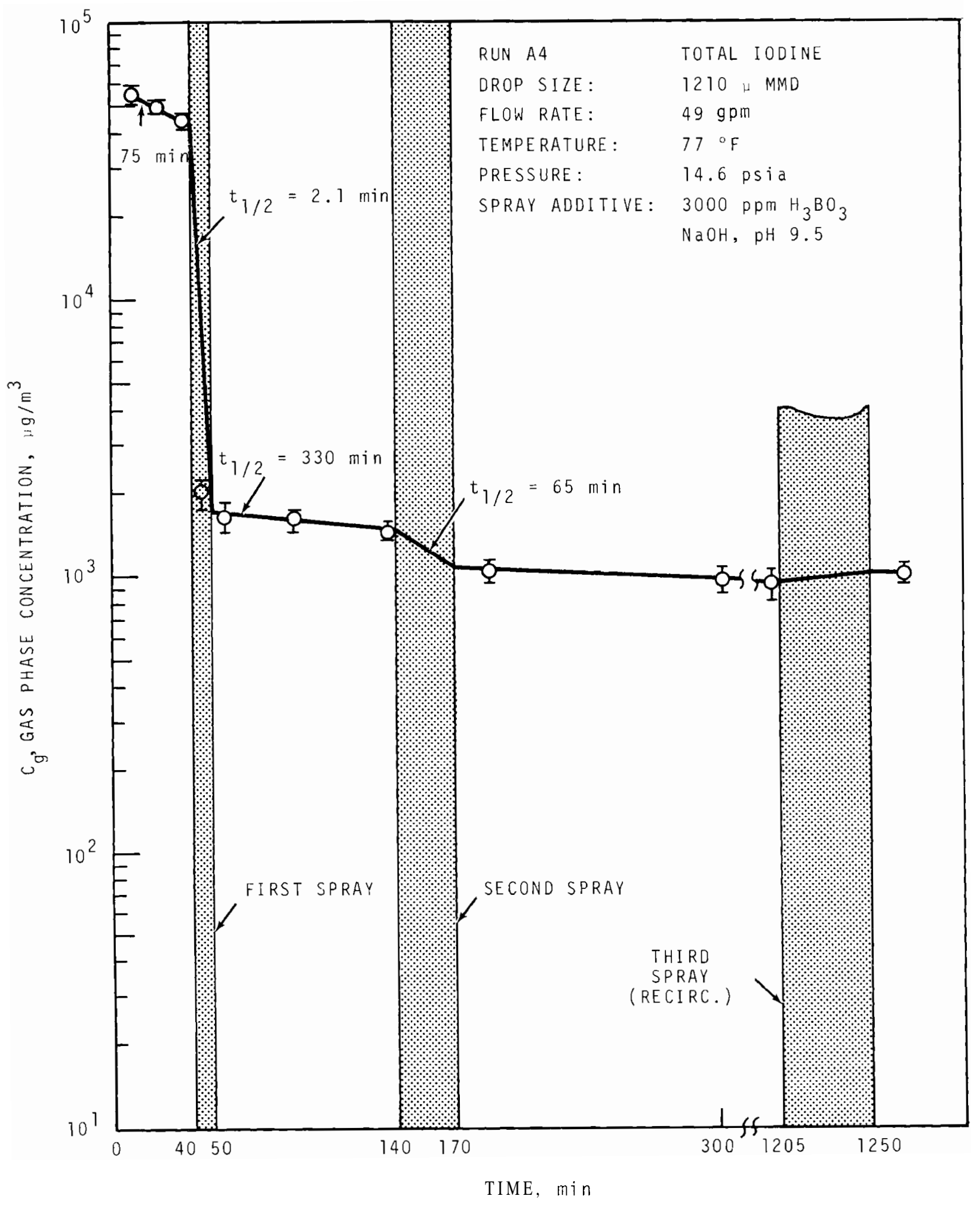

FIGURE 28. Total Iodine Concentration in the Main Room, Run A4 
BNWL-1244

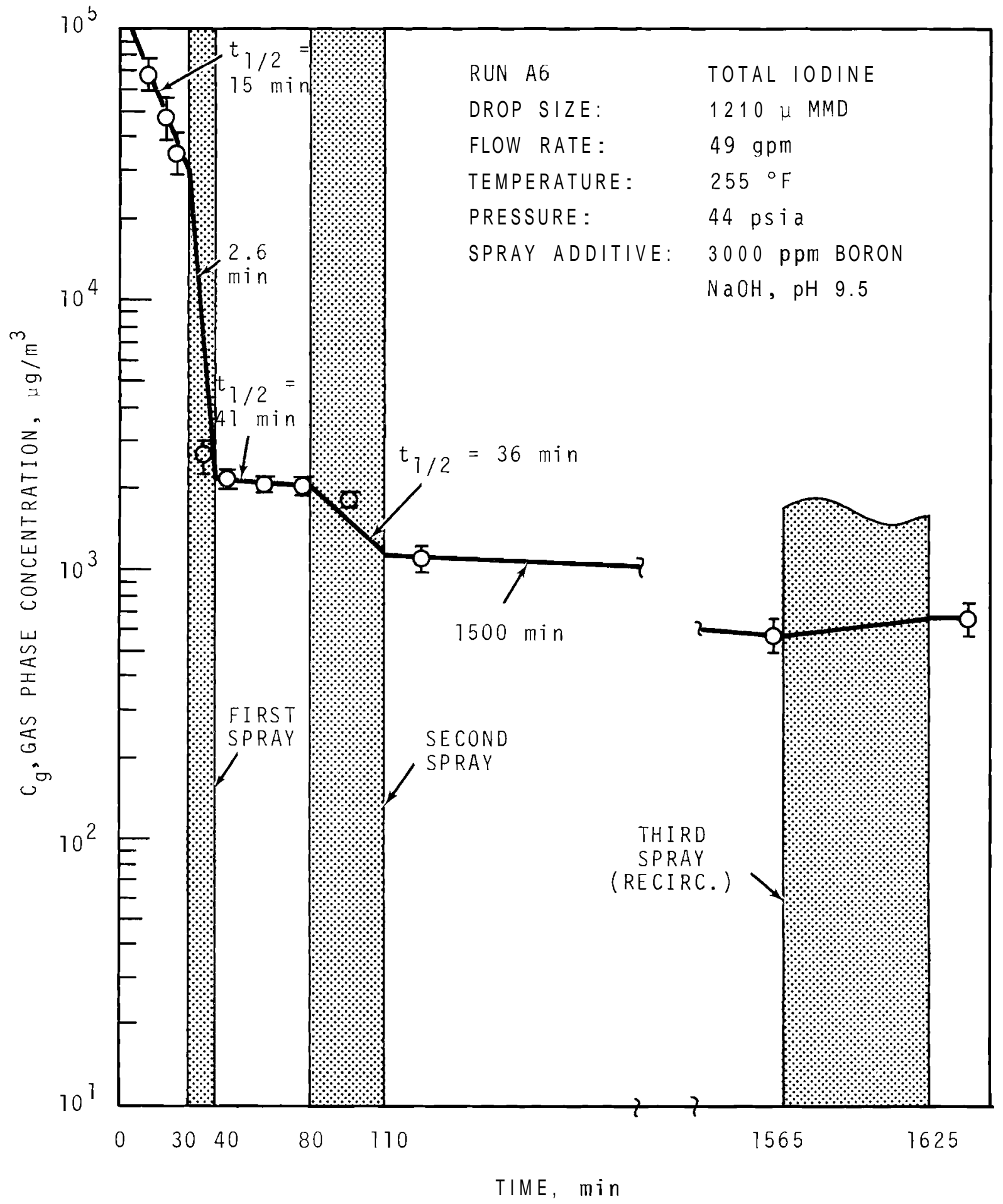

FIGURE 29. Total Iodine Concentration in the Main Room, Run A6 
BNWL - 1244

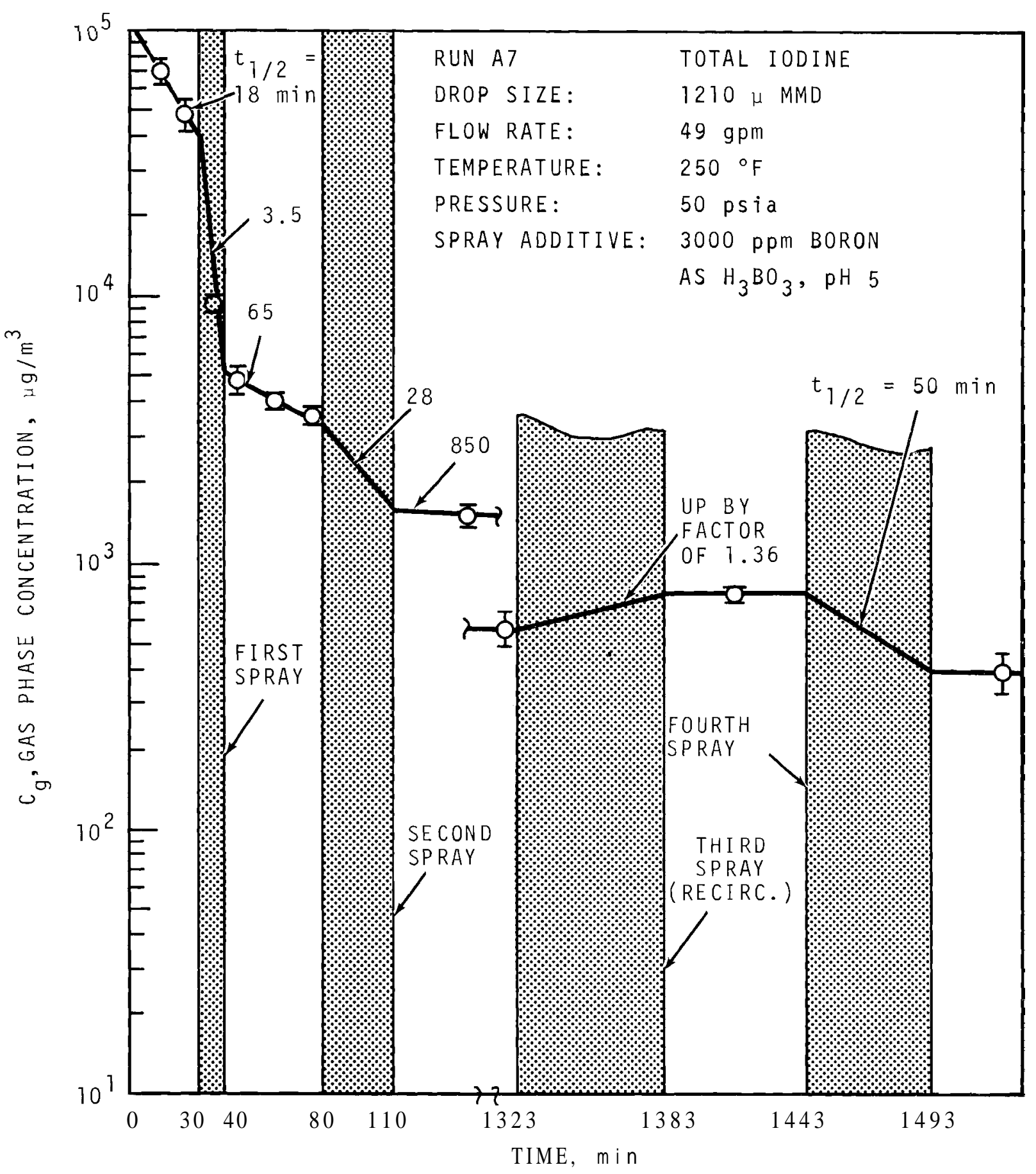

FIGURE 30. Total Iociine Concentration in the Main Room, Run A7 
BNWL -1244

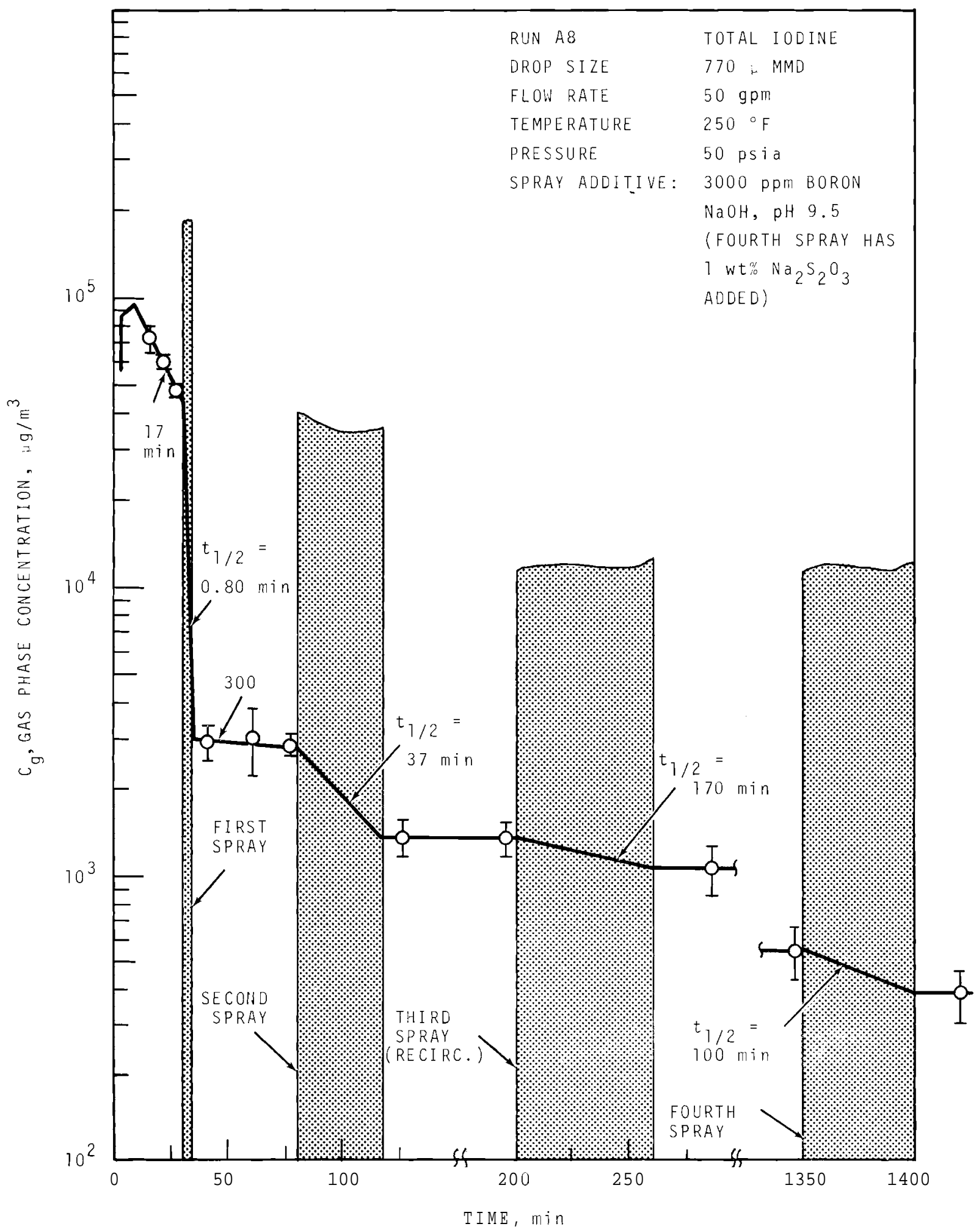

FIGURE 31. Total Iodine Concentration in the Main Room, Run A8 


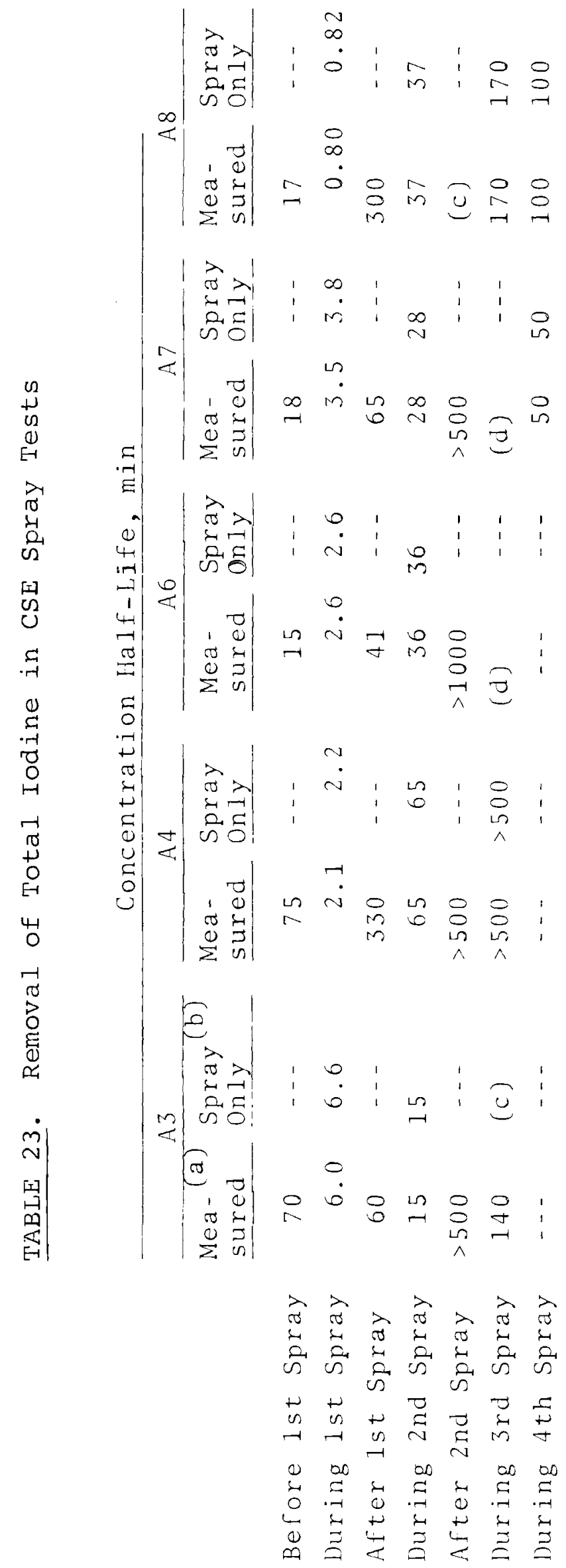

BNWL- 1244 
Cesium

The time dependence of the gas phase cesium concentration in the main room is shown for each experiment in Figures 32 through 36. Standard deviations of experimental points are small, except for late in the experiments when most of the cesium has been removed. Removal rate during the first spray was quite high in all of the experiments, but succeeding sprays were less effective. This result probably reflects more efficient removal of the larger cesium particles, and the leaving behind of smaller, less easily removed particles. A discussion of particle size measurements is given in a later section of this report. Table 24 lists the measured concentration halflives and also those corrected for natural removal processes.

Uranium

The time dependence of the gas phase concentration of uranium-associated particles in the main room is shown in Figures 37 through 41 for each experiment. That removal was not quite as fast as for cesium suggests the uranium particles to be of a smaller size distribution than cesium. However, the uranium concentration was depleted by a factor of about 100 by 40 min of spraying, plus the natural process removal for all runs except $A 3$, the low flow rate experiment. Table 25 lists the concentration half-lives for uranium measured for each experiment and also that due to sprays alone. 
BNWL - 1244

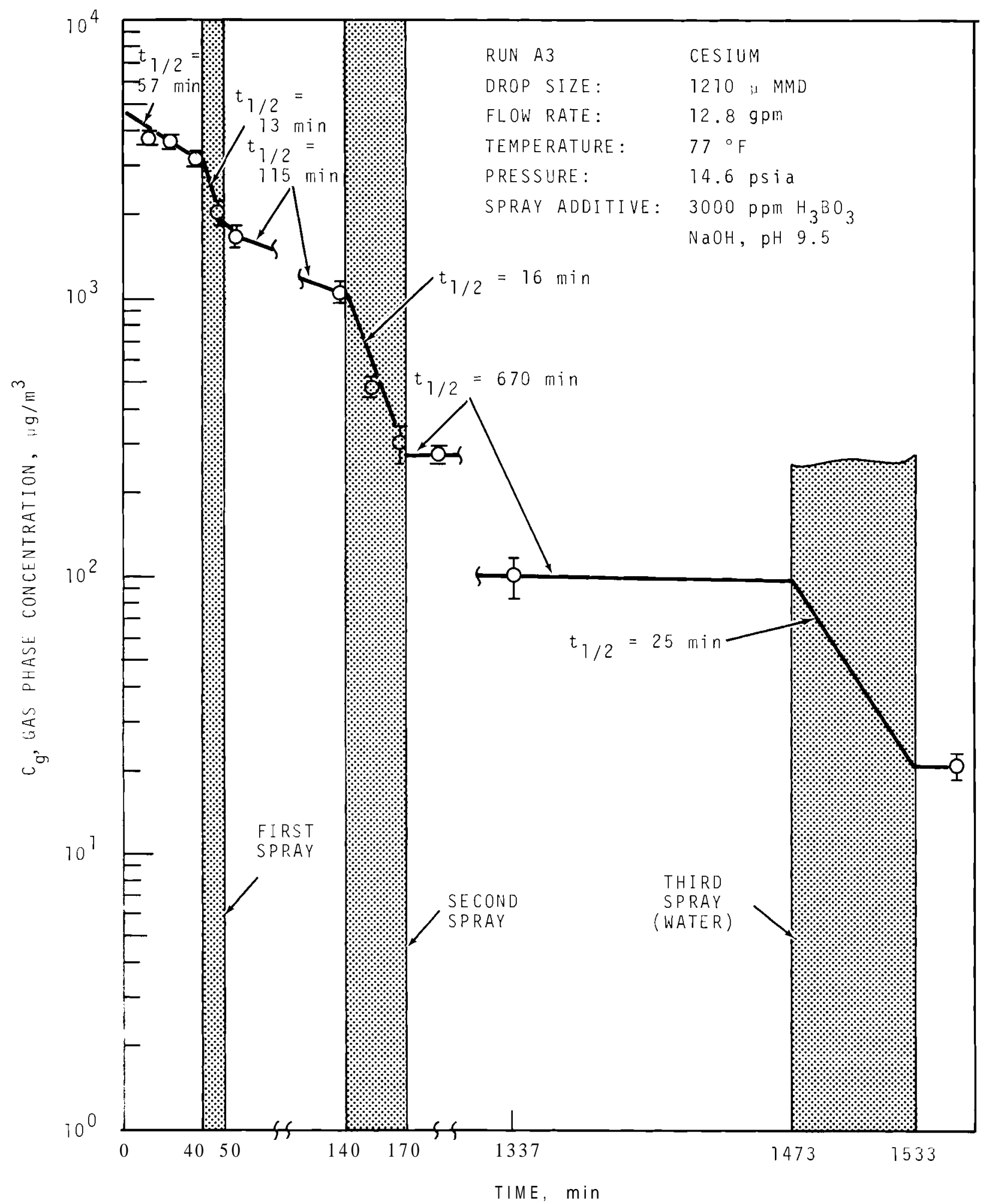

FIGURE 32. Cesium Concentration in the Main Roon, Run A3 


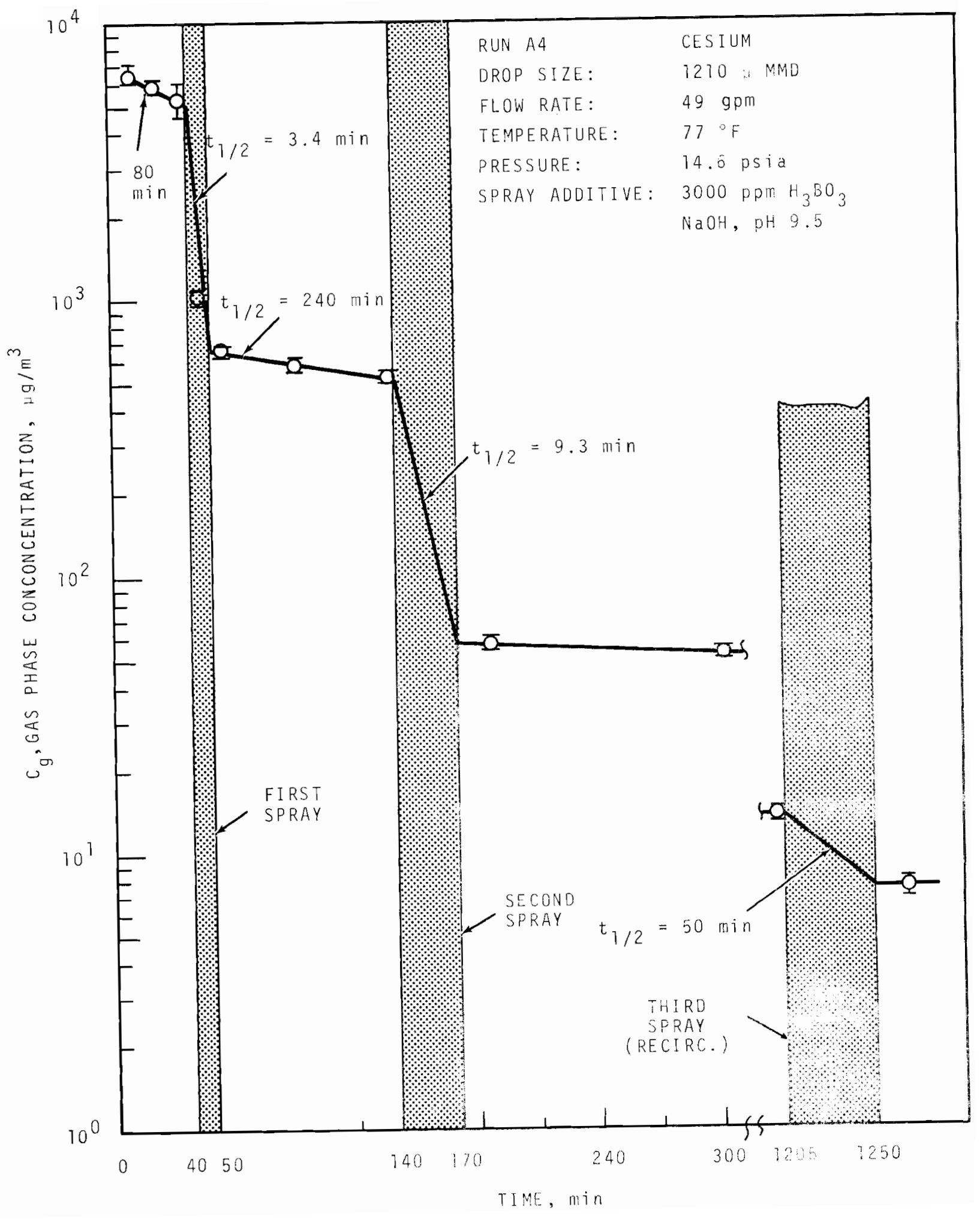

FIGURE 33. Cesium Concentration in the Main Room, Run A4 
BNWL - 1244

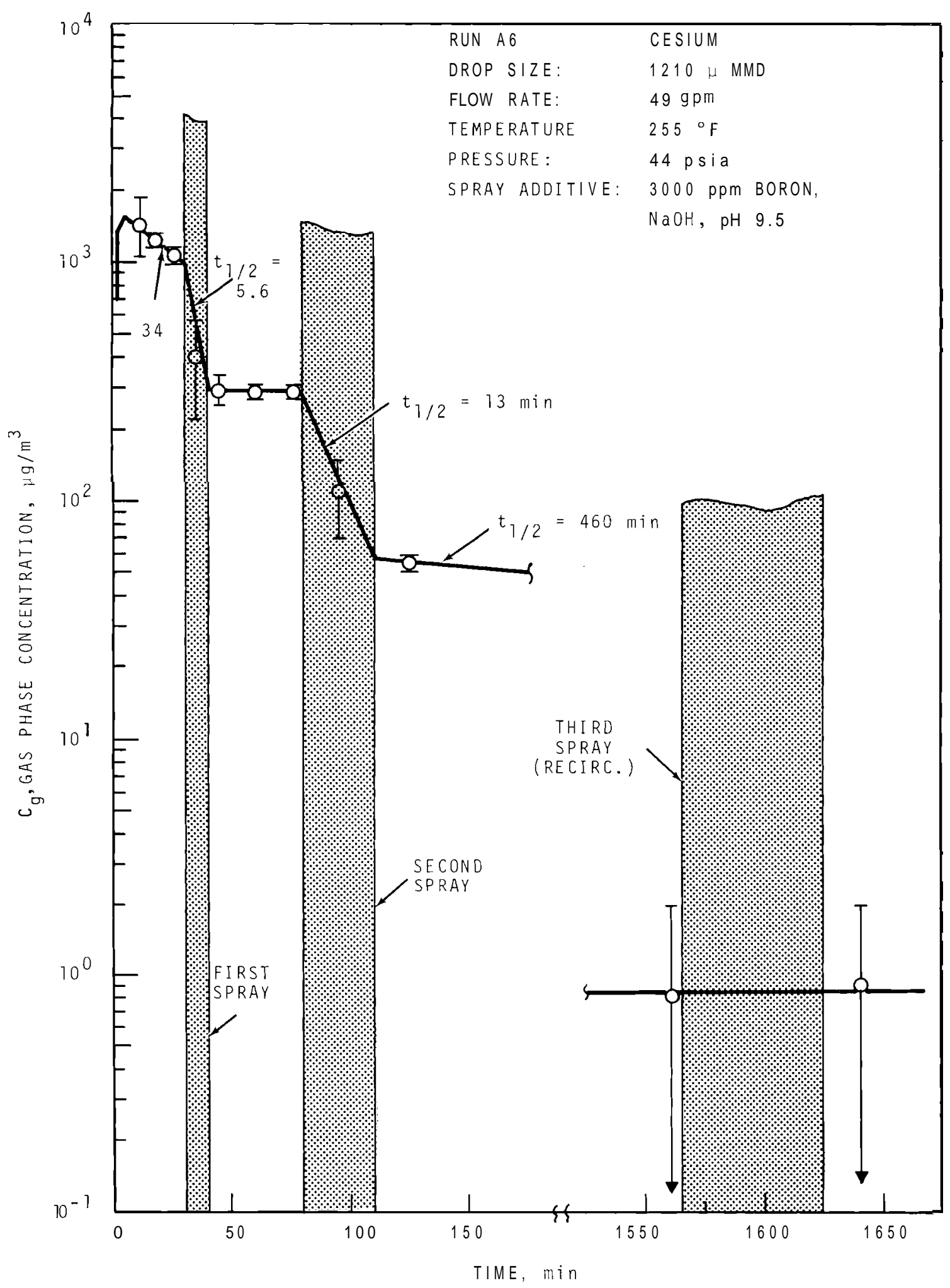

FIGURE 34. Cesium Concentration in the Main Room, Run A6 


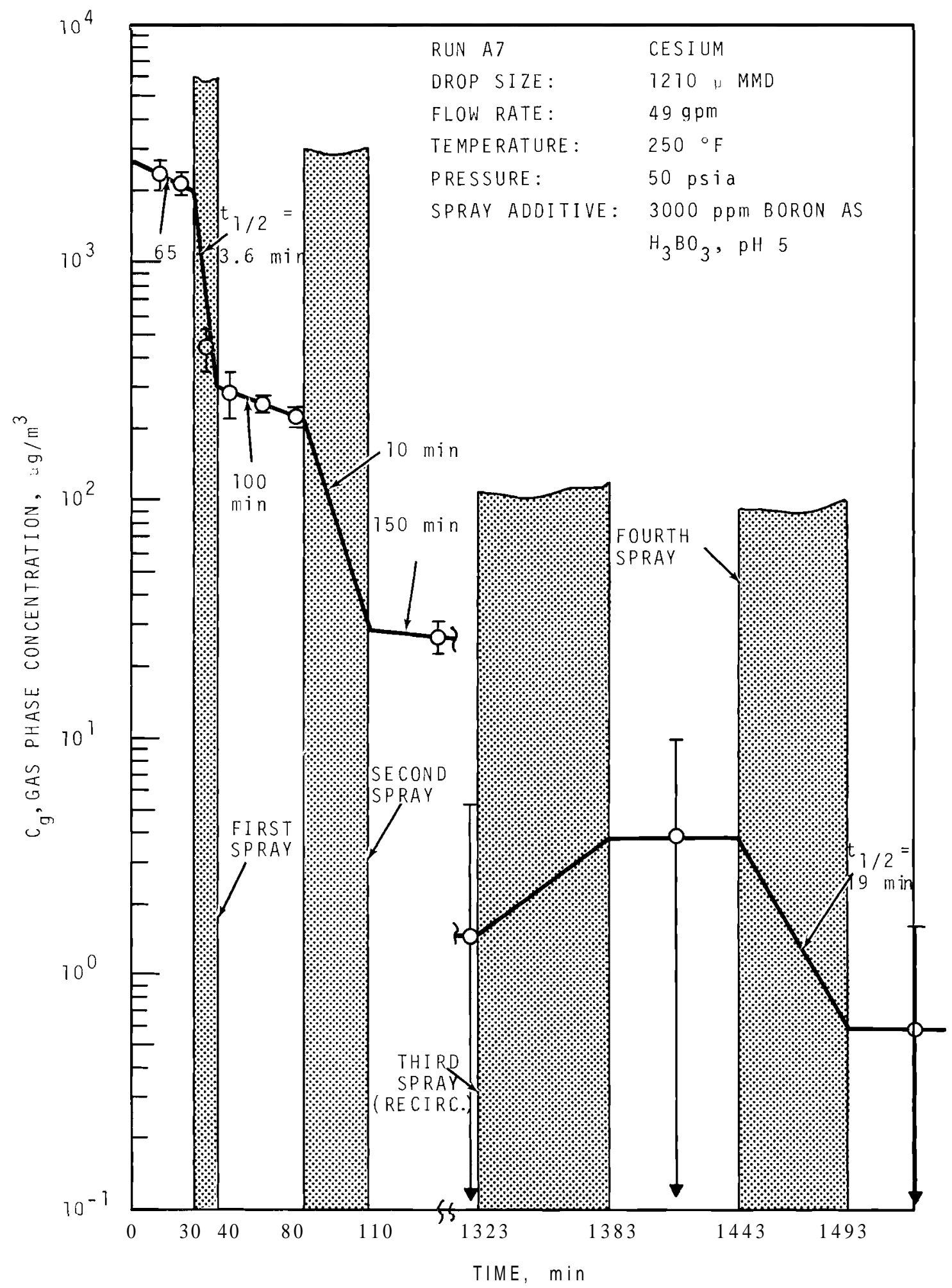

FIGURE 35. Cesium Concentration in the Main Room, Run A7 


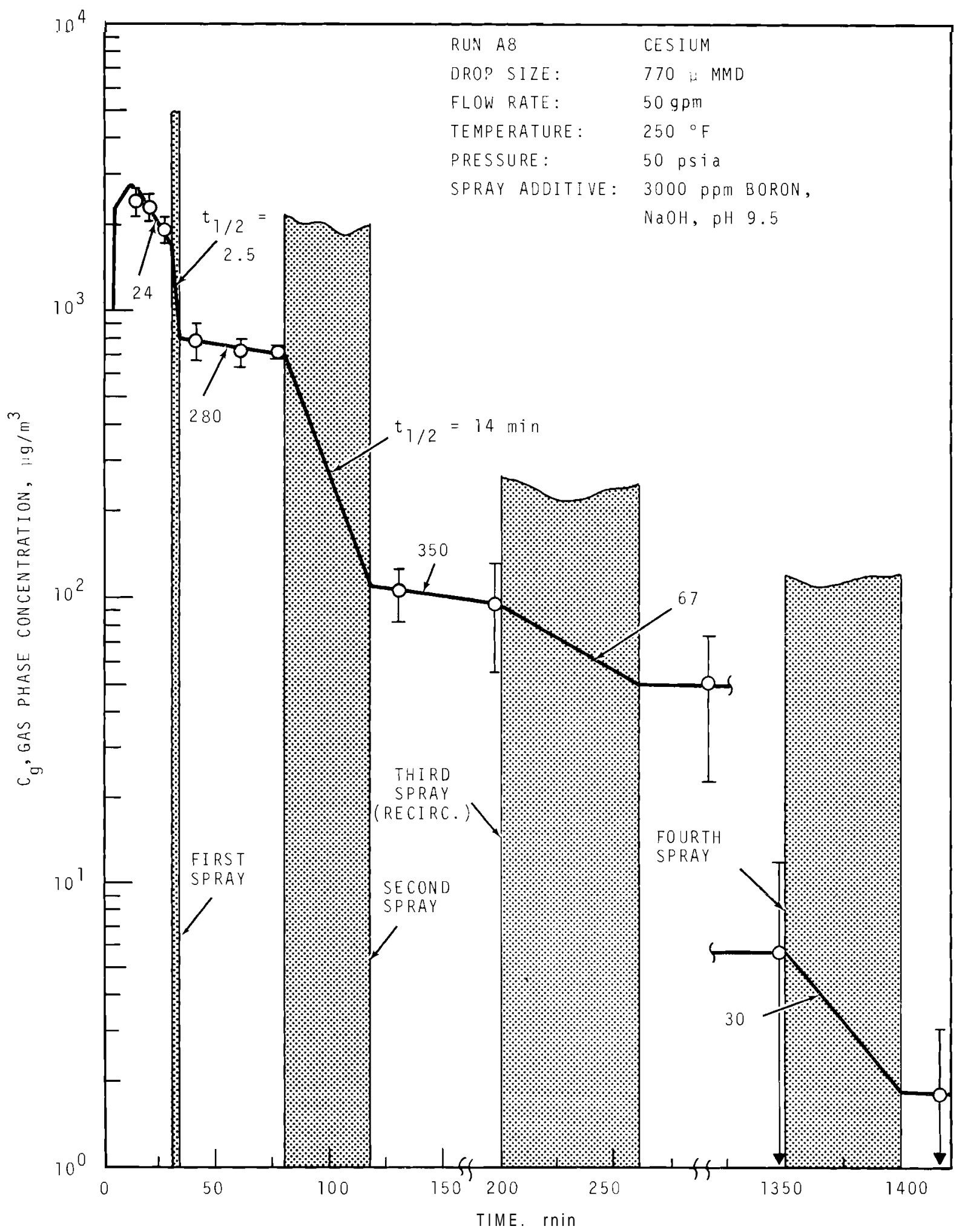

FIGURE 36. Cesium Concentration in the Main Room, Run A8 


\section{TABLE 24 Removal of Cesium in CSE Spray Tests}

Acrosol Concentration Half-Life, min

\begin{tabular}{|c|c|c|c|c|c|c|c|c|c|}
\hline \multicolumn{2}{|c|}{ A 3} & \multicolumn{2}{|c|}{ A4 } & \multicolumn{2}{|c|}{ A6 } & \multicolumn{2}{|c|}{ A 7} & \multicolumn{2}{|c|}{ A 8} \\
\hline $\begin{array}{l}\text { Mea-(a) } \\
\text { sured }\end{array}$ & $\begin{array}{l}\text { Spray } \\
\text { Only }\end{array}$ & $\begin{array}{l}\text { Mea- } \\
\text { sured }\end{array}$ & $\begin{array}{l}\text { Spray } \\
\text { On } 1 \text { y }\end{array}$ & $\begin{array}{l}\text { Mea- } \\
\text { sured }\end{array}$ & $\begin{array}{l}\text { Spray } \\
\text { On1y }\end{array}$ & $\begin{array}{l}\text { Mea- } \\
\text { sur }\end{array}$ & $\begin{array}{l}\text { Spray } \\
\text { Only }\end{array}$ & $\begin{array}{l}\text { Mea- } \\
\text { sured }\end{array}$ & $\begin{array}{l}\text { Spray } \\
\text { On } 1 y\end{array}$ \\
\hline
\end{tabular}

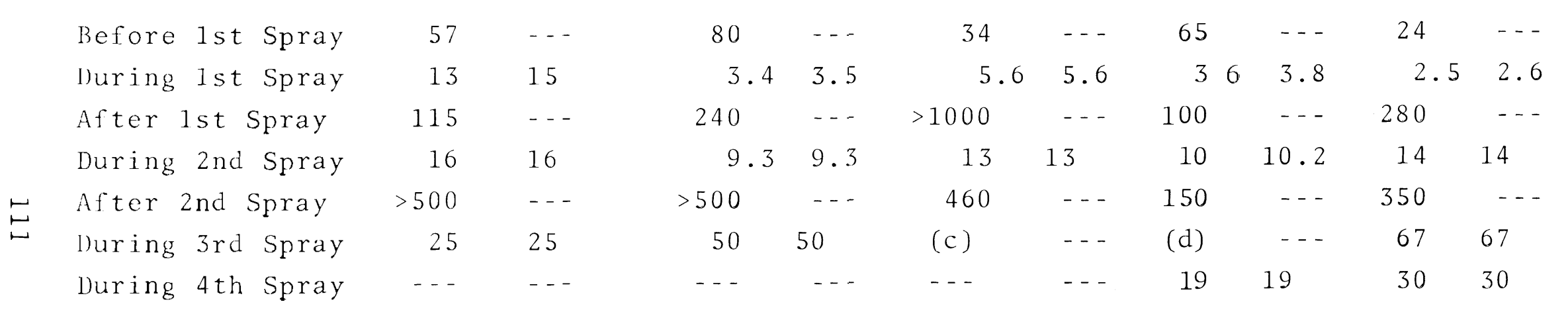

a. observed half-iife.

b. Corrected for natural processes.

c. Indeterminate.

a. Concentration increased. 
BNWL -1244

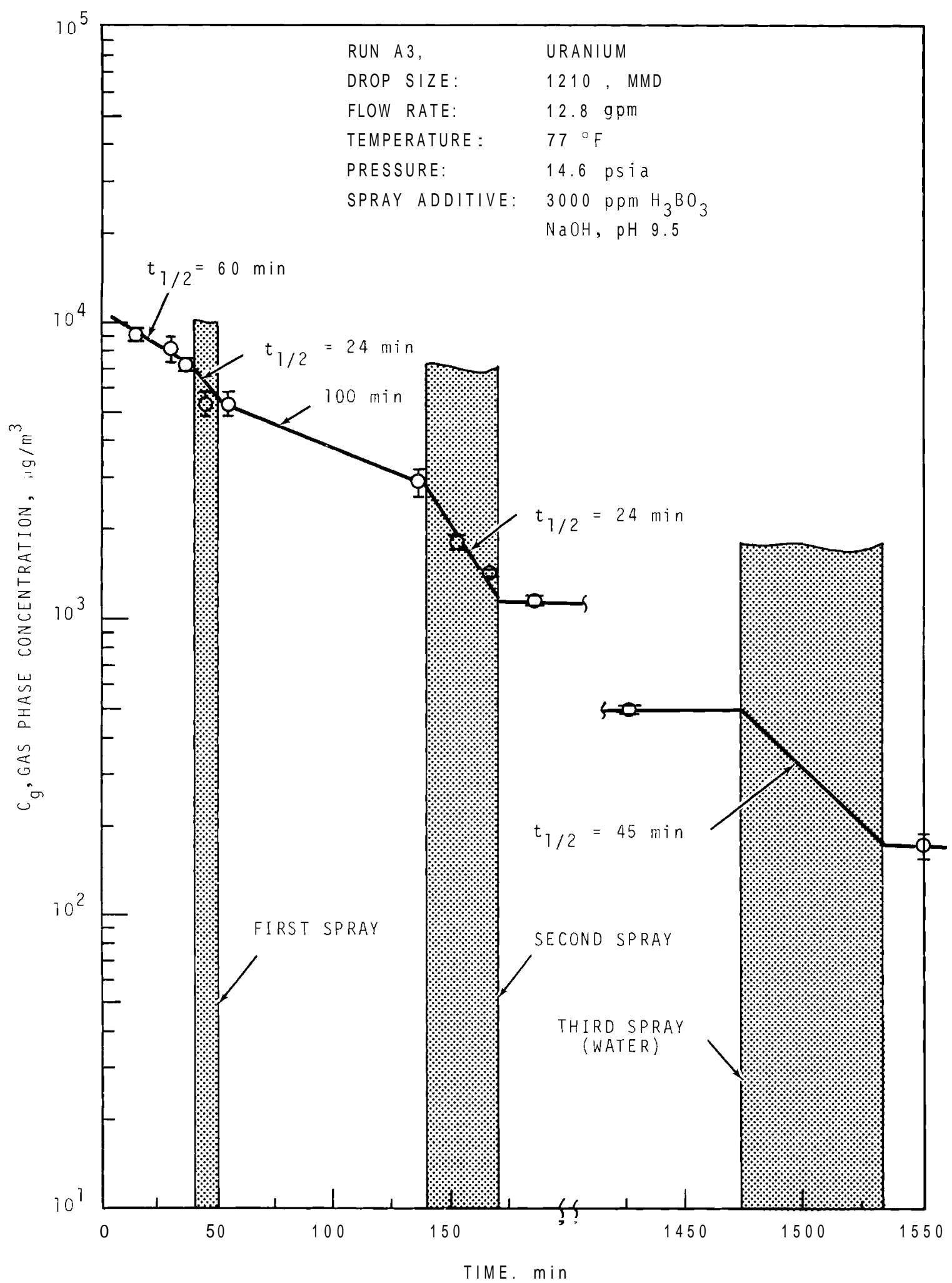

FIGURE 37. Uranium Concentration in the Main Room, Run A3 
BNWL- 1244

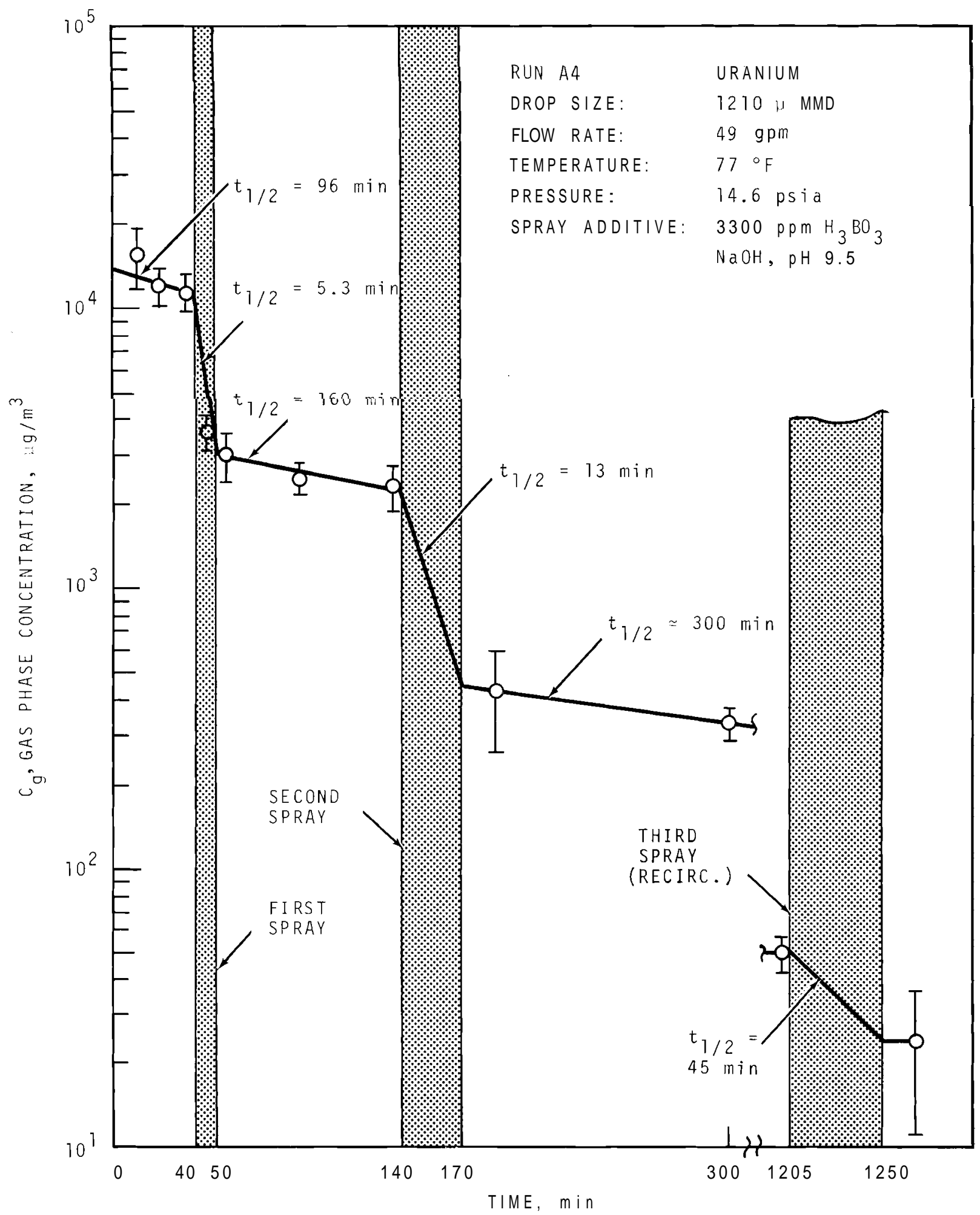

FIGURE 38. Uranium Concentration in the Main Room, Run A4 
BNWL - 1244

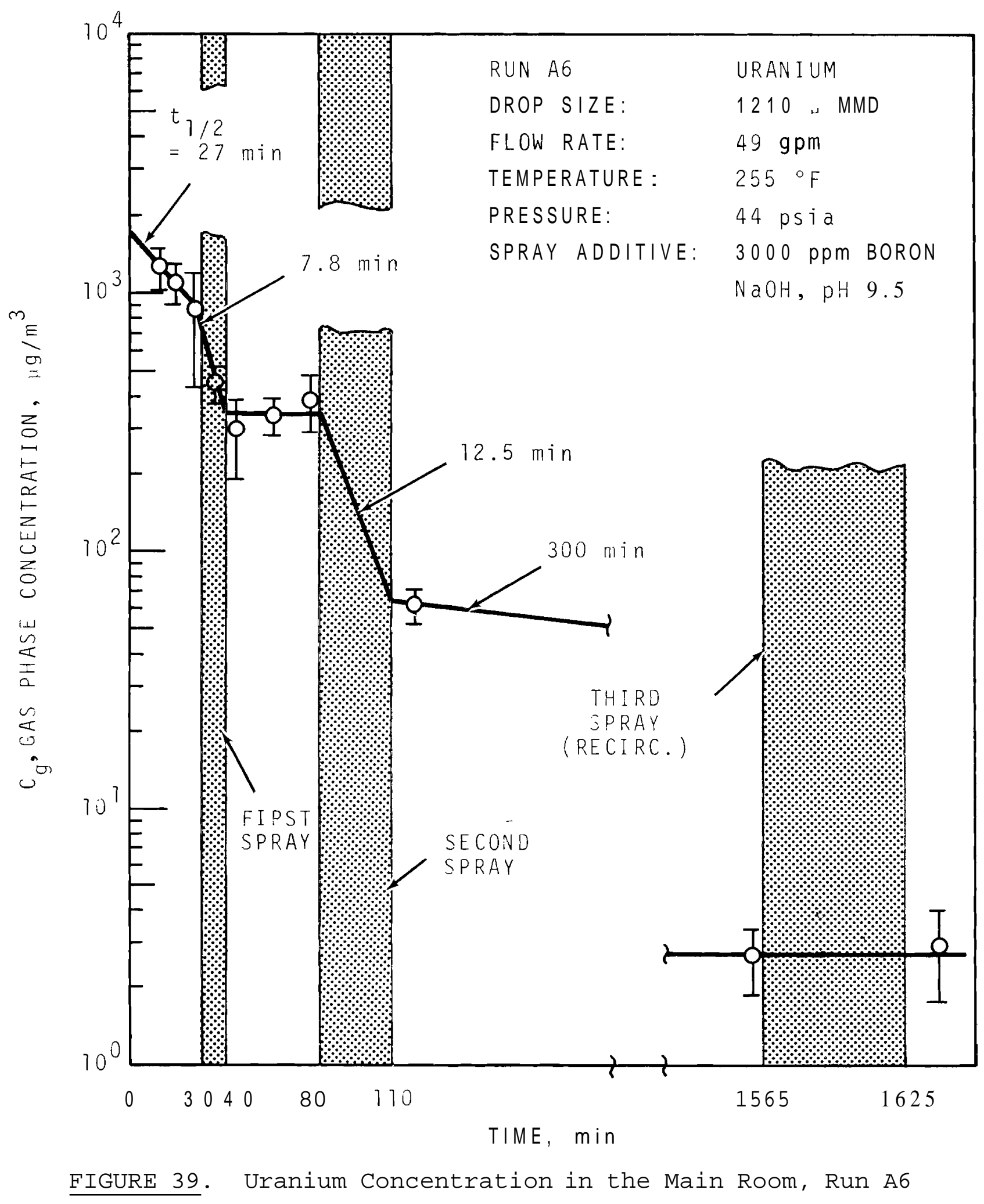




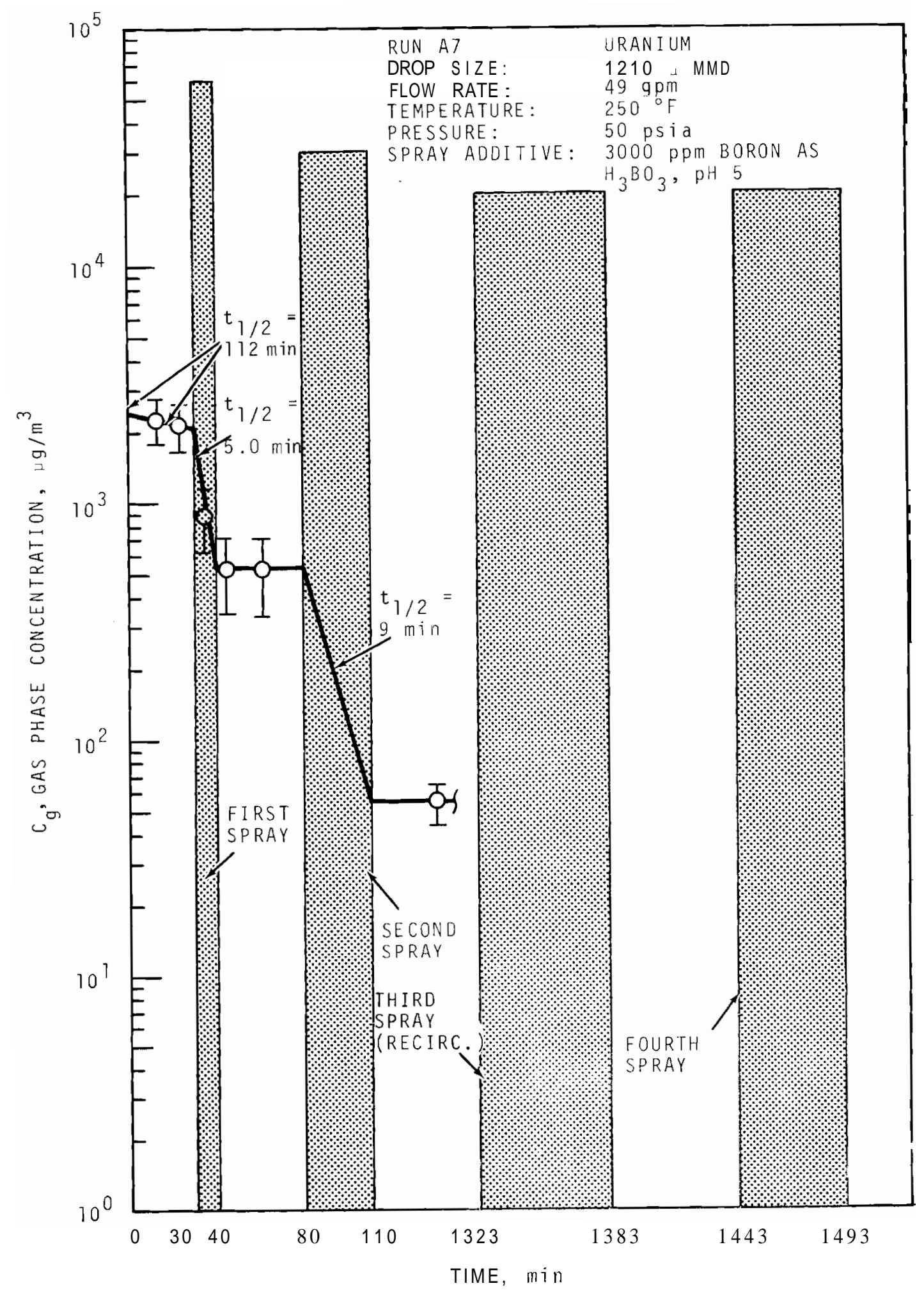

FIGURE 40. Uranium Concentration in the Main Room, Run A7 


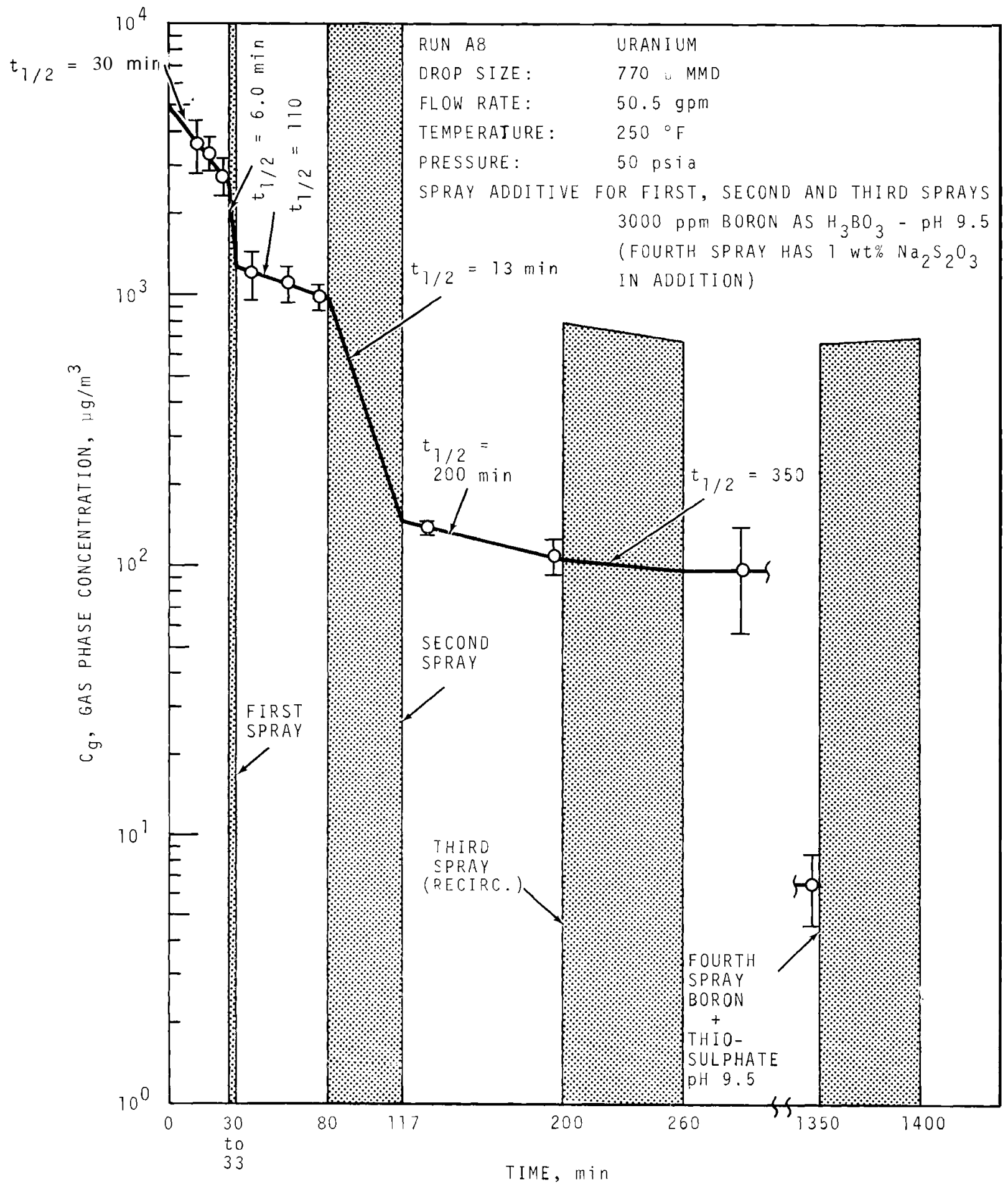

FIGURE 41. Uranium Concentration in the Main Room, Run A8 
TABLE 25. Removal of Uranium in CSE Spray Tests

Aerosol Concentration Half-Life, min

\begin{tabular}{|c|c|c|c|c|c|c|c|c|c|}
\hline \multicolumn{2}{|c|}{ A 3} & \multicolumn{2}{|c|}{ A4 } & \multicolumn{2}{|c|}{ A6 } & \multicolumn{2}{|c|}{ A 7} & \multicolumn{2}{|c|}{ A8 } \\
\hline $\begin{array}{l}\text { Mea-(a) } \\
\text { sured } \\
\end{array}$ & $\begin{array}{l}\text { Spraw (b) } \\
\text { On } 1 y \\
\end{array}$ & $\begin{array}{l}\text { Mea- } \\
\text { sured }\end{array}$ & $\begin{array}{l}\text { Spray } \\
\text { Only } \\
\end{array}$ & $\begin{array}{l}\text { Mea- } \\
\text { sureh }\end{array}$ & $\begin{array}{l}\text { Spray } \\
\text { On1y }\end{array}$ & $\begin{array}{l}\text { Mea- } \\
\text { sureo }\end{array}$ & $\begin{array}{l}\text { Spray } \\
\text { Only }\end{array}$ & $\begin{array}{l}\text { Mea- } \\
\text { sured }\end{array}$ & $\begin{array}{l}\text { Spray } \\
\text { On1y }\end{array}$ \\
\hline 60 & -- & 96 & $\ldots$ & 27 & - - - & 2 & -- & 30 & -- \\
\hline 24 & 34 & 5.3 & 5.5 & 7.8 & 7.8 & 5 & 5.0 & 6.0 & 6.6 \\
\hline 100 & - - & 160 & - - & (c) & - - & $>500$ & --- & 110 & --- \\
\hline 24 & 24 & 13 & 13.5 & 12.5 & 12.5 & 9 & 9 & 13 & 14 \\
\hline$>500$ & $\cdots$ & 300 & $\cdots$ & 300 & -- & $>1000$ & -- & 200 & --- \\
\hline 45 & $\ldots$ & 45 & $\ldots$ & (d) &.- & $(\mathrm{O})$ & -- & 350 & $\ldots$ \\
\hline-- & -- & $\cdots$ & $\cdots$ & -- & -- & $\left(\mathrm{O}_{3}\right.$ & -- & (d) & --- \\
\hline
\end{tabular}

observed half-life.

Corrected for natural processes.

Concentration increased.

Indeterminate. 
BNWL- 1244

\section{CONCENTRATION IN LIQUID PHASES}

The data presented in the previous section clearly show most of the fission product simulant materials studied to have vanished quite rapidly from the gas phase during early spray periods. The disappearance rates can be obtained from curves of gas phase concentration versus time. That these rates can be used to verify mass transport theory will be shown in a later section of this report. A more direct method of verifying the theory of transfer between gas and liquid phases is to measure the rates of transfer to the liquid drops and wall film. This measurement has proved difficult to make accurately in the CSE vessels because of the large, complex geometry and resultant excessive lag time in obtaining liquid samples when dealing with the very rapid transfer rates involved. Nevertheless, measurements were made and, despite great uncertainty during spray periods, these measurements of mass added to the liquid phases substantiate the theory and confirm that iodine and particles were indeed transferred to the liquid at approximately the rates indicated by loss from the gas phase.

Three types of measurements made on the liquid phase were (1) the concentration and volume in vessel sumps, (2) the concentration in the liquid spray drops caught in flight by funnels located at several locations in the main room, and (3) the concentration and flow rate down the outer containment vessel wall.

Collection in Vessel Sumps

Most of the liquid sprayed through the nozzles fell through the atmosphere in the main room and either settled on the main deck or fell to the bottom of the drywell vessel. A small fraction impinged on the vertical walls at an elevation about $3 \mathrm{ft}$ below the nozzles. Table 10 gives the distribution between these three locations. The liquid entering the drywell fell 
BNWL- 1244

directly into the drywe11 sump. The volume in the drywe11 sump thus increased abruptly when spraying started, and stopped increasing abruptly when spraying stopped. Flow of the liquid falling onto the deck, however, was directed over the horizontal surface and drained through the two 4-ft diam openings into the lower rooms before entering the main containment vessel sump. A significant delay resulting, at times, in unaccounted for material balances of up to 3000 liters thus was caused. The liquid continued to drain into the containment vessel sump for about 90 min after the sprays were stopped. A typical water balance is presented in Table 26 for Run A7.

The concentrations of iodine and cesium in the two sumps are plotted versus time for each experiment in Figures 42 through 46. Also shown are the observed liquid volumes in the sumps. It is possible to make mass balances as a function of time for the iodine and cesium by combining the information obtained from these graphs with the gas phase data from Figures 27 through 36. Typical results for iodine are shown in Figures 47 and 48 for Run A3 and A7, respectively. The reader will recall that Run $A 3$ was made with room temperature air, while Run A7 was with steam at a nominal temperature of $250^{\circ} \mathrm{F}$. Similar curves are presented for cesium in Figures 49 and 50. In these figures, the difference between the mass released into containment (from Tables 6 and 7) and that accounted for by summing the airborne mass and mass in the vessel sumps is shown as a broken line labeled "unaccounted for." Material reacting with the paint on structural surfaces, and material in liquid pools not yet drained into the sumps are probably represented. The unaccounted for cesium balances followed closely the water balances, as can be seen by comparing Figures 49 and 50 with Table 26, and thus indicates that very little cesium reacted with the paint. Unaccounted for iodine, however, exceeded the unaccounted for water at all times, thus suggesting that a significant fraction of the iodine was reacted with the paint. 
TABLE 26. Typical Water Balance--Run A7

\begin{tabular}{|c|c|c|c|c|c|c|c|c|}
\hline $\begin{array}{c}\text { Time, } \\
\text { min } \\
\end{array}$ & $\begin{array}{l}\text { Volume } \\
\mathrm{DW} \\
\end{array}$ & $\frac{e \text { in } S u}{C V}$ & $\frac{\text { umps, } \ell}{\text { Total }}$ & $\begin{array}{l}\text { Cumulative } \\
\text { Steam Feed, } \\
\qquad\end{array}$ & $\begin{array}{l}\text { Cumulative } \\
\text { Spray Added, } \\
\ell^{\text {Ad }}\end{array}$ & $\begin{array}{c}\text { Total to } \\
\text { Accounted for, } \\
l\end{array}$ & $\begin{array}{l}\text { Unaccounted } \\
\text { for, } \ell \\
\end{array}$ & Remarks \\
\hline 0 & 125 & 700 & 825 & 0 & 0 & 825 & 0 & $\begin{array}{l}\text { Start Aerosol } \\
\text { Release }\end{array}$ \\
\hline 30 & 140 & 750 & 890 & 60 & 0 & 885 & $(+) 5$ & $\begin{array}{l}\text { Start 1st } \\
\text { Spray }\end{array}$ \\
\hline 40 & 650 & 1300 & 1950 & 80 & 1900 & 2805 & 755 & End 1st Spray \\
\hline 80 & 550 & 2000 & 2550 & 160 & 1900 & 2885 & 335 & $\begin{array}{l}\text { Start 2nd } \\
\text { Spray }\end{array}$ \\
\hline 110 & 1900 & 4700 & 6600 & 220 & 7550 & 8595 & 1995 & End 2nd Spray \\
\hline 150 & 1950 & 6100 & 8050 & 300 & 7550 & 8675 & 625 & \\
\hline 200 & 1950 & 6500 & 8450 & 400 & 7550 & 8775 & 325 & \\
\hline 1323 & 2500 & 8900 & 11,400 & 2825 & 7550 & 11,200 & $(+) 200$ & $\begin{array}{l}\text { Start } \\
\text { Recirculation }\end{array}$ \\
\hline 1383 & 4500 & 4200 & 8700 & 2950 & 7550 & 11,360 & 2625 & $\begin{array}{l}\text { End } \\
\text { Recirculation }\end{array}$ \\
\hline 1443 & 4500 & 5850 & 10,350 & 3070 & 7550 & 11,445 & 1095 & $\begin{array}{l}\text { Start } 4 \text { th } \\
\text { Spray }\end{array}$ \\
\hline 1493 & 6700 & 11,600 & 18,300 & 3185 & 16,750 & 20,760 & 3010 & End 4 th Spray \\
\hline 1600 & 6800 & 13,570 & 20,370 & 3400 & 16,750 & 20,875 & 605 & \\
\hline
\end{tabular}


BNWL -1244

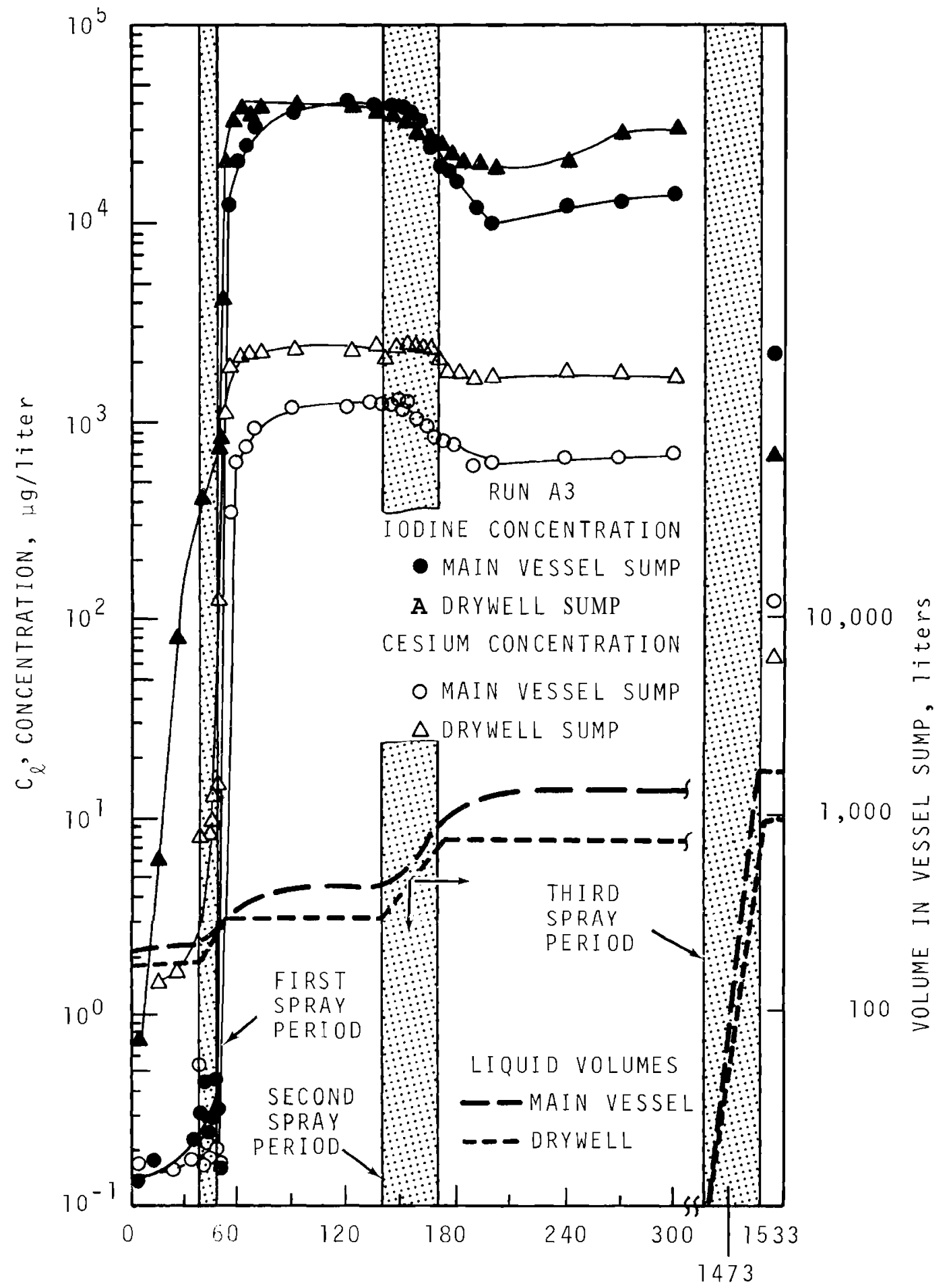

TIME, min

FIGURE 42. Liquid Volumes and Concentrations in Vessel Sumps, Run A3 
BNWL -1244

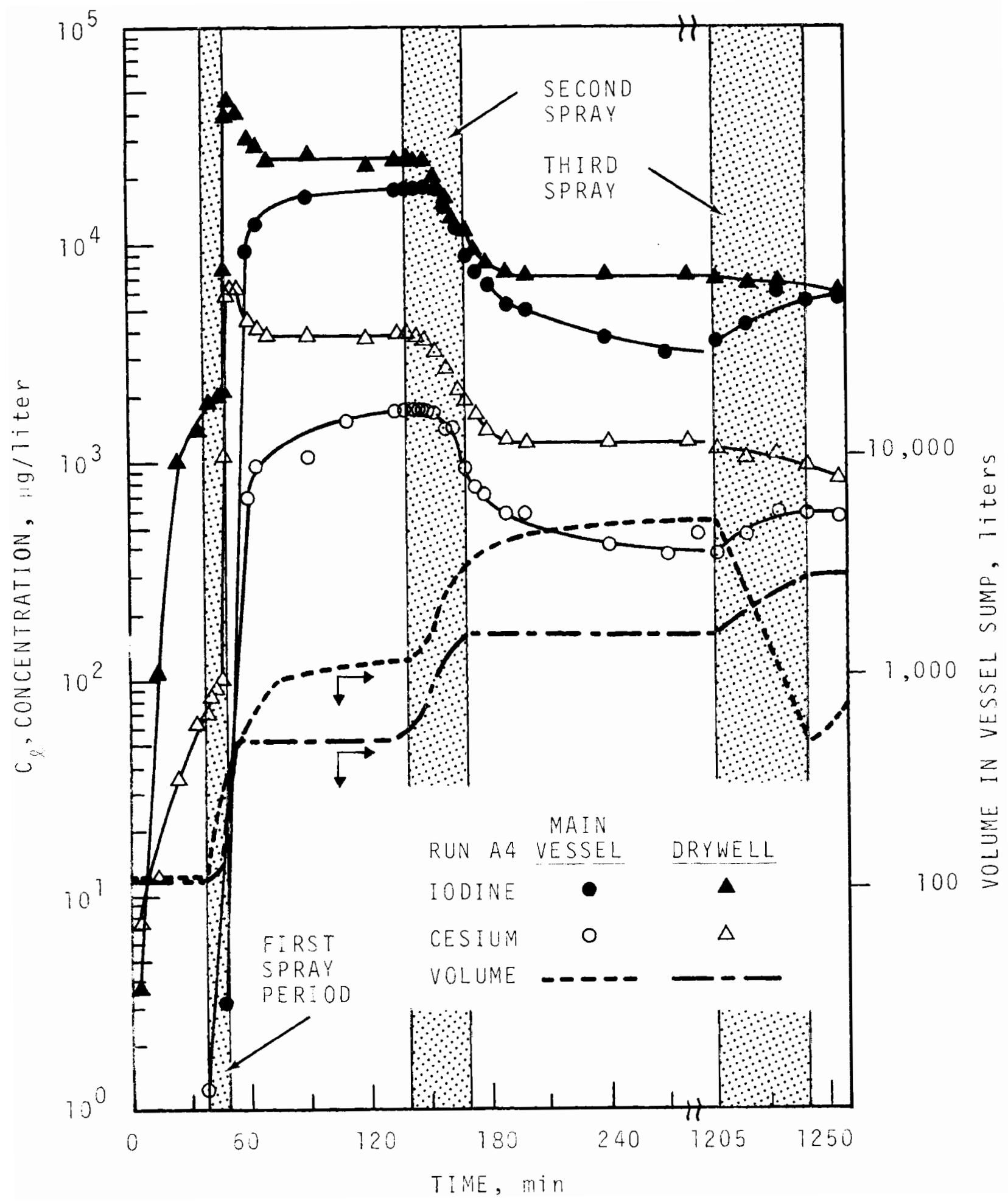

FIGURE 43. Liquid Volumes and Concentrations in Vessel Sumps, Run A4 
BNWL -1244

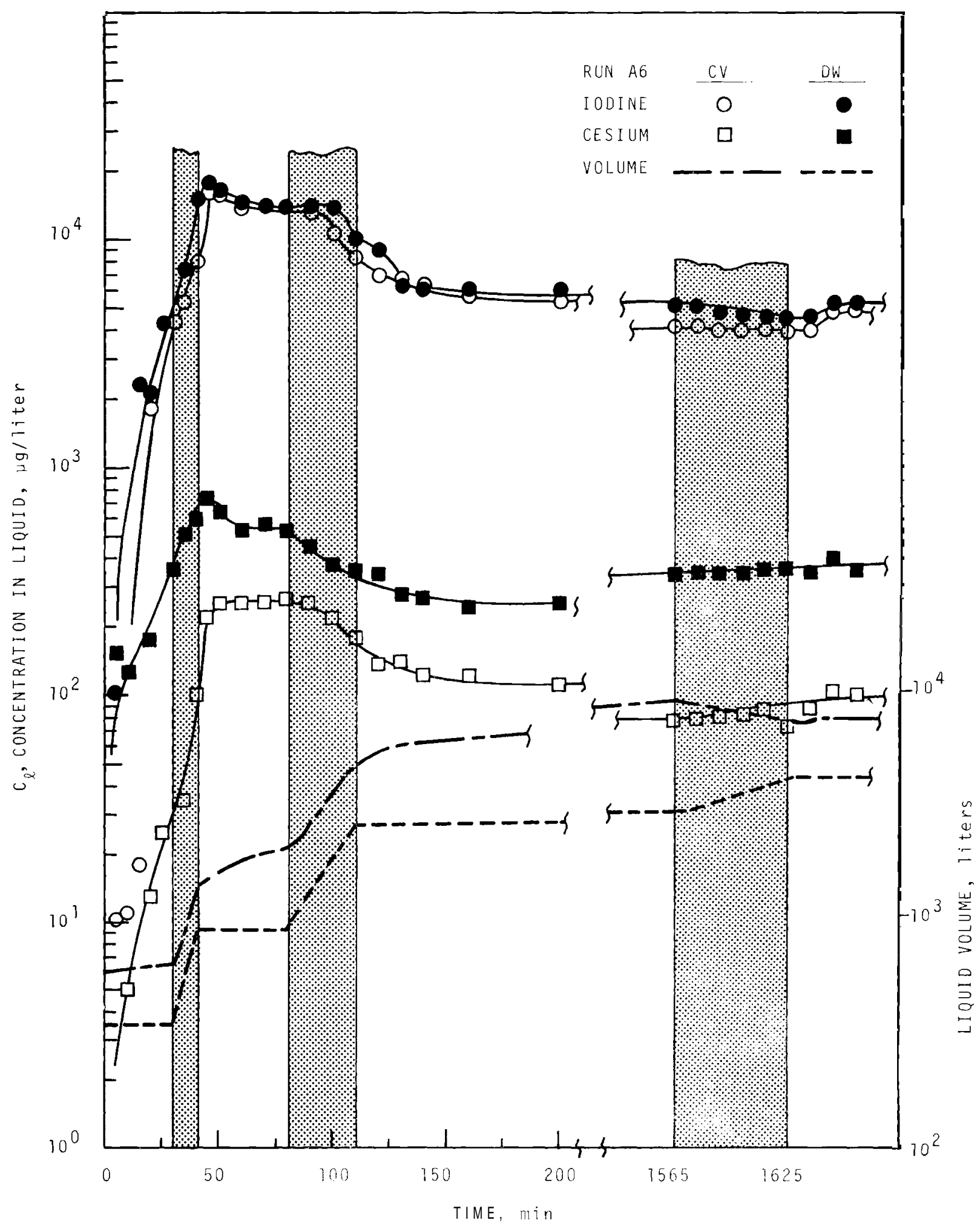

FIGURE 44. Licuià Volumes and Concentrations in Vessel Sumps, Run A6 
BNWL - 1244

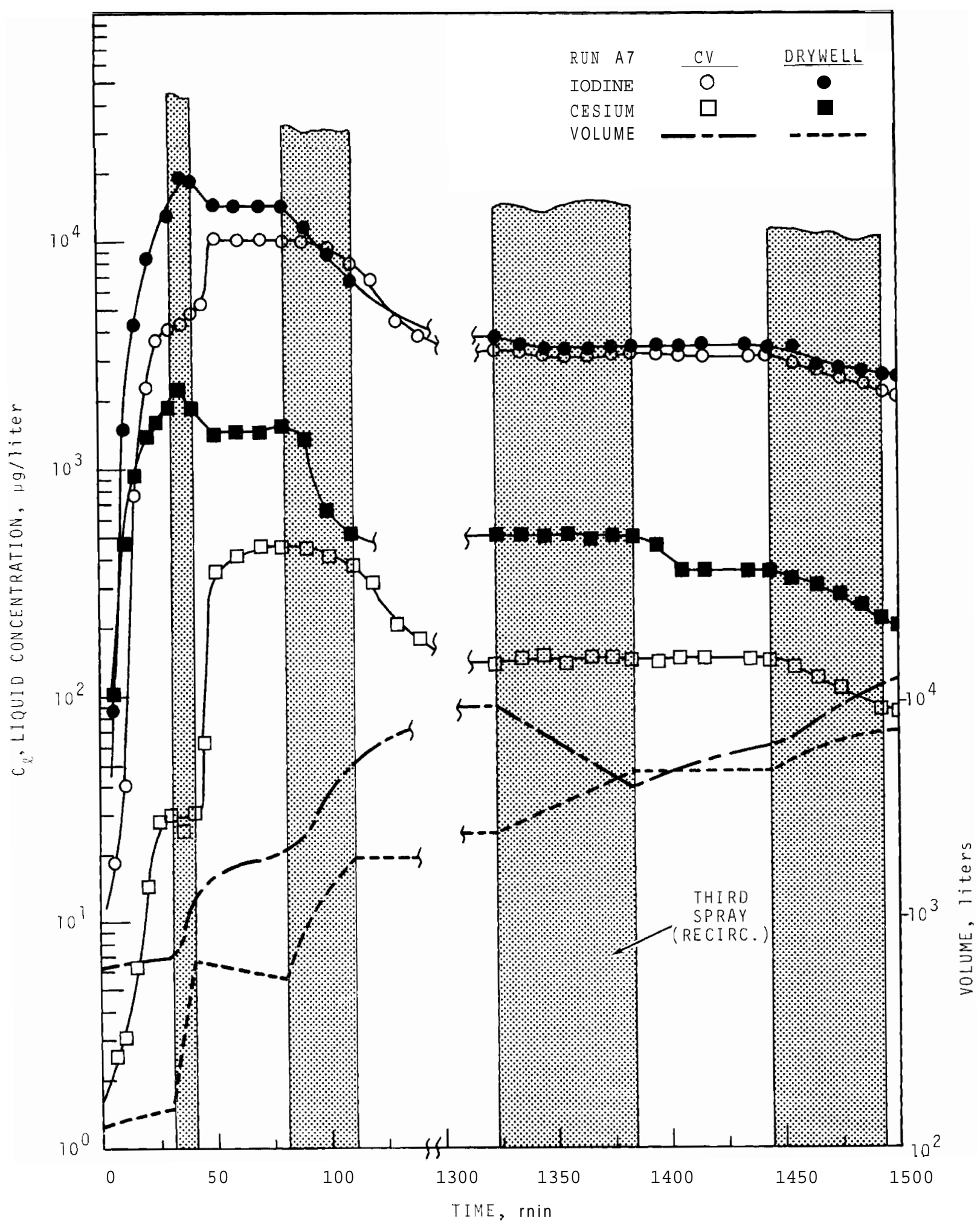

FIGURE 45. Liquid Volumes and Concentrations in Vessel Sumps, Run A7 
BNWL - 1244

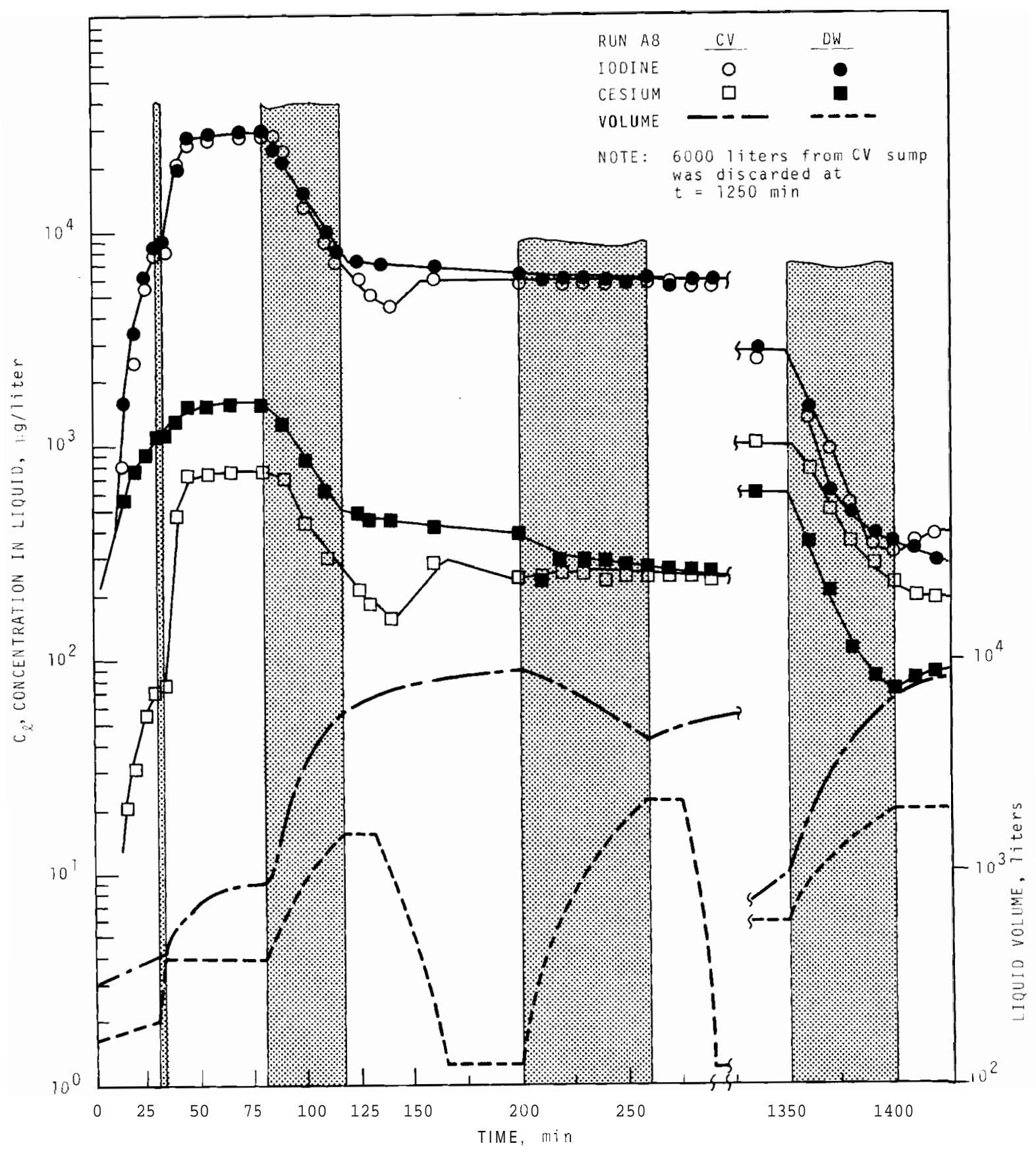

FIGURE 46. Liquid Volumes and Concentrations in Vessel Sumps Versus Time--Run A8 
BNWL - 1244

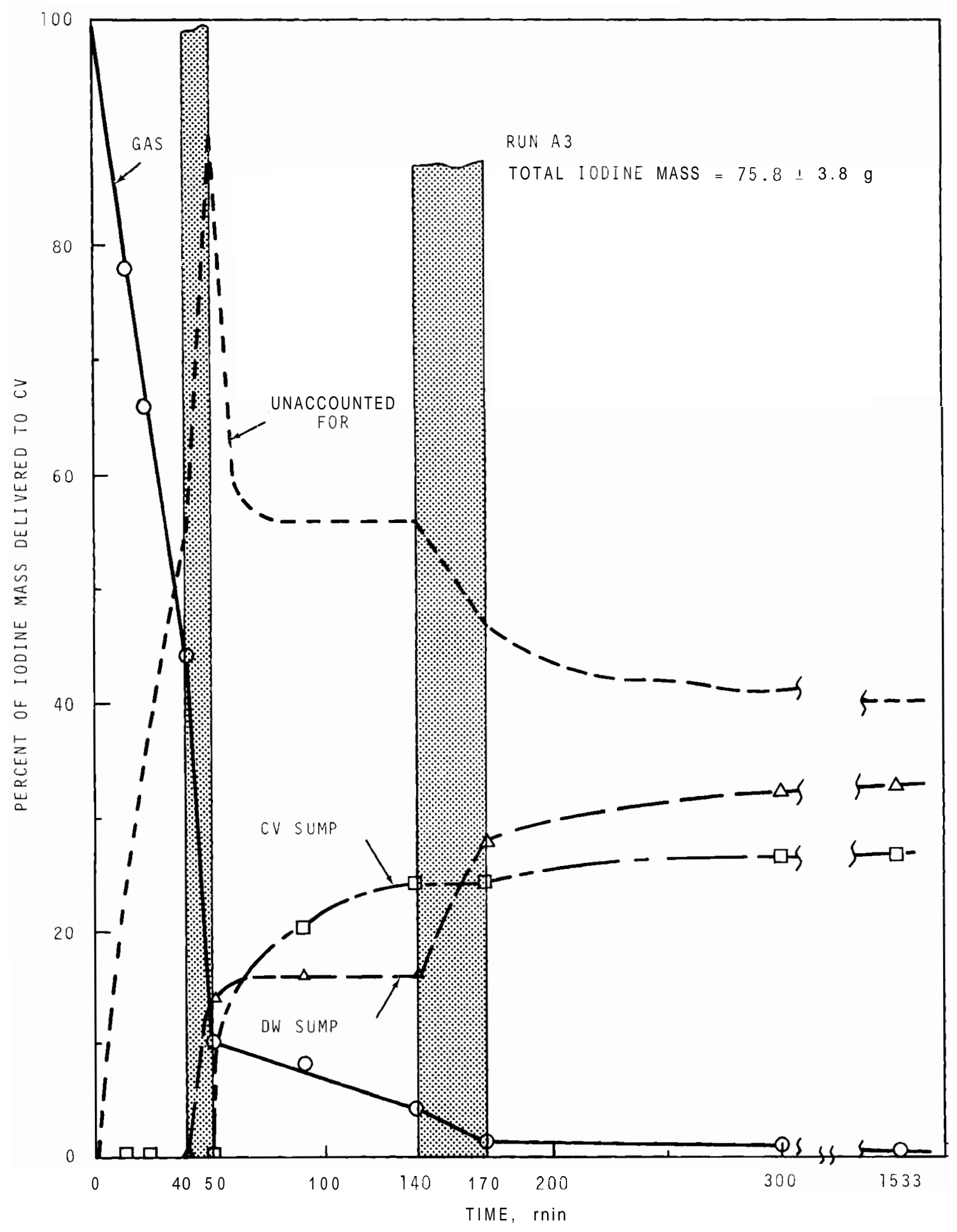

FIGURE 47. Iodine Distribution Versus Time--Run A3 
BNWL -1244

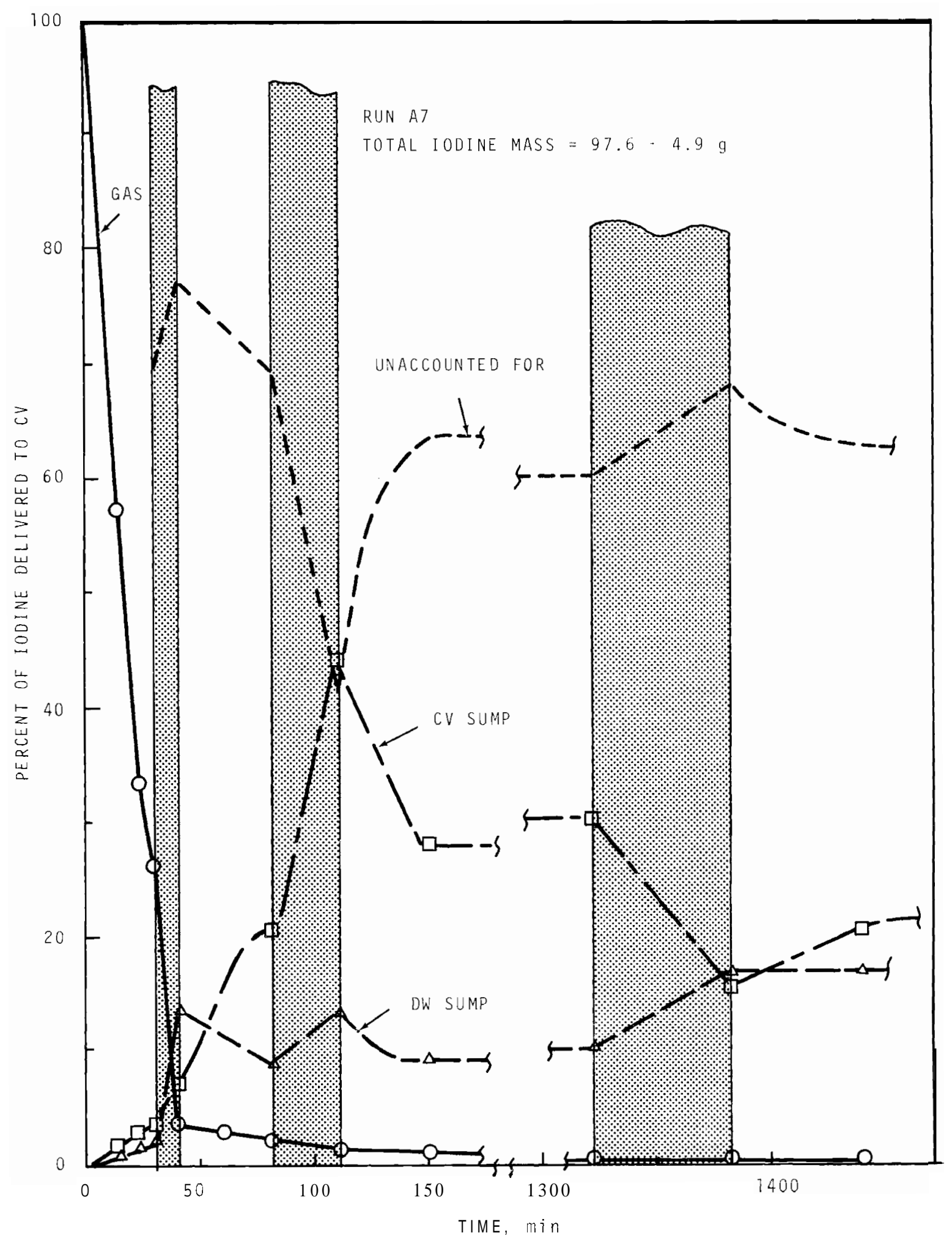

FIGURE 48. Iodine Distribution Versus Time--Run A7 
BNWL - 1244

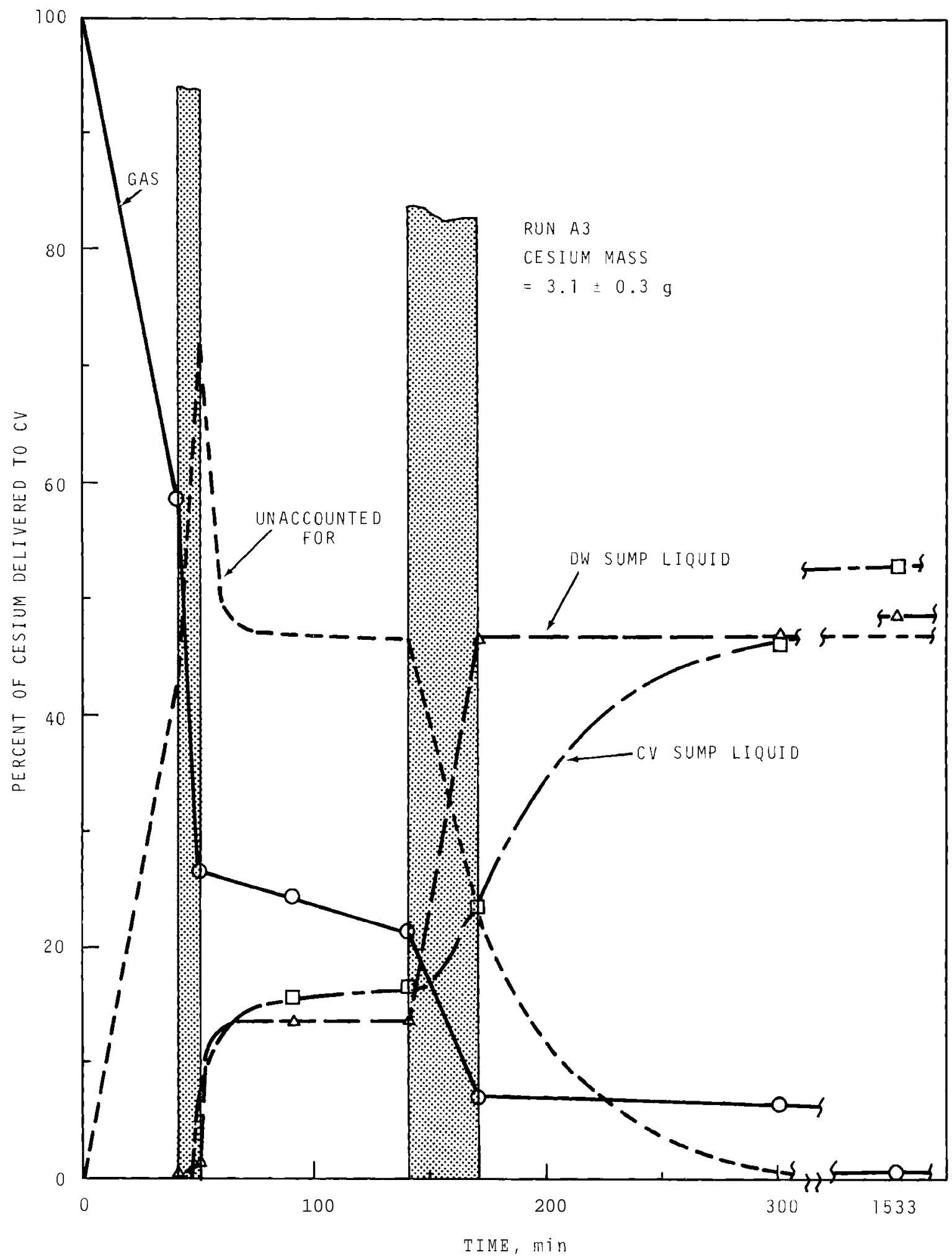

FIGURE 49. Cesium Distribution Versus Tine--Run A3 
BNWL - 1244

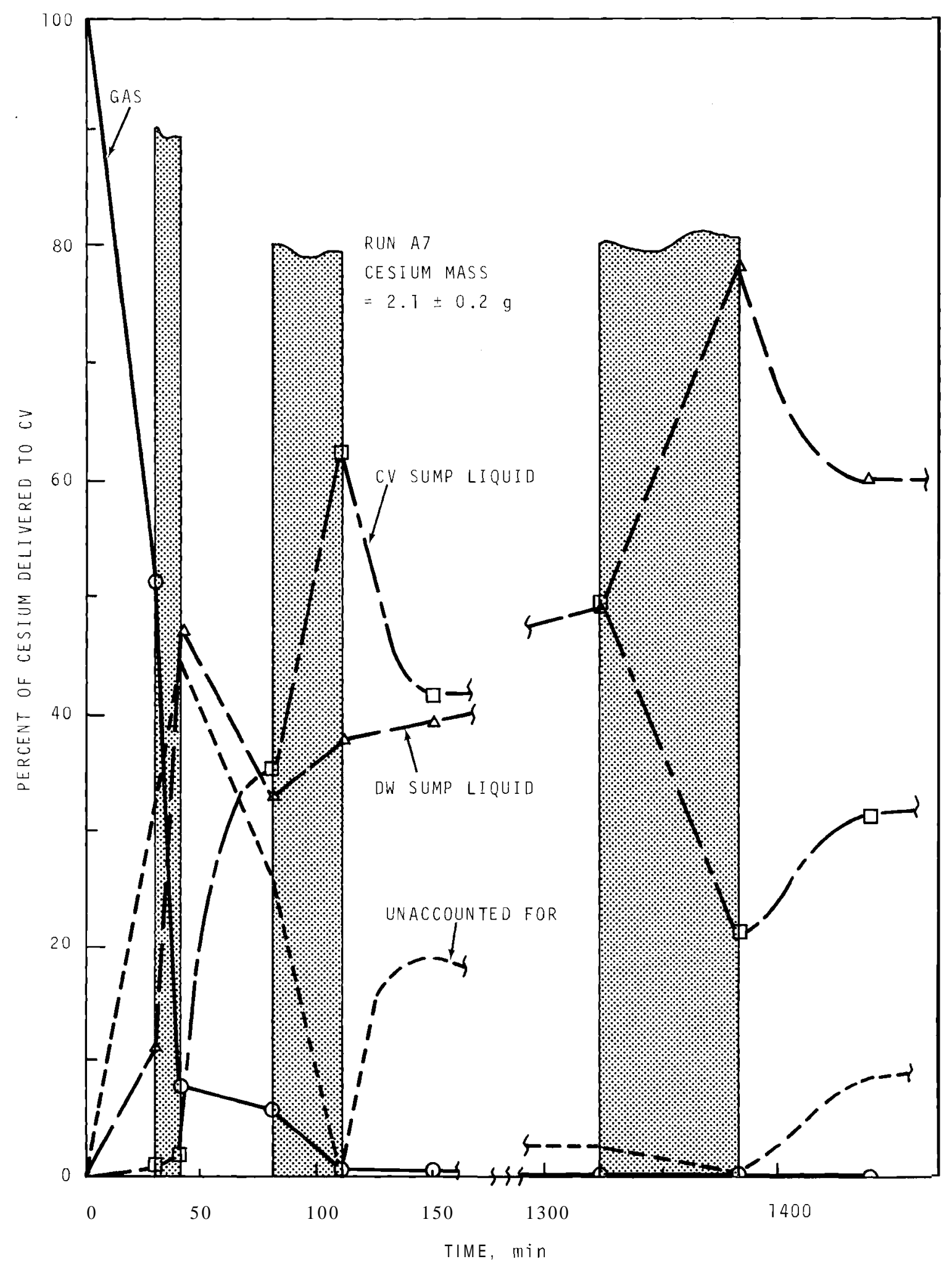

FIGURE 50. Cesium Distribution Versus Time--Run A7 
These conclusions are substantiated by the overall mass balances shown in Tables 6 and 7 and by deposition coupon data, tabulated in a later section.

Concentration in Spray Drops

An attempt was made to measure the concentration of iodine and cesium in the spray drops at several elevations and radii. Funnels intercepted the drops in flight and the collected liquid was drained to collection pots outside the containment vessel. The pots were emptied manually every one or two minutes during early spray periods. One disadvantage of this method was the lag time, introduced between the time of interception by the funnel and the time the liquid was drawn off from the pot, was estimated to be $2.6 \pm 0.4 \mathrm{~min}$ for all funnel locations. In addition, contamination from previous, higher concentration liquid was inevitable.

Figures 51 through 54 show the concentration in the spray liquid as a function of time. Sampling problems were encountered in Run $A 6$ and data for this experiment are not shown. The curves should be adjusted to earlier times by the previously referenced 2.6 -min lag time.

These data are difficult to interpret, not only because of sampling inadequacies, but because the relative fractions of the various iodine forms and particle size were changing rapidly with time. However, they do show that iodine and cesium were collected by the spray drops in about the right amount compared to that lost by the gas phase. For example, in Run A4, integration of the iodine mass in the spray drops during the first period gives $29 \mathrm{~g}$ picked up by the spray, compared with $24 \mathrm{~g}$ lost by the gas phase. This result is considered an adequate agreement considering the uncertainty in the spray liquid measurement. 
BNWL - 1244

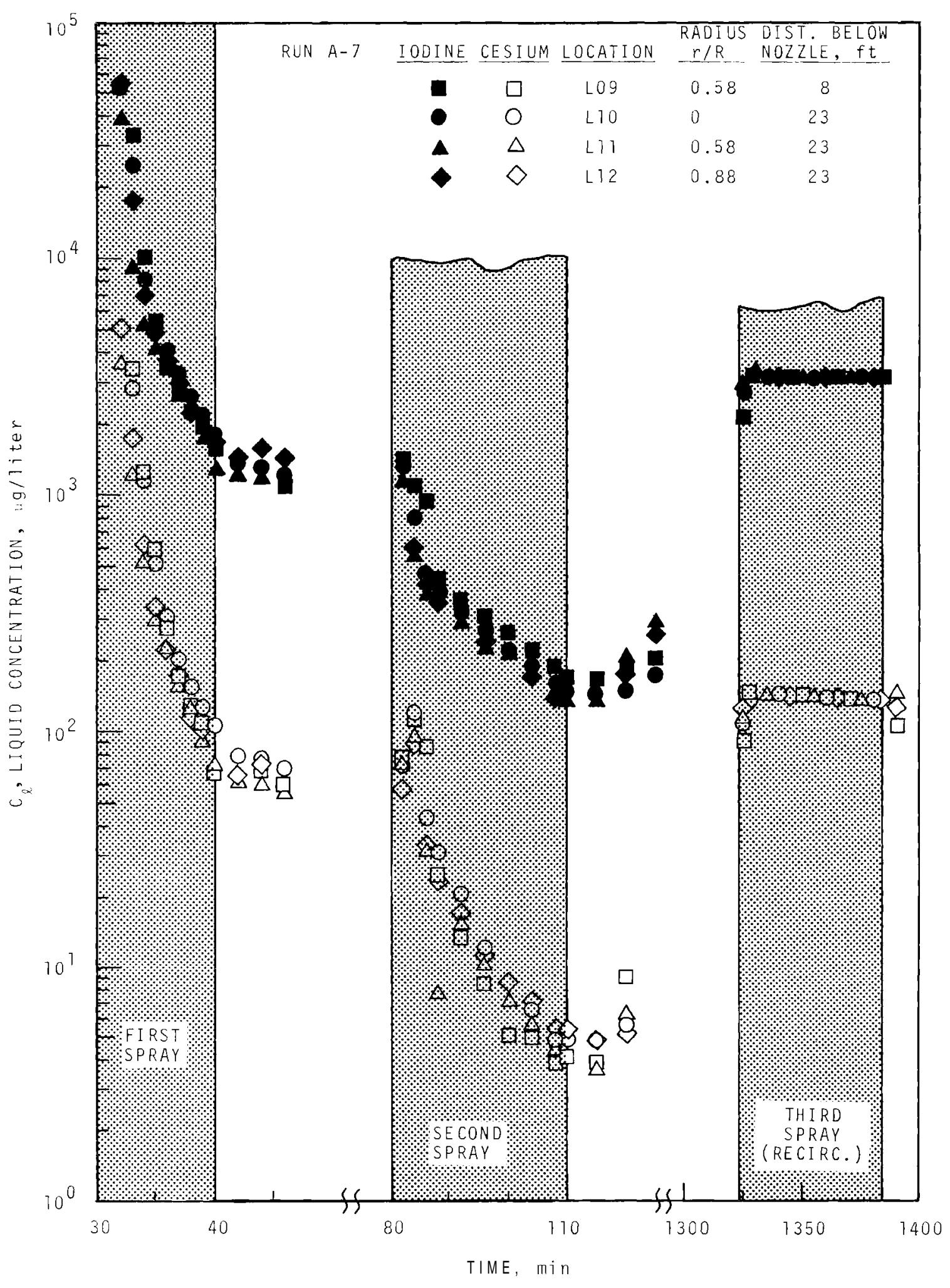

FIGURE 53. Iodine and Cesium Concentration in Spray Drops-Run A7 
BNWL - 1244

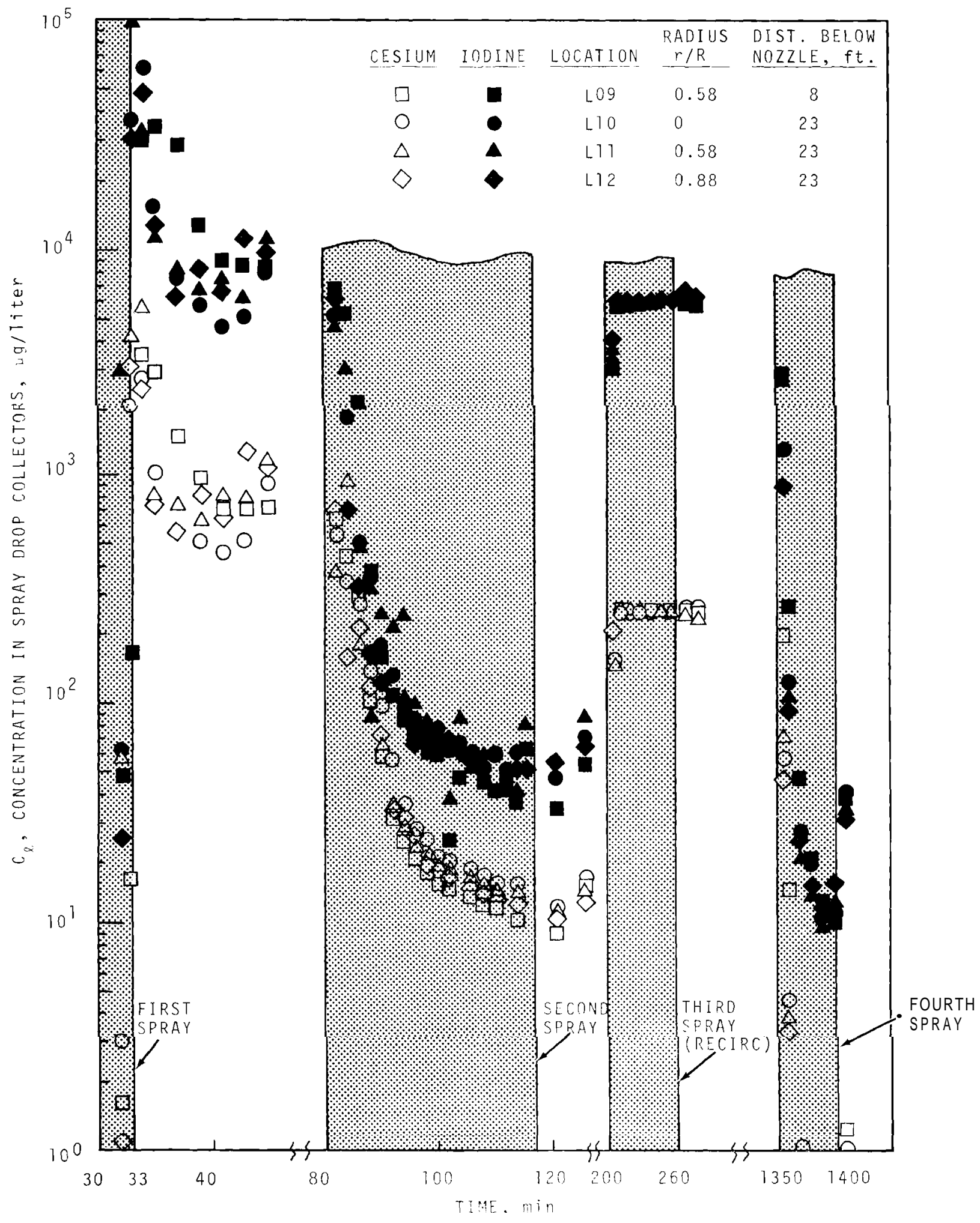

FIGURE 54. Iodine and Cesium Concentration in Spray Drops-Run A 8 
The data obtained from analyses of the liquid collected by the funnels are not sufficiently definitive to make a conclusion concerning the concentration in drops as a function of fall height. Improvements in sampling techniques are available for future tests.

Concentration in the Wall Film

A trough running completely around the outer vessel wall collected the spray intercepting the vertical walls. The flow rate of solution from this trough was metered, sampled periodically, and returned to the main containment vessel sump.

Table 10 lists the flow rates for each experiment. Figures 55 through 58 show the concentrations of iodine and cesium in the liquid as a function of time. Integration of the product of the concentration and flow rate gives the mass of iodine and cesium leaving the wall film. During the first period, the mass of iodine and cesium leaving the wall film was about the same fraction of total removed by sprays as the volume fraction intercepted by the walls. This finding suggests that most of the iodine and cesium was collected by spray drops in the gas before impinging on the walls.

During the second spray period, cesium behavior was similar to that in the first period, but iodine mass in the wall film was nearly equal to the iodine captured by drops and that falling to the deck or drywell. This behavior could be explained by iodine desorbing from the paint, or to the fact that organic forms of iodine prevailed during the second period, and removal at the wall could, therefore, be relatively more important than for elemental iodine.

Table 27 gives a comparison of the total measured gain by liquid streams with that lost from the gas phase for Run A4. The amount picked up by liquids exceeded that lost by the gas in every case, but the agreement is within experimental error and substantiates that the iodine and cesium entered the spray liquid at the rates indicated by Maypack analyses of the gas phase. 
BNWL - 1244

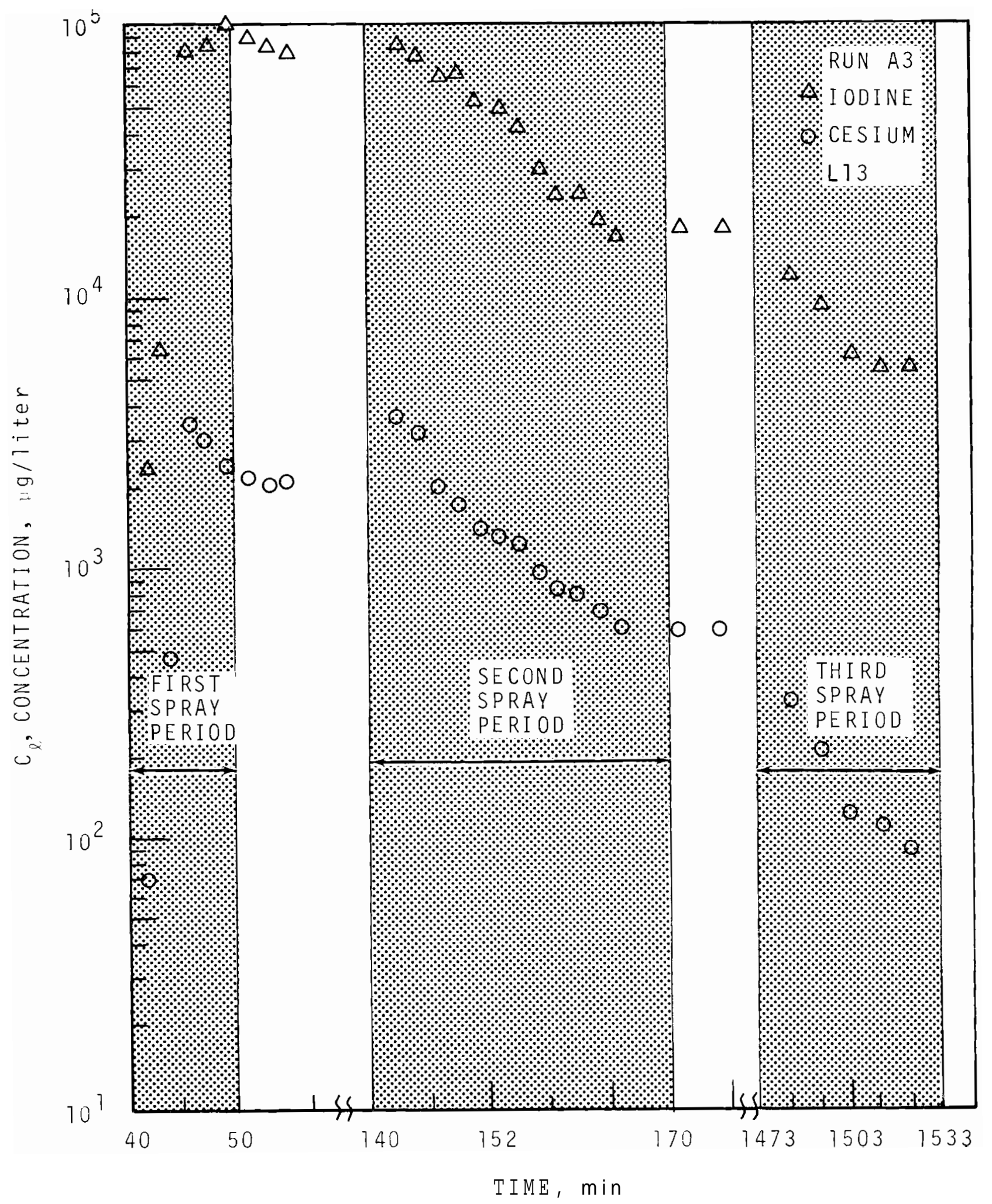

FIGURE 55. Iodine and Cesium Concentration in Wall Film, Run A3 


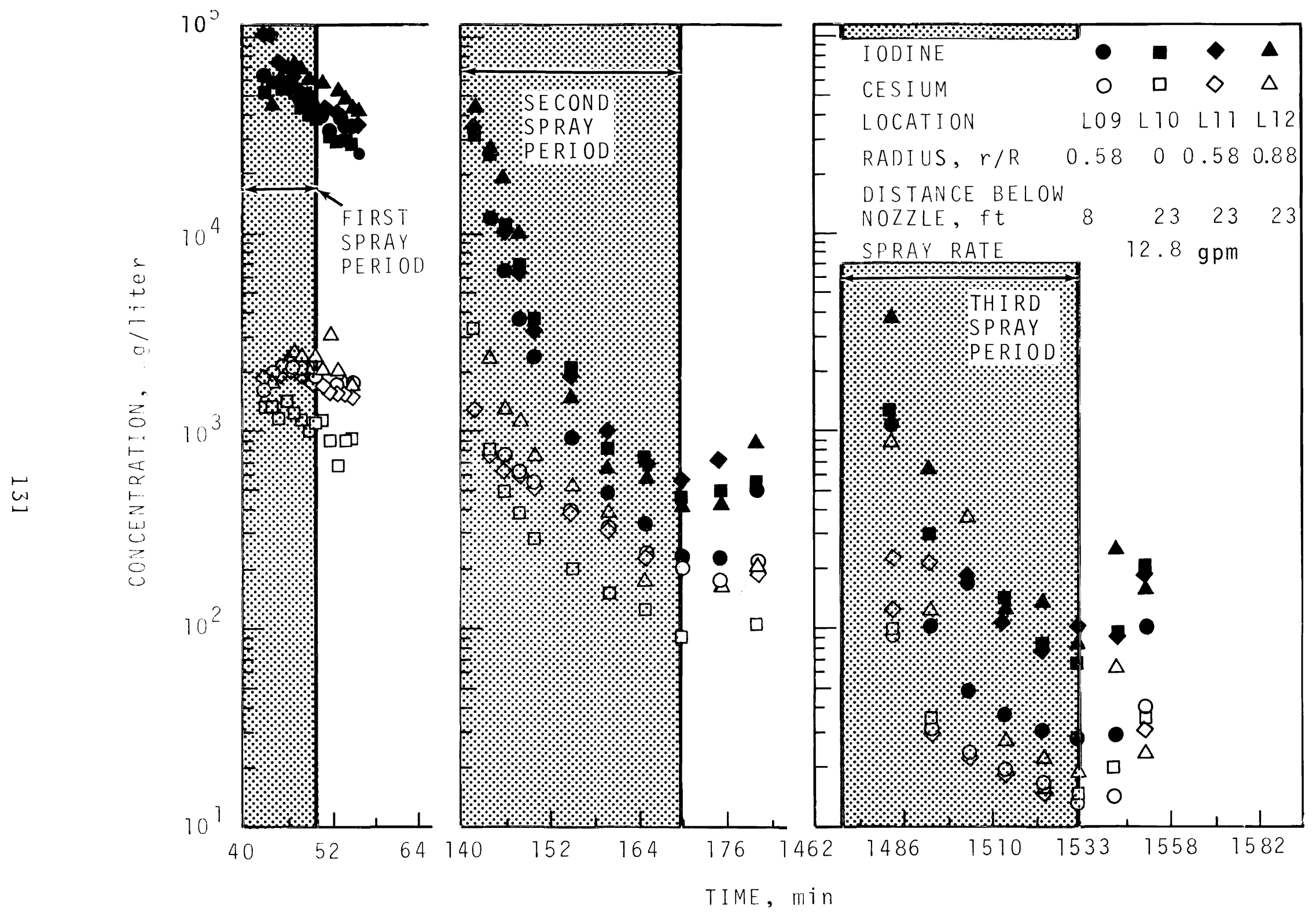

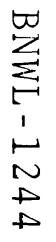

FIGURE 51. Iodine and Cos:.um Concentrations in Spray Drope--Run A3 


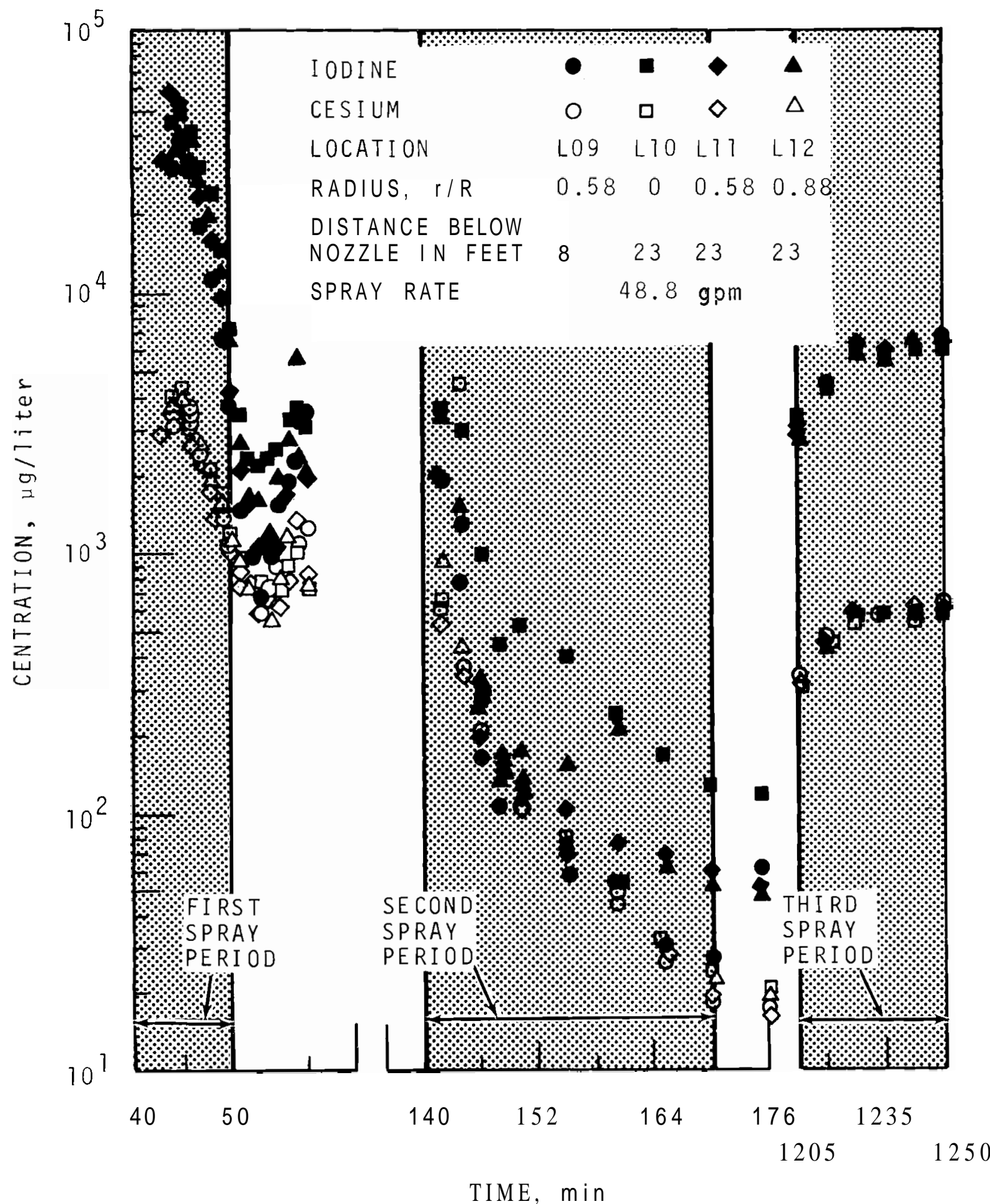

FIGURE 52. Iodine and Cesium Concentration in Spray Drops-Run A4 
BNWL -1244

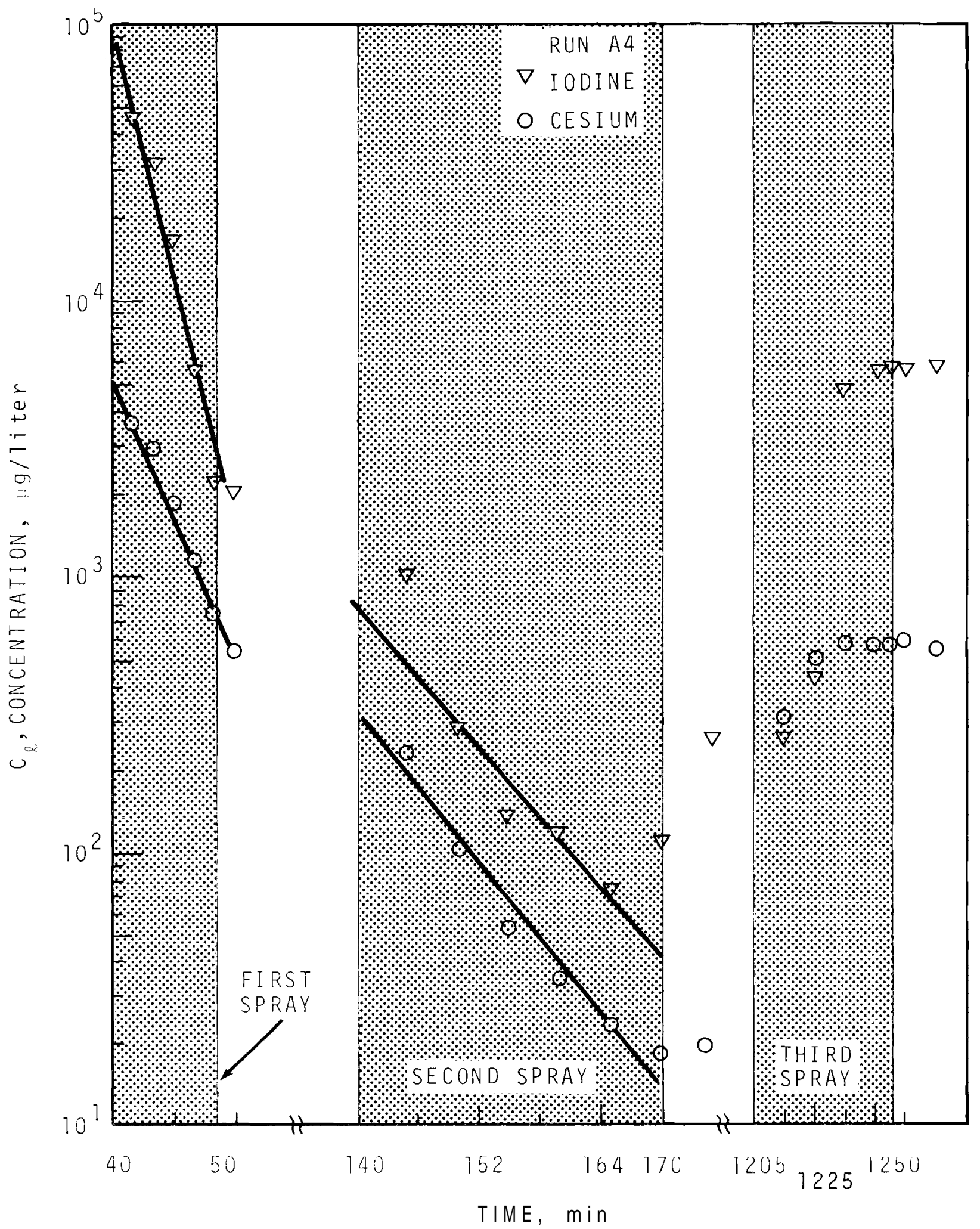

FIGURE 56. Iodine and Cesium Concentration in Wall Film, Run A4 
BNWL - 1244

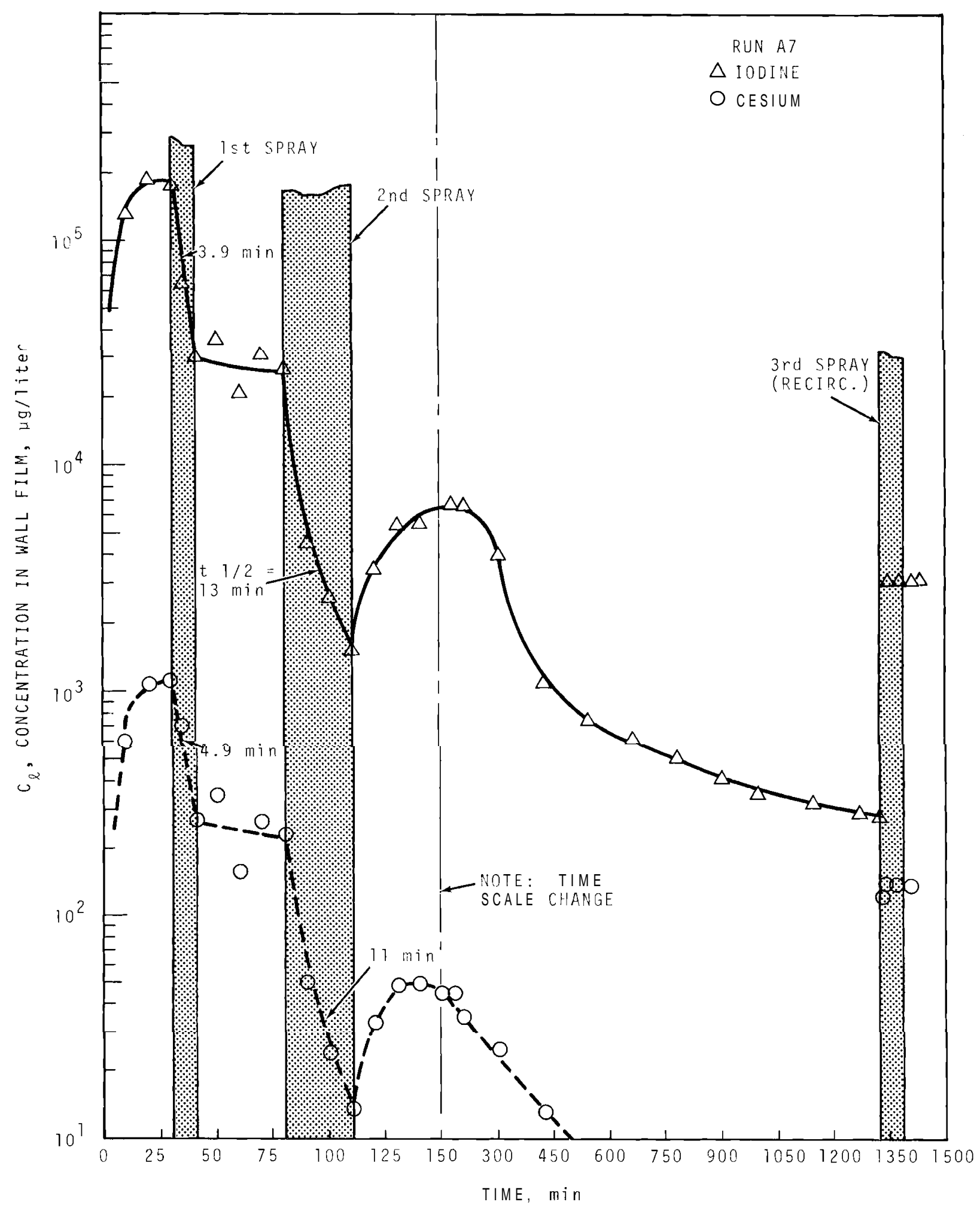

FIGURE 57. Iodine and Cesium Concentration in Wall Film, Run A7 
BNWL-1244

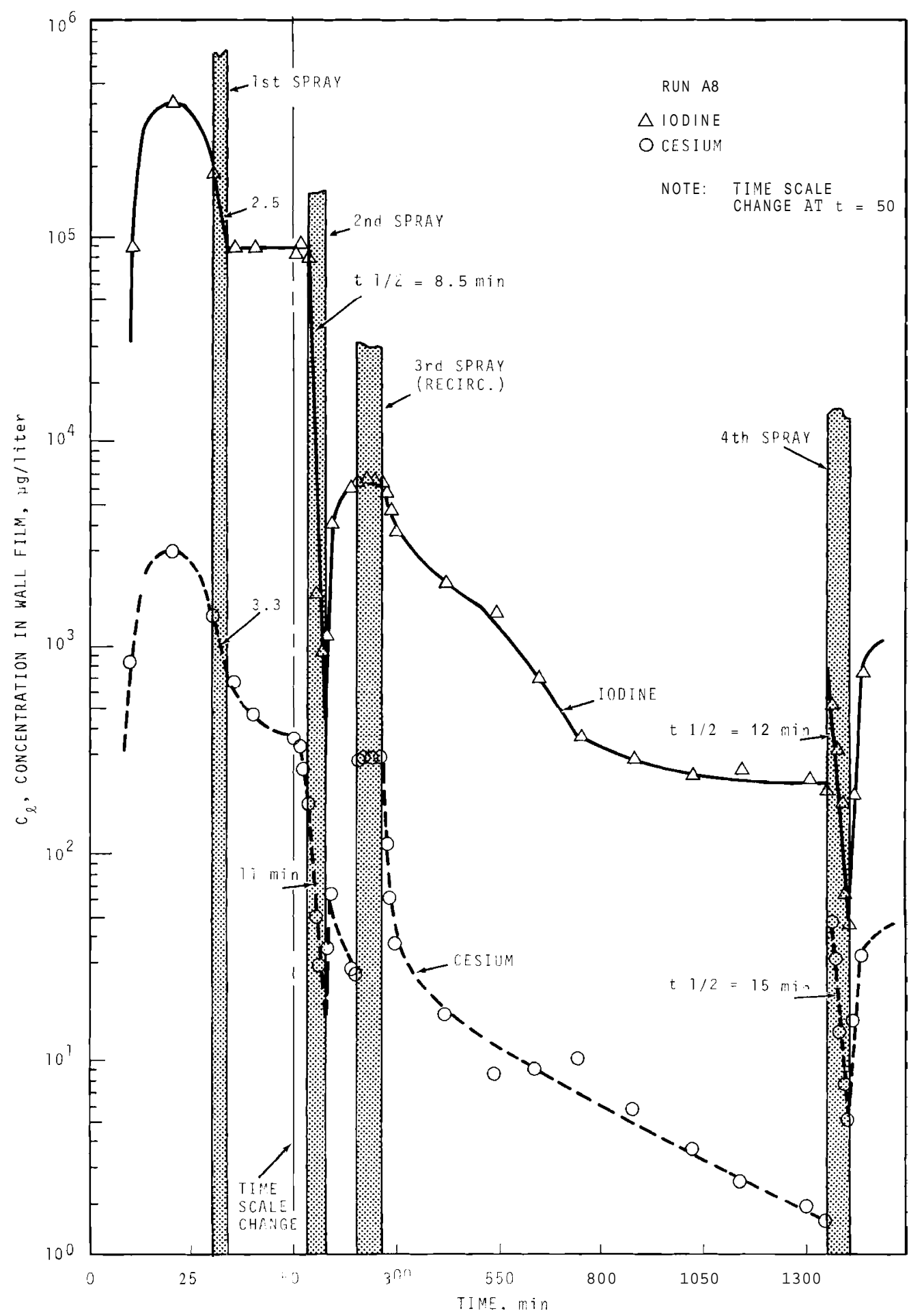

FIGURE 58. W a 11 Trough Concentration Versus Time--Run A8 
BNWL -1244

TABLE 27. Comparison of Iodine and Cesium Mass Gained by Liquids with Loss by Gas--Run A4

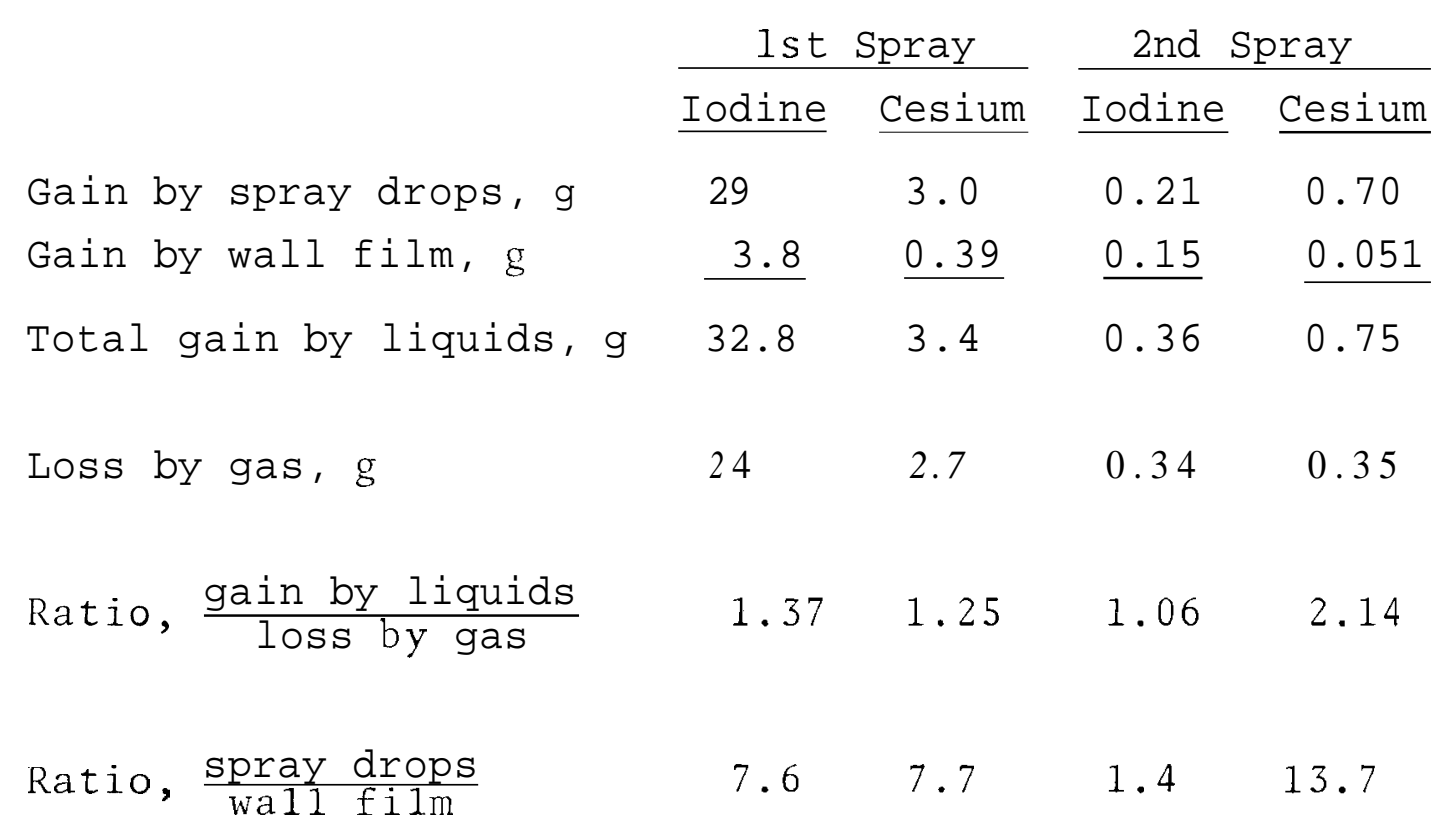

Final Equilibrium

Not much change in the concentration of any of the gasborne materials occurred during the third recirculation period in any of the experiments. This lack of change may indicate that an equilibrium between gas and liquid was reached prior to recirculation. In a few cases, the slight concentration increase during recirculation was considered compatible with an equilibrium condition. Re-exposure of the more concentrated liquid in the lower sump to the dilute gas atmosphere could increase the gas concentration by desorption or formation of small liquid particles.

Table 28 lists the total concentration reduction factors resulting from the combined processes of spraying and natural effects from time zero to the end of the recirculation period. Because the amount of liquid and spray plus steam condensate probably affects the overall decontamination, the ratio of gas to liquid volume at the end of the recirculation period is also 
TABLE 28. Equilibrium After Recirculation

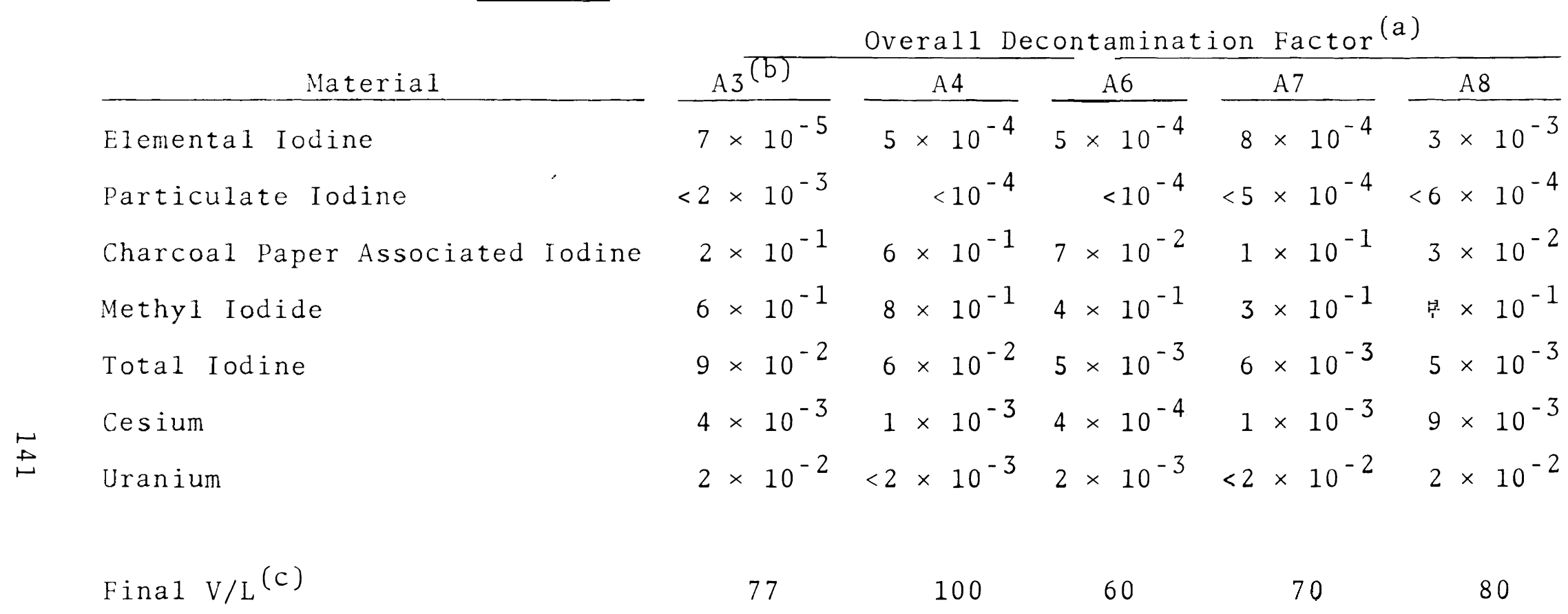

a. Gas phase concentration at end of recirculation spray recircuzation divided by concentration at time zero.

b. No recirculation in Run A3.

c. Total gas volume divided by total liquid volume at end of recirculation period. 
shown. Data for Run A3 are included, but the reader should recall that a fresh water spray instead of recirculation was used in the test.

Table 28 shows that elemental iodine and particulateassociated iodine concentrations were reduced by a factor of about 1000, material on the charcoal paper by a factor of about 10, methyl iodide by a factor of about 2, cesium by about 1000, and uranium by about 500. Total iodine concentration was reduced by a factor of 15 in the air tests, but by about 200 in the steam-air atmosphere tests. The higher reduction in steam atmospheres was caused by the greater removal of methyl iodide at the higher temperatures.

PARTICLE SIZE MEASUREMENT

The size distribution of particles in the containment atmosphere was measured in all the experiments except Run A3. Measurements for Run A4 were obtained by pulling a sample of the containment atmosphere (room temperature air) through a short tube and a Cassella* type impactor. Measurements in the other experiments involving pressurized steam-air atmospheres were made by inserting a Scientific Advancesk* type inertial impactor directly into the vessel atmosphere. The impactor was preheated to $2300^{\circ} \mathrm{F}$ before insertion to prevent steam condensation in the instrument. Stage cut-off 1 imits for unit density particles are $0.25,0.5,1.0,2.0,4.0$, and 8 and greater microns for the Scientific Advances impactor.

Size data for the four experiments are given in Table 29. In general, the aerodynamic mass median diameter for both cesium and uranium was reduced by the action of the sprays. The absolute values of the data presented in Table 28 are probably biased toward the low side because of the sampling

\footnotetext{
* C. F. Cassezza \& Co., Lta., London, Englana. Scientific Advances, Inc., Columbus, Ohio.
} 
method used. The particles are believed to be associated with condensed water in the form of fog droplets (see section on visual observations). The equilibrium size of liquid fog drops is very dependent on the relative humidity of the air surrounding the drops. Use of a preheated sampler, together with pressure drop across the orifices of the impactor, probably caused water to evaporate from the drops during sampling, with smaller sizes being indicated than actually existed in the containment environment. Improvements in particle size sampling techniques are being developed.

TABLE 29. Particle Size Analyses - CSE Spray Tests

\begin{tabular}{|c|c|c|c|c|c|c|c|c|}
\hline & \multicolumn{3}{|c|}{ Aerodynamic } & Particl & \multicolumn{4}{|r|}{1} \\
\hline & \multicolumn{2}{|c|}{ Run $A 4^{(b)}$} & \multicolumn{2}{|c|}{ Run $A 6^{(\mathrm{C})}$} & \multicolumn{2}{|c|}{ Run $A 7^{(\mathrm{C})}$} & \multicolumn{2}{|c|}{ Run ${ }^{A} 8^{(c)}$} \\
\hline & $\mathrm{Cs}$ & $\mathrm{U}$ & $\mathrm{Cs}$ & $\mathrm{U}$ & $\mathrm{Cs}$ & $\mathrm{U}$ & Cs & $\mathrm{U}$ \\
\hline Before 1st Spray & 0.9 & 1.6 & 0.5 & 1.0 & 2.0 & 1.8 & 0.5 & 0.8 \\
\hline After 1st Spray & 0.5 & 0.7 & 0.4 & 0.9 & 0.3 & 0.6 & 0.6 & 0.9 \\
\hline
\end{tabular}

a. Diameter relative to settling velocity of a unit density spherical particle.

b. Cassezza Impactor; sampled outside the containment vessel.

c. Scientific Advances Inertial Impactor; sampled within containment vessez.

DEPOSITION COUPON DATA

Coupons of various types of materials were suspended at different locations throughout the gas space to measure deposition on noncondensing surfaces. Some were also pressed against the outer wall to measure deposition concurrent with heat transfer. The latter coupons extended about $1 / 16$ in. out from the vessel wall, so it is doubtful that condensate from higher elevations ran over them. But since they were attached to the colder wall, condensate did form on them. The coupons were 
2.5-in. diam washers, 1/16-in. thick, and with a 17/32-in. hole in the center. All coupons were installed before the test and removed after the vessel had been purged. All were oriented vertically and exposed to the spray liquids.

Table 30 lists the average iodine deposition remaining on five types of materials exposed to noncondensing conditions. The standard deviations from the mean are shown also. Similar data for cesium are given in Table 31. The relative affinity of each of the five materials for iodine and cesium can be inferred by examining the depositions for a single experiment. In air (Runs A3 and A4), the retention of both iodine and cesium decreased in the order of silver, Phenoline 302, Amercoat 66, carbon steel, and SS-304. In steam-air atmospheres, the order for iodine was carbon steel, Phenoline 302, Amercoat 66, silver, and SS-304. In steam-air, cesium followed the order of Phenoline 302, Amercoat 66, carbon steel, silver, and SS-304.

The variation for a given material from test to test reflects the differences in test conditions (atmosphere, temperature, initial gas phase concentration, spray additives). For example, the silver coupons in Kuns A7 and A8 retained very little iodine compared to the other tests. The sodium thiosulfate sprays used in these two tests apparently removed most of the iodine deposited earlier in the run.

The deposition on small coupons should not be expected to represent accurately the deposition on large surface areas. Other investigators $(41,42)$ have shown that orientation, heat transfer, and location affect deposition rates. Gas boundary layer thicknesses are dependent on length along the surface and angle of inclination of the surface to the gas stream. (43) However, the data obtained from coupons were extrapolated to the entire CSE vessel area for a check on material balance calculations. Since $>99 \%$ of the interior surfaces in the CSE 
were coated with Phenoline 302 paint, the data used for this material were prorated between noncondensing and heat transfer surface as shown in Table 32.

TABLE 30. Iodine Deposition on Various Noncondensing Surfaces Deposition at End of Experiment,

Surface Material ${ }^{(a)}$

Silver (b)

Carbon Stee $1(b)$

Stain les s Stee $1304^{(b)}$

(ASTM A240-63)

Phenoline $302^{(C)}$

Amercoat $66(\mathrm{~b}, \mathrm{~d})$

$$
\mu \mathrm{g} / \mathrm{cm}^{2} \text { and } 1 \text { o }(\%)
$$

Run A3 Run A4 $\underline{\text { Run A6 Run A7 }}$ Run A8

$\begin{array}{lllll}109 & 66.2 & 8.58 & 0.085 & 0.135\end{array}$

$\pm 26 \% \quad \pm 20 \% \quad \pm 56 \% \quad 554 \% \quad \pm 63 \%$

$\begin{array}{lllll}5.38 & 0.284 & 19.8 & 17.0 & 17.3\end{array}$

$\pm 148 \% \quad \pm 30 \% \quad 17 \% \quad \pm 35 \% \quad+48 \%$

$\begin{array}{lllll}0.052 & 0.041 & 0.52 & 0.088 & 0.050\end{array}$

$\pm 110 \% \quad \pm 170 \% \quad 275 \% \quad 35 \% \quad \pm 66 \%$

$\begin{array}{lllll}8.14 & 2.55 & 15.3 & 22.3 & 13.4\end{array}$

$\pm 45 \% \quad+30 \% \quad \pm 25 \% \quad \pm 28 \% \quad \pm 40 \%$

$\begin{array}{lllll}1.05 & 0.49 & 0.25 & 16.9 & 9.88\end{array}$

$\pm 18 \% \quad \pm 16 \% \quad \pm 20 \% \quad \pm 18 \% \quad \pm 38 \%$

a. $21 / 2$ in. diam, 1/16 in. thick, 17/32 in. center hole. Total surface $=64 \mathrm{~cm}^{2}$.

b. Average of 11 locations in main room.

c. Coating manufactured by Carboline Co., St. Louis, Mo. Average of 22 Zocations.

d. Coating manufactured by Amercoat Corp., South Gate, CaZif. 
TABLE 31. Cesium Deposition on Various Noncondensing Surfaces

Deposition at End of Experiment, $\mu \mathrm{g} / \mathrm{cm}^{2}$ and $1 \sigma(\%)$

\begin{tabular}{|c|c|c|c|c|c|}
\hline \multirow{2}{*}{ Surface Material (a) } & \\
\hline & Run A3 & Run A4 & Run A6 & Run A7 & Run A8 \\
\hline Silver $(b)$ & $\begin{array}{l}0.0118 \\
569 \%\end{array}$ & $\begin{array}{l}0.0095 \\
265 \%\end{array}$ & $\begin{array}{l}0.0039 \\
\pm 57 \%\end{array}$ & $\begin{array}{l}0.00134 \\
235 \%\end{array}$ & $\begin{array}{l}0.00062 \\
262 \%\end{array}$ \\
\hline Carbon Steel(b) & $\begin{array}{l}0.0042 \\
\pm 41 \%\end{array}$ & $\begin{array}{l}0.0020 \\
\pm 32 \%\end{array}$ & $\begin{array}{l}0.0034 \\
\pm 96 \%\end{array}$ & $\begin{array}{l}0.00637 \\
280 \%\end{array}$ & $\begin{array}{l}0.0049 \\
234 \%\end{array}$ \\
\hline $\begin{array}{l}\text { Stainless Ste e } 1304 \text { (b) } \\
\text { (ASTM A240-63) }\end{array}$ & $\begin{array}{l}0.0016 \\
\pm 76 \%\end{array}$ & $\begin{array}{l}0.0026 \\
\pm 57 \%\end{array}$ & $\begin{array}{l}0.00003 \\
\pm 68 \%\end{array}$ & $\begin{array}{l}0.00056 \\
284 \%\end{array}$ & $\begin{array}{l}0.00002 \\
\pm 61 \%\end{array}$ \\
\hline Phenoline $302^{(c)}$ & $\begin{array}{l}0.0025 \\
\pm 52 \%\end{array}$ & $\begin{array}{l}0.0035 \\
\pm 36 \%\end{array}$ & $\begin{array}{l}0.0042 \\
\pm 40 \%\end{array}$ & $\begin{array}{l}0.0079 \\
513 \%\end{array}$ & $\begin{array}{l}0.0066 \\
\pm 55 \%\end{array}$ \\
\hline Amercoat $66^{(b}$ & $\begin{array}{l}0.0039 \\
233 \%\end{array}$ & $\begin{array}{l}0.0054 \\
\pm 43 \%\end{array}$ & $\begin{array}{l}0.063 \\
\pm 45 \%\end{array}$ & $\begin{array}{l}0.0100 \\
237 \%\end{array}$ & $\begin{array}{l}0.0018 \\
\pm 45 \%\end{array}$ \\
\hline
\end{tabular}

a. $21 / 2$ in. diam, 1/16 in. thick, 17/32 in. center hole.

Total surface $=64 \mathrm{~cm}^{2}$.

b. Average of 11 Zocations in main room.

c. Coating manufactured by Carbozine Co., St. Louis, Mo. Average of 22 locations.

d. Coating manufactured by Amercoat Corp., South Gate, Calif.

TABLE 32. Deposition oh, Vessel Surfaces Inferred from
Coupon Data (a) Coupon Data( $)$
$\frac{\text { Fraction of Injected Mass on Vessel Surfaces }}{\text { Nonheat }}$ $\begin{array}{ccc}\text { Injected Mass, } & \text { Heat Transfer } \\ \text { Surface(c) } & \text { Transfer } & \text { Surface } \\ \text { (b) } & \text { Total Vessel } & \text { Surface }\end{array}$

\begin{tabular}{llllllll} 
Run $I$ & $\mathrm{Cs}$ & $\mathbf{I}$ & $\mathrm{Cs}$ & $\mathrm{I}$ & $\mathrm{Cs}$ & $\mathrm{I}$ & $\mathrm{Cs}$ \\
\hline
\end{tabular}

$\begin{array}{lllllllll}\text { A3 } & 75.75 & 3.078 & 0.266 & 0.00211 & 0.260 & 0.00197 & 0.526 & 0.00408 \\ \text { A4 } & 70.91 & 6.378 & 0.0653 & 0.00145 & 0.0869 & 0.00135 & 0.152 & 0.00280 \\ \text { A6 } & 98.34 & 2.589 & 0.162 & 0.00495 & 0.375 & 0.00388 & 0.537 & 0.00883 \\ \text { A7 } & 97.57 & 2.125 & 0.320 & 0.00555 & 0.553 & 0.00851 & 0.873 & 0.0141 \\ \text { A8 } & 95.61 & 4.351 & 0.263 & 0.00169 & 0.339 & 0.00268 & 0.602 & 0.00437\end{array}$

a. Phenoline 302 coupons.

b. From Tables 6 and 7 .

c. $327 \mathrm{~m}^{2}$ in CSE main room.

d. $242 \mathrm{~m}^{\ddot{z}}$ in Cse main room. 
The two methods of estimating the fractional mass deposited and retained on vessel surfaces are compared in Table 33. The agreement is surprisingly good and substantiates as reasonable the values obtained from material balances reported in the first part of this section.

TABLE 33. Comparison of Deposition by Coupon Data with Material Balance Calculations

\begin{tabular}{|c|c|c|c|c|}
\hline \multirow[b]{2}{*}{$\underline{\text { Run }}$} & \multicolumn{2}{|c|}{$\begin{array}{r}\text { Fraction of } \\
\text { Iodine }\end{array}$} & \multicolumn{2}{|c|}{ Cesium } \\
\hline & $\begin{array}{l}\text { Coupon } \\
\text { Data(a) }\end{array}$ & $\begin{array}{l}\text { Material } \\
\text { Balance(b) }\end{array}$ & $\begin{array}{l}\text { Coupon } \\
\text { Data(a) }\end{array}$ & $\begin{array}{l}\text { Material } \\
\text { Balance (c) }\end{array}$ \\
\hline A3 & 0.53 & 0.31 & 0.0041 & 0.043 \\
\hline A4 & 0.15 & 0.26 & 0.0028 & 0.11 \\
\hline A6 & 0.54 & 0.44 & 0.0088 & 0.008 \\
\hline A 7 & 0.87 & 0.58 & 0.0141 & $(-) 0.21$ \\
\hline A 8 & $\underline{0.60}$ & 0.42 & $\underline{0.0044}$ & 0.16 \\
\hline $\operatorname{Avg}$ & 0.54 & 0.40 & 0.0068 & 0.022 \\
\hline
\end{tabular}

a. From Table 33 .

b. From Table 6 .

c. From Table 7 . 
BNWL -1244

\section{COMPARISON OF THEORY WITH EXPERIMENT}

\section{ELEMENTAL IODINE}

Initial Spray Washout Kate

An important measure of the effectiveness of a spray for removing elemental iodine is the initial washout rate. This rate is important from a hazards analysis viewpoint because the greatest leakage hazard for iodine would exist initially. From a model verification viewpoint, the initial washout rate is most amenable to simple analysis because factors such as inter-room transport, reversible adsorption phenomena, backpressure of dissolved iodine, and changes in thermodynamic conditions are relatively unimportant initially. For long spray periods, these factors may have a controlling influence on the gas phase concentration.

The washout of elemental iodine due to operation of sprays was calculated by subtracting from the measured washout rate, the washout rate observed when the spray was not operating. The purpose of this correction was to permit separation of the washout due to spray drops alone and that occurring at wall surfaces. This method of correction is not strictly correct because the wall film absorption would be influenced by the increased liquid flow rate over the wall surfaces during the spray period. Better methods for accounting for wall film absorption are currently being explored. In Table 34, the spray washout rates for elemental iodine are shown along with the removal rates observed before and after the spray period. 
TABLE 34. Observed Washout of Elemental Iodine During First Spray Period

$t_{1 / 2}$, Gas Concentration Half-Life, min

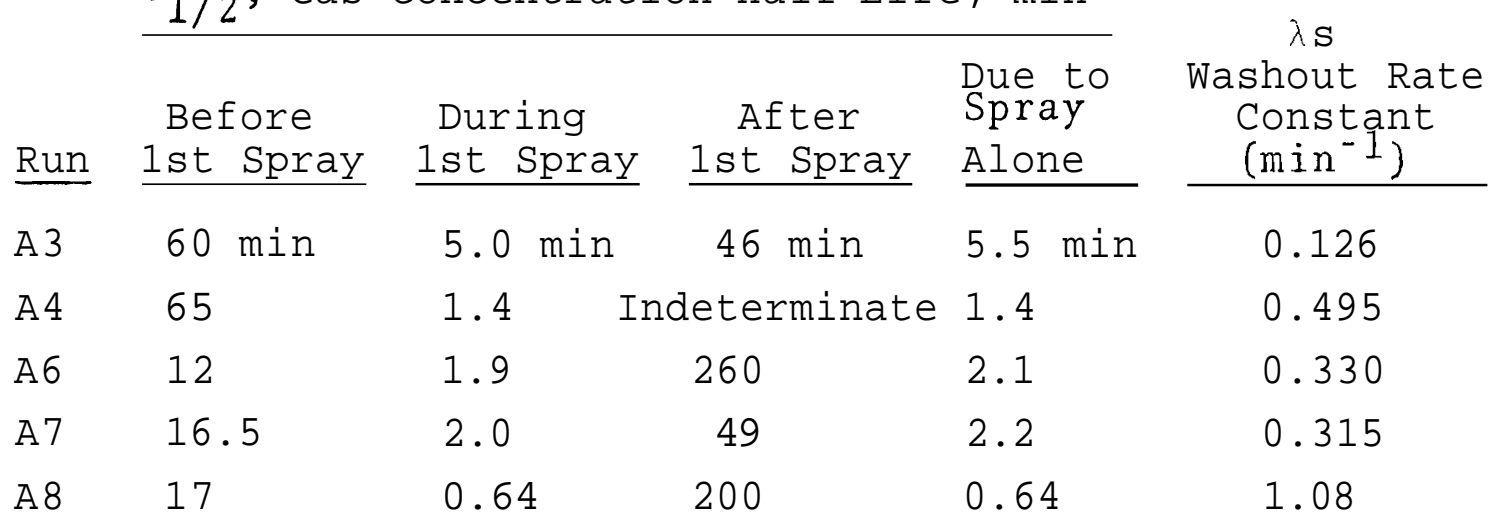

The washout rate for the spray alone was compared to predictions based on Equation (16). This equation is based on the following simplifying assumptions: (1) puff release of iodine, (2) atmosphere is well mixed, (3) the backpressure of dissolved iodine at the gas-liquid interface is negligible, (4) inter-room transport is negligible, and (5) the thermodynamic and flow conditions are constant. These assumptions appear reasonable for the first spray period in the CSE experiments. The release of iodine to the containment vessel was completed some 30-40 min prior to spray initiation and, hence, there was no iodine injection source term. The concentration levels were relatively high so that desorption from surfaces would not constitute a major iodine source term. The first relatively short spray periods would prevent lowering of the concentration to a level where desorption, and inter-room transport could act as significant source terms.

The mixing within the containment vessel has been assessed during each CSE run by comparing concentrations measured at each of the sampling positions. These measurements indicate that, within a few minutes after aerosol injection, the atmosphere may be considered well mixed. 
BNWL - 1244

Backpressure of iodine from spray drops is minimized by use of a fresh spray solution. Absorption of iodine by a drop as it falls causes the liquid concentration to increase from zero at its formation point to a level of about 1500 times the gas concentration at the termination of its exposure as a drop. This concentration level is only a few percent of the equilibrium saturation concentration and, hence, backpressure of the dissolved iodine would be expected to be minor. However, the liquid phase iodine concentration admittedly is large compared to that which could be absorbed without chemical reaction, and the foregoing conclusion that iodine backpressure is minor is based on the assumption that the liquid phase chemical reactions are very fast compared to the drop fall times.

Temperature and pressure within the containment vessel decrease due to the use of fresh spray. For the temperatures and pressure changes encountered in the first spray periods, the change in absorption rate for a gas phase limited process is predicted to be small.

Theoretically, calculation of the drop exposure time for each drop size increment of the spray should allow for initial velocity. Example calculations using the drop size spectrum do not yield results greatly different than those using a mean of the distribution and assuming terminal velocity for the entire fall distance.

An estimate of the effect of distribution of drop sizes was made by calculating the spray washout incrementally and assuming terminal settling velocity for the whole fall height. The drop size distribution used in this calculation was that supplied by the manufacturer of the spray nozzles.* This distribution is reproduced in Figure 59.

* Spraying Systems Co., Belzwood, Illinois. 


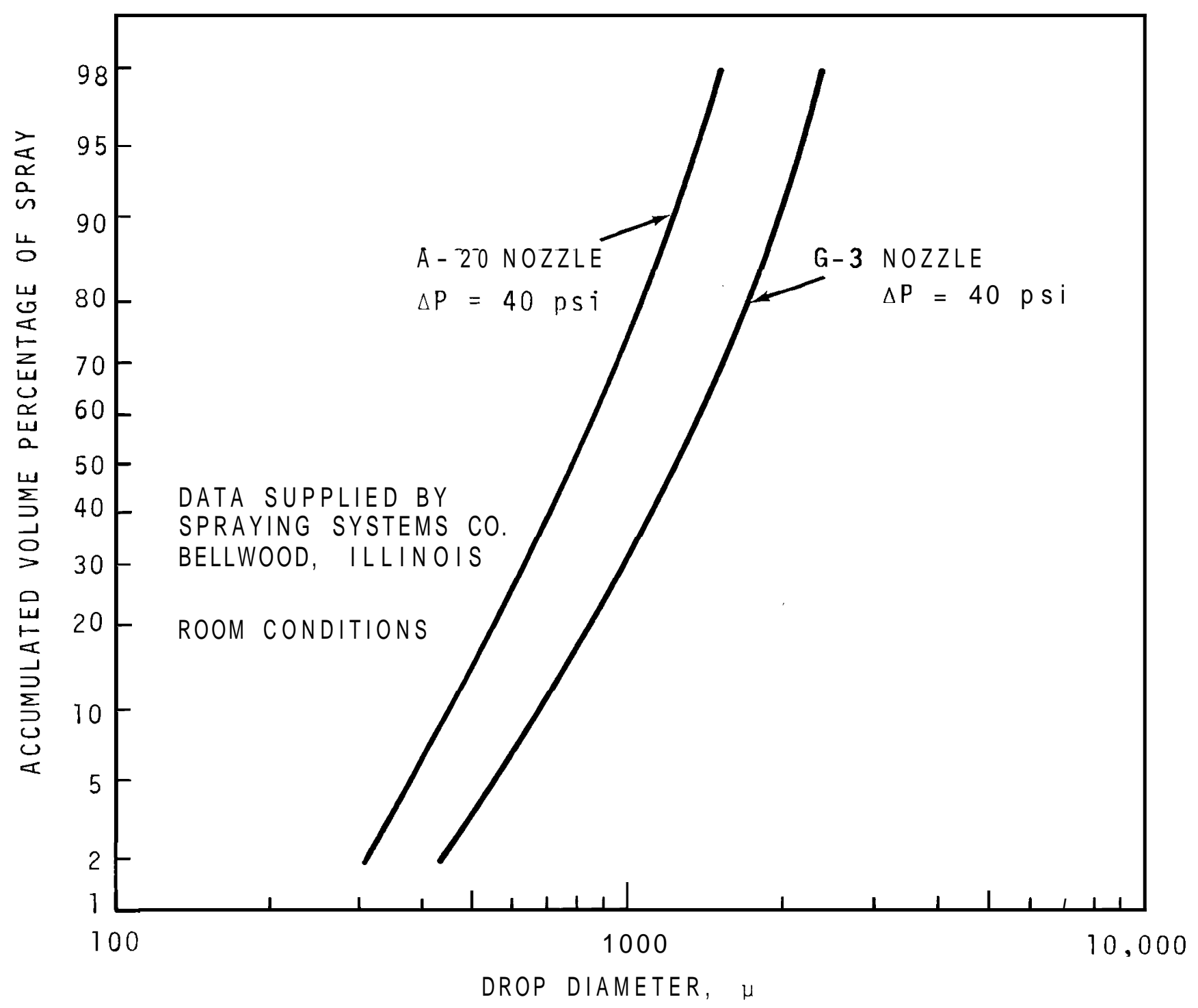

FIGURE 59. Drop Size Distribution for Sprays Used in CSE 
The mean drop size found to represent the whole spray was very nearly equal to the surface mean diameter of $980 \mu$. The surface mean diameter was computed from the mass median diameter of $1210 \mu$ by using the log-probability distribution as modified to account for a maximum drop size by Mugele and Evans. (44)

The influence of initial velocity on reducing the absorption compared to that for terminal velocity was estimated by calculating the velocity as a function of distance from the nozzle. The initial velocity at the nozzle was taken to equal to the flow rate divided by the orifice cross section area. It was assumed that all drops were directed downward. The results of this calculation are shown in Figure 60 where the net absorption is compared to an estimate based on terminal settling velocity. The decrease in absorption when initial velocity is accounted for is less than the decrease in exposure time because of increased mass transfer coefficients at the higher velocities Figure 60 shows that the effect of initial velocity will not be of great importance for containment vessels with fall heights greater than $30 \mathrm{ft.}$ A summary of predicted values for falling drops for five CSE spray tests is given in Table 35.

The last two columns of Table 35 represent the washout rate constants $\left(\lambda_{S}=\frac{0.693}{\mathbf{t}_{1 / 2}}\right)$ predicted first on the basis of the mass median diameter and terminal velocity, and then on the basis of the surface mean diameter to account for initial velocity. For the surface mean diameter, initial velocity was accounted for first by calculating the washout coefficient, $\lambda_{s}$, based upon an assumption of terminal velocity for the entire fall height. l'his $\lambda_{S}$, based on terminal velocity, was then multiplied by a factor to account for the effect of changing velocity on the exposure time and for the mass transfer coefficient. The integrated effect of initial velocity on drop absorption limited 
BNWL -1244

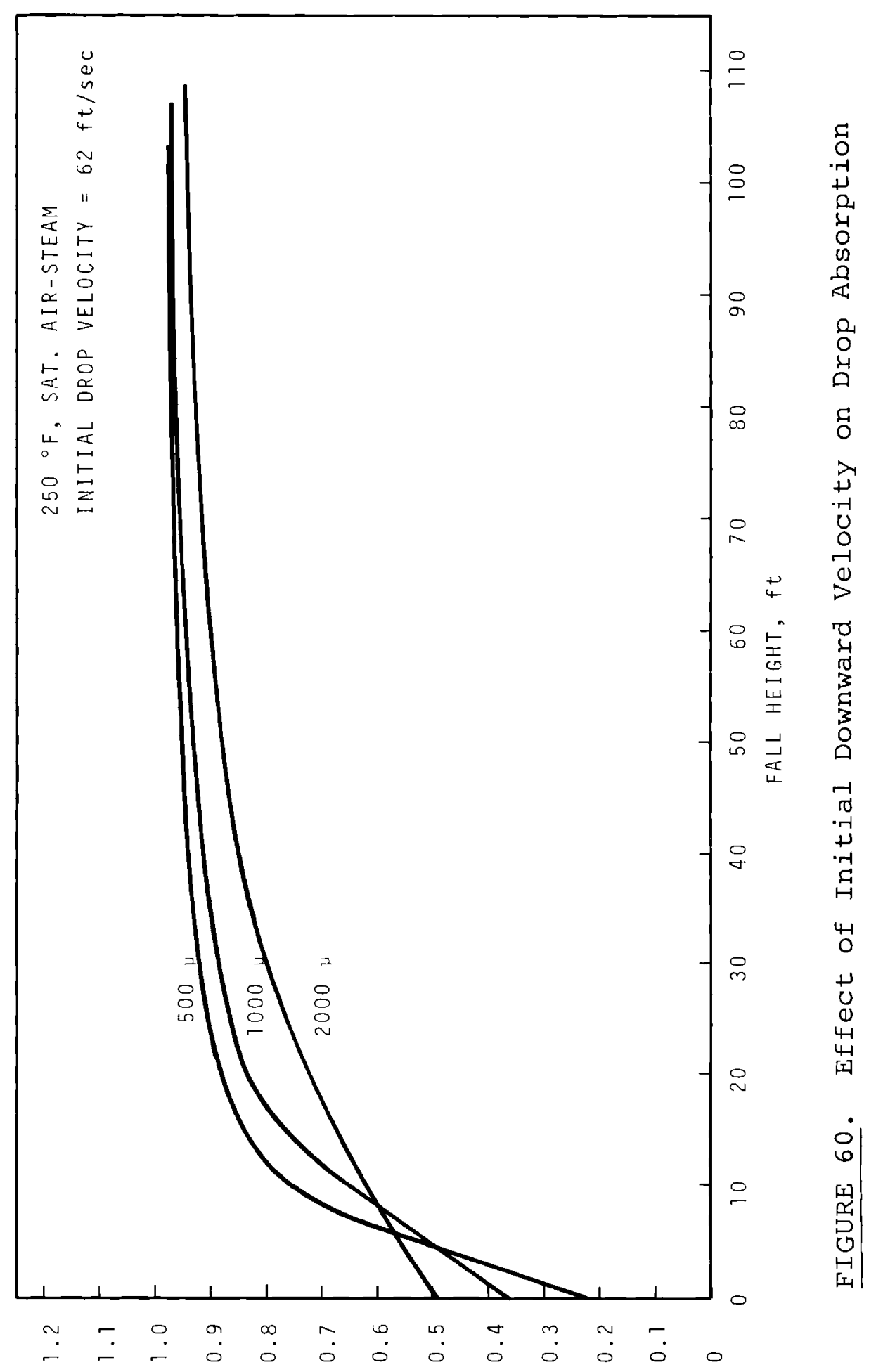

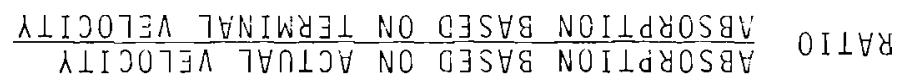


BNWL -1244

TABLE 35. Predicted Drop Washout Constants

for CSE Spray Tests

\begin{tabular}{|c|c|c|c|c|c|c|c|}
\hline \multirow[b]{2}{*}{$\underline{\text { Run }}$} & \multirow{2}{*}{\multicolumn{2}{|c|}{ Drop Size, $\mu$}} & \multirow[b]{2}{*}{$\begin{array}{l}\text { Spray } \\
\text { Rate? } \\
\mathrm{ft}^{3} / \mathrm{min} \\
\end{array}$} & \multirow[b]{2}{*}{$\begin{array}{c}\text { Fall } \\
\text { Helght, } \\
f t(c)\end{array}$} & \multirow[b]{2}{*}{$\begin{array}{l}\text { Chamber } \\
\text { Volume } \\
\text { ft }^{3} \text { (d) }\end{array}$} & Predicted & As, min-1 \\
\hline & & & & & & $\begin{array}{l}6 \mathrm{Fh} \mathrm{k}_{\mathrm{g}}^{(\mathrm{e})} \\
\mathrm{V} \mathrm{v}_{\mathrm{t}} \mathrm{d}\end{array}$ & $\begin{array}{l}6 \mathrm{~F} \quad \mathrm{~kg}_{\mathrm{g}}(\mathrm{f}) \\
\underline{\mathrm{V}} \mathrm{v} \mathrm{g} \\
\end{array}$ \\
\hline A3 & 1210 & 980 & 1.70 & 38.5 & $21 \times 10^{3}$ & 0.109 & 0.153 \\
\hline A 4 & 1210 & 980 & 6.35 & 38.5 & $21 \times 10^{3}$ & 0.408 & 0.571 \\
\hline A6 & 1210 & 980 & 6.35 & 38.5 & $21 \times 10^{3}$ & 0.365 & 0.513 \\
\hline A 7 & 1210 & 980 & 6.35 & 38.5 & $21 \times 10^{3}$ & 0.365 & 0.513 \\
\hline A 8 & 770 & 650 & 6.65 & 38.5 & $21 \times 10^{3}$ & 0.978 & 1.278 \\
\hline
\end{tabular}

a. Mass median diameter.

b. Surface mean diameter.

c. Average effective fall height.

d. Main room.

e.. Using MMD and terminal velocity.

f. Using SMD and correcting for initial drop velocity.

by gas phase resistance is shown in Figure 60. For a drop size of $980 \mu$, the correction factor was 0.91 , and for $650 \mu$ drops, the correction factor was 0.92 . Theoretically, the latter method of calculation should provide the best estimate.

A comparison of the predicted washout rate constants shown in Table 35 with the measured decay constants reported in Table 34 is presented in Figure 61. Perfect agreement between theory and experiment would be represented by a $45^{\circ}$ line passing through the origin. As expected, the predicted washout rate based on the mass median diameter is somewhat lower than that obtained from the surface mean diameter. The difference in the predictions is not great, however, and a firm judgment of the type of mean to be used cannot be drawn from the data shown in Figure 61. 
BNWL -1244

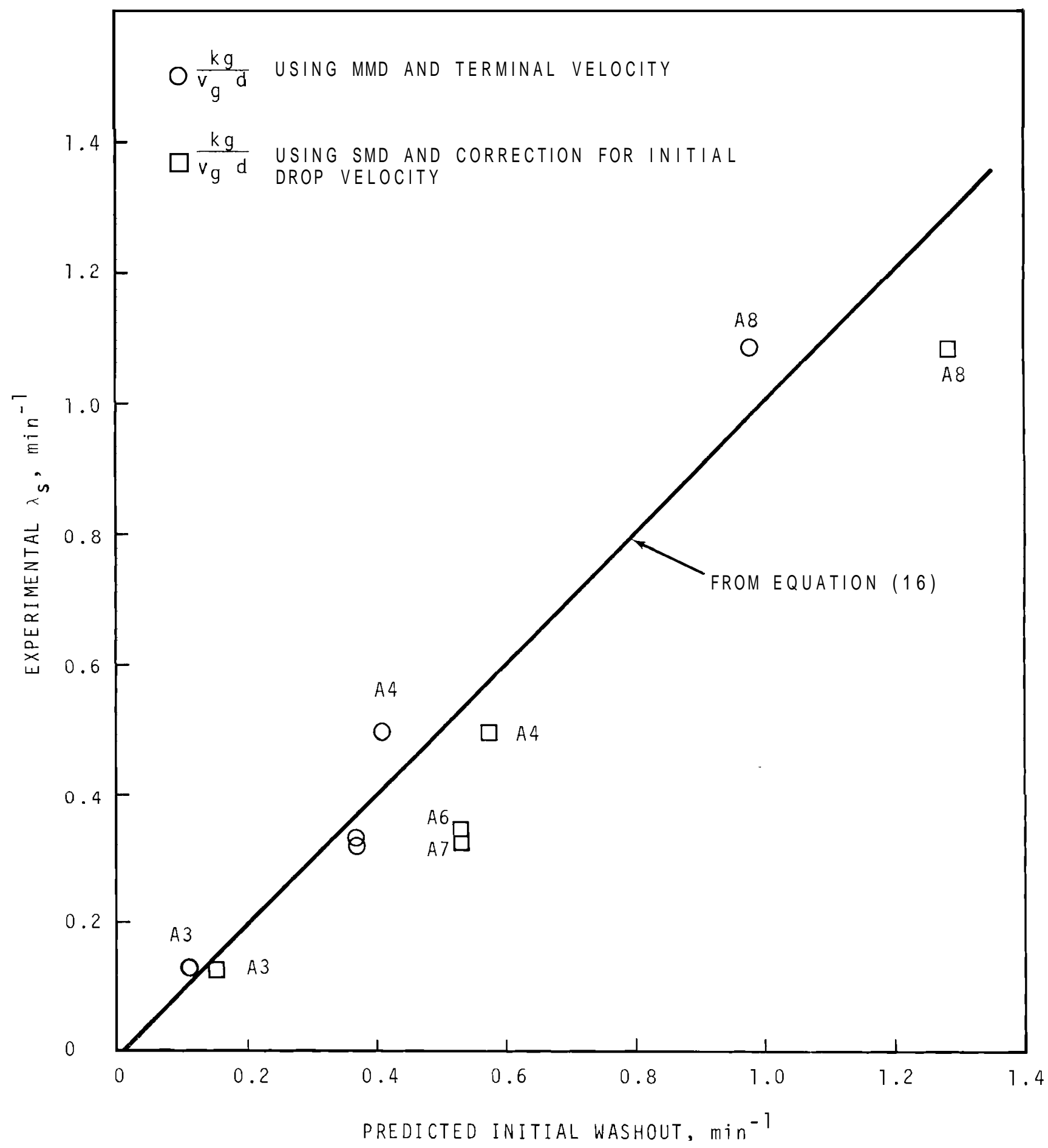

FIGURE 61. Comparison of Experimental Initial Washout of Elemental Iodine with Drop Absorption Model 
BNWL -1244

Perhaps the most striking feature of Figure 61 is the excellent agreement between predicted and measured washout rates, The agreement is within the limits of accuracy of the prediction $( \pm 20 \%)$ when potential inaccuracies in drop size, diffusivities, settling velocities, and mass transfer coefficients are considered.

The agreement between the observed washout rate and that predicted from the simple model suggests that iodine backpressure at the drop surface and inter-room transport are small factors initially. The first of these factors could not be true unless a rapid chemical reaction should cause dissolved iodine to react as shown in Equation (3) and, hence, we must conclude that even at low values of $\mathrm{pH}$, dissolved iodine quickly reacrs to form species of low volatility. Equilibrium Gas Phase Concentration

The initial washout rate for elemental iodine continued until the iodine concentration had decreased to about $1 \%$ of its initial value. In all five experiments, the gas phase concentration decreased more slowly at longer times. This behavior can be explained by the possibility that (1) small source terms presc it have a negligible early effect but become more important as the concentration decreases, or (2) the material determined b. Mawach analysis to be elemental iodine is actually a mixture of elemental iodine and one or more other iodine forms not absorbcd effectively by fresh sprays. Several sources were present in the CSE tests. Sprays were not initiated until 20 or $30 \mathrm{~min}$ after iodine release was completed. During this period, 50 to $75 \%$ of the iodine was deposited on structural surfaces by natural transfer processes. If these processes were reversible, some of the iodine would be released back into the gas phase after the iodine concentration in the gas phase was reduced hy spray washout. Another source of iodine is diffusion from the middle room. 
BNWL-1244

Before terminating these experiments, the liquid in the sumps was recirculated through the spray nozzles to equilibrate the gas and liquid phases. The approach to equilibrium would be similar to that described by Equation (26). The time dependency during the course of extended periods will disappear, and the equilibrium concentration will be

$$
\frac{u_{g e}}{\mathrm{C}_{\mathrm{gO}}}=\frac{1}{1+\frac{\mathrm{LH}}{V}}
$$

where

$$
\begin{aligned}
\mathrm{C}_{\text {ge }} & =\text { gas phase solute concentration at equilibrium, } \\
\mathrm{C}_{\text {go }} & =\text { gas phase solute concentration at time zero, } \\
\mathrm{L} & =\text { liquid volume, } \\
\mathrm{V} & =\text { gas volume, } \\
\mathrm{H} & =\text { equilibrium distribution coefficient. }
\end{aligned}
$$

Equation (43) is not strictly valid because it neglects irreversible reaction of the solute (iodine) with paint or other structural materials and assumes gas volume, $V$, to be constant, i.e., that the volume occupied by the spray liquid is negligible compared to that occupied by gas. About one-fourth to one-half of the iodine released into the CSE containment atmosphere reacted irreversibly with the paint (see Table 8). Thus Equation (43) could be wrong by a factor of 2 .

Partition coefficients calculated according to Equation (43) are listed in Table 36. Run A3 data are omitted because fresh water was used in that test instead of recirculated sump liquid. Partition coefficients were also calculated using Equation (4), which defines $\mathrm{H}$ as

$$
H=\frac{C_{\ell e}}{C_{g e}}
$$


where $C_{l e}$ is the concentration of all forms of the solute in the liquid at equilibrium. Values obtained by Equation (4) are also listed in Table 36. Good agreement between values of $\mathrm{H}$ calculated by the two methods is evident.

TABLE 36. Partition Coefficients for Elemental Iodine

\begin{tabular}{|c|c|c|c|c|}
\hline & Run A4 & Run A6 & Run A 7 & Run $A 8$ \\
\hline Final V/L & 100 & 60 & 70 & 80 \\
\hline $\begin{array}{l}\text { Time of } \\
\text { Sampling, min }\end{array}$ & 1300 & 1630 & 1500 & 260 \\
\hline$C_{g e}, \mu g / \ell$ & $3.0 \times 10^{-2}$ & $5.0 \times 10^{-2}$ & $8.0 \times 10^{-2}$ & $4.0 \times 10^{-1}$ \\
\hline$C_{\ell e}, \mu g / \ell$ & $5.6 \times 10^{3}$ & $4.0 \times 10^{3}$ & $3.4 \times 10^{3}$ & $5.6 \times 10^{3}$ \\
\hline$C_{g O}, \mu g / \ell$ & $5.5 \times 10^{1}$ & $1.2 \times 10^{2}$ & $1.0 \times 10^{2}$ & $1.1 \times 10^{2}$ \\
\hline $\mathrm{pH}$ & 9.5 & 9.5 & 5.0 & 9.5 \\
\hline $\mathrm{C}_{\mathrm{ge}} / \mathrm{C}_{\mathrm{go}}$ & $5 \times 10^{-4}$ & $5 \times 10^{-4}$ & $8 \times 10^{-4}$ & $3 \times 10^{-3}$ \\
\hline$H, E q(43)$ & $2 \times 10^{5}$ & $1 \times 10^{5}$ & $9 \times 10^{4}$ & $3 \times 10^{4}$ \\
\hline $\mathrm{H}, \mathrm{Eq}$ (4) & $2 \times 10^{5}$ & $8 \times 10^{4}$ & $4.0 \times 10^{4}$ & $1 \times 10^{4}$ \\
\hline $\begin{array}{l}\text { H, predicted, } \\
\text { Ref (45) }\end{array}$ & $6.7 \times 10^{3}$ & $3.2 \times 10^{5}$ & $2.5 \times 10^{1}$ & $2.3 \times 10^{5}$ \\
\hline
\end{tabular}

The partition coefficients predicted from Eggleton's(45) theory are also listed in Table 36. This theory accounts for the following chemical reactions:

$$
\begin{array}{lll}
\mathrm{I}_{2} \text { (gas-phase) } & \stackrel{\mathrm{K}_{1}}{=} \mathrm{I}_{2} \text { (aqueous) } \\
\mathrm{I}_{2}(\mathrm{aq})+\mathrm{I}^{-} & \stackrel{\mathrm{K}_{2}}{=} \mathrm{I}_{3}- \\
\mathrm{I}_{2}(\mathrm{aq})+\mathrm{H}_{2} \mathrm{O} & \stackrel{\mathrm{K}_{3}}{=} \mathrm{H}^{+}+\mathrm{I}^{-}+\mathrm{HIO} \\
\mathrm{I}_{2}(\mathrm{aq})+\mathrm{H}_{2} \mathrm{O} & \stackrel{\mathrm{K}_{4}}{=} \mathrm{H}_{2} \mathrm{OI}^{+}+\mathrm{I}^{-}
\end{array}
$$


where the K's are the equilibrium constants. The numerical values of the equilibrium constants were those suggested by Eggleton. (45) These constants were evaluated at $225^{\circ} \mathrm{F}$ by the Arrhenius extrapolation of data listed for $25{ }^{\circ} \mathrm{C}$ and $100{ }^{\circ} \mathrm{C}$.

The measured values of partition coefficient do not appear to be as dependent on the temperature and $\mathrm{pH}$ of the water as was predicted, particularly for Run A7, where boric acid at pH of 5 was found to react with $\mathrm{I}_{2}$ as well as when the solution was made basic by addition of $\mathrm{NaOH}$. This disagreement likely arises because all of the important chemical reactions observed have not been accounted for properly in the theory. The partition coefficients measured in these studies are of the order of magnitude reported in other experiments. $(6,33,39,46)$

\section{Dose Reduction Factors}

If a containment vessel leaks at a constant rate and fission products are not plated out in the leak paths, the rate of fission product emitted to the environs is directly proportional to the concentration in the contained gas.

$$
M_{L}=\int_{0}^{t} F_{L} V C_{g} d t
$$

where

$$
\begin{aligned}
M_{L} & =\text { mass leaked in time } t \\
F_{L} & =\text { fractional leak rate of contained gas, } \\
V & =\text { contained gas space volume, } \\
C_{g} & =\text { instantaneous average concentration in gas space. }
\end{aligned}
$$

The dose reduction factor ( $D R F$ ) is the ratio of mass which would leak if the concentration was invariant with time at its initial value, $C_{0}$, divided by the mass which will actually leak while the concentration is decreasing: 
BNWL -1244

$$
\operatorname{DRF}=\frac{C_{0}}{\int_{0}^{t} C_{g} d t}
$$

For cases where the gas concentration decreases exponentially as in Equation (49),

$$
C_{g}=C_{0} e^{-\lambda t}
$$

the dose reduction factor can be expressed as

$$
\mathrm{DRF}=\frac{\lambda t}{1-\mathrm{e}^{-\lambda t}}
$$

where $t$ is the time for which the reduction factor applies. However, as discussed in this report, the concentration does not decrease exponentially forever, but approaches an equilibrium at about $\mathrm{C}_{\mathrm{g}} / \mathrm{C}_{\mathrm{o}}=0.01$. Therefore, Equation (48) should be solved numerically. As an example, if $\lambda_{S}=1 \mathrm{~min}^{-1}$ until $\mathrm{C}_{\mathrm{g}} / \mathrm{C}_{\mathrm{o}}=0.01$, after which the concentration remains constant, the DRF for the initial 2-hr period would be 55 and the 24-hr DRF would be 94 . These estimates are probably low because (1) release probably would not be instantaneous and (2) the concentration would probably continue to decrease below $0.01 \mathrm{C}_{\mathrm{o}}$, as it did in the present tests.

\section{METHYL IODIDE}

Methyl iodide is only slightly soluble in water and reacts relatively slowly in solution. Thus, the transfer rate to a liquid would be controlled by mass transfer within the liquid phase. For relatively slow chemical reaction, methyl iodide absorption by wall films is highly important because of the large interfacial areas and the long exposure times as compared to spray drops. For a spray rate of $50 \mathrm{gpm}$, and with drops of 1200- $\mu$ diam, the drop surface area is calculated to be $600 \mathrm{ft}$. The wetted wall area within the main room of the CSE vessel is about 10 times this value. 
Methyl Iodide Reaction Rates

Analysis of absorption with chemical reaction shows that, for first order chemical reactions, the absorption coefficient is enhanced by a factor of

$$
\frac{k_{\ell}^{*}}{k_{\ell}}=1+k t_{e}
$$

where

$$
\begin{aligned}
\mathrm{k}_{\ell}{ }^{*}= & \text { liquid phase mass transfer coefficient with chemical } \\
& \text { reaction }
\end{aligned}
$$

for small values of $k t_{e}$. Thus, appreciable enhancement will

not occur unless $\mathrm{kt}$ is of the order of unity or larger. Estimates of the reaction rates for the solutions used in CSE were made on the basis of data tabulated in Reference (18). Evaluation of the reaction rates at a temperature of $248^{\circ} \mathrm{F}$ required extrapolation of data obtained at lower temperature and, for this reason, the pseudo-first-order reaction rates listed in Table 37 are of unknown accuracy.

\begin{tabular}{|c|c|c|c|c|}
\hline $\begin{array}{l}\text { Solution } \\
\text { Composition }\end{array}$ & $\begin{array}{l}\mathrm{k}\left(\mathrm{H}_{2} Q\right) \\
\sec \end{array}$ & $\begin{array}{l}\mathrm{k}_{(\mathrm{OH}-\mathrm{j}} \\
\mathrm{sec}\end{array}$ & $\begin{array}{l}\left.\mathrm{sec}_{2} \mathrm{Na}_{2} \mathrm{~S}_{2} \mathrm{O}_{3}\right) \\
\end{array}$ & $\begin{array}{l}\mathrm{k}(\operatorname{tot} \operatorname{ta} 1) \\
\sec \end{array}$ \\
\hline $\begin{array}{l}\mathrm{H}_{3} \mathrm{BO}_{3}+\mathrm{NaOH} \\
\mathrm{H}=9.5\end{array}$ & $3.3 \times 10^{-3}$ & $1.7 \times 10^{-5}$ & 0 & $3.3 \times 10^{-3}$ \\
\hline $\mathrm{H}_{3} \mathrm{BO}_{3}, \mathrm{pH}=5$ & $3.3 \times 10^{-5}$ & $\sim 0$ & 0 & $3.3 \times 10^{-5}$ \\
\hline $\begin{array}{l}{ }_{3} \mathrm{BO}_{3}, \mathrm{NaOH} \\
\mathrm{wt} \% \mathrm{Na}_{2} \mathrm{~S}_{2} \mathrm{O}_{3} \\
\mathrm{H}=9.5\end{array}$ & $3.3 \times 10^{-3}$ & $1.7 \times 10^{-5}$ & 4.7 & 4.7 \\
\hline
\end{tabular}

TABLE 37. Estimated Reaction Rate Constants of Spray Solutions with Methyl Iodide(a)

a. At $248^{\circ} \mathrm{F}$. 
Drop contact times in the CSE vessel are of the order of one to $10 \mathrm{sec}$. For the wall film, contact times are of the order of minutes. The data presented in Table 37 indicate that enhanced drop absorption per pass would occur only for the thiosulfate spray. For the wall film, some enhancement due to reaction would be expected for all of the spray solution listed in Table 37. A modest rate of removal of methyl iodide by reaction with the $\mathrm{H}_{2} \mathrm{O}$ molecule would be expected in long term tests because of the relatively large liquid volumes and the long times for reaction.

Removal of Methyl Iodide by Nonreactive Sprays

The first three spray periods in each run employed water without sodium thiosulfate. The reaction rate of methyl iodide with the spray solution was slow and, as a first approximation, the washout by these sprays may be considered as absorption with no chemical reaction. An upper limit to the washout rate with a nonreactive solution may be obtained by assuming that all spray liquid reaches equilibrium with the gas phase, and is then removed from the chamber. A material balance on the gas phase gives the gas phase concentration as a function of time:

$$
\frac{\mathrm{C}_{\mathrm{g}}}{\mathrm{C}_{\mathrm{gO}}}=\exp \left(-\frac{\mathrm{L}_{\mathrm{s}} \mathrm{H}}{\mathrm{V}}\right)
$$

where

$$
L_{\mathbf{s}}=\text { volume of fresh solution sprayed. }
$$

If the liquid in the pools accumulating in the bottom of spray chamber is exposed to the gas, dissolved methyl iodide would re-equilibrate with the gas phase. A lower limit of absorption by once-through nonreactive sprays may be estimated by assuming all the liquid in the vessel to be at instantaneous equilibrium with the gas phase. For this case, the gas phase concentration would be given by 
BNWL -1244

$$
\frac{\mathrm{C}_{\mathrm{g}}}{\mathrm{C}_{\mathrm{gO}}}=\frac{1}{1+\frac{(\mathrm{H}-1) \mathrm{L}_{\mathrm{s}}}{\mathrm{V}_{\mathrm{gO}}+\mathrm{HL}_{\mathrm{O}}}}
$$

where

$$
\begin{aligned}
& \mathrm{V}_{\mathrm{go}}=\text { initial containment gas volume, } \\
& \mathrm{L}_{\mathrm{O}}=\text { initial volume of liquid in containment. }
\end{aligned}
$$

The changes in methyl iodide concentration measured for fresh water sprays in the CSE vessel are compared to predictions based on Equations (52) and (53) in Table 38. The partition coefficients listed are from data reported in Reference (47).

The results shown in Table 38 demonstrate that essentially no removal of methyl iodide would be expected for nonreactive water sprays. This indication is due to the low partition. coefficient for methyl iodide in water. Most of the measured washout fractions would be close to the predicted zero where allowance is made for diffusion into the middle and lower rooms. From Maypack samples taken within these rooms, it was observed that these rooms became mixed with the main containment volume during the second spray period. The first spray period was not of sufficient duration to cause effective inter-room mixing of methyl iodide and, for simplicity, it was assumed that no mixing had occurred during the first spray period, but that mixing was complete for the second and third spray periods.

The observed concentration reduction factors are generally less than unity, thus indicating that some methyl iodide removal may be occurring. However, the rate is too slow to be determined from the measurements reported in Table 38, and it is concluded that the washout rate of methyl iodide by basic borate solution is slow. 
TABLE 38. Methyl Iodide Washout by Unreactive Water Sprays

\begin{tabular}{|c|c|c|c|c|c|c|c|c|}
\hline$\underline{\text { Run }}$ & $\begin{array}{l}\text { Spray } \\
\text { Period } \\
\end{array}$ & $\begin{array}{c}\text { Spray } \\
\text { Duration, } \\
\text { min } \\
\end{array}$ & $\begin{array}{l}\text { Liquid } \\
\text { Vol. } \\
\text { Added, } \\
\mathrm{ft}^{3} \\
\end{array}$ & $\begin{array}{c}\text { Average } \\
\text { Temp. Over } \\
\text { Spray Period, } \\
{ }_{F}\end{array}$ & $\begin{array}{c}\text { Estimated } \\
\text { Average } \\
\text { Partition } \\
\text { Coef. } \\
\end{array}$ & $\begin{array}{l}\text { Observed } \\
\text { Concen. } \\
\text { Reduction } \\
\text { Factor } \\
\end{array}$ & $\begin{array}{c}\text { Predicted } \\
\mathrm{C}_{\mathrm{Eg}}{ }_{\mathrm{C}}^{\mathrm{C}_{\mathrm{gg}}(52)} \\
\end{array}$ & 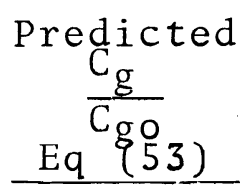 \\
\hline A 3 & 1 & 10 & 17.1 & 76 & 4.0 & 0.95 & 1.00 & 1.00 \\
\hline A 3 & 2 & 30 & 51.4 & 76 & 4.0 & $1.00^{(a)}$ & 0.99 & 0.99 \\
\hline A 3 & 3 & 60 & 103 & 76 & 4.0 & 0.75 & 0.98 & 0.99 \\
\hline A 4 & 1 & 10 & 65.3 & 78 & 4.0 & 0.92 & 0.99 & 0.99 \\
\hline A 4 & 2 & 30 & 196 & 78 & 4.0 & $1.14^{(\mathrm{a})}$ & 0.96 & 0.98 \\
\hline A4 & 3 & 45 & 0 & 78 & 4.0 & 1.09 & 1.00 & 1.00 \\
\hline A 6 & 1 & 10 & 65.5 & 243 & 1.1 & $1.00 \mathrm{(a)}$ & 1.00 & 1.00 \\
\hline A6 & 2 & 30 & 197 & 213 & 1.1 & 1.03 & 0.99 & 1.00 \\
\hline A 6 & 3 & 30 & 0 & 240 & 1.1 & 1.10 & 1.00 & 1.00 \\
\hline A7 & 1 & 10 & 65.5 & 243 & 1.1 & 1.00 & 1.00 & 1.00 \\
\hline A 7 & 2 & 30 & 197 & 213 & 1.1 & $0.92^{(a)}$ & 0.99 & 1.00 \\
\hline 07 & 3 & NO & 0 & 239 & 11 & 098 & 100 & 100 \\
\hline A 8 & 1 & 3 & 203 & 247 & 11 & $09 Z$ & 100 & 100 \\
\hline A 8 & 2 & 37 & 250 & 219 & 1.2 & 1.01 & 0.99 & 1.00 \\
\hline A 8 & 3 & 60 & 0 & 218 & 1.2 & 0.82 & 1.00 & 1.00 \\
\hline
\end{tabular}

a. observed concentration reduction factor divided by 0.80 to account for mixing in middle and lower rooms. 
Removal of Methyl Iodide by Reactive Sprays

In Runs A7 and A8, sprays of 1 wt $\frac{0}{0}$ sodium thiosulfate were included near the end of the experiments to assess the washout of methyl iodide by a reactive spray. Fresh spray solution was used for the entire 50-min spray periods. The temperature decreased appreciably over the duration of the run and, since the calculated reaction rates are highly dependent on temperature, a stepwise estimation of the cumulative washout was carried out. Temperatures, calculated reaction rates, and estimated partition coefficients at 10-min intervals are listed in Table 39.

\section{TABLE 39. Estimated Reaction Rates and Partition Coefficients for Thiosulfate Sprays}

\begin{tabular}{|c|c|c|c|c|c|c|}
\hline \multirow{2}{*}{$\begin{array}{l}\text { Time from } \\
\text { Beginning } \\
\text { of Spray, } \\
\text { min } \\
\end{array}$} & \multicolumn{2}{|c|}{ Temperature, ${ }^{\circ} \mathrm{F}$} & \multicolumn{2}{|c|}{$\begin{array}{c}\text { Reaction Rate (a) } \\
\text { sec }^{-1}\end{array}$} & \multicolumn{2}{|c|}{$\begin{array}{l}\text { Partition(b) } \\
\text { Coefficient }\end{array}$} \\
\hline & Run $A 7$ & Run A8 & Run A7 & Run A8 & Run A7 & Run $A 8$ \\
\hline 0 & 232 & 245 & 2.69 & 4.42 & 1.10 & 1.09 \\
\hline 10 & 221.5 & 228 & 1.91 & 2.30 & 1.12 & 1.11 \\
\hline 20 & 211 & 212 & 1.28 & 1.28 & 1.13 & 1.13 \\
\hline 30 & 202 & 197 & 0.904 & 0.729 & 1.16 & 1.18 \\
\hline 40 & 193.5 & 184 & 0.628 & 0.418 & 1.19 & 1.24 \\
\hline 50 & 187 & 174.5 & 0.468 & 0.278 & 1.23 & 1.30 \\
\hline
\end{tabular}

a. Estimated from data reviewed in Reference (18). b. Estimated from data presented in Reference (47).

The effective average temperature for washout of methyl iodide by the thiosulfate sprays was $210^{\circ} \mathrm{F}$ for Run $\mathrm{A} 7$ and $212^{\circ} \mathrm{F}$ for Run A8. The washout rate was calculated for these average temperatures by simple models for drops and wall films. For the drops, calculation of absorption assumed that the drops fell at terminal velocity for the entire fall height, that the 
drops were at all times well mixed, and that the mass median diameter adequately represented the drop size distribution. The mass transfer coefficient for this model is given by:

$$
\left(\mathrm{k}_{\mathrm{g}} \mathrm{A}\right)_{\mathrm{drops}}=\mathrm{FH}\left(1+\mathrm{kt} \mathrm{e}_{\mathrm{e}}\right) .
$$

This expression will likely overestimate drop absorption but, since drop absorption does not appear to govern the overall absorption rate, this overestimate is not of great practical importance.

The wall film was assumed to be laminar, of uniform thickness, and that all surfaces within the upper room of the containment vessel were wet by a film similar to that calculated for the cylindrical walls of the vessel. Inlet effects related to film absorption were neglected. For this simple model, the mass transfer coefficient, for a film of thickness 6 , is:

$$
\left(\mathrm{k}_{\mathrm{g}}^{\mathrm{A}}\right)_{\text {wa11 }}=\mathrm{A}_{\mathrm{W}}\left[\mathrm{H} \sqrt{\mathrm{kD}_{\ell}} \tanh \left(\sqrt{\frac{\mathrm{k}}{\mathrm{D}_{\ell}}} \delta\right)\right] \text {. }
$$

The film thickness, 6, was predicted from the measured liquid flow rate on the vertical cylindrical walls of the vessel. The simple laminar flow theory of Nusselt ${ }^{(48)}$ gives for the film thickness:

$$
\delta=\left(\frac{3 \Gamma v}{g}\right)^{1 / 3}
$$

where

$$
\begin{aligned}
& \Gamma=\text { volumetric rate of flow per unit width of wall, and } \\
& \nu=\text { kinematic viscosity of liquid. }
\end{aligned}
$$

The methyl iodide absorption rates predicted for the drop and wall film models described in the foregoing are compared to the measured washout rates in Table 40 . 
TABLE 40. Methyl Iodide Absorption by Thiosulfate Sprays in CSE

\begin{tabular}{|c|c|c|c|c|c|c|}
\hline$\underline{\text { Run }}$ & $\begin{array}{l}\text { Drop } \\
\text { Flow } \\
\text { Rate, } \\
\text { gas } / \mathrm{min}\end{array}$ & $\begin{array}{l}\text { Predicted } \\
t_{1 / 2 \text { for }} \\
\text { Drops, } \\
\text { min }\end{array}$ & $\begin{array}{c}\text { Wall Film } \\
\text { Flow } \\
\text { Rate, } \\
\text { gal/min }\end{array}$ & $\begin{array}{l}\text { Predicted } \\
\mathrm{t}_{1} / 2 \text { for } \\
\text { Whi1 Film, } \\
\text { min }\end{array}$ & $\begin{array}{c}\text { Predicted } \\
\text { Overall } \\
t_{1 / 2}, \\
\text { min }\end{array}$ & $\begin{array}{c}\text { Measured } \\
\text { Washout } \\
t_{1 / 2}, \\
\text { min } \\
\end{array}$ \\
\hline 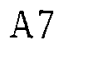 & 47.2 & 520 & 1.7 & 200 & 145 & 130 \\
\hline$A 8$ & 47.5 & 340 & 3.0 & 180 & 133 & 130 \\
\hline
\end{tabular}

The data presented in Table 40 show the predicted washout halftime to be in good agreement with the measured values. Also, the calculations indicate that the wall film absorption is relatively more important than absorption by drops, for methyl iodide. This indication is expected, since wetted wall areas expose about $6000 \mathrm{ft}^{2}$ of interface as compared to $600 \mathrm{ft}^{2}$ of interfacial area calculated for the falling drops. This large contribution by the wall film would occur only for absorption in which liquid resistance dominates. For gas phase limited transfer, drop absorption would be controlling due to the much higher gas phase mass transfer coefficient to falling drops, compared to the wall surfaces.

The observed washout rates shown in Table 40 are in agreement with the washout rate predicted on the basis of smaller scale spray studies using hydrazene in place of sodium thiosulfate. (18)

\section{AEROSOL PARTICLES}

Aerosol particles may be captured by surfaces within a containment vessel or by spray drops during a spray period. In this report, we will estimate the washout due to drops alone and compare this estimated washout with that obtained experimentally. The experimental washout rates were obtained by subtracting from the total washout rate the average of the washout rates due to natural processes before and after the spray period. 
The target efficiencies for Brownian diffusion, inertial impaction, interception, and diffusiophoresis were calculated for drops of diameter 500, 1000, and $2000 \mu$ using the methods discussed in the theory section of this report (Equation 28 through 34). An example of these calculations is shown in Figure 62 where the equivalent target efficiency is shown for particle sizes ranging in diameter from 0.001 to $10 \mu$. These calculations were made for a steam-air atmosphere at $250{ }^{\circ} \mathrm{F}$ saturated with air initially at a partial pressure of 0.97 atm and at $80^{\circ} \mathrm{F}$. Spray inlet temperature of $120^{\circ} \mathrm{F}$ and a fall height of $33.8 \mathrm{ft}$ were assumed. The result for unit density spheres is shown in Figure 62.

Particle density enters only for the impaction mechanism. Hence, the calculation for unit density spheres would apply for more dense particles with a density correction for inertial impaction.

Particle sizes were measured by means of a cascade impactor. Since the impactor measures aerodynamic diameter, a density must be used to calculate geometrical sizes. For cesium, a density of unity was assumed since the cesium particles would likely be present as solution droplets. For uranium, a density of $7.2 \mathrm{~g} / \mathrm{cm}^{3}$, the same as for oxide $\mathrm{U}_{3} \mathrm{O}_{8}$, was assumed. This is probably higher than the actual density because uranium oxide aerosol particles consist of agglomerated smaller particles. The predicted and measured washout rates are compared for cesium in Table 41 and for uranium in Table 42.

Comparison of the predicted and measured washout rates shows the measured particle removal rate to be significantly larger than the predicted washout rate. This larger than predicted removal rate implies that either (1) one of the capture mechanisms has been underestimated, or (2) incorrect particle size data was used. The most likely explanation is that 


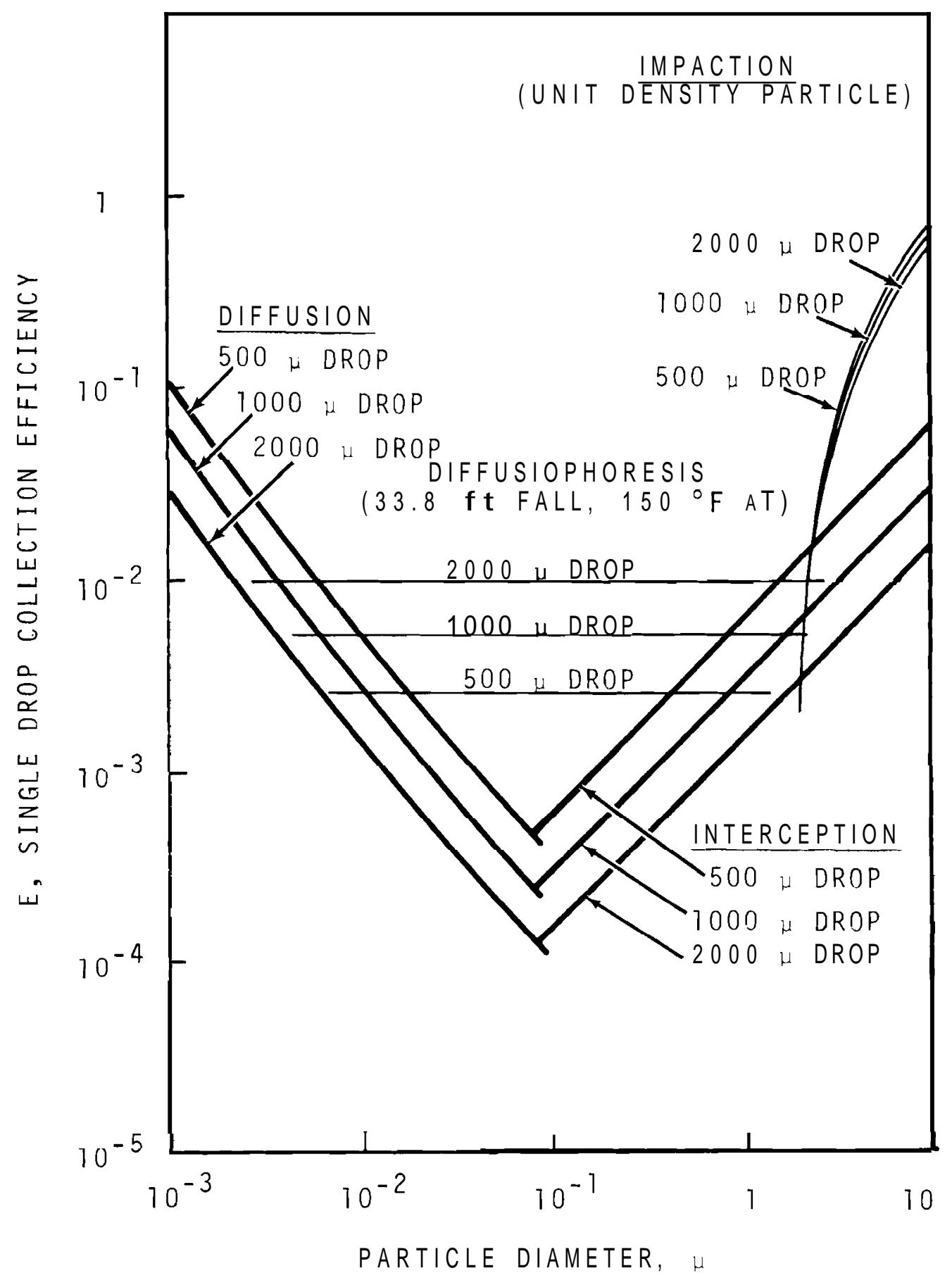

FIGURE 62. Predicted Particle Collection Efficiency fcr Falling Drops 
TABLE 41. Washout of Cesium Particles by CSE Sprays

\begin{tabular}{|c|c|c|c|c|c|c|c|c|}
\hline Run & $\begin{array}{l}\text { Nominal } \\
\text { Temp, }{ }^{2} \mathrm{~F} \\
\end{array}$ & $\begin{array}{l}\text { Spray } \\
\text { Period }\end{array}$ & $\begin{array}{l}\text { MMD } \\
\text { P a rti c le } \\
\text { Diam, } \mu \\
\end{array}$ & $\begin{array}{c}\text { MMD } \\
\text { Spray, } \mu \\
\end{array}$ & $\begin{array}{l}\text { Measured } \\
t_{1 / 2}, \min \end{array}$ & $\begin{array}{c}\text { Target Effect } \\
\text { from Measured } \\
\text { Washout }\end{array}$ & $\begin{array}{c}\text { Target } \\
\text { Effect } \\
\text { Predicted } \\
\end{array}$ & $\begin{array}{c}t_{1 / 2}, \min \\
\text { Washout } \\
\text { from Predicted } \\
\text { Target Effect }\end{array}$ \\
\hline \multirow[t]{2}{*}{ A4 } & 80 & 1 & 0.9 & 1200 & 3.5 & 0.0445 & 0.0023 & 67.7 \\
\hline & & 2 & 0.5 & 1200 & 9.3 & 0.0168 & 0.0013 & 120 \\
\hline \multirow[t]{2}{*}{ A 6} & 250 & 1 & 0.4 & 1200 & 5.6 & 0.0277 & 0.0072 & 21.5 \\
\hline & & 2 & 0.4 & 1200 & 13 & 0.0119 & 0.0072 & 21.5 \\
\hline \multirow[t]{2}{*}{ A 7} & 250 & 1 & 2.0 & 1200 & 3.8 & 0.0408 & 0.011 & 14.1 \\
\hline & & 2 & 0.4 & 1200 & 10.2 & 0.0152 & 0.0072 & 21.5 \\
\hline \multirow[t]{2}{*}{ A8 } & 250 & 1 & 0.5 & 770 & 2.6 & 0.0387 & 0.0057 & 17.7 \\
\hline & & 2 & 0.6 & 770 & 14 & 0.00718 & 0.0061 & 16.5 \\
\hline
\end{tabular}

TABLE 42. Washout of Uranium Oxide Aerosol by CSE Sprays

\begin{tabular}{|c|c|c|c|c|c|c|c|c|c|}
\hline$\underline{\text { Run }}$ & $\begin{array}{l}\text { Nominal } \\
\text { Temp, }{ }^{\circ} \mathrm{F}\end{array}$ & $\begin{array}{l}\text { Spray } \\
\text { Period }\end{array}$ & $\begin{array}{c}\text { MMD } \\
\text { P a r t i c le } \\
\text { Diam, } \mu\end{array}$ & $\begin{array}{r}\text { MMD } \\
\text { Spray, }\end{array}$ & $\mu$ & $\begin{array}{l}\text { Measured } \\
t_{1 / 2}, \mathrm{~min}\end{array}$ & $\begin{array}{c}\text { Target Effect } \\
\text { from Measured } \\
\text { Washout }\end{array}$ & $\begin{array}{c}\text { Target } \\
\text { Effect } \\
\text { Predicted }\end{array}$ & $\begin{array}{c}t_{1 / 2}, \text { min } \\
\text { Washout } \\
\text { from Predicted } \\
\text { Target Effect }\end{array}$ \\
\hline \multirow[t]{2}{*}{ A4 } & 80 & 1 & 0.64 & 1200 & & 5.5 & 0.0284 & 0.002 & 78.2 \\
\hline & & 2 & 0.25 & 1200 & & 13.5 & 0.0115 & 0.0008 & 195 \\
\hline \multirow[t]{2}{*}{ A 6} & 250 & 1 & 0.37 & 1200 & & 7.8 & 0.0199 & 0.0072 & 21.5 \\
\hline & & 2 & 0.33 & 1200 & & 12.5 & 0.0124 & 0.0069 & 22.5 \\
\hline \multirow[t]{2}{*}{ A 7} & 250 & 1 & 0.67 & 1200 & & 5.0 & 0.0310 & 0.0079 & 19.6 \\
\hline & & 2 & 0.22 & 1200 & & 9.0 & 0.0172 & 0.0067 & 23.1 \\
\hline \multirow[t]{2}{*}{ A 8} & 250 & 1 & 0.29 & 770 & & 6.6 & 0.0152 & 0.0046 & 21.9 \\
\hline & & 2 & 0.33 & 770 & & 14.0 & 0.0072 & 0.0046 & 21.9 \\
\hline
\end{tabular}


BNWL -1244

inertial impaction has been underestimated. This mechanism would account for the observed washout for particle diameters of 2-4 $\mu$. Since appreciable pressure changes occur within a cascade impactor, it is possible that evaporation of water from the sampled particles reduced their size.

The theoretical calculations indicate that diffusiophoresis acts as a removal mechanism of importance for particles of any size. For the fresh spray periods of Runs A6, 7, and 8, calculations indicate that a minimum particle washout half-time of about $30 \mathrm{~min}$ for $50 \mathrm{gpm}$ spray flow would be maintained. All of the measured removal rates exceed that expected for diffusiophoresis alone.

Because the washout rate (and therefore the concentration in the gas space) of particles is very dependent on the particle size distribution, behavior of particulate matter after a LOCA in a large power reactor cannot be confidently predicted unless the particle size is accurately known. However, assuming the particles in the present experiments to be typical of those present in the postaccident containment atmosphere, a 2-hr dose reduction factor (DRF) of 20 for cesium and about 10 for uranium could be expected. 
BNWL -1244

\section{ACKNOWLEDGEMENTS}

Successful performance of these large-scale experiments would not have been possible without the coordinated teamwork of the entire staff of the Reactor Safeguards Experiments Section. The authors wish to acknowledge that much of the hard work was done by many individuals whose names do not appear but whose cooperation was invaluable. The authors also acknowledge the guidance and consultations which helped in planning the experiments. Special thanks are due Dr. J. G. Knudsen, Oregon State University; Tom H. Row, Oak Ridge National Laboratory; and our sponsor, the Research and Development Branch-Nuclear Safety, Reactor Development and Technology, U.S. Atomic Energy Commission. D. H. Stevens, Douglas United Nuclear, Inc., correlated the data reported for heat transfer. 


\section{NOMENCLATURE}

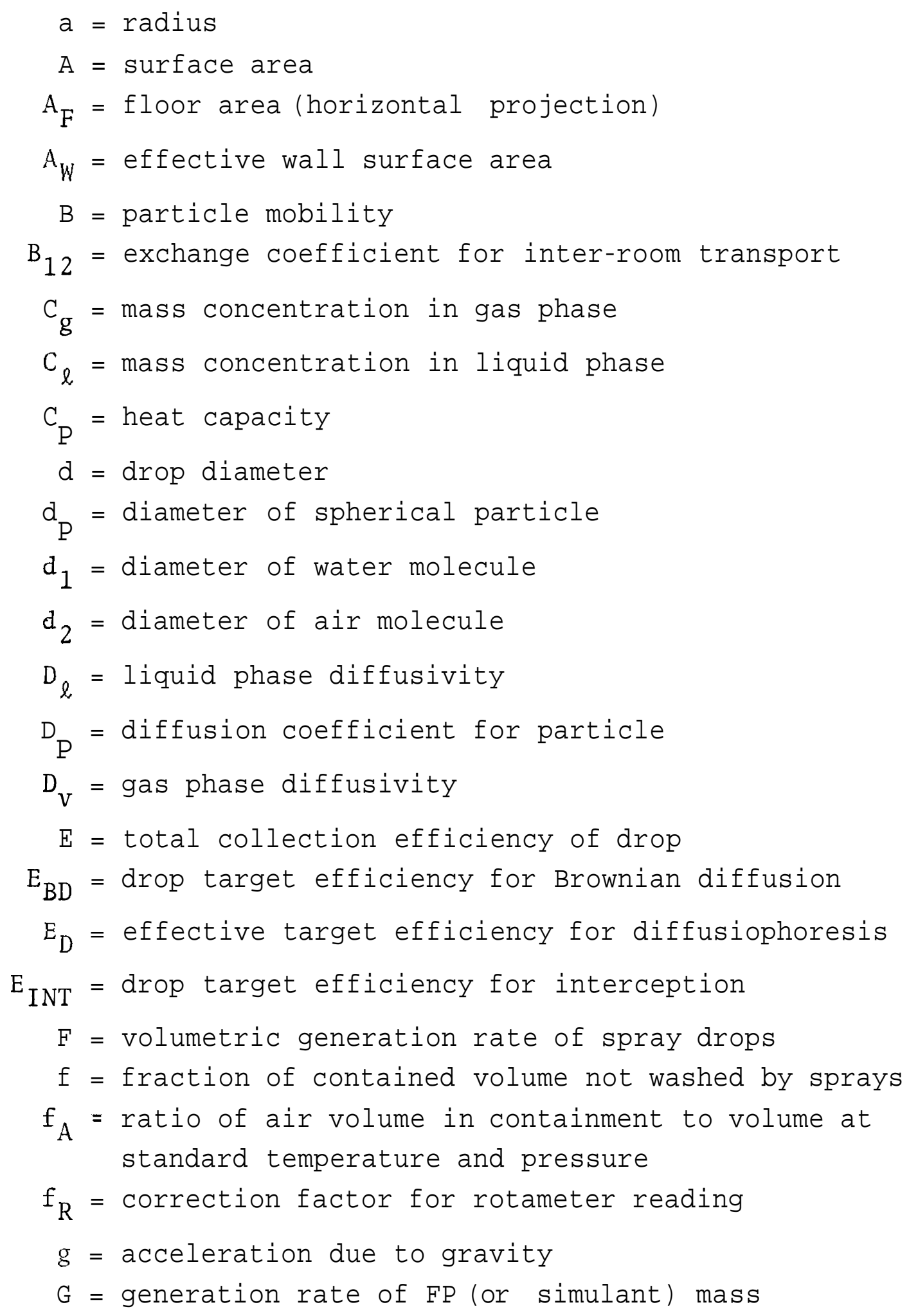




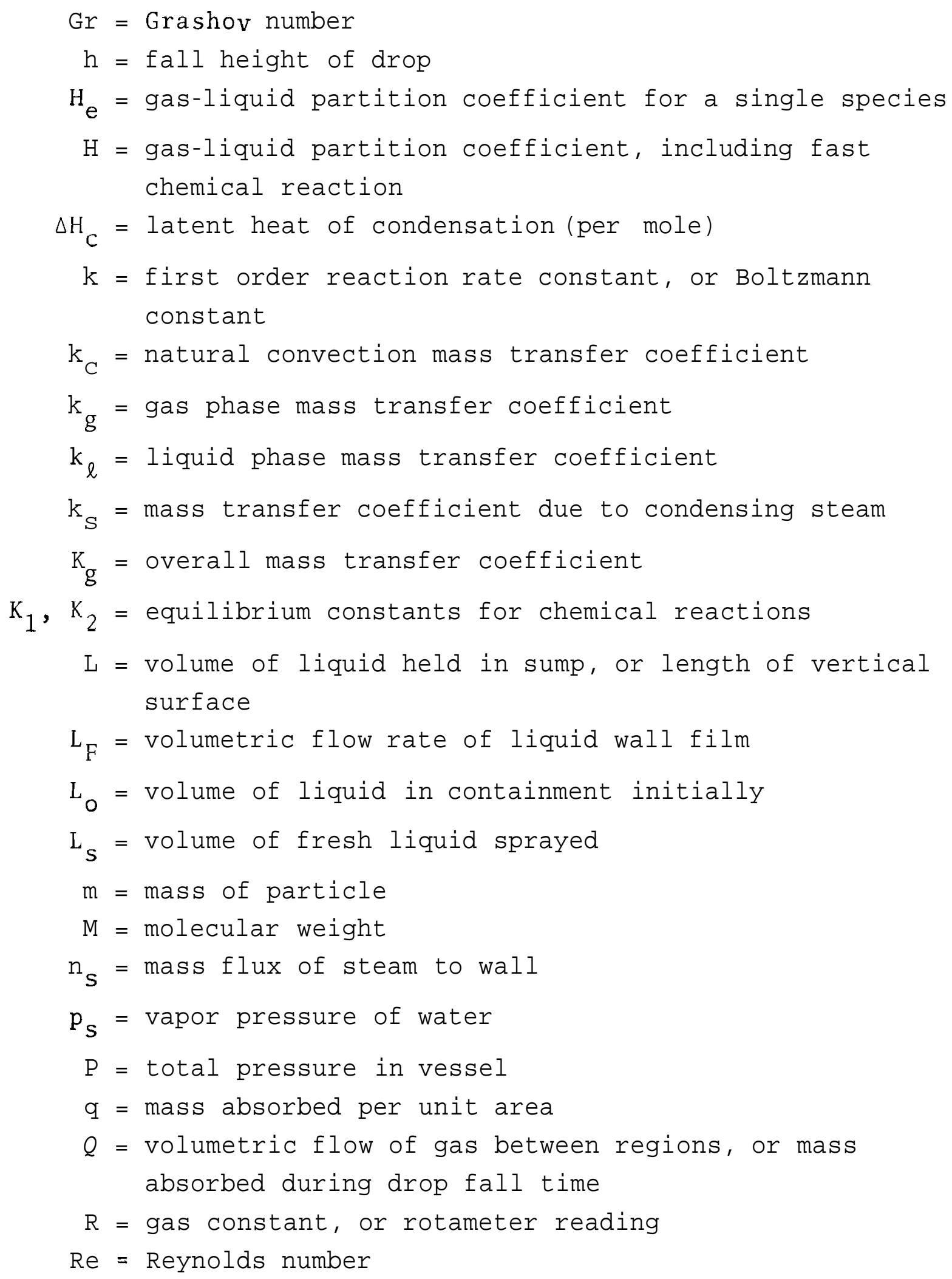




$$
\begin{aligned}
{ }_{\mathrm{G}} & =\text { gas phase reaction rate } \\
\mathrm{SC} & =\text { Schmidt number } \\
t & =\text { time } \\
t_{\mathrm{e}} & =\text { exposure time of drops to atmosphere } \\
t_{\mathrm{S}} & =\text { sample duration time } \\
t_{1 / 2} & =\text { concentration half-life } \\
\mathrm{T} & =\text { absolute temperature } \\
\mathrm{AT} & =\text { temperature difference } \\
\mathrm{u}_{\mathrm{max}} & =\text { gas velocity at gas-liquid interface } \\
\mathrm{V}_{\mathrm{g}} & =\text { terminal settling velocity of drop or particle } \\
\mathrm{v}_{\mathrm{S}} & =\text { gas sample volume (containment conditions) } \\
\mathrm{v}_{\mathrm{W}} & =\text { wall deposition velocity for particle } \\
\mathrm{V} & =\text { free gas volume in containment vessel } \\
\mathrm{V}_{\mathrm{g}} & =\text { initial containment gas volume } \\
\mathrm{V}_{W F} & =\text { volume of liquid held up on wall as film } \\
\mathbf{x} & =\text { distance from surface of film } \\
\mathrm{y} & =\text { distance measured along film }
\end{aligned}
$$

\section{GREEK SYMBOLS}

$$
\begin{aligned}
\gamma_{1} & =\text { mole fraction of water vapor } \\
\gamma_{2} & =\text { mole fraction of air } \\
\Gamma & =\text { wall flow rate per unit width of perimeter } \\
\delta & =\text { film thickness } \\
X & =\text { first order removal rate constant } \\
\lambda_{\mathrm{N}} & =\text { removal rate constant due to natural processes } \\
& =\text { removal rate constant due to spray drops } \\
\mathrm{v} & =\text { kinematic viscosity } \\
\rho & =\text { density } \\
\mathrm{a}_{12} & =\text { slip factor }
\end{aligned}
$$




\section{SUBSCRIPTS}

$$
\begin{aligned}
& \mathrm{b}=\mathrm{bulk} \text { phase } \\
& \mathrm{g}=\text { gas phase } \\
& \mathbf{i}=\text { interface or species type } \\
& \ell=\text { liquid phase } \\
& \mathrm{o}=\text { initial condition } \\
& 2=\text { second chamber }
\end{aligned}
$$


BNWL -1244

\section{REFERENCES}

1. H. N. Culver. "Effect of Engineered Safeguards on Reactor Siting," Nuclear Safety, vol. 7, no. 3, p. 342. Spring, 1966.

2. Code of Federal Regulations, Title 10, Part 100, Reactor Site Criteria. Federal Register, vol. 26, no. 28, p. 1224.

3. T. H. Row. Spray and Pool Absorption TechnoZogy Program, ORNL-4360. Oak Ridge National Laboratory, Oak Ridge, Tennessee, April, 1969.

4. V. Griffiths. The Removal of Iodine from the Atmosphere by Sprays, AHSB(S)R45. UKAEA, Authority and Safety Branch, Risley, Lanes, England, January, 1963.

5. T. K. Sherwood and R. L. Pigford. Absorption and Extraction. MeGraw-Hizl Book Co.., New York, 1952. 2nd ed.., p. 54.

6. J. G. Knudsen and R. K. HiZZiard. Fission Product Transport by Natural Processes in Containment Vessels, BNWL-943. BatteZZe-Northwest, Richland, Washington, January, 1969.

7. Staff of BatteZZe-Northwest. Nuclear Safety Quarterly Report for November, December, 1967, January, 1968, BNWL-816, pp. 2.41-2.46. Battelle-Northwest, Richland, Washington. September, 1968.

8. G. M. Watson, R. B. Perez and M. H. Fontana. Effects of Containment Size on Fission Product Behavior, ORNL-4033. Oak Ridge National Laboratory, Oak Ridge, Tennessee, January, 1967.

9. T. K. Sherwood and R. L. Pigford. Absorption and Extraction. McGraw-Hizl Book Co., New York, 1952. 2nd ed., $\overline{p .2} 70$.

10. W. E. Ranz and W. R. Marshall, Jr. "Evaporation from Drops, Part I and II," Chem. Eng. Progr., vol. 48, pp. 141-146 and pp. 173-180. 1952.

11. R. B. Bird, W. E. Stewart and E. L. Lightfoot. Transport Phenomena. John Wiley \& Sons, Inc., New York, 1960. pp. 674-675.

12. L. F. Parsly and J. K. Franzreb. Removal of Iodine Vapor from Air and Steam-Air Atmospheres in the Nuclear Safety Pilot Plant bu Use of Soraus, ORNL-4253. Oak Ridge

National Laboratory, Oak Ridge, Tennessee, June, 1968. 
13. P. V. Dankwerts. "Absorption by Simultaneous Diffusion and ChemicaZ Reaction into Particles of Various Shapes and into Falzing Drops," Trans. Faraday Soc., vol. 47, pp. 1014-1023. 1951 .

14. G. L. Constan and S. Calvert. "Mass Transfer in Drops Under Conditions that Promote oscizzation and Internal Circulation," AIChE J., vol. 9, pp. 109-115. 1963.

15. F. H. Garner and J. J. Lane. "Mass Transfer to Drops of Liquid Suspended in a Gas Stream, Part II. Experimental Work and Results," Trans. Inst. Chem. Engrs., vol. 37, pp. 162-172. 1959.

16. F. H. Garner and P. J. Haycock. "Circulation in Liquid Drops," Proc. Royal Soc., vol. 252A, pp. 457-475. 1959.

17. R. Kronig and J. C. Brink. "On the Theory of Extraction from Falling Droplets," Appl. Sci. Res., vol. A2, pp. 142154. 1949.

18. L. C. Schwendiman, R. A. Hasty and A. K. Postma. The Washout of Methyl Iodide by Hydrazine Sprays. Final Report, BNWL-935. BattelZe-Northwest, Richland, Washington, November, 1968.

19. P. V. Dankwerts. "Absorption by SimuZtaneous Diffusion and ChemicaZ Reactions," Trans. Faraday Soc., vol. 46, pp. 300-304. 1950 .

20. J. M. Genco et al. Fission Product Deposition and Its Enhancement Under Reactor Accident Conditions, BMI-1865. BattelZe Memorial Institute, Columbus, Ohio, May, 1969.

21. G. D. Fulford. Advances in ChemicaZ Engineering. Academic Press, New York, 1964. vol. 5, pp. 151-236.

22. N. A. Fuchs. The Mechanics of Aerosols. The Macmizzan Co., New York, 1964. p. 181.

23. N. A. Fuchs. The Mechanics of Aerosols. The Macmizzan Co., New York, 1964. pp. 159-170.

24. W. E. Ranz and J. B. Wong. "Impaction of Dust and Smoke Particles on Surface and Body Colzectors," Ind. Eng. Chem. vol. 44, pp. 1371-1381. 1952. 
25. L. WaZdmann and K. H. Schmitt. "Thermophoresis and Diffusiophoresis of Aerosols," Aerosol Science, edited by C. N. Davies. Academic Press, London, 1966. pp. 137-162.

26. T. W. Horst. A Review of Particle Transport in a Condensing Steam Environment. BNWL-848. Battelle-Northwest. RichZand, Washington, June, 1968.

27. W. B. Cottrezz et al. ORNL Nuclear Safety Research and Development Program Bimonthly Report for May-June, 2968, ORNL-TM-2283, pp. 33-37. Oak Ridge National Laboratory, Oak Ridge, Tennessee, Juzy, 1968.

28. H. F. Kraemer and H. F. Johnstone. "ColZection of Aerosol Particles in Presence of Electrostatic Fields," Ind. Eng. Chem., vol. 47, pp. 2426-2434. 1955.

29. D. L. Morrison and S. J. Basham. An Evaluation of the Applicabizity of Existing Data to the Analytical Description of a Nuclear Reactor Accident, BMI-1810, pp. 29-39. Battelze Memorial Institute, Columbus, Ohio, July, 1967.

30. Staff of BatteZZe-Northwest. NucZear Safety Quarterly Report for November, December, 1967, January, 1968, BNWL-816, pp. 2.30-2.33. BattelZe-Northwest, RichZand, Washington, September, 2968.

31. L. F. Coleman. Preparation, Generation and Analysis of Gases and Aerosols for the Containment Systems Experiment, BNWL-1001. Battelle-Northwest, RichZand, Washington, Apriz, 1969.

32. J. D. MeCormack. Maypack Behavior in the Containment Systems Experiment, A Penetrating Analysis, BNWL-1145. BattelZe-Northwest, RichZand, Washington, September, 1969.

33. R. K. Hizziard, L. F. CoZeman and J. D. McCormack. Comparisons of the Containment Behavior of a Simulant with Fission Products Released from Irradiated UO 2, BNWL-581. BattelZe-Northwest, RichZand, Washington, March. 1968

34. B. F. Roberts et aZ. Evaluation of Various Methods of Fission Product Aerosol Simulation, ORNL-TM-2628. Oak Ridge National Laboratory, Oak Riage, Tennessee, September, 1969.

35. N. P. Wizburn and L. D. Coffin. "Combination of On-Line Anazysis with Colzection of Multicomponent Spectrain an On-Line Computer," IBM J. Res. Dev., vol. 13, pp. 46-51. 1969. 
36. L. D. Coffin. On-Line Computer Storage and Retrieval of Processed Gamma Spectra Data, BNWL-506. BattelZeNorthwest, Richland, Washington, July, 1967.

37. J. M. Genco et aZ. Fission Product Deposition and Its Enhancement Under Reactor Accident Conditions, BMI-X-10229. Battelle Memorial Institute, Columbus, Ohio, Apriz, 1968.

38. Staff of BatteZZe-Northwest. NucZear Safety Quarterly Report for November-December, 1968, January, 1969, BNWL-1009, pp. 2.23-2.27. Battelle-Northwest, RichZand, Washington, March, 1969.

39. Staff of BatteZZe-Northwest. NucZear Safety Quarterly Report for JuZy-October, 1967, BNWL-754, pp. 2.5-2.7. Battelze-Northwest, RichZand, Washington, June, 1968.

40. D. L. Morrison, W. A. Carbiener and R. L. Ritzman. An Evaluation of the Applicability of Existing Data to the Analytical Description of a Nuclear-Reactor Accident, BMI-1850, pp. 39-43. Battelze Memorial Institute, Columbus, Ohio, October, 1968.

41. W. B. CottreZ2. NucZear Safety Program Annual Progress Report for Period Ending December 31, 1968, ORNL-4374, p. 28. Oak Ridge National Laboratory, Oak Ridge, Tennessee, June, 1969.

42. W. A. Freeby et al. Fission Product Behavior Under SimuZated Loss-of-CooZant Accident Conditions in the Contamination-Decontamination Experiment, IN-1171. Idaho NucZear Corp., Idaho FaZzs, Idaho, January, 2969.

43 J. G. Knudsen and D. L. Katz. FZuid Dynamics and Heat Transfer. McGraw-Hilz Book Co., Inc., New York, 1958. Chapter 11 .

44. R. A. Mugele and H. D. Evans. "Droplet Size Distribution in Sprays," Ind. Eng. Chem., vol. 43, p. 1318. 1951.

45. A. E. J. EggZeton. A Theoretical Examination of IodineWater Partition Coefficients, AERE-R-4887. UKAEA, Atomic Energy Research EstabZishment. Harwe ZZ, Berks, EngZand, February, 1967.

46. L. C. Watson, A. K. Bancroft and C. W. Hoelke. Iodine Containment by Dousing in NPD-11, CRCE-979. Atomic Energy of Canada, Ltd., Chalk River, Ontario, October, 1960. 
47. A. K. Postma. Absorption of Methyl Iodide by Aqueous Hydrazine Solutions Within Spray Chambers, Ph. D. Thes is in Chem Eng., Oregon State University, Corvalzis, Oregon. 1969. (In Preparation)

48. G. D. Fulford. Advances in Chemical Engineering. Academic Press, New York, 1964 . vol. 5, p. 157. 
BNWL -1244

\section{AP P ENDIX}

\section{FACILITY DESCRIPTION}

\section{CONTAINMENT VESSEL}

The containment vessel is in actuality three integral vessels; an outer vessel termed the containment vessel, an inner vessel termed the drywe11, and a compartmented section between the outer surface of the drywell and the inside surface of the containment vessel termed the wetwells. The significant features of the containment systems vessels are shown in Figure A-1. All three of the components were designed, fabricated, and tested in accordance with the ASME Unfired Pressure Vessel Code, Section VIII, 1962 Edition. For the spray studies, only the containment vessel and drywell were used. The wetwells were sealed off from the other two vessels by the installation of blinds on the various ports and nozzles. The reactor simulator vessel was not installed and the lid of the drywell was upright, in the open position.

The $66 \mathrm{ft}-8 \mathrm{in}$. high and $25 \mathrm{ft}$ diam carbon steel containment vessel was designed for maximum operating condition of 75 psig and $320^{\circ} \mathrm{F}$. The carbon steel plate, SA 212-B, ranged in thickness from $0.75 \mathrm{in.}$ for the heads, and $0.672 \mathrm{in.}$ for the bottom shell quarter down to 0.645 in. for the upper three quarters of the shell. The vessel is located in a concrete cell within a large building. Approximately half of the vessel extends above the cell.

The drywe11 was designed for a maximum pressure of $150 \mathrm{psig}$ and a temperature of $330^{\circ} \mathrm{F}$. The vessel is $25 \mathrm{ft}$ high and $11 \mathrm{ft}$ in diameter. The heads are standard ASME ellipsoidal 2:1 dished heads with a 0.688-in. minimum thickness. The shell is a minimum of 0.669 in. thick. The top head is hinged to provide access for other large equipment pieces. 
BNWL - 1244

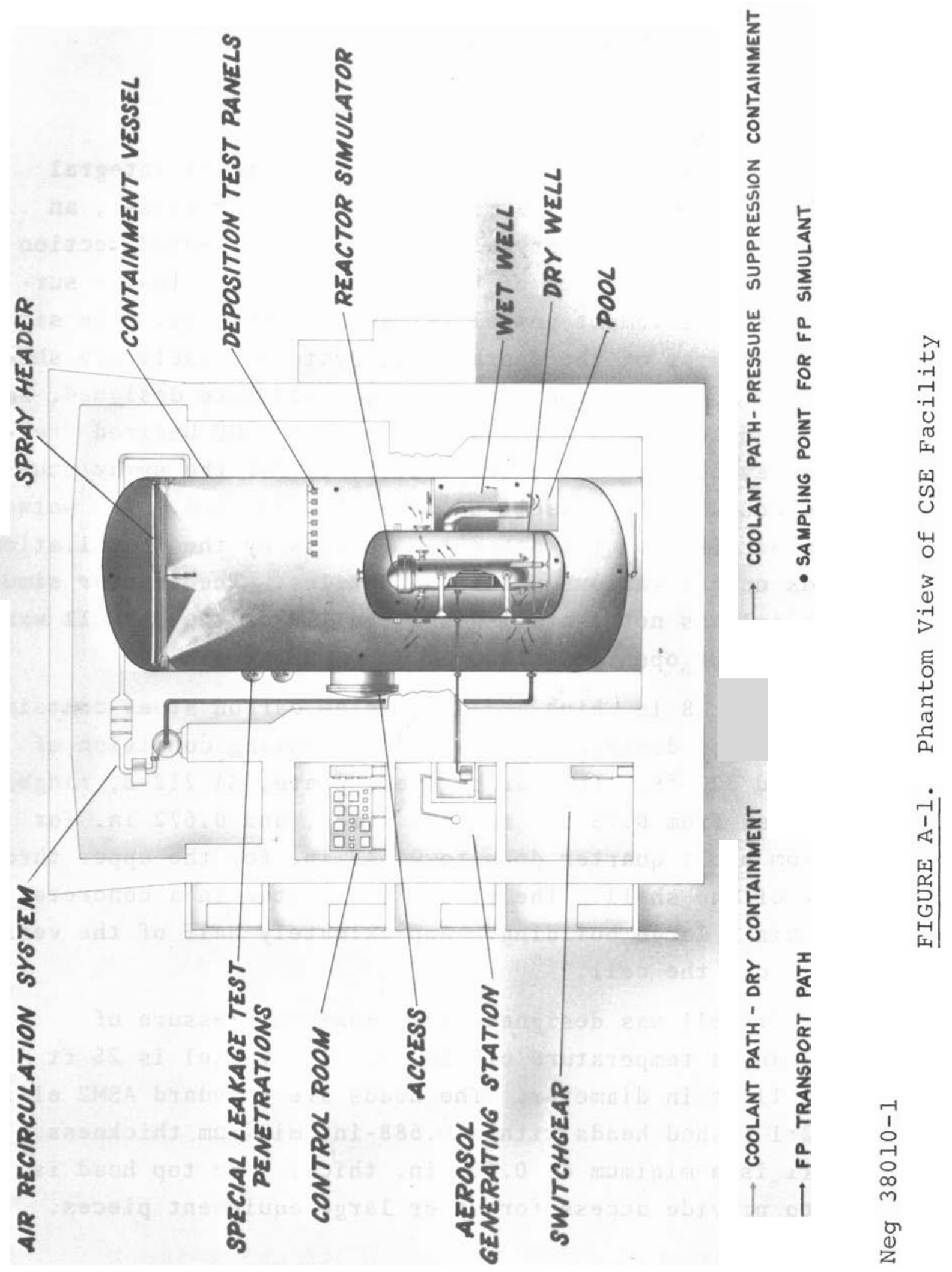


For these spray experiments, the drywell lid was open for aerosol dispersion and to obtain maximum fall distance for the spray. The contained gas volume for the containment vessel and drywel1 is $26,477 \mathrm{ft}^{3}$ (excluding the wetwells).

All vessel surfaces inside the containment vessel, including the inside wall of the containment vessel, are coated with a modified phenolic paint.* After Run A4, the external surface of the containment vessel was covered with a 1-in. layer of glass fiber insulation $\left(6.0 \mathrm{lb} / \mathrm{ft}^{3}\right.$ density, $\mathrm{k}=0.027 \mathrm{Btu} /$ (hr) $\left.\left(\mathrm{ft}^{2}\right)\left({ }^{\circ} \mathrm{F} / \mathrm{ft}\right)\right]$ with a factory applied vapor shield. A view of the upper half of the containment vessel before the insulation was applied as shown in Figure A-2.

\section{INSTRUMENTATION}

A critical part of these experiments was the accurate measurement of physical conditions existing inside containment. Knowledge of average temperature and pressure, as well as heat loss, velocity of convection currents, liquid levels, and opportunity for direct visual observation are required. Thermocouples are located throughout the vessels as well as in the sealed-off wetwell and outside the vessel. They are so located that simple arithmetic averages will provide an accurate average temperature in the vessel. Thermocouples are also located near the inside, on the inside, on the outside, and near the outside wall of the containment vessel to obtain data for calculating heat losses. A series of commercially available anemometers*" is installed in a horizontal line across the containment vessel and at several elevations near the walls. Visual observation, accomplished by the use of a standard 6-in. diam pressure glass installed on a nozzle $13 \mathrm{ft}$

* Two coats of Phenoline 302 over one coat of Phenoline 300 primer, a product of the Carboline Co., St. Louis, Mo.

** Heated thermopile type S-22AX, power supply mode2 AM-62R 10X, manufactured by Hastings, Raydist, Inc., Hampton, Virginia. 


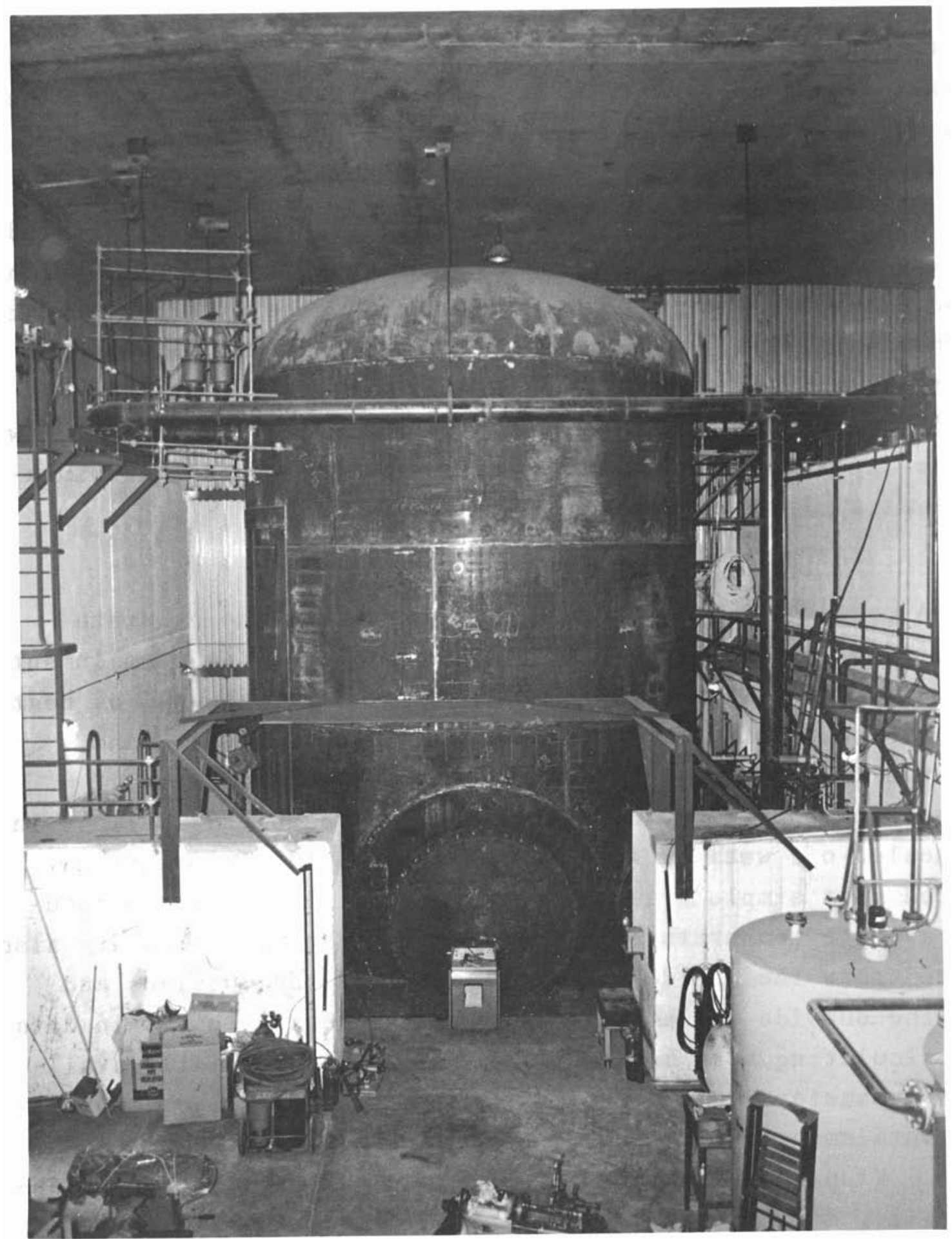

Neg 47381-57

FIGURE A-2. An Exterior View of the Upper Half of the CSE Vessel Before Thermal Insulation Was Installed 
above the main vessel deck, was also useful for evaluating the quality of the atmosphere, the injection of the aerosol, and also the fall of the spray solution. Standard dip tube level gages with manometer readout were used for liquid level measurements of the drywell pool, containment vessel pool, and the spray solution storage tank.

\section{AEROSOL GENERATING AND INJECTION EQUIPMENT}

The aerosol generating and injection station and equipment consist of a cave, two standard radiochemical hoods, high frequency induction units, a heated transfer line, a steam jet, and a panel board. The equipment is located in laboratories close to the containment vessel. The volatilization of the radioactive simulant fission product aerosol components, as well as the generation of the uranium oxide and cladding fumes, is done in a cave constructed of 6 -in. steel walls and equipped with manipulators. An air stream sweeps the volatilized simulant materials through the $\mathrm{UO}_{2}$ melting furnace via the 2-in. ID injection line through penetrations in the main CSE vessel into the vapor space in the drywel1.

The motive force for aerosol injection is provided by a steam jet. Since the containment systems may be at pressures of up to 75 psig, the use of 225 psig steam is necessary to obtain desired flow rates against this back pressure. Advantages of the technique include the capability of operating the generating apparatus without pressure and for using inert friable materials such as glass for the aerosol generation apparatus. Other significant features of the system provide for:

- Wrapping the line with electrical heating tape and insulation to maintain the line at a temperature greater than $250{ }^{\circ} \mathrm{F}$ to prevent condensation when steam is used as the carrier gas. 
- Electrically heating the 225 psig steam line and supplying dry or superheated steam to the steam jet by means of a superheater.

- Locating aerosol samplers in the line near the point of discharge so that the amounts and forms of the aerosol components entering containment can be determined.

Additional details of the CSE aerosol generation system are given by Coleman. (26)

\section{S.AMPLING SYSTEMS}

During each aerosol transport and behavior experiment, many liquid and gas samples were taken during the course of the experiment for radiochemical analyses at a later time. Samples of the spray solution as it falls, samples of the spray solution running down the containment vessel wall surface, samples of solution accumulating in the bottoms of containment vessel and the drywell, deposition coupons of various materials and, finally, samples of the gas phase are all important in the conduct of spray experiments.

The flowsheet for the gas sampling system is shown in Figure A-3. The scheme consists primarily of Maypack clusters (multiple filters and adsorbers) located at 14 positions inside containment for sampling both gaseous and particulate components. Also included are heated sampler exhaust lines to the laboratory provided with condensers for collecting condensate, and with pressure reducing valves, cold traps to dry the air, refrigerated charcoal traps to collect any iodine penetrating the Maypacks, and the necessary sample flow control apparatus.

Figure A-4 is a photograph of a partly disassembled cluster showing the 12 solenoid valves and quick disconnects, with cover removed. Figure A-5 shows the arrangement and types of filter media in a Maypack. 


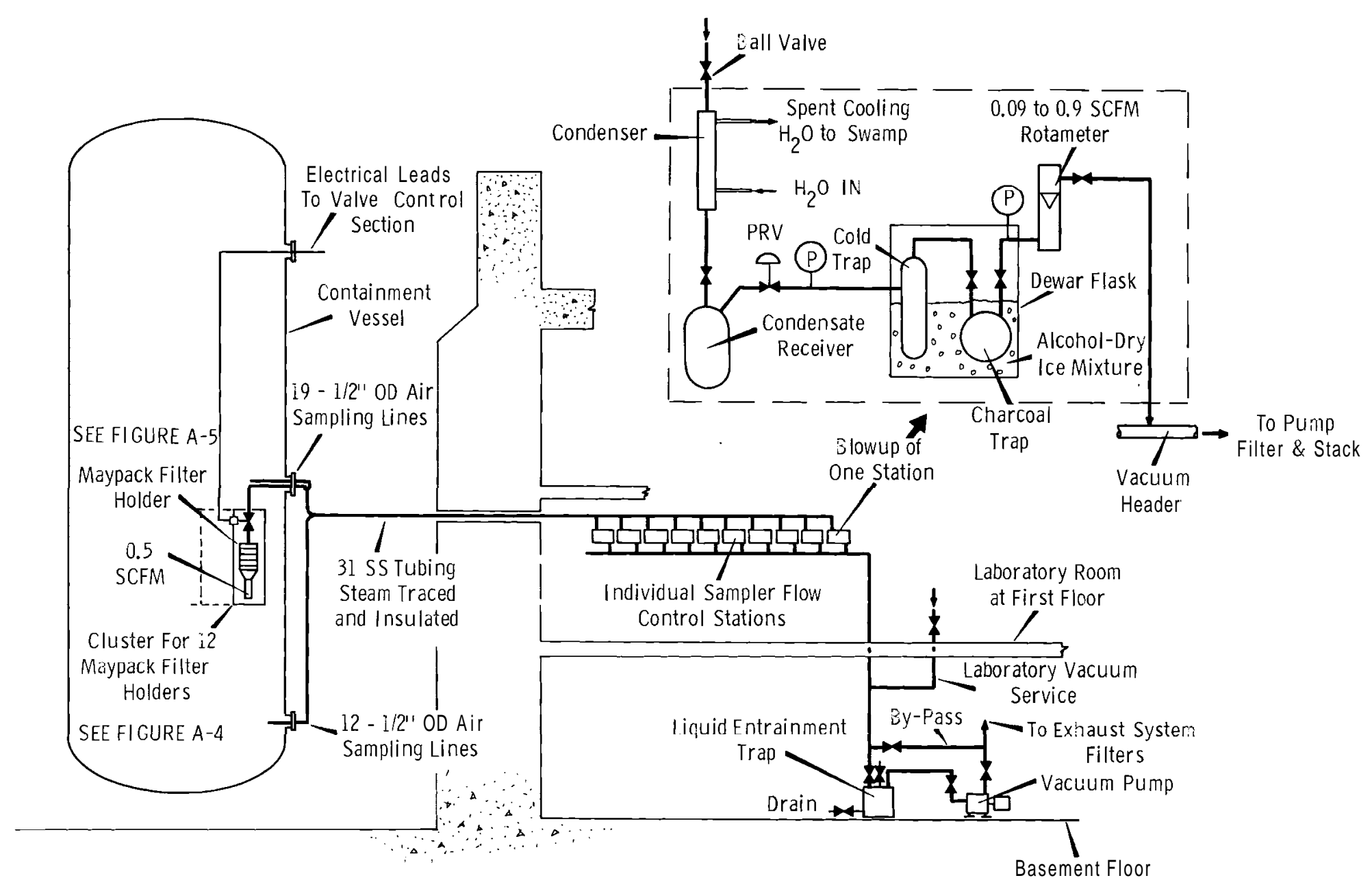

GENERAL NOTE

All Air Sampling Lines to the Sampler

Stations Snall e Stean Traced and

Insulated io Maintain Air Samples at

$2 x-300^{\circ} \mathrm{F}$.

FIGURE A-3. Schematic Diagram of CSE Aerosol Sampling System 
BNWL - 1244

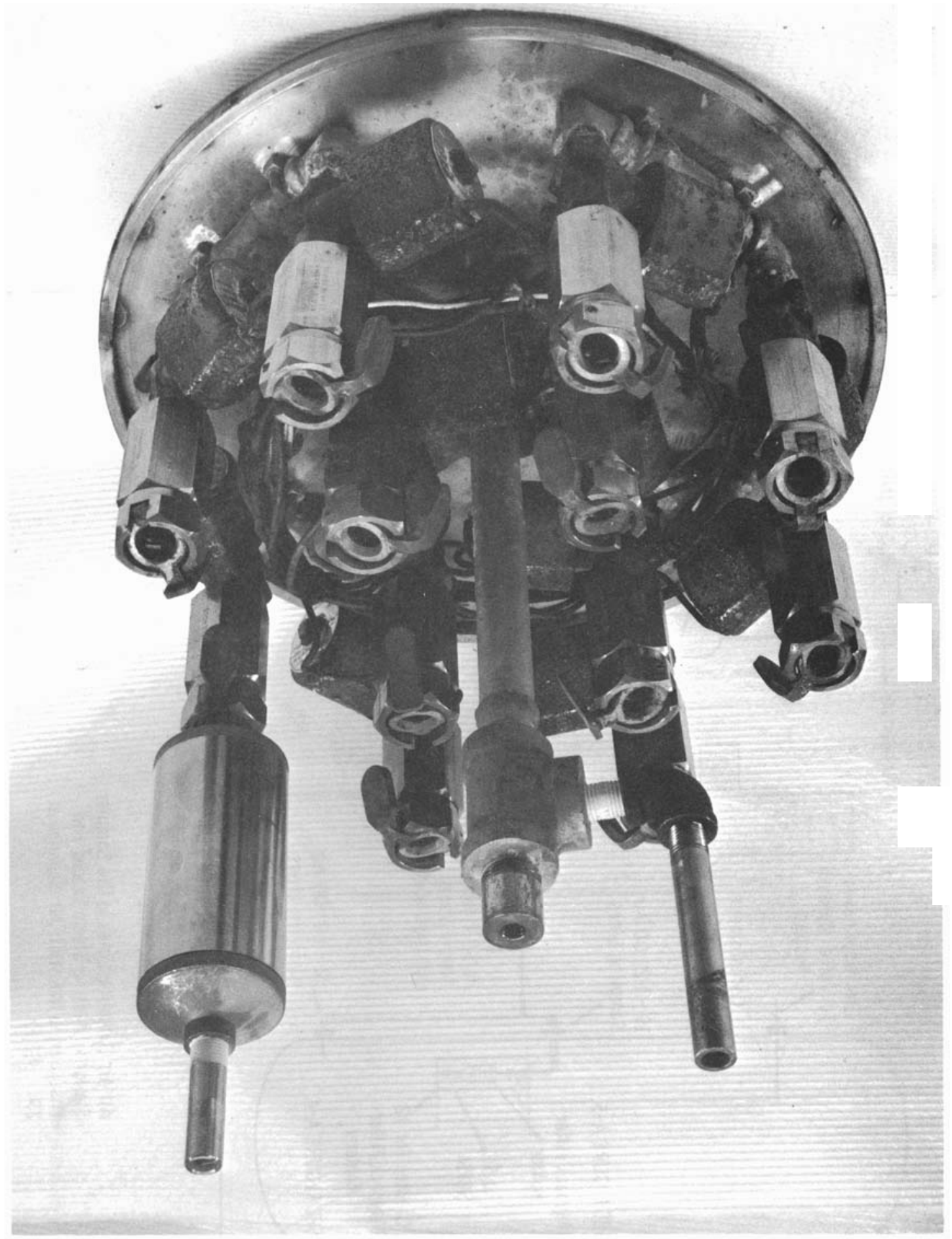

Neg 0692095-2

FIGURE A-4. A View of CSE Maypack Cluster with Cover Removed 
BNWL - 1244

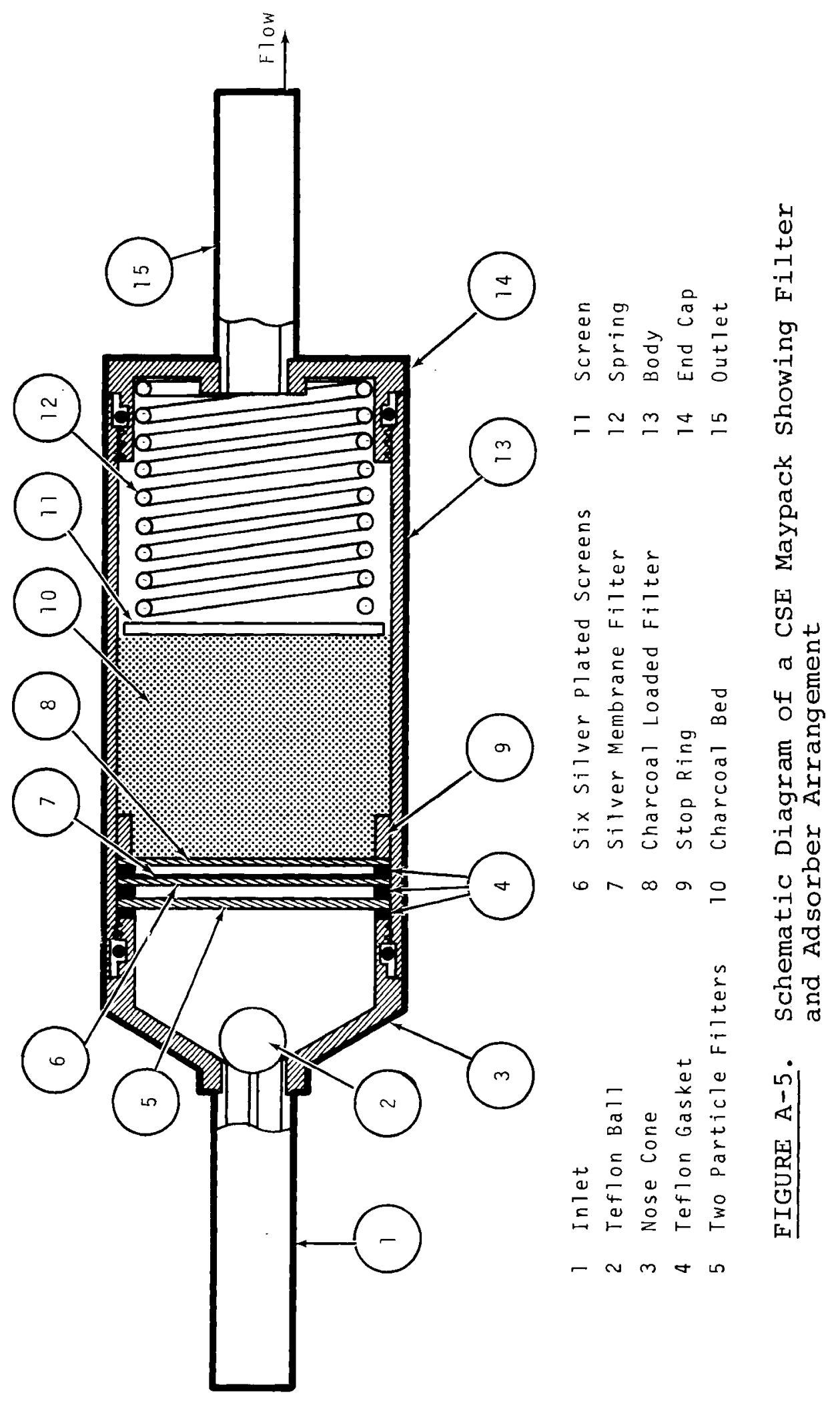


BNWL -1244

Each of the 12 solenoid valves of a Maypack cluster assembly is individually controlled at a panel in the laboratory so that samples of the atmosphere can be taken at a specified point in containment as a function of time. A system of pulleys, cables, and winches is provided for raising or lowering an assembly to a desired location. Flexible Teflon tubing serves as the exhaust line from an assembly to the vessel wall where it connects to a 0.5-in. diam stainless steel tube. The stainless tube penetrates the vessel wall and then is gathered into a bundle with the other sample exhaust lines. The bundle of stainless steel tubes continues the run into the laboratory to the final sampling and metering equipment. The sample exhaust line bundle is steam traced from the containment vessel to the laboratory to prevent condensation. Retrieval of the samples taken by the Maypacks located within containment is postponed until the experiment is ended and the containment vessel thoroughly purged with fresh air.

Each terminal aerosol sampling station in the laboratory consists of a condenser, condensate receiver, pressure reducing valve, cold trap, refrigerated charcoal trap, rotometer, and the appropriate valves and gages required for flow control. The total gas volume is determined by correcting the rotometer readings to temperature and pressure conditions at the respective Maypack location within the containment vessel. All gas samples taken by Maypacks in the CSE are routinely obtained for a 3 -min flow duration at $0.5 \mathrm{ft}^{3} / \mathrm{min}$ (STP) flow of dry air.

Samples of the liquid collected in the bottoms of the drywe1l and containment vessel are taken from separate recirculating loops located externally to the vessels. Each loop is an independent system and consists of a pump, heat exchanger, a sample spigot, a mixer-eductor, and associated transfer line and valves. The heat exchanger is necessary to prevent 
flashing of the liquid when the sample spigot is opened. Volumetric samples are taken and radiochemically counted directly under known geometries.

Solution flowing down the walls of the containment vessel is collected by a circumferential trough located near the main deck level. The trough is drained through a flow recorder to a sample spigot. Only a small fraction of the flow is taken for samples, with the remainder returned to the pool at the vessel bottom.

Samples of the falling spray drops are taken at two elevations and three radii. Suspended in the vessel are funnels of known geometry which drain via 1/2-in. tubing into small pressure vessels located outside the containment vessel. Each small vessel is vented back to the containment vessel to assure good drainage. Frequently during the spray periods, the small pots are isolated, vented to atmosphere, and drained of the solution collected. The volume collected is recorded and a portion is saved for radiochemical analysis.

In order to obtain gas samples during the course of the run, a special chamber is installed on a vessel nozzle so that individual Maypacks can be inserted into the vessel at any time, a sample drawn, and the Maypack removed from the vessel. Analyses of these "thief" samples permit preliminary appraisal of the experiment.

\section{SPRAY SYSTEM}

The basic equipment flowsheet used for the CSE spray system is shown in Figure A-6. Changes, if any, from one experiment to the next were found primarily to involve alterations to the spray distribution system. In some instances, only the nozzles were changed. In other instances, changes to the dis tributor piping were required. The system, though simple, was very flexible. Sanitary water or demineralized water, or either 
BNWL- 1244

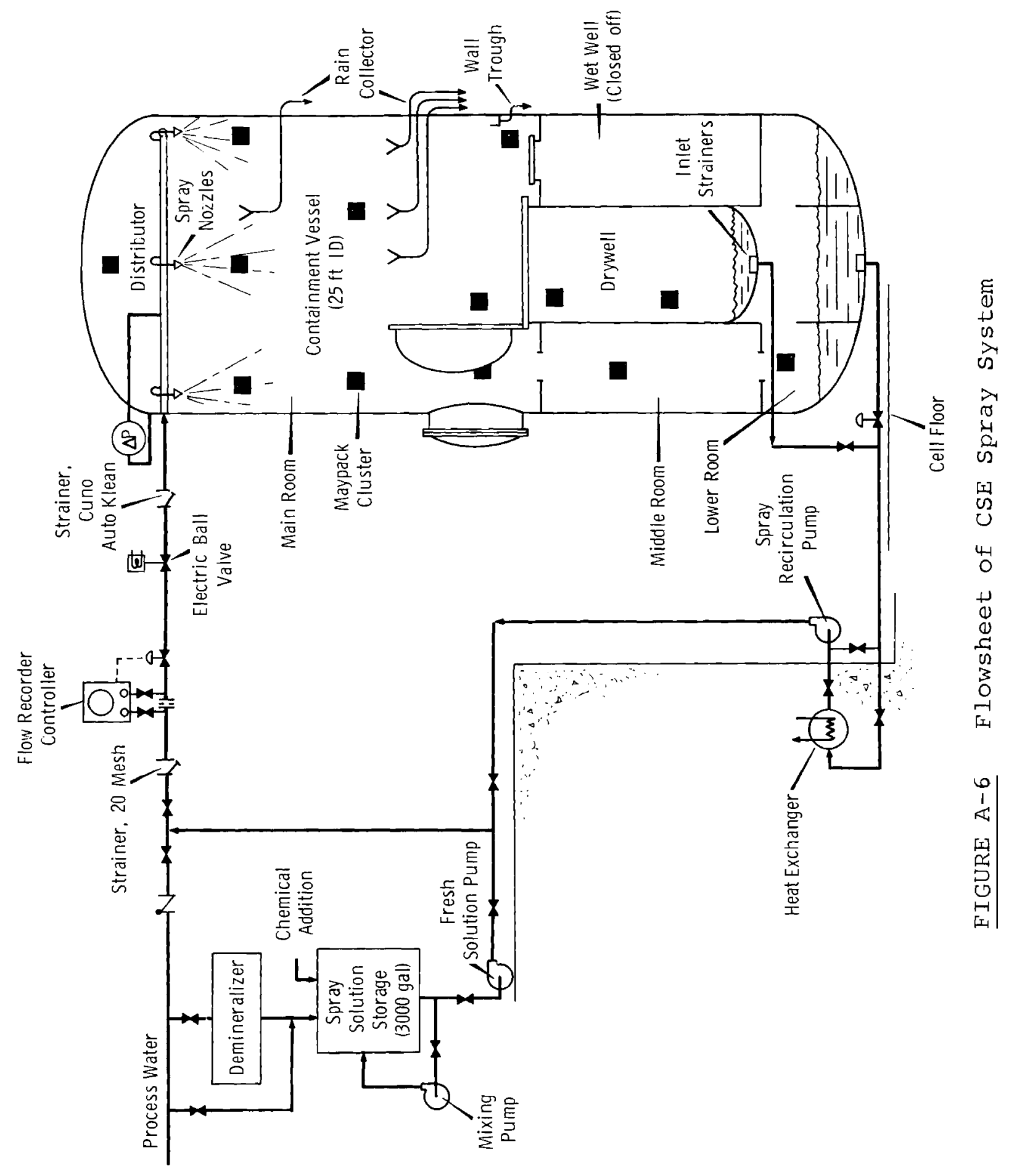


BNWL -1244

of these with chemicals added, could be used for the spray solution. Also the spray solution could be recirculated from the containment vessel sump back to the spray distributor and nozzles. The recirculated solution could be cooled as desired by routing it through a heat exchanger.

The header and nozzles were installed so that the system could be filled prior to the start of the experiment. Thus when the ball valve was opened or closed, start or stoppage of flow through the nozzles was realized immediately. This accurate and close timing of spray periods was important later for the correlation of the data. The flow was manually controlled by adjusting the control valve to give a specific pressure drop across the nozzles. The nozzle manufacturer's data on flow rate and droplet size were used to determine the pressure drop desired. Pictures of the types of nozzles used, along with some specifics, are shown in Table 2. The nozzles were installed at plus $28.5 \mathrm{ft}$ to provide a drop height of $33.8 \mathrm{ft}$ to the deck and $50.5 \mathrm{ft}$ to the bottom of the drywel1. A course strainer (0.053-in. openings) was installed at the outlet of each vessel sump. Two additional strainers were located in the supply line leading to the spray nozzles, as shown in Figure A-6. 


\section{I S TRIBUTION}

No. of

Copies

OFFSITE

1

30

272

37
AEC Chicago Patent Group

G. H. Lee

AEC Division of Reactor Development and Technology

W. G. Belter

R. S. Brodsky (2)

J. W. Crawford

R. L. Ednie

D. E. Erb

W. P. Gammil1

A. Giambusso

H. L. Hamester

H. G. Hembree

E. E. Kintner

R. R. Newt on (5)

R. E. Pahler (2)

A. J. Pressesky (5)

H. J. Reynolds

I. C. Roberts

M. A. Rosen

E. E. Sinclair

S. A. Szawlewicz

G. W. Wensch

M. J. Whitman

$\underline{\text { AEC Division of Technical Information Extension }}$

AEC Library, Washington

Advisory Committee on Reactor Safeguards

F. R. Fraley (18)

Division of Compliance

L. Kornblith, Jr.

L. D. LOW

Division of Compliance, Region IV

J. W. Flora

Division of Operational Safety

H. Gilbert 
No. of

Copies

Division of Production

G. B. Pleat

Division of Reactor Licensing

R. S. Boyd

G. Burley

Brian Grimes

S. Levine

D. J. Skovholt

Division of Reactor Standards

G. Burley

E. G. Case (5)

A. B. Holt

J . E. McEwen, Jr.

J. R. Miller

I. Spickler

1

AEG-Telefunken, Germany

816 Jeri Ave.

Idaho Falls, Idaho 83401

Dieter Ewers

1

Aerojet - General

Idaho Falls

W. E. Nyer

3

American Electric Power Service Corp.

2 Broadway, New York, N. Y. 10004

P. Dragoumis

S. J. Milioti

A. Sherman

8

Argonne National Laboratory

C. E. Dickerman

S. Fistedis

R. O. Ivins

P. Lottes

R. C. Vogel

LMFBR Program Office

A. Amorosi

L. Baker

C. E. Miller, Jr. 
No. of

Copies

1

Atomic Energy Control Board

Ottawa, Canada

F. C. Boyd

3

Atomics International

H. Morewitz (2)

Liquid Metals Engr Center

R. W. Dickinson

3

Babcock \& Wilcox Co.

Lynchburg, Virginia

W. S. Delicate

D. A. Nitti

R. Wascher

7

Battelle Memorial Institute

A. R. Duffy

D. L. Morrison

S. Paprocki (2)

R. L. Ritzman

D. N. Sunderman (2)

2

Battelle Memorial Institute Frankfort, Germany

G. Leistner/K. J. Kober

N. Henzel

2

Bechtel Corporation (AEC)

B. K. Lee

G. S. C. Wang

1

Bechtel Corporation

P.O. Box 607

Gaithersburg, Md. 20760

H. W. Osgood

1

Brookhaven National Laboratory

A. W. Castleman

1 Canadian General Electric Co.

Petersborough, Ontario

S. Davies 
No. of

Copies

1

1

1

1

1

3

1
Canoega Park Area Office

R. L. Morgan

Centre d'Etudes Nucleaires de Saclay

P.O. BoX 2

Gif sur Yvette

(Seine-et-Oise), France

$$
\text { P. Candes }
$$

Chalk River Nuclear Laboratories

Chalk River, Ontario, Canada

Station 3

G. Hake

Chicago Operations Office Atomic Energy Commission

D. M. Gardiner

Combustion Engineering

M. F. Valerino

Consolidated Edison Company

J . J . Grob

Consumers Power Company

Jackson, Michigan 49203

G. S. Keeley

G. B. Matheny

H. S. Tsai

Dilworth, Secord, Meagher, and Associates, Ltd. 4195 Dundas St.

Toronto, Ontario, Canada

I. J . Billington

duPont Company (AEC)

A. H. Peters

Ebasco Services, Inc.

2 Rector Street

New York, N. Y. 10006

Harold Oslick 


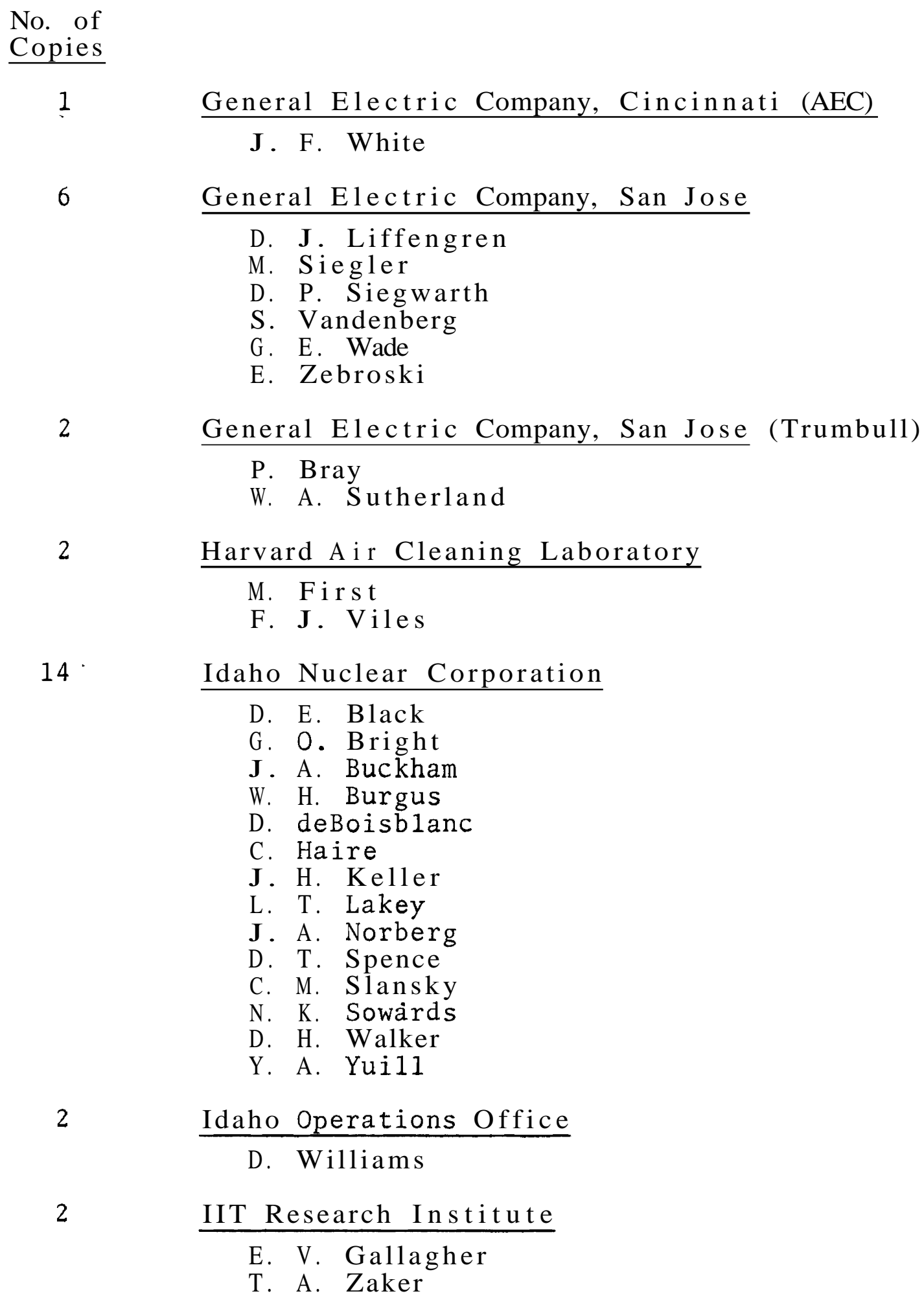

General Electric Company, San Jose

D. J. Liffengren

M. Siegler

D. P. Siegwarth

S. Vandenberg

G. E. Wade

E. Zebroski

General Electric Company, San Jose (Trumbull)

P. Bray

W. A. Sutherland

Harvard A ir Cleaning Laboratory

M. First

F. J. Viles

14. Idaho Nuclear Corporation

D. E. Black

G. O. Bright

J . A. Buckham

W. H. Burgus

D. deBoisblanc

C. Haire

J. H. Keller

L. T. Lakey

J. A. Norberg

D. T. Spence

C. M. Slansky

N. K. Sowärds

D. H. Walker

Y. A. Yuill

Idaho Operations Office

D. Williams

IIT Research Institute

E. V. Gallagher

T. A. Zaker 
No. of

Copies

1 Inst. f. Mess- u. Regelungstechnik D8046 Garching, Germany-West

Dr. H. Karwat

Los Alamos Scientific Laboratory

J. H. Russel

1

MPR Associates, Inc.

T. Rockwe11 I I

1

National Bureau of Standards

C. Muehl hause

1

Naval Ordinance Laboratory

J. Proctor

North Carolina State University

M. N. Ozisik

1

Nuclear Fuels Services

R. P. Wischow

1

NUS Corporation 2351 Research Blvd.

Rockville, Md 20850

M. I. Goldman

1

NUS Corporation

Washington, D.C.

R. S. Denham

19

Oak Ridge National Laboratory
R. E. Adams
B. F. Roberts
R. L. Bennett
T. H. Row
R. Blanco
D. B. Trauger
J. Buchanan
G. M. Watson
W. B. Cottrell
(4)
H. E. Zittel
D. Ferguson
M. H. Fontana
G. W. Parker
L. F. Parsly, Jr.
P. Rittenhouse 


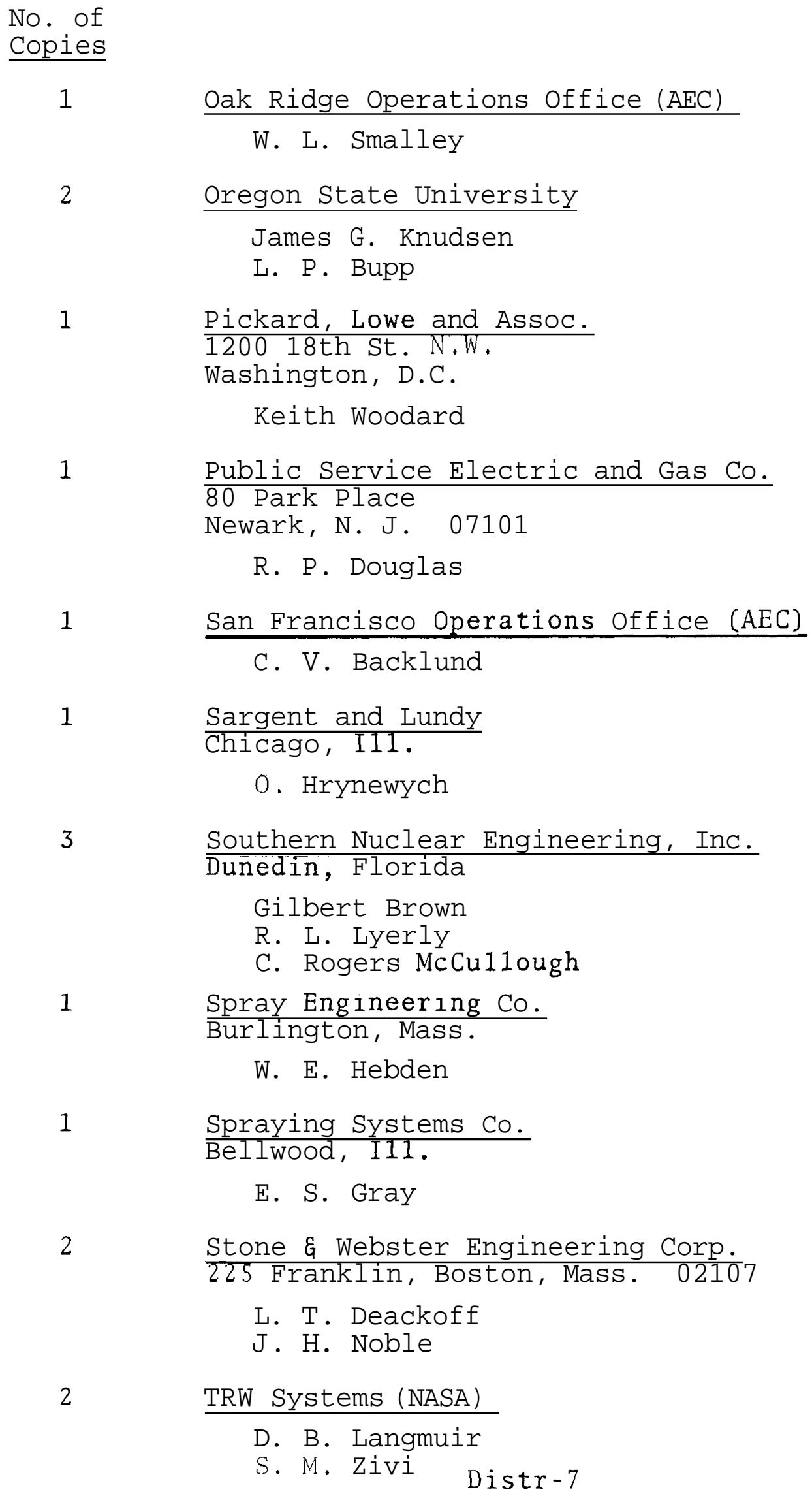

D. B. Langmuir

S. M. Zivi 
No. of

Copies

2

$\frac{\text { University of California, Berkeley }}{\text { Institute of Engineering Research }}$

H. A. Johnson

V. E. Schrock

1

University of Minnesota

Department of Chemical Engineering

H. S. Isbin

1

University of Washington

R. W. Moulton

4

Westinghouse Electric Corp. (APD)

E. Beckjord

W. D. Fletcher

J. D. McAdoo

R. A. Wiesemann

1

Westinghouse Electric Corp. (HTD)

A. Lohmeier

2

Yankee Atomic Electric Co.

441 Stuart St., Boston, Mass.

$J$. Devincentis

P. S. Littlefield

ONSITE-HANFORD

AEC Chicago Patent Group

R. K. Sharp (Richland)

3

AEC RDT Site Representative

P. G. Holsted (2)

J. B. Kitchen

4

AEC Richland Operations Office

A. Brunstad

C. L. Robinson (2)

W. E. Lotz 
No. of

Copies

3

3

6

73
Atlantic Richfield Hanford Company

O. F. Hill

G. R. Kiel

ARHCO File

Battelle Memorial Institute

Douglas United Nuclear

T. W. Ambrose

E. L. Etheridge

N. R. Miller

J. W. Riches

J. R. Spink

DUN File

Battelle-Northwest

F. W. Albaugh

E. R. Astley

R. T. Allemann

J. M. Batch

R. H. Bond

S. H. Bush

L. F. Coleman

D. L. Condotta

F. G. Dawson

J. M. Hales

M. M. Hendrickson

R. K. Hilliard (10)

T. W. Horst

R. L. Junkins

J. P. Hale

B. M. Johnson

C. E. Linderoth

J. D. McCormack

R. E. Nightingale

A. K. Postma

D. L. Reid

G. J. Rogers (30)

C. L. Simpson

J. C. Spanner

N. P. Wilburn

M. E. Witherspoon

N. G. Wittenbrock

Technical Information Files (5)

Technical Publications (3) 